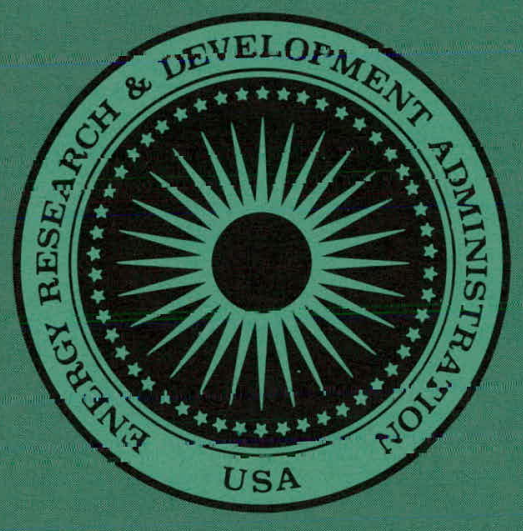

BERC/TPR-77/5

NORTH BURBANK UNIT TERTIARY RECOVERY PILOT TEST

SECOND ANNUAL REPORT, MAY 1976-MAY 1977

By

Phillips Petroleum Company

Date Published-August 1977

Bartlesville Energy Research Center

Energy Research and Development Administration

Bartlesville, Oklahoma 


\section{DISCLAIMER}

This report was prepared as an account of work sponsored by an agency of the United States Government. Neither the United States Government nor any agency Thereof, nor any of their employees, makes any warranty, express or implied, or assumes any legal liability or responsibility for the accuracy, completeness, or usefulness of any information, apparatus, product, or process disclosed, or represents that its use would not infringe privately owned rights. Reference herein to any specific commercial product, process, or service by trade name, trademark, manufacturer, or otherwise does not necessarily constitute or imply its endorsement, recommendation, or favoring by the United States Government or any agency thereof. The views and opinions of authors expressed herein do not necessarily state or reflect those of the United States Government or any agency thereof. 


\section{DISCLAIMER}

Portions of this document may be illegible in electronic image products. Images are produced from the best available original document. 


\section{NOTICE}

This report was prepared as an account of work sponsored by the United States Government. Neither the United States nor the United States Energy Research and Development Administration, nor any of their employees, nor any of their contractors, subcontractuis, or their employees, makes any warranty, express or implied, or assumes any legal liability or responsibility for the accuracy, completeness or usefulness of any informa. tion, apparatus, product or process disclused, or reprogents that its use would not infringe privately owned rights.

This report has been reproduced directly from the best available copy.

Available from the National Technical Information Service, U.S. Department of Commerce, Springfield, Virginia 22161.

\begin{tabular}{cccccccccccccc}
\multicolumn{10}{c}{ NATIONAL TECHNICAL INFORMATION SERVICE PAPER COPY PRICES } \\
EFFECTIVE JAN. 1, 1976
\end{tabular}

For additional pages, add $\$ 4.50$ for each beginning 100 pages. Add $\$ 2.50$ per copy for foreign price.

Microfiche $\$ 3.00$ (domestic) $\$ 4.50$ (foreign). 


\title{
NORTH BURBANK UNIT TERTIARY RECOVERY PILOT TEST SECOND ANNUAL REPORT, MAY 1976-MAY 1977
}

By

J. C. Trantham, Editor

\author{
Contributors: D. F. Boneau \\ R. F. Kleinschmidt \\ W. B. North \\ C. B. Threlkeld
}

Phillips Petroleum Company

Prepared for the Energy Research and Development Administration Under Contract No. E(34-1)-0021

Roger F. Kleinschmidt, Principal Investigator Phillips Petroleum Company

Philip B. Lorenz, Technical Project Officer

Bartlesville Energy Research Center Energy Research and Development Administration

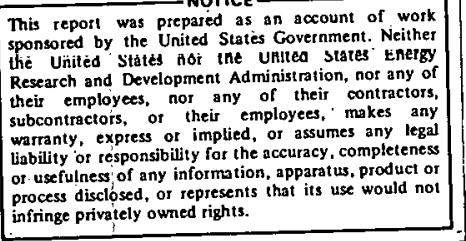
resents that its use would $n$ infringe privately owned rights.

Date Published-August 1977

\section{ENERGY RESEARCH AND DEVELOPMENT ADMINISTRATION} TECHNICAL INFORMATION CENTER 

SECOND ANNUAL REPORT

NORTH BURBANK UNIT TERTIARY RECOVERY PILOT TEST

MICEIJAR/POLYMER FIOOD

MAY 1977

INDEX

Page No.

Summar

I. Introduction . . . . . ....... 2

A. Phillips/ERDA Contract . . . . . 2. 2 .

B. Field and Site Selection 2

C. Project Description and Status 2

II. Reservoir Studies . . . . . . . . . . 4

A. Control of Pressure Gradients Across Tract 97 . . 4

B. Tracer Program .............. 9

C. Allocation of Injection and Production on Tract $97 \quad 11$

III. Laboratory Work . . . . . . . . . . . 14

A. Phase Behavior of Surfactant System . . . . . 14

B. Optimum Salt Concentration With Live Crude Oil • • 15

c. Chemical Analysis of Fluids . . . . . . . 17

IV. Field Operations . . . . . . . . . . 18

A. Sampling and Testing ........... 18

B. Completion of the Saline Preflush . . . . . . 20

C. Gelled Polymer Treatment at Well 97-W25 . . . 21 
IV. Field Operations (Continued)

D. Chemical Handling Logistics . . . . . . 23

E. Operation of Chemical Mixers . . . . . . 24

F. Chemical Injection . . . . . . . . . 26

G. Project Performance . . . . . . . . 45

V. Milestone Chart and Decision Points . . . . . 57

VI. Schedule of Expenditures . . . . . . . . 58

VII. Third Year Plans ............ 58

VIII. Acknowledgments . . . . . . . . . 59

References......................... 60 
SECOND ANNUAL REPORT

NORTH BURBANK UNIT TERTIARY RECOVERY PILOT TEST

MICELLAR/POLYMER FLOOD

MAY 1977

\section{Summary}

During the second year of the cooperative project jointly funded by Phillips Petroleum Company and the other Working Interest Owners of the North Burbank Unit together with the United States Energy Research and Development Administration, reservoir conditioning was completed on August 2, 1976, and surfactant injection was begun. The surfactant injection phase spanned a 44 -day period ending September 15, 1976, and the first phase of the graded polyacrylamide slug (2500 ppm) was begun. By the end of the reporting period five phases of the polymer had been injected and the sixth, $600 \mathrm{ppm}$, was in progress. Beginning about January 1977 tertiary oil production was confirmed and the total oil rate had reached a level of $185 \mathrm{BPD}$ at a water/oil ratio of 65 at the end of the project year, May 15, 1977. A total of about 14,000 bbl. of tertiary oil had been produced. Polymer injection is expected to be complete by the end of 1977 and peak oil production is anticipated about the end of the third project year. 


\section{INTRODUCTION}

\section{A. Phillips/ERDA Contract}

The North Burbank Unit Tertiary Recovery Pilot Test is a cooperative project funded jointly by Phillips Petroleum company with its working interest partners and the United States Research and Development Administration (ERDA). A contract, now designated No. EY-76-C-02-0021, was awarded to Phillips on May 12, 1975, in the amount of $\$ 9,764,514$. This is a cost-sharing contract of 39 months duration with ERDA funds amounting to $\$ 3,402,042$.

\section{B. Field and Site Selection}

The North Burbank Unit, Figure 1, was selected as a highly desirable reservoir for a surfactant/polymer tertiary recovery pilot test because it had been successfully waterflooded for over 25 years and production had declined to the stripper level. However, the reservoir still contains about 400 million barrels of sweet $39^{\circ}$ API oil and thus offers a worthwhtle upuirtunity to increase recoverable reserves. The site selected was a 90-acre portion of NBU Tract 97 which had a history of good performance under waterflood. It is characterized by an average net pay of $43 \mathrm{feet}$, average permeability of $52 \mathrm{md}$ and a current oil saturation estimated at about 30 percent. The sand is oil-wet, and laboratory tests showed that a specially designed surfactant formulation would be required for effective oil recovery. The test pattern of 25 wells consists of nine inverted ten-acre five-spots, as shown in Figure 1.

C. Project Description and Status

The sequence of steps described in the original proposal to ERDA has not been altered; only minor modifications of process details have been made to 
provide additional data or to cope with minor operational problems.

At the conclusion of the first contract year, the following steps had been accomplished:

1. A total of 21 new wells had been drilled, including nine injection, eleven production and one disposal well.

2. The desired reservoir properties had been measured, including logs, cnre analyses, proosure falloff lests, etc.

3. All injection and gathering lines were complete and the chemical handling facilities were being constructed.

4. The freshwater preflush had been completed and the controlled salinity preflush was in progress.

5. Radioactive tracers had been injected and the produced water was being monitored.

6. The required quantities of sulfonate and alcohol had been pruchased and were in storage.

During the second contract year, the project proceeded according to the plan:

1. Chemical handling facilities were completed.

2. Injection of controlled salinity preflush was completed.

3. The surfactant.slug was prepared and injected without difficulty.

4. Injection of the polymer solution was started immediately after the surfactant slug. and was more than half completed at the end of the second year.

This report contains a detailed description of the second year operations and the initial response of tertiary oil production, together with supporting tables, figures and graphs.

References and illustrations at end of report. 


\section{RESERVOIR STUDIES}

\section{A. Control of Pressure Gradients Across Tract 97}

In any pilot project is is extremely important to control the operation of the reservoir adjacent to the pilot in such a way as to minimize the influence the remainder of the reservoir has on the particular portion selected for the pilot. This is essential in the case of expensive processes, such as surfactant flooding, because fluid drift could force expensive chemicals and/or mobilized oil to move out of the pilot pattern so that a proper accounting of oil production could not be obtained. For this reason a great deal of attention was placed on the leveling of pressure gradients across the pilot area.

\section{Procedure}

To control the tendency of fluid to drift across the pattern, the following procedure was used:

(1) Reservoir pressures were determined at nine injection wells surrounding Tract 97 (Figure 2).

(2) A computer model was used to match the pressure history of these wells and to predict the reservoir pressure at a selected point in time (April 1, 1976) and at selected positions in the Tract 97 area.

(3) The north-south and east-west components of the pressure gradients were determined and were related to injection and production rates in tracts over a wide area surrrounding Tract 97. The production of freshwater preflush at Tract 97 producers and tracer behavior were also correlated with the observed pressure gradients.

(4) Adjustments in injection rates were made to reduce the pressure gradients to acceptable levels. 


\section{Pressure Measurements}

To obtain meaningful values of average reservoir pressures without keeping wells shut in for extended periods of time, use is normally made of transient pressure measurements and the average reservoir pressure calculated from transient pressure theory. This calculation involves the drainage area of the well (injection area for an injection well) and is also affected by the shape of the area. For a five-spot pattern in a fluid injection process, the area is taken ${ }^{(2)}$ as that of the square whose sides are drawn along the 50 percent equipressure contours lying between the injector and the producing wells. The pressure on these contours, $p_{e}=\vec{p}$, is the average reservoir pressure. Unfortunately, in a mature waterflood such as the North Burbank Unit, many wells will have been plugged and abandoned so that the drainage/injection area will be very irregular and no accurate assignment of area can be made. Experience in running pressure falloff measurements in the Tract 97 area has shown that when a water injection well is shut in for 48 hours, it approaches the average reservoir pressure fairly closely so a 48-hour shut in was taken as the basis for estimating the average reservoir pressure where the area could not be assessed. Approximately the same results can be obtained in a theoretically more satisfying way by using the bottomhole pressure for a shut-in period such that the dimensionless time $\left(t_{D}\right)$ is equal to 10 :

\section{Model Study}

A computer program using superposition of line source functions was used to calculate the pressure distribution within the reservoir at the selected time - April 1, 1976. The wells used in the model are shown on the map given in Figure 2. Note that for the purposes of this study the influence of the injection and production in the areas outside the model 
was simulated by eight dummy wells. The injection and production data for the wells dating back to December 1, 1975, were used along with reservoir data obtained from pressure falloff measurements where such information was available. For wells for which these values were not available, the $\mathrm{X}$-component of permeability was estimated to be $65 \mathrm{md}$ and the $Y$-component $13 \mathrm{md}$. The $X / Y$ ratio of 5 was used to account for the east-west fracture system known to exist in this reservoir. Porosity and thickness values were obtained from the isoporosity and isopach maps given in the First Annual Report. (1) Uniform values of $0.6 \mathrm{cp}$ for fluid viscosity, 1.0 for formation volume factor, and $7.5 \times 10^{-6}$ for reservoir compressibility were used. For the wells which were shut in for the study and for eight other wells adjacent to the test wells, east-west fractures were simulated by using dual wells spaced two-thirds of the estimated fracture length. The line source solution is considered sufficiently accurate for more distant wells.

Using a starting (December 1, 1975) pressure of 1,250 psia (àssumed to be uniform over the area considered) the program was run to predict the pressure at a selected test well at a time for which the pressure was known. To achieve a match between the calculated and observed pressure at the test well, the rates of the dummy wells were varied. In only two instances was it necessary to vary any other parameter: (1) The X-component of the permeability in Well 97-21 was reduced from 65 to 35 md to obtain a better match to Well 96-W4 data and (2) the permeability in Well 105-W8 was lowered to $60 \mathrm{md}$.

In six of the nine wells, excellent matches were obtained. The match is poorer in Wells 105-W6 and 105-W8 which are located near each other. The observed shut-in pressures at these wells differ by 171 psi. It may be 
that the fracture from 105-W6 runs towards the high-pressure area to the west and that from 105-w8 runs towards the low-pressure area to the east. Figure 3 shows the history match obtained at Well 96-W7 as an example:

The final rates for the dummy wells which gave the best history matches in the test wells are shown on Figure 2. These should not be regarded as quantitative values since the model assumes an infinite reservoir, while the actual reservoir is bounded. The rates do, however, identify regions of excess injection and excess production. The match required excess injection to the west and excess production to the north and east of the pilot.

Once the history match had been attained, the model was used to calculate the pressure on April 1, 1976, at a distance of 350 feet from each corner of the pilot, away from pilot producers or surrounding injectors. Figure 4 shows that the pressure on April 1, 1976, ranged from 1,29.0 psia in the southwest corner to $987 \mathrm{psia}$ in the northeast corner, a difference of 303 psi. The X-component was about $100 \mathrm{psi}$ and the $\mathrm{Y}$-component about $200 \mathrm{psi}$. Calculating the drift velocity from these gradients gave rates of 0.075 feet/day for the X-direction and $0.166 \mathrm{feet} /$ day for the $\mathrm{Y}$-direction. Figure 5 shows the effect of a west-to-east drift of $0.21 \mathrm{feet} /$ day in an idealized multiple five-spot for comparison. This clearly shows that the success of the pilot could be jeopardized by an uricuntrolled pressure gradient.

\section{Pilot Freshwater and Tracer Production}

As freshwater preflush injection proceeded, the producing wells were monitored for dilution of the produced water by the fresh water being injected. The production of radioactive tracers was also examined in the light of the pressure gradient discussed above. As Figure 6 shows, breakthrough of both 
freshwater and radioactive tracers as of April 1, 1976, was significant in some wells lying to the north and east of their offset injectors, while there was relatively little breakthrough at wells lying to the south and west. These facts support the conclusions reached in the previous section since the northeast trending pressure gradient would tend to make fluids move in that direction.

5. Net Injection and Production in Surrounding Tracts

Injection and production data for the entire southern half of the North Burbank Unit were studied for the period from December 1, 1975, to March 31, 1976, to determine the cause of the gradient across Tract 97 . Figure 7 shows the results of that study. It will be noted that a few areas were in a state of imbalance which could result in the pressure gradient observed. These were:

(1) A four-tract area (Tracts. 100, 101, 102, and 103) west and slightly south of Tract 97 where there was an excess of more than 7,000 BPD of injection.

(2) A four-tract area (Tracts 98, 99, 106, and 107) east of Tract 97 with an excess production of about $600 \mathrm{BPD}$ and

(3) Tract 90 where an excess production of about 1,200 BPD prevailed. The control of injection/production immediately to the east of the pilot is especially critical because the area is backed up by the boundary of the reservoir just east of Tracts 99 and 107. Here even relatively small changes in the balance of injection and production can quickly influence the pressure gradient across the pilot.

\section{Method of Control}

Based on the study of the pressure gradient and its causes, a program of adjustment of fluid balance was begun in May 1976. This was done by 
transferring injection from areas of excess to areas of deficiency, while monitoring bottomhole pressures in Wells 89-W2, 96-W4, 98-W1, and 105-W6. The calculated drift velocity and direction since May 1976 is given in Table 1. The data show that both components of the fluid drift were being maintained below 0.07 feet/day by mid-July 1976. The direction of the $\mathrm{X}$-component was reversed during this period, going from positive (west-to-east) to negative (east-to-west). This condition continued through the first week of September 1976, but during the period between September 9, 1976, and January 20, 1977, the direction of drift reversed (along both axes) and increased in magnitude. This was corrected within a few weeks and has been held to about 0.06 feet/day since March 1977. Monthly. pressure surveys are being used to keep track of the gradient, and changes in injection rates in tracts surrounding the pilot will be made as necessary to keep the gradient as small as possible.

\section{B. Tracer Program}

The major objectives of the tracer program were to locate any channels which would result in bypassing significant portions of the reservoir and to gain insight on the approximate volume of the reservoir swept by the freshwater preflush. Injection of the four radioactive tracers and early tracer production data were discussed in the First Annual Report. (1) This section is concerned with presenting the final tracer production data and an analysis of these data to help define the reservoir volume swept by the freshwater prefiush.

Complete analyses of produced water samples for radioactive tracers from each producing well were conducted, covering the period from January 22 , 1975, when the tracers were injected, to March 30, 1977. Samples were analyzed weekly until August 4, 1976, then every two weeks until November 24, 1976, and finally once a month through March 30, 1977. Table 2 shows the data 
obtained for Well $97-28$ as an example of the kind of information obtained. Figure 8 indicates all areas defined by the tracers in which fluid communication was established between specific injection/production well pairs. While the previous report ${ }^{(1)}$ contained a discussion of those areas where early breakthrough of tracers was found, of even greater significance, perhaps, are those areas shown in Figure 8 which have failed to show fluid communication. Although sweep of these areas remains basically undefined after eight months injection, they are significant since they include two of the four quadrants of the completely confined five-spot pattern.

The volume of the reservoir displaced by the freshwater preflush was determined on the basis of the radioactive tracer data. Neglecting any adsorption or dispersion effects upon tracer movement, the displaced volume calculations were made by dividing the preflush injected into a given well among the four quadrants in proportion to the total produced radiation. The fluid thus injected in a quadrant was assumed to be confined to that quadrant and was either itself produced or it displaced brine from the quadrant. F'igires 9, 10 and 11 show graphically the volume of displaced brine from each quadrant for January 22, April 19, and August 2, 1976, respectively. This analysis indicates that at the start of surfactant injection on August 2, 1976, the $37.4^{*}$ percent pore volume preflush slug had displaced brine from 28.4 percent of the pore volume in the 90-acre pilot area..

A similar analysis of the displacement efficiency of the preflush was made on the basis of chemical analysis of the weekly produced water samples for sodium, calcium, and chlorides. As an example of these analyses, the data

* This is slightly smaller than the original design ( 40 percent) because the actual pore volume was slightly larger than the prepilot data indicated. 
for Well 97-28 are presented in Table 3. The produced fresh water for each week was estimated from smoothed curves for both sodium and chloride ions and the average value was used for calculation. The amount of produced fresh water was then apportioned equally according to the number of pilot test quadrants in which the producing well was included. By this method it was determined that 27.7 percent of the pore volume was displaced (Figure 12) by the 37.4 percent pore volume slug.

Although reasonable agreement in overall displacement efficiency was obtained by these two methods, the chemical analysis offers no indication of directional displacement as afforded by the radioactive tracers. The tracers allow a better representation of preflush distribution as shown in the comparison of Figures 11 and 12 by utilizing the specific directional movement of fluids in the reservoir. The total fresh water produced by each well, as determined by chemical analysis and radioactive tracers, is shown in Table 4 and the calculated displaced brine from each quadrant is shown in Table 5. It is believed these distributions can be used with an improved computer model in a manner similar to that employed in analysis of the early tracer breakthrough data to obtain an updated prediction of overall surfactant flood performance. This work is now in progress.

C. Allocation of Injection and Production on Tract 97 Prior to the start of preflush, a decision was made to maintain Tract 97 as a pressure sink by holding a net excess of production over injection within the pilot pattern. This choice was made because the off-tract fluid, flowing at water/oil ratio approaching 200 , would contribute very little oil to pattern well production. Thus, very little correction for off-tract fluid production would be required and the error would be low. The extent of loss of chemicals 
or chemically-mobilized oil off Tract 97 by over-injection in the pilot would be difficult or impossible to evaluate because there are very few producers in the surrounding tracts to capture the oil. The net excess production has averaged about 6,600 BFPD through May 15, 1977.

\section{Basis for Allocation to Individual Wells}

Initially, when freshwater preflush injection began, no actual fluid flow information was available to guide the selection of optimum rates in the various Tract 97 wells. The reservoir description given in the First Annual Report provided data which were used in a 2-D model to calculate the arrival times of fluid fronts so that the well rates could be adjusted to give approximately equal arrival times at the various producing wells. These rates were then used for freshwater injection while pressure interference test data, freshwater production data, and radioactive tracer results were being collected and analyzed. When sufficient data were available, the findings were used in optimizing the fluid flow in the pattern curing the final two months of preflush injection, and with modifications, during the injection of various chemical slugs.

The following approach was taken:

(1) The degree of under or over coverage of the sand within each fivespot as of June 1, 1976, was estimated from the pore volume map (Figure 13).

(2) Injection rates were determined for making up any deficiencies by August 1, 1976, when surfactant injection was due to start.

(3) Production rates were then assigned to obtain fluid balance within each five-spot and finally these were modified as necessary to reduce excessive flow in some areas and to correct local deficiencies in others. 
First, each of the inner producers, Wells 97-06, 97-22, 97-23, and 97-28, was allocated approximately the amount theoretically supplied by its four offset injectors. This condition of volumetric balance was modified slightly by allocating about 10 percent less than the calculated amount to discourage flow along the line of a channel from Well 97-W25 indicated by radioactive tracers and freshwater production. (1) Similarly, a small reduction was made in the allocation to Well 97-22 to allow for a slight tendency for fluid to channel from 97-W26.

Next, assignments were made to side wells taking into account any tendency for fresh water and/or tracers to channel from offset injection wells (Figure 6). Also, the side wells on the south row were allocated more than those in the north row since the pressure gradient had impeded movement of preflush towards the south line and had aided its movement towards the north. Well 97-34 was assigned a lower rate than $97-35$ because of a strong channeling tendency from 97-W30. Well 97-24 was given a small allocation for the twomonth period becuase it was a large producer of fresh water, and Well 97-14 A was given a smaller quota than Well 97-21 because of the former's proximity to an offset injector (Well 97-W25). Finally, all corner wells were assigned large quotas to encourage flow from their single offset injection wells.

The final quotas assigned are shown in Figure 14. The rates given in parentheses for Wells $97-8$ and $97-21$ indicate that although the quota was set at $1000 \mathrm{BPD}$, these wells were considered inherently unable to produce more than about 800 BPD. Thus, they were to be produced at the maximum possible rate.

\section{Discussion}

One point of special interest was that in analyzing the fluid flow in the various five-spots the desirability of fluid diversion treatments became 
apparent and were considered in two quadrants - W25-NE and W30-NE. A treatment, described in another section of this report, was performed in W25-NE and achieved some success in enhancing coverage by preflush, and probably chemical slugs injected later. The other quadrant was not treated because of the experimental nature of the gelled polymer treatment used and because there was insufficient time to evaluate the treatment of Well 97-W25 and then treat 97-W30 before chemical injection could start.

Allocation of chemical slugs will be discussed in the sections dealing with the injection of these materials.

\section{LABORATORY WORK}

\section{A. Phase Behavior of Surfactant System}

A surfactant system was chosen for the North Burbank Unit after studying the bulk phase behavior, the interfacial tension properties and the oil displacement characteristics of many surfactant formulations. Details of the oil displacement tests were discussed earlier $(1,3)$, but some discussion of the phase studies may clarify the screening process. The more efficient surfactant systems formed three bulk phases when equilibrated with Burbank crude oil. The sulfonate was concentrated in the phase with intermediate density. The phase-volume diagram in Figure 15 displays relative volumes of the phases formed when two parts of an aqueous surfactant system containing 5 percent Witco TRS 10-410 petroleum sulfonate, 3 percent isobutyl alcohol, and varying concentrations of sodium chloride were equilibrated with one part of centrifuged (dead) Burbank crude oil. The minimum interfacial tension between adjacent phases occurred at sodium chloride concentrations from 1.0 to 1.7 percent where the sulfonate was concentrated in the intermediate phase. Tests in cores showed that dead Burbank crude oil could be displaced effectively when the sodium chloride concentration was 1.5 percent. After 
injection into a porous medium, such an aqueous surfactant system reached equilibrium, in situ, with the crude oil to form a sulfonate-rich and oil-rich microemulsion that displaced most of the residual oil. Thus, the equilibration into three bulk phases correlates with both low interfacial tensions and efficient displacement of oil.

B. Optimum Salt Concentration with Live crude Oil The sodium chloride concentration for the surfactant system injected into the pilot area was altered from the planned 15,000 ppm to 9,000 ppm after further study of the phase-volume and interfacial tension behavior with fresh crude oil from Tract 97. The reduction of the concentration of sodium chloride was required because the fresh oil contained a greater amount of dissolved gas. The sulfonate concentration was also changed from 5 to 6 weight percent TRS 10-410 petroleum sulfonate. The use of the higher concentration of sulfonate in the surfactant slug tends to allow for higher losses expected in the reservoir due to higher adsorption and incomplete preflushing. The higher concentration of sulfonate does not significantly alter the phasevolume or interfacial tension behavior of the surfactant system.

Earlier laboratory work $(1,3)$ with dead Burbank oil showed effective oil displacement from cores when the sodium chloride concentration was $15,000 \mathrm{ppm}$. The surfactant system used for these oil displacement tests contained 5 weight percent TRS 10-410 petroleum sulfonate and 3 percent isobutyl alcohol in Ark-Burbank water containing 15,000 ppm of sodium chloride. Figure 16 gives the phase-volume behavior at reservoir temperature for mixtures of the Tract 97 surfactant system using 6 weight percent TRS 10-410 with dead Burbank crude oil. Comparison of Figures 15 and 16 shows that the phase-volume behavior of the system is not very sensitive to changes in the amount of TRS $10-410$ used ( 5 percent or 6 percent). 
In the above-mentioned study, surfactant systems were prepared from sulfonate, alcohol, water and crude oil from the Tract 97 pilot. The live crude oil was collected at stock tank pressure of 30 to 38 psig and brought to Bartlesville in pressurized containers. Figures 17 and 18 illustrate the phases obtained by equilibrating live Burbank crude oil from Tract 97 with the surfactant system that contained 6 percent sulfonate and 3 percent isobutyl alcohol. In the first case (Figure 17), the crude oil was collected at stock tank pressure and then equilibrated with the surfactant system under 30-50 psig pressure so that no solution gas could escape from the oil. In the second case (Figure 18), the crude oil was collected under pressure but was mixed with the surfactant system at atmospheric pressure. The resulting mixtures were then sealed to prevent further loss of solution gas. The two phase-volume diagrams are so similar that little change in the characteristics of the crude oil could have occurred during the brief depressurization step. The three-phase region in Figures 17 and 18 extends only from about 0.8 to 1.3 percent sodium chloride. For dead crude oil (Figures 15 and 16), the three-phase region exists from 0.9 or 1.0 percent to about 1.7 percent sodium chloride. This difference indicates a change in the properties of the crude oil, probably an increased amount of light hydrocarbons or dissolved gas.

Since the live crude oil better represents the oil actually present in the reservoir, interfacial tensions were measured between the adjacent phases represented in Figure 18. The controlling interfacial tension reached a minimum at about $10,000 \mathrm{ppm}$ sodium chloride, where the tension between top and middle phases became equal to the tension between middle and bottom phases. Figure 19 shows this minimum interfacial tension for live crude oil. For comparison, the figure also shows the corresponding curve for dead oil. For these curves a sodium chloride concentration of 9,000 ppm - about the level 
which gives the minimum interfacial tensions - was chosen for the Tract 97 pilot. It is expected that dilution of the injected surfactant system with a portion of the saline reservoir brine will automatically shift the phase behavior to an equivalent higher salinity.

C. Chemical Analysis of Fluids

Samples of injected and produced fluids were taken routinely by field personnel according to a schedule discussed in a later section. The resulting samples, plus many samples taken by R\&D personnel, were analyzed by R\&D, either in the field laboratory at Tract 97 or at the Phillips Research Center in Bartlesville, Oklahoma. In addition, many samples were analyzed for radioactive tracers by Teledyne Isotopes. Analyses performed by Phillips were:

1. Produced Water

Analyzed for sodium, chlorine, calcium, iron, corrosion inhibitor, isobutyl alcohol, sulfonate, polyacrylamide and, after August 2, 1976, radioactive tracers. Sodium was determined by flame emission and ionspecific electrode methods, chlorine by activation analysis, calcium by atomic absorption, iron by colorimetry with ortho phenanthroline, and corrosion inhibitor by colorimetry (for amines) after chloroform extraction. Isobutyl alcohol was measured by gas chromatography, sulfonate by a methylene blue colorimetric titration ${ }^{(4)}$, and polyacrylamide by an iodine colorimetric technique (5). The activity levels for the four radioactive tracers were determined by beta-ray and gamma-ray scintillation spectrometry.

\section{Produced $\mathrm{O} i 7$}

Analyzed for surfonate and alcohol about once a month. When a component began to appear in the fluid the frequency of these analyses was increased to define the trend more closely. 


\section{Injected Fluid}

During injection of the surfactant slug from August 2 to September 15, 1976, the injected fluid was analyzed every two to eight hours for sulfonate, alcohol and sodium chloride. These tests were run at Tract 97 and the Clarke mercuric nitrate method ${ }^{(6)}$ was used to determine the concentration of sodium chloride. Since there was a good possibility that air could enter the injection lines through the polymer mixing equipment, the freshwater feed and the solutions exiting from the mixers and entering Wells $97-W 18$ and $97-W 32$ were monitored frequently to ensure there was a residual hydrosulfite content. Oxygen levels were also measured at the mixer outlets, and at the above wellheads, using a Beckman Fieldlab Dissolved Oxygen Meter. Polymer concentrations and viscosities were measured on samples taken at these two wells. The latter measurements. were made on air-free samples in an air-free environment using a Brookfield viscometer. In addition to the samples discussed above, field personnel collected samples twice daily at the wellhead of 97-W18 and these were analyzed at the Phillips Research Center by Analysis Branch personnel.

\section{FIETD OPERATIONS}

During the second year the major field operations consisted of continuation of injecting saline preflush, preparation and injection of the surfactant slug and injection of the polymer solution at various graded concentrations.

\section{A. Sampling and Testing}

1. Individual Well Production Rate Test Production tests of producing wells in the area offsetting the pilot were made monthly, and tests of pilot producing wells were made weekly during all phases of the project. The data obtained were 
used to determine instantaneous oil and water production rates, annulus fluid level, and produced water salinity.

2. Individual Well Injection Rate Test

Injection well rates were determined every eight days in the area offsetting the pilot during all phases of the project. Tests on pilot injection wells were made at four day intervals during the saltwater preflush injection phase, daily during the surfactant solution injection phase and during the first week of polymer solution injection, and every other day (three per week) for the polymer solution injection phase between the first week and mid-May 1977. Data obtained from the injection well tests included instantaneous injection rates and injection pressures.

3. Total Pilot $\mathrm{Oil}$ and Water Production Volume

Total pilot produced water and oil were measured daily.

4. Fluid Sampling Schèdúe

Numerous samples of injected and produced fluids were collected from various points according to the schedule given in Table 6. In addition to samples from Tract 97 producers, three producers lying to the east and two lying to the west of Tract 97 were sampled monthly. These were monitored to check for movement of fluid injected into Tract 97 along the east-west fracture trend. The locations of these wells are given on Figure 2. The components measured and methods üsed were discussed previously. The gathering of samples, transmission to the laboratory, analysis, and reporting have proceeded smoothly and the information obtained has been very useful in maintaining close control of the operation. 


\section{B. Completion of the Saline Preflush}

Injection of the saline preflush solution was begun April 19, 1976, and was completed August 2, 1976. The injection fluid consisted of a solution of 15,000 ppm sodium chloride in Ark-Burbank fresh water. Daily monitoring of the solution by a standard titrating technique ensured that the salt concentration was maintained within the specified limits.

A total volume of 966,561 barrels of saline preflush solution was injected into the nine pilot injection wells. Cumulative volumes of the solution injected into the individual pilot injection weils are tabulated in Table 10, Production/Injection Data, August 1976, under the heading "Cumulative Injected Brine Solution".

Initially, attempts were made to use both the brine maker system and the dry salt proportioning system, but it was soon realized that the brine maker was more reliable and easier to control. The brine maker produced a concentrated brine averaging 31 weight percent salt, with a range of $30-32$ percent, dependent upon temperature variations. During most of the saline preflush period the brine maker was used.

The dry salt system involved a long screw conveyor (about 80 feet long) to transport the dry salt from the outside bulk storage bins to the mixing tank inside the building. The overload on the drive motor from periodic caking of the salt under high humidity conditions caused numerous operating problems. When the motor was resheaved to drive the screw conveyor at a greater speed, satisfactory operations could be maintained for longer periods but the mixing tank exposed the solution to more oxygen than the brine maker. A considerably shorter, smaller, high speed conveyor and protection from high humidities would be necessary for long-term continuous operation. 
During the first month of saline preflush, analysis of produced fluids showed that well $97-8$ had failed to respond to the previous prolonged freshwater preflush. A casing leak was found which was squeeze-cemented on May 18, 1976, to shut off the influx of extraneous water.

\section{Gelled Polymer Treatment at Well 27-W25}

Radioactive tracers broke through at Wells 97-28 and 97-35 within two days after injection of tracers on January 22, 1976. co57 from injection Well 97-W25 was found at Well 97-28 and tritium from injection Well 97-W32 was found at Well 97-35. Of the two cases, the breakthrough of $c^{57}$ at Well 97-28 caused more concern since a higher concentration of tracer was found there, and since Well 97-28 was one of the four inner-production wells.

Computer simulations of the fluid flow around Wells 97-W25 and 97-W32 showed that the high-permeability paths in these areas would not have catastrophic effects on oil production from the surfactant flood. Calculations similar to those reported earlier ${ }^{(1)}$ were repeated with revised values for oil saturation, reservoir thickness and pore volume. The early breakthrough of co 57 tracer was modeled with a reservoir simulator in which heterogeneity was represented by a system of noncommunicating layers. The normal permeability distribution (Figure 20) for the five-spot with injection well 97-W25 as its center and Well 97-28 at one corner was constructed from analyses of cores taken at nearby Welis $97-$ W26 and 97-W30. The reservoir thickness was estimated to be 42.1 feet in the simulations, and the maximum permeability was taken as $850 \mathrm{md}$. To account for the early breakthrough of $\mathrm{co}^{57}$ tracer, five additional layers (Figure 20), having a combined thickness of about five . inches and permeability ranging up to eleven darcys, were postulated to exist in the quadrant where flow proceeds from injection well 97-W25 to Well 97-28. 
Figure 21 shows that this modified permeability distribution led to reasonable agreement between the $\mathrm{Co}^{57}$ concentrations predicted in a computer simulation of a traced waterflood and that actually observed at Well 97-28. In actual practice, various modifications of the permeability distribution were tested before the match in Figure 21 was obtained. The computer model was then used to forecast oil production due to a surfactant flood in the five-spot centered on Well 97-W25 for both the normal and the modified permeability distributions. Figure 22 shows that surfactant flood oil from the 97-W25 five-spot would be reduced by about four percent because of the high-permeability path to Well 97-28. A similar analysis showed that oil production would be reduced by about two percent due to the high-permeability path from Well 97-W32 to Well 97-35.

Because of this anticipated reduction in oil recovery, the decision was made to treat injection Well 97-W25 with a gelled polyacrylamide to improve the distribution of fluids before the start of surfactant injection. Table 20 gives an outline of the procedure used in the gelled-polymer treatment. A total of about 850 pounds of Betz Hi-Vis polyacrylamide was gelled in situ with a proprietary Phillips technique ${ }^{(7)}$ during the period June 14-17, 1976. Adjacent Wells $97-14,97-21$ and $97-22$ were shut in so that the flow of polymer would be primarily from injection Well 97-W25 to Well 97-28. The polymer treatment in Well 97-W25 consisted of injecting alternate slugs of (1) 5000 ppm polyacrylamide and 500 ppm sodium dichromate dihydrate in preflush brine, and (2) $700 \mathrm{ppm}$ sodium hydrosulfite in preflush brine. Four cycles were used, each slug in a cycle containing about 100 barrels of fluid. The injection rate was held near 400 barrels per day during the treatment, and the maximum surface pressure was 100 psi. At these rates and pressures, there. was very little risk of increasing the conductivity between wells by parting the formation. 
A second tracer test conducted on July 1, 1976, with Co 57 at Well 97-W25 showed the effectiveness of the gelled polymer treatment. Figure 23 shows that after the treatment, tracer breakthrough was delayed and the maximum concentration was reduced. Figure 24 shows a comparison between computed and actual profiles for $\mathrm{Co}^{57}$, and Figure 20 gives the permeability distributions required for the match.

Other evidence of response to the gelled polymer treatment included an increase in injection pressure, a sudden rise in produced water salinity at Well $97-28$ and a definite rise in oil production rate and an associated decrease in water/oil ratio. These latter effects are shown in the production curves of Figure 62 where the oil production rate rose to a maximum of $30 \mathrm{~B} / \mathrm{D}$ during July, 1976, and the water/oi工 ratio dropped from about 70 to 25.

Using the computer model matched to tracer behavior, surfactant flood performance calculations were made to show the effects of the gelled polymer treatment on oil recovery. Figure 22 shows the comparison for treated and untreated channel and the case for the absence of a channel. The treated channel case give the best recovery șince it would cause some improvement to heterogeneity even in the absence of a channel. These calculations showed that the treatment would result in an increase of 2300 barrels of oil.

\section{Chemical Handling Logistics}

A steam generator was connected to the steam-coil piping of the spheroid sulfonate storage tank in Oklahoma City and warming of the sulfonate was begun on July 7, 1976. One week was required to raise the bulk sulfonate temperature from ambient to $160^{\circ} \mathrm{F}$. Circulation and warming of the sulfonate was by natural convection through the fluid. Heat was supplied by the steam generator continuously until the tank was empty.

Seven rail tank cars of sulfonate were moved to a rail siding 35 miles from the pilot site as a contingency measure during transport of the sulfonate 
from the Oklahoma City storage location. The sulfonate from these tank cars was trucked to the pilot site near the end of the surfactant injection phase. Two insulated tank trailers were used to transport the sulfonate from the storage tank to the pilot site, requiring three deliveries per day. The tank trailers were equipped with steam-heating coils, but these were not used because of extremely low heat losses during transport.

The alcohol was delivered by tank trailer from the Wichita storage location to the pilot site as needed and the salt delivery continued as during the saltwater preflush phase.

The polyacrylamide, purchased from Betz Laboratories, Inc., was stored in a nearby warehouse and trucked as needed to the chemical mixing building. The bags were opened as required and emptied by hand into the floor hoppers of the two GACO Continuous Mix Polymer Feeders. During the injection of the maximum polymer concentration (2500 ppm) about 64 bags of polymer were required for each mixer during a 24 -hour period.

In similar future operations or scale-up to commercial expansion the use of bulk polymer, stored in large bins, is strongly advised. Other contractors have experienced little difficulty in automatic feed systems with bulk storage.

\section{E. Operation of Chemical Mixers}

The surfactant slug, an aqueous solution of the petroleum sulfonate, isobutyl alcohol and sodium chloride, was prepared as described in the First Annual Report (1) (page 39). Figure 25 shows the revised mechanical flowsheet for injecting the surfactant solution, showing the modifications made during and after construction. 
Just prior to the end of the saltwater preflush injection phase, the surfactant blending system was started up for operational testing. Four hundred barrels of surfactant solution were blended and the proportioning pumps were calibrated during the test. The surfactant solution was flushed through the injection system piping to remove particles and scale that could be dislodged by the cleansing action of the surfactant. The injection lines were disconnected from the wellheads during the flushing operation to prevent the entry of any sand-face-plugging material into the wells. The flushed solution was collected in portable tanks and reclaimed. The lines were purged with saltwater preflush solution before reconnecting to the wellheads.

Figures 26 and 26A show the mechanical flow for injecting the polymer solu-" tion, with modifications made during and after construction. The solid polyacrylamide (in 50-pound bags) was transferred manually as needed to the floor hopper of the GACO feeders: Because of the considerable dust generated when the bags are emptied into the hoppers, face masks with filters must be worn by operating personnel. In addition, since the polymer is very hygroscopic, contact with water or high humidity must be minimized to prevent "balling" and subsequent dissolution problems. If dry polymer is spilled on the floor, as much as possible must be removed in a dry state before attempting to flush it to a water drain. Aqueous solutions are very sticky and slippery underfoot; metal grill walkways are strongly advised for areas around the GACO feeder.

The GACO feeders operate by feeding finely granulated polymer from a vibrating tray. The feed rate can be checked by collecting the dry polymer discharge over a closely timed period (e.g., 30 seconds timed by a.stopwatch) and 
then weighing. It was observed that the grain sizes of the various lots varied considerably and thus affected the feed rate (and concentration of polymer solution). This source of concentration variation was minimized by using only one lot at a time.

Problems encountered with the polymer blenders were as follows:

1. Air, used initially to transfer solid polymer to the overhead hoppers, contained enough moisture to cause the polymer to plug off the air intake every 24 hours or less. This problem was solved by substituting dry nitrogen for air.

2. Friction wear on the rubber flapper valves of the overhead hoppers required that the rubber be replaced every two to three months to ensure steady gravity feed to the mixers.

3. In spite of the nitrogen blanket maintained over the vibrating tray feeders, moisture from the mixing tanks interfered with the steady flow of solid polymer. To prevent the gradual reduction in polymer feed rate, it was necessary to clean the moisture-affected polymer from the trays every day.

4. The paddles inside the flow sensors have broken off several times causing an entire blending unit to shut down. Since the function of this sensor was adequately performed by the low pressure alarm on the fresh water supply and the low level shut-down on the mixing tank, the flow sensors were considered unnecessary and were removed.

\section{F. Chemical Injection}

1. Surfactant

\section{a. Allocation of Surfactant to Various Five-Spots}

It was important to distribute the 288,000 barrels of surfactant 
solution scheduled for injection into Tract 97 in some logical manner among the nine injection wells supplying the pilot area. The problem was studied theoretically, and then the computer results were modified slightly to fit field operations. The objective selected in allocáting the surfactant was to maximize the oil contacted by surfactant in the total pilot. It was assumed that each 10-acre pattern was uninform throughout and that total silfonate adsorption was 4500 pounds per acre-foot. (Recent laboratory studies indicate that this estimate may be more realistic than the 3,500 pounds per lacre-foot used in earlier computer model studies.) Curves representing the oil contacted by surfactant as a function of surfactant slug size were prepared for all nine five-spots using the layered reservoir model* referred to in previous studies. (1) The maximum oil: contacted for the pilot as a whole by the 288,000 barrels of surfactant solution was then found by picking points on the nine curves where the slopes were equal and where the individual slug sizes added up to 288,000 barrels. These curves are shown in Figure 27. The points of equal slope are indicated on each curve by a small triangle. For clarity, the results are listed on Table 21. The optimum slug size varied from a minimum of 16,524 barrels in 97-W25 to a maximum of 66,192 barrels in 97-W20. Similarly, the oil contacted in Well 97-W20 was about four times as great as in Well 97-W25.

Two other surfactant distributions were considered in addition to the optimal distribution. Table 22 gives the results for equal

* The specifics of the application of the model to allocation of surfactant are described in Appendix A. 
volumes of surfactant solution injected into each five-spot. This represents a reduction for Wells $97-\mathrm{W} 18$ and $97-\mathrm{W} 20$ and an increase for all the others. The total oil contacted is about 5.8 percent less than for the optimal distribution. For the third distribution (Table 23), the slug size for each five-spot was made proportional to the pore volume of that five-spot. In this case, total oil contacted is about 4.5 percent less than the optimal. It appears reasonable to conclude that, in the range of slug sizes being considered, the contacted oil is not highly sensitive to variations in the slug distribution.

The above analysis ignored time and additional oil due to polymer control of sweep efficiency. In addition, extremely uneven distributions of injected fluids are not practical from an operational point of view. Radioactive tracer data showed (as discussed previously) that the injected.fluid distributions were not uniform across each of the nine patterns. The computer analysis was used as a guide in deciding to inject 28,000 barrels of surfactant into each well in the north row (Wells 97-WBO, 97-WB1, and 97-WB2), 20,000 barrels into each well in the middle row (Wells 97-W25, 97-W26, and 97-W27) and 48,000 barrels into each well in the south row (Wells $97-\mathrm{W} 18,97-\mathrm{W} 19$, and $97-\mathrm{W} 20)$

\section{b. Start-up Procedure}

During the 246 days of preflush injection, the fluid moved through the injection well fracture system into the formation establishing a sweep pattern which was unique to the conditions of fluid injection and production. The surfactant solution has a viscosity of about 
five cp or about eight times that of the preflush at reservoir conditions. Therefore, injecting it at the same rate as the preflush would risk extending the fractures, causing some of the surfactant to move through sand which had not been conditioned by preflush. Laboratory experience has shown that as the surfactant displaces oil from the sand the permeability to the solution increases, offsetting the increased viscosity significantly. Therefore, a start-up procedure was developed to permit the displacement of the oil adjacent to the fractures at reduced injection rates before $f u l$ injection rates were imposed. As a further safeguard against extension of the fractures, the pressure was continuously recorded to reveal the occurrence of sudden breaks in the pressure curve signifying the opening up of more sand face to fluid flow. Well 97-W19 was selected as the most rigorous test since it was allocated 1,200 $\mathrm{BPD}$ ( $\mathrm{f}$ inal rate) and had the poorest injectivity of the nine injection wells. The start-up procedure was as follows (see Figure 30): (1) With pressure recorders on the tubing at the wellheads of 97-W18, 97-W19, and 97-W20, adjusted preflush rates to the levels selected for the surfactant (i.e., 1,200 BPD for W18, W19, and W20; $500 \mathrm{BPD}$ for W25, W26, and W27; and $700 \mathrm{BPD}$ for WBO, W31, and W32). This was started on July 30 and continued until August 2 to allow time for the reservoir to adjust to these rates.

(2) On August 2, an Amerada gauge was run into Well W19 to permit bottomhole pressure measurements after wells went on vacuum at reduced rates.

(3) After two hours recording of bottomhole pressure with preflush 
at $f u l l$ rate, the rate for all nine wells was cut by 50 percent by shutting off one injection pump.

(4) After six hours recording at half rate, surfactant injection was begun without changing the rates.

(5) Surfactant injection was continued at half rate until 11:15 a. m. August 4 (a total of about 44 hours). At this time the rate was doubled and the pressures were monitored continuously for evidence of pressure breaks indicative of fracture extension. Bottomhole pressures were monitored in Well 97-W19 until the surface pressure recorder reading became positive. At that point, bottomhole pressure readings were ended.

\section{c. Monitoring}

\section{(1) Chemical Composition}

The quality of the injected surfactant system was monitored around-the-clock by research personnel. In all, 599 samples of the surfactant solution were taken from the injection system and analyzed. Initially, samples were taken from the trunk line and at the wellheads of the nine injection wells. After the first two weeks, samples were gathered only at well 97-W19 and at sample point three in the trunk line just downstream of the injection pump. The goal was to maintain the concentrations of sulfonate, alcohol and sodium chloride within five percent of the target values, although deviations of up to 20 percent should not destroy the ability of the surfactant system to displace oil. The concentration of sulfonate was maintained within the five percent tolerance of the target value of six weight percent TRS 10-410 sulfonate for 95 percent of the samples analyzed: The isobutyl alcohol concentration fell within the 
same five percent tolerance of the target value of three weight percent in 63 percent of the samples, and the salt concentration was maintained within a five percent tolerance of the target value of 0.9 weight percent sodium chloride in 86 percent of the samples. Figures 28 and 29 show the variations in the concentrations of sulfonate, alcohol and sodium chloride in samples taken at sample point three and 97-W19, respectively. The average concentrations of the components were 6.04 percent sulfonate, 2.92 percent isobutyl alcohol and 0.888 percent sodium chloride. The sodium chloride concentration was maintained at an average value of 1.473 percent from August 2 to August 5, 1976, before the target concentration was revised. Of the 568 samples analyzed for alcohol, 160 had concentrations of isobutyl alcohol below 2.85 percent, and 43 had concentrations below 2.7 percent. Overall, the injection of the surfactant system proceeded on schedule.

(2) Pressure

Figure 30 shows the bottomhole pressure record for Well 97-W19 with the injection rate plotted on the same graph. The pressure rise which occurred when the surfactant reached the sand face shows up clearly at just under ten hours of elapsed time. There was a steady decline caused by the reduced injection rate, lasting until the rate was doubled at 44 hours. During the remainder of the time the pressure rose smoothly except for a break at about 56 hours and another at 90 hours. These are believed to have been caused by small extensions of the fracture. The larger of these (at 90 hours) was analyzed by assuming the fluid was in linear flow away from the fracture; 
that the fracture, before and after extension, reached across the entire sand thickness; and that the pressure break of 15 psi was due totally to extension of the fracture. Calculation, using Darcy's Law for linear flow, showed that the increase in cross section area open to flow which would account for the 15-psi break corresponded to about 14 feet of additional fracture length. A decision was made to continue the selected rate $(1,200 \mathrm{BPD})$ unless further pressure breaks occurred, in which case the rate would be reduced. There were no indications of any further pressure breaks so the rate was maintained at 1,200 BPD for the duration of surfactant injection.

\section{d. Production Well Rates}

During the critical phases of surfactant start-up, the production wells were operated at the rates which were in effect during the latter stages of preflush. After injection had been stabilized, a new set of production well quotas was put into effect. These quotas were determined in a manner similar to that used in optimizing the rates during the final two months of preflush, as discussed previously. For surfactant the injection rates had already been specified as discussed above. It was necessary, therefore, only to select production rates which would balance fluid production and injection inside the pattern and take into account, as much as possible, the channeling tendencies which tracer studies and freshwater production had revealed. The resulting quotas are shown on Figure 31. 


\section{Polymer}

a. Schedule

When the pilot was designed, the specifications provided by Phillips R\&D called for injection of a total of $787,500 *$ pounds of Betz Hi-Vis polyacrylamide. The slug was to be logarithmically graded from an initial concentration of $2,500 \mathrm{ppm}$ to a final 250 ppm. To provide the schedule of polymer concentration targets, the following equation was developed:

$$
C=C_{0} e^{-D N}
$$

Where $\mathrm{C}=$ polymer concentration, $\mathrm{lbs} / \mathrm{bbl}$.

$$
\mathrm{C}_{\mathrm{O}}=\text { initial concentration, } \mathrm{lbs} / \mathrm{bbl} \text {. }
$$

$\mathrm{N}=$ number of bbls injected

$\mathrm{D}=$ decline coefficient given by

$\frac{C_{0}-C_{f}}{D}=$ total weight of polymer to be injected

$$
\mathrm{C}_{\mathrm{f}}=\text { final concentration, lbs/obi. }
$$

For the case at hand

$$
\begin{aligned}
& C_{0}=0.876 \mathrm{lbs} / \mathrm{bbl}=2,500 \mathrm{ppm} \\
& C_{f}=0.0876 \mathrm{Ibs} / \mathrm{bbl}=250 \mathrm{ppm} \\
& D=1.00 \times 10^{-6}
\end{aligned}
$$

Thus, specifically,

$$
\mathrm{C}=0.876 \mathrm{e}^{-1.00 \times 10^{-6} \mathrm{~N}}
$$

This equation provided the basis for the continuous curve given in Figure 32. It was not practical to change the concentration continuously, so the slug was broken up into a series of nine portions which would approximate the continuous curve as shown by the stepwise

* Scaled from $1,400,000$ pounds for 160 acres. 
graph in Figure 32. Table 24 gives the concentrations and volumes of these portions. During the course of polymer injection the actually realized values were compared with the continuous curve and when necessary, the schedule was revised. One revision was made when polymer concentration was reduced from 2,000 ppm to 1,500 ppm. During. the first two phases of polymer injection, it was noted that any interruptions caused the average concentrations to fall below the planned levels. To avoid this in subsequent phases, the target levels were raised about $100 \mathrm{ppm}$ so that the average would fall slightly above, rather than below, the planned (nominal) level. These revisions are shown in Figure 32 and Table 24.

\section{b. Allocation of Polymer Among the Five-Spots}

The polymer appears to have a dual role in the surfactant/polymer process. First, it serves as a buffer to preserve the integrity of the surfactant slug by maintaining a favorable mobility ratio between the drive fluid and the surfactant. Second, it supplements the surfactant action by improving the volumetric sweep, resulting in additional enhancement of oil displacement aside from surfactant action. The former effect will be supported by allocating polymer to those five-spots which have had the largest surfactant slugs. These are generally the more homogeneous five-spots. On the other hand, the latter effect would be most pronounced in the more heterogeneous five-spots. Thus, a choice must be made as to which effect should receive the most consideration. In making this decision, a further factor must be considered: that the most homogeneous five-spots which received the largest slugs of surfactant are the tightest. Therefore, limitations of injectivity, are involved.

By computer modeling, it was determined that the minimum reguirements 
for protection of the surfactant slugs in the three south five-spots would be met by an equal apportionment of polymer among the nine five-spots. After careful consideration of the alternatives a compromise was selected, namely, that the best approach would be to begin polymer injection with equal rates in all five-spots, study the behavior of the polymer in the reservoir through pressure measurements and then, if feasible, modify the allocation of polymer to approach, as nearly as possible, slug sizes proportional to those used for surfactant. This would be 30 percent in north row, 20 percent in center row, and 50 percent in south row.

\section{c. Polymer Start-Up}

\section{(1) Planning}

As with the surfactant solution, injection of the polymer solution had to be carefully monitored and controlled to avoid extending the fractures. At a concentration of $2,500 \mathrm{ppm}$, the effective viscosity was estimated to be over $300 \mathrm{cp}$ by measurements in Berea cores. (1) In the initial plans for injecting the polymer, the rates were scheduled to rise from an initial value of $400 \mathrm{BPD}$ at $2,500 \mathrm{ppm}$ in each well up to a maximum level of 900 BPD at $250 \mathrm{ppm}$. Calculations showed that it would not be possible to inject at $400 \mathrm{BPD}$ without extending the fractures if the polymer behaved in the reservoir as it did in the Berea core. Accordingly, further study was conducted by Phillips R\&D to get a more realistic estimate of in situ polymer mobility to determine whether the initial rate or concentration should be modified. These studies indicated that the polymer mobility in the reservoir could be expected to range between $0.97 \mathrm{md} / \mathrm{cp}$ and $2.5 \mathrm{md} / \mathrm{cp}$ at the $2,500 \mathrm{ppm}$ concentration. Calculations of total 
pressure drop across the sequence of polymer concentrations and the micellar zone showed that if maximum mobility was assumed, the total pressure drop would be about 160 psi at an injection rate of $400 \mathrm{BPD}$ and about $220 \mathrm{psi}$ at $600 \mathrm{BPD}$. At minimum mobility these values would become $470 \mathrm{psi}$ and $710 \mathrm{psi}$, respectively. Based on experience in injecting preflush and surfactant, under normal operation of injection and production wells, it can be reasonably expected that a pressure drop of $350-450$ psi can be used without excessive extension of fractures. It appeared, therefore, that there was a reasonable chance that the initial $400 \mathrm{BPD}$ rate could be achieved at 2,500 ppm without extending the fractures and the experience gained at that rate could then be used in setting rates for the lower concentrations. Accordingly, the start-up procedure was designed for $400 \mathrm{BPD}$ injection into all injectors at 2,500 ppm.

(2) Control of Injection Well Rates A polymer flow rate control device is of particular importance in the Tract 97 pilot because there is a wide range of injectivity (discussed in detail in a later section of this report) among the nine injection wells. It is anticipated that in more heterogeneous areas of the North Burbank Unit and other reservoirs where polymer may be injected, the range of injectivities could be even greater. The primary problem in controlling polymer flow rate is that shear degradation of the polymer must be minimized. Phillips R\&D developed a system, referred to as the Phillips Polymer Flow Rate Controller, which has proved very effective in maintaining flow control with very little polymer degradation. This device is described below. 
The approach taken was to dissipate the fluid energy in the form of friction along smooth tubing walls rather than across shear-producing devices such as orifices, etc. The problem was to provide an adequately variable rate without undue complication in constructing the system. This was done by manifolding together a set of eight 100-foot coils of copper tubing of various diameters to provide a means of combining the coils in paraileil so that $3 \dot{z}$ different flow settings could be made. To avoid shearing in the selector valves, ball valves were used so that when fully opened these offered essentially no resistance to flow and no tortuous paths. A photograph of the Phillips Polymer Flow Rate Controller is shown in Figure $32 \mathrm{~A}$.

Before putting the system into operation it was tested carefully to determine its effectiveness in maintaining the desired properties of the polymer solutions. Solutions of variaus concentrations of Betz $\mathrm{Hi}$-Vis polyacrylamide were passed through the controller at a series of rate settings and the viscosity and screen factor of the solution before and after it passed through the controller were measured. The tests showed that 83 percent of the samples had less than 10 percent loss in viscosity, the average loss being 7.7 percent. The loss of screen factor was slightly greater, with 83 percent of the samples having a loss below 17 percent. The average loss was 11 percent. Separate studies, also made by Phillips R\&D, showed that reductions in screen factor of the above levels have a very small effect on the mobility of the solution in a porous medium. For example, a screen factor loss of 11 percent corresponds to essentially no change in mobility for a 2000 ppm solution of Betz Hi-Vis. 
Accordingly, it was concluded that the Phillips Polymer Flow Rate Controller would be very effective in maintaining the desired solution properties and provide an adequate selection of rates. Tests (described in a later section) made on polymer solution samples taken downstream of the controllers during polymer injection showed that the system worked well in practice.

(3) Start-up Procedure

As with the surfactant start-up, one well was chosen for special special attention to provide as much information as possible on reservoir behavior. For the polymer, Well 97-W31 was selected because it was centrally located in the north line of injectors where fracture extension was least likely due to the greater permeability in this area. The procedure was as follows:

(a) On September 10, 1976, the surfactant solution was routed through the tubing coils installed for polymer flow control, and rates were adjueted to $800 \mathrm{BPD}$ at all injcctors.*

(b) The total surfactant rate was cut to 3,600 BPD by shutting in one of the injection pumps, and injection was continued until the remainder of the surfactant had been injected.

(c) The wellheads of Wells 97-W18, W19, and W20 were equipped with 0-100 psig pressure recorders.

(d) A few hours before the end of surfactant injection, bottomhole pressure measurements were made in Wells 97-W19 and 97-W26. Then a bottomhole gauge was run into Well 97-W31 for bottomhole pressure monitoring.

* The setting was made at 800 BPD instead of 400 BPD because the latter rate was below the limits of the coil flow controllers while injecting surfactant. 
(e) Polymer was started at 3,600 BPD on September 15, 1976. Rate adjustments were made at individual wells using a low shear meter which was switched into the line only long enough to check the flow rate.

\section{d. Monitoring}

\section{(1) Chemical Composition}

Injection of a solution of polyacrylamide at a nominal concentration of 2,500 ppm began on September 15, 1976, after completion of the surfactant slug. Both the viscosity and the concentration of the injected polyacrylamide solution were monitored. Air-free samples of the polymer solution were gathered twice each week at injection Wells 97-W18 and 97-W32 and returned to the laboratory for measurement of viscosity. Figures 33 and 34 show the average viscosity of the polyacrylamide solutions at reservoir temperature of $120^{\circ} \mathrm{F}$ as polymer injection progressed. The average viscosity of the polyacrylamide solution during each of the first six phases of the graded mobility buffer is included in Table 25. The concentration of polyacrylamide in the mobility buffer was monitored directly from the weight of polymer and volume of water injected each day. For comparison, colorimetric analyses were run in the laboratory on samples gathered each day at injection Well 97-W18. Figures 33 and 34 also show the trend of polymer concentrations determined by analyses on solutions taken at Wells 97-W18 and 97-W32. The data in Figure 33 for polymer concentration were abbreviated to include only those samples taken the same day as those on Figure 34 to eliminate a large number of overlapping points. The extra points resulted from polymer analyses on samples taken twice daily at Well 97-W18. The summary data in Table 25 show that there has been good agreement between the target and the actual injected concentrations for the polymer. 


\section{(2) Pressure}

As with surfactant, the purpose of the start-up procedure for polymer was to provide a smooth transition from one fluid to another under conditions which would reduce the risk of extending the fractures. Careful monitoring of pressures helped to define the limits on injectivity as rates were stabilized at operating levels and also permitted evaluation of fluid flow behavior under actual field conditions.

Examination of the bottomhole pressure data collected during the first fifteen days of polymer injection showed no evidence of pressure breaks which could be interpreted as extension of the fracture in Well 97-W31. As soon as the well showed a positive surface pressure, monitoring was taken over by a surface pressure recorder and is continuing. As of May 15, no indications of any significant fracture extension had been found.

(a) Evaluation of Polymer Mobility

It is extremely difficult to transfer laboratory polymer mobility data into reservoir behavior. In addition to the differences in preparation of the solution under field-mixing conditions, the solution can undergo deterioration due to exposure to oxygen, mechanical shear and reaction with any divalent cations which may remain in the reservoir rock from imperfect sweep of the reservoir by the preflush. Careful design of equipment and operating pro-cedures can hold polymer degradation to a minimum up to the point of entry into the wellheads. Analyses of samples taken at the wellheads (discussed above) showed that polymer solution of satisfactory characteristics was entering the injection wells. The following paragraphs summarize an analysis of the pressure data taken at Well 97-W31 to estimate the effectiveness of the polymer 
flowing in the reservoir. Details are given in Appendix B.

The evaluation of in situ mobility of the polymer required that:

/1/ The pattern of fluid flow be identified so that a valid model could be set up,

/2/ The mobility of fluids moving ahead of the polymer be estimated so that their contributions to the total pressure drop could be determined, and

13/ The reservoir pressure be estimated so that the pressure gradient across the polymer bank could be related to the measured bottomhole pressure.

Tracer and freshwater production behavior indicated that the fracture in Well 97-W31 extended towards the east and pressure fall-off measurements made in November 1975 gave a fracture length of 329 feet (Figures 6 and 38). This information suggested that a linear flow model might be a reasonable approximation to the flow configuration in the south half of the northeast quadrant of the 97-W3 1 five-spot. A streamline flow study (Figure 39) showed that flow was roughly linear in that area so that Darcy's equation for linear flow could be applied using the model shown in Figure 40. Estimates were then made of the mobility and pressure drop across the preflush zone and the microemulsion zone. Before the pressure drop across the polymer zone could be determined (by difference), the average reservoir pressure (at the 50 percent equipressure contour as discussed in a previous section) had to be estimated. No data were available since the reservoir had been depressured an indeterminate amount during injection of fluids at reduced rates 
since September 10, 1976. To estimate the reservoir pressure, the calculation of mobility of the polymer bank as a function of the volume of injected polymer was made for a series of assumed reservoir pressures. These were then plotted (Figure 41). As the figure shows, the curves tend to flatten out and converge after about 4,000 barrels of polymer had been injected. The high mobility value (passing through a maximum at 2,000 barrels injected) may be due to low polymer concentrations which occurred early in the 2,500 ppm slug while mixer shake-down was in progress. In selecting the best estimate for polymer mobility and reservoir pressure, the curves of Figure 41 for pressures of 600,650 and 670 psig were taken for trial against the measured bottomhole pressures. This was done by selecting a mobility value from Figure 41 for each of the pressures as the average for the flat portion of the curve. These values and the corresponding assumed average reservoir pressures were then used to back-calculate the bottomhole pressures as shown in Table 26, and the results were plotted in Figure 42. It will be noted that the dashed curve representing the 670 psig reservoir pressure and mobility of $0.11 \mathrm{md} / \mathrm{cp}$ fits the observed data most closely. Also, the trend is towards curves of lower slope as the assumed reservoir pressure increases, so that the agreement will probably be worse with values above 670 psig. Accordingly, the mobility of $0.11 \mathrm{md} / \mathrm{cp}$ and reservoir pressure of $670 \mathrm{psig}$ appear to be the best estimates attainable from the treatment of the data.

It must be emphasized that the mobilities determined as discussed above are highly approximate because: /1/ The flow is not strictly linear, 
/2/ The fracture length and height may not be constant for all fluids,

13/ The fracture orientation may not be exactly east-west,

/4/ The mobilities estimated for the preflush and microemulsion slugs may not be very accurate,

15/ Heterogeneities in the formation are not considered, and /6/ The reservoir pressure is not accurately known.

The fracture length referred to in item /2/ above is uncertain. even though it was calculated from pressure fall-off measurements. Obviously, there are uncertainties arising from the measurements themselves, but in this case these are increased because the fracture length is dependent on injection rate and viscosity of the fluid. These mobility estimates were made while injecting a highviscosity polymer solution at $426 \mathrm{BPD}$. On the other hand, the fracture length was measured during injection of water at $870 \mathrm{BPD}$, so there could be a significant difference in the fracture length for the two sets of measurements. However, the higher viscosity of the polymer tends to compensate for the lower injection rate during its injection so the error is probably not as bad as might be expected. In any future measurements of this type it would be preferable to run a pressure fall-off with the viscous fluid at the actual injection rate used in the mobility measurements to minimize this error.

In spite of these weaknesses, the calculation should be good enough to provide a semiquantitative measure of polymer quality within the reservoir rock and perhaps a means for extrapolation of pressure trends during polymer injection. 
Since the calculated values of Figure 42 are based on the assumption of constant fracture length, polymer mobility, etc., any divergence of the calculated from the measured pressure may be interpreted as a failure of one or more of the assumptions. For example, if the pressure rose at a lower rate than the calculations predicted, this might indicate either extension of the fracture or deterioration of the polymer in situ. It would be expected that the fracture extension would tend to occur suddenly while polymer degradation in the pay would be more gradual. On the other hand, a gradual rise in pressure above the calculated values could indicate a tendency towards plugging, although changes in reservoir pressure would produce ambiguity. Thus, the application of pressure measurements during polymer injection can serve as a useful diagnostic tool as well as an indicator of polymer quality in situ.

The estimate of polymer mobility in the North Burbank Unit reservoir should be useful in designing the mobility buffer in any expansion of the surfactant pilot. The applicability will, of course, depend on the accuracy of our knowledge of the reservoir configuration and other factors discussed previously.

It would be worthwhile to perform some additional carefully controlled measurements to pin down some of the uncertainties in the measurements since a more accurate assessment of the polymer quality in situ could lead to a decision to reduce polymer concentration with substantial savings in chemical costs in a commercial expansion. Additional measurements of mobility were obtained by pressure buildup tests on Wells $97-35$ and 97-23. These are discussed in a later section.

$$
-44-
$$




\section{e. Well Rates}

During the first three concentrations of polymer solution, the injection rates were increased as the solutions of successively lower concentrations were begun. These increases were always made with pressure monitoring to avoid extending the fractures. Also, to the extent possible, advances in rates were made to move in the direction of allocating the polymer in the same proportions used for the surfactant; i.e., 50 percent in the south line of injectors, 20 percent in the center line, and 30 percent in the north line.

Production well quotas were adjusted after injection was stabilized following each change in injection rate using the same basis as that discussed in the section on Production Well Rates during surfactant injection. The well quotas arrived at are listed in Table 27.

Further details relating to well quotas and the degree of attainment of these are discussed in the section on Project Performance.

\section{G. Project Performance}

\section{Injection Wells}

The operation of the injection wells during all phases of the project has offered very few problems. The critical factor, discussed earlier, has been to monitor these wells to assure that the fractures formed and held open during the preflush would not be extended during chemical injection to open up areas not previously preflushed. The techniques and results of these operations have been discussed in previous sections of this report.

Figures 43-51 show the injection rates and wellhead pressure of the individual pattern injectors since the start of continuous operation on 
December 1, 1975. The target rate of each well is also shown. It will be noted that the rates were held quite close to the target values during the injection of surfactant and polymer. Control was not regarded to be so critical during preflush. The fact that the wells were all manifolded to a single feed line made individual well control more difficult since any adjustment of one well affected all the others.

Wellhead pressures reached the highest levels along the south injection line because the sand is tighter in that area and also higher rates were required because the pore volumes in these five-spots were larger. At times all wells took fluid on vacuum, when injection rates were held down as in the period in September 1976 when polymer was first being injected. These periods are indicated by breaks in the pressure curves. The most consistently elevated pressure was found at Well 97-W19 since it had the lowest injectivity and a high quota. The wells in the center line were on vacuum most of the time because their five-spots had the smallest pore volumes, and hence, the lowest quotas. By the first of February 1977, all the wells except 97-W27 were showing some wellhead pressure due to the accumulation of low-mobility fluid in the sand. This increase was partially due to the fact that efforts were made to inject the fluids at as high rates as possible subject to the limitation of fracture extension. Consequently, during the first three phases of polymer injection any tendency for pressure to decline due to injection of a less viscous solution was offset by an increase in injection rate.

In January 1977, however, the productivity of some of the producing wells began to decline as the low-mobility fluids began to occupy substantial portions of their drainage volumes. This placed a limit on injection 
rates since injection at rates exceeding the capability of the production wells to produce would lead to loss of chemicals and/or oil outside the pattern. Therefore, the injection rates were not raised after the increase which was put into effect on December 28, 1976.

\section{Production Wells}

a. Oil Production and Water/Oil Ratio

Figures 52 to 67 give the production behavior of the pattern producers. These figures show that there has been substantial response to chemical flooding in Wells $97-06,17,23$ and 28 . Also, a small response has appeared at Wells $97-22,33$ and possibly 35 and 36. In all these wells there has been a progressive decrease in water/oil ratio reaching its lowest level in Well 97-28 at a value under 10.

Most of the response has occurred at interior wells. This was to be expected since response should come from all four quadrants offsetting these producers. However, it would seem likely that most of the oil produced at these wells thus far has come from one such quadrant since it is improbable that the oil being banked in all four quadrants would reach the producer at the same time. Also, it is expected that the response to date represents flow through the more permeable zones while the bulk of the chemicals is moving through zones of greater thickness and lower permeability. This hypothesis is supported by the fact that sulfonate has been produced at only one well (97-28) and the total amount of any single chemical species produced is only about four percent of the amount injected. Thus, 96 percent is still in the pay. Chemical production is discussed in detail below. 


\section{b. Chemical Content of Produced Fluids}

(1) Surfactant Components

Minor amounts of alcohol have been observed at several production wells. Petroleum sulfonate was detected in the produced fluids only at Well 97-28. Figure 68 gives the trend of sulfonate concentration in the oil from Well 97-28. The figure shows that the sulfonate hit a peak near three weight percent in September of 1976 and decreased to zero by January 1977. Spot checks on the sulfonate content of the produced water showed that most of the sulfonate is contained in the oil phase, confirming laboratory experience. In all, about 5,300 pounds of sulfonate were produced in the oil and about 1,200 pounds* in the water from Well 97-28. This totals only 0.1 percent of the total sulfonate injected into Tract 97.

Measurable amounts of isobutyl alcohol have been detected in the produced water at 12 wells in the Tract 97 pilot area. In addition, a trace of alcohol has been found at Wells $97-1$ and 97-29. Only Wells 97-21 and 97-33 had not produced any isobutyl alcohol by May 15, 1977. Production of alcohol has stopped completely at Wells 97-24 and 97-35, while the concentrations of alcohol in the produced water at Wells $97-9$ and $97-14$ have dropped to only a trace. Figure 69 shows the dates of appearance and quantities of alcohol which have been produced with the fluid from various pilot wells. The date of confirmed breakthrough was defined as that date when the concentration of alcohol in the water first exceeded 30 ppm with

* Water/oil ratio was between 70 and 100 during this period. 
the condition that the concentration held above $30 \mathrm{ppm}$ for at least a month. In all, alcohol production to May 15, 1977, totaled about 111,000 pounds, or approximately four percent of the quantity injected. Less than 1,000 pounds of the isobutyl alcohol was produced in the oil phase. This was partly due to the fact that the distribution ratio between oil and water was about three to one in favor of the water and partily that the water/oil ratio of most of the wells was over 100 to one.

The trend of isobutyl alcohol content in the produced water is shown for several wells in Figures 70-75. There appears to be some correlation between the production of isobutyl alcohol and oil since four of the six wells $(97-6,97-17,97-23$, and 97-28) have produced significant amounts of tertiary oil (see Figures $53,57,60$ and 62). Other factors must also be involved, however, because Wells $97-24$ and 97-35 have not contributed appreciable amounts of tertiary oil. A complete analysis of this situation must await accumulation of additional data.

\section{(2) Mobility Buffer}

Polyacrylamide production has been confirmed at Wells $97-6,97-17$, $97-23,97-24,97-28$ and $97-35$. The history of polymer production from the above wells is shown on Figures 70-75. These graphs show that by May 12, 1977, the concentrations of polyacrylamide in the produced water appeared to be leveling off near $400 \mathrm{ppm}$ at Well 97-35, $250 \mathrm{ppm}$ at Well 97-28 and $200 \mathrm{ppm}$ at Well 97-23. The concentrations at Wells 97-6, 97-17 and 97-24 were rising slowly, but still remained below 100 ppm. Figure 76 shows the date of polymer breakthrough and 
the pounds of polyacrylamide produced at each well. In all, about 15,000 pounds of polyacrylamide were produced, or 2.5 percent of the quantity injected into Tract 97.

Some insight into the fluid flow patterns can be obtained by comparing the profiles of alcohol concentration and polyacrylamide concentration at the wells shown in Figures 70-75. The appearance of polyacrylamide correlates with a definite decrease in alcohol concentration for every case with the possible exception of Well 97-23 where polymer and alcohol broke through almost simultaneously. Apparently, the polyacrylamide followed the same flow channels through which at least part of the produced alcohol had moved. In the case of edge Wells $97-24$ and $97-35$, the isobutyl alcohol was produced through relatively few flow channels. When polymer arrived through these same flow-paths, alcohol production stopped and the well productivity declined.* It is possible that alcohol arrived at the other weils through relatively numerois flow channels and puly acrylamide initially occupied only a portion of those flow paths. Thus, the alcohol concentration declined but did not drop to zero.

It was expected that minor amounts of surfactant flood chemicals would appear at some of the production wells. The heterogeneity of the reservoir requires early breakthrough of chemicals at some wells to ensure sufficient sweep of a significant fraction of the reservoir. In addition, laboratory tests in cores showed that production of alcohol and polyacrylamide should predominate over production of sulfonate.

* This is discussed in the following section. 


\section{Well Problems}

\section{a. Productivity}

Wells $97-08$ and 97-21 have consistently failed to make their quotas of fluid during the operation of the pilot. Figures 77 and 78 show the fluid level history and production rates and quotas of these wells. Well $97-08$ is an old producer drilled in the early $1920^{\prime}$ s. It was shot with nitroglycerine upon completion and has ' been hydraulically fractured twice but was improved only slightly each time. Because of weak casing, the risk of loss of the well was too great to justify the small prospects of improvement by any efforts to stimulate it so the decision was made to accept its lower-than-desired productivity. Well 97-21 appeared initially to be an adequate producer, and only after preflush operations were fairly far advanced was it recognized that it would not make a reasonable quota. At that point, it was considered unwise to introduce a change of flow geometry by fracturing the well. It has been making slightly more than its quota since April, however, when the pump was positioned lower in the well.

Well 97-24 (Figure 79) made its quota without difficulty until surfactant injection began in early August 1976. At this point the fluid level dropped rapidly to a near pumped-off condition and, as polymer was injected into the pattern it failed to make its quota. The reason for the decline of this well is not known. It would seem that the onset occurred too soon to have been caused by the injection of chemicals, although they could have contributed at a later time.

Well 97-35 (Figure 80) was a good producer until January 1977 when 
the well rapidly lost its capacity to make its quota and reached a pumped-off condition. At this time the well was making substantial amounts of polymer and was thought to be undergoing some kind of well bore damage. Since there was no evidence of barium sulfate or other mineral build-up on the down-hole equipment, the problem was taken to be a reaction product of the polymer and the divalent cations present in the produced water. This would be amenable to acid treatment, so a treatment was performed, but no improvement was obtained. During the treatment the well took fluid easily, suggesting that the problem was not formation damage, but perhaps a more general impairment of fluid flow. A pressure build-up was run using the Sonolog to determine bottomhole pressures. Analysis of the data confirmed that there was no formation damage and, in fact, the skin factor was -2.25 , corresponding to an effective well-bore radius of 3.5 feet. The mobility of fluid in the drainage radius of Well 97-35 was estimated to be about $4.5 \mathrm{md} / \mathrm{cp}$. Calculations show that productivity might possibly be doubled by creating a propped fracture of 65 feet, but this is being held in abeyance pending further study of the causes of the low productivity and the risks involved in fracturing.

Well 97-23 (Figure 81) has shown a decline in productivity similar to that of Well $97-35$ but is not as far advanced. A pressure buildup test at Well 97-23 gave the same fluid mobility ( $4.5 \mathrm{md} / \mathrm{cp}$ ) as at $97-35$ and showed that the well was connected to a fracture about 450 feet long. This well has been hydraulically fractured at the start of the project but the fracture length was estimated to be 
about one-third as long as the pressure build-up test showed. A reasonable explanation is that the fracture communicates with an old east-west fracture system associated with the old waterflood injection Wells 97-W1, W2, W3, and W4 which have been plugged. Since the fractures tend to run east and west, this condition should pose no problem. In view of the long fracture in Well 97-23, it is clear that no additional stimulation treatment is indicated for that well.

Reduced productivity may be encountered at other producers as polymer injection continues. Considerable study is being given to this problem since it is very important to the economics of the process to produce the wells as rapidly as possible.

\section{b. Downtime}

As with any oil field operation, producing wells go down due to storms, and engine failures, tubing leaks, or pump failures, etc. This project was given top priority so that rarely was a well down for more than a few hours. Periods of such suspensions of production are shown at the top of Figures 52-67. These interruptions are considered to have had no ill effects on the pilot.

Interruption in polymer injection occurred on January 9, 1977, as the result of sub-zero atmospheric conditions. The injection system froze when the gas engine (used as a prime mover for the triplex injection pump) shut-down due to a magneto failure. Approximately 20 minutes were required to replace the magneto and restart the engine. In the sub-zero temperatures and with a $-40^{\circ} \mathrm{F}$ chill factor, the polymer solution in the above ground injection system piping froze. 
To minimize the imbalance which would result from continued production without injection, it would have been desirable to shut in the pilot production.wells. Since doing so would subject them to freezing, their rates were cut by about 50 percent during the thawout period for the injectors. The salinity of the produced water helped keep the producing wells from freezing at the reduced rate. By the afternoon of January 12, 1977, the injection lines to Wells 97-W18, 97-W19, 97-W25, 97-W26, 97-W30, and 97-W31 had been thawed, necessary repairs and replacements made and the wells were put back into operation. On the following afternoon, the remaining three wells, 97-W20, 97-W27, and 97-W32, were returned to normal operation.

\section{Other Operating Problems}

No significant operating problems were encountered during the transporting, blending or injection of the surfactant solution. Engineers and technicians monitored and operated the chemical blending equipment aroundthe-clock during this phase of the project. All systems and equipment performed as designed.

During the initial stages of injection of polymer solution, occasional problems were experienced with the hydrosulfite pumps. The use of hydrosulfite in the fresh Ark-Burbank water had been initiated many months previously during injection of preflush water to prevent the formation of rust particles which could plug the down-hole formation and lead to excessive damage to the water supply. Iines. The occasional presence of excess oxygen (and absence of residual hydrosulfite) was noted in the feed to Well 97-W18, as shown in Figure 33. Monitoring was then extended to Well 97-W32 and to the inlets and outlets of the GACO polymer mixers (see Figures 34-37). It soon became apparent that a sufficient hydrosulfite 
level could be maintained in the mainstream of make-up water (used to dilute the concentrated polymer solution) by periodic cleaning of the pump valves and by maintaining a positive pressure on the hydrosulfite tanks. In addition, the hydrosulfite level was monitored after mid-December 1976 by a continuous analyzer equipped with an alarm to indicate a low residual level.

5. Total Pilot Performance

a. Decline Curve for Continued Waterflooding

To establish an "official" starting point for calculating tertiary oil, a study was made of the oil production rate during the preflush period.* A mathematical expression was derived to permit the calculation of the waterflood oil rate at any specified time after preflush began, as follows:

$$
\begin{aligned}
& q_{t}=116.75 t^{-0.11} \\
& \text { where } q_{t}=\text { oil production rate in barrels/day at any time } \\
& t=\text { time in days since start of preflush }
\end{aligned}
$$

The equation was derived by first correcting the production rates of individual wells for variation of offet well injection rates and then plotting these production rates as a function of elapsed time (since start of preflush). Next, decline curves were drawn for the individual wells, taking into account any localized factors which could significantly affect the oil production rate.** Then, the total tract oil rates versus time were obtained by

* A longer history could not be used because eleven of the producers were not put into operation until December. 1, 1975.

** e. g. Well 97-28 produced at a higher rate during July and August 1976 due to a gelled polymer treatment. 
summing up the individual well rates at selected times. Finally, the decline equation was determined from a linear regression analysis of the total tract rates assuming a log-log plot of rate versus time was a straight line. Details of the procedure for deriving the decline equation are given in Appendix C. The curve representing the equation is shown as "pre-tertiary oil" rate on Figure 82.

The sharp downturn near the beginning is probably due to the rapid flood-out of the area surrounding some of the new wells which encountered areas which had not previously been fully swept. Since the well spacing was reduced in drilling the pilot pattern wells, flooding became much more intensive during preflush than it had been and any higher oil saturation areas were quickly reduced to the level of the average. Thus the curve rapidly flattened as shown.

Figure 82 gives the picture of total pilot performance showing total oil rate, tertiary oil rate, water production rate, total fluid injection rate, and water/oil ratio, all expressed as averages over a seven-day period. The most significant points are the rapid rise in tertiary oil rate and the steady decline in water/oil ratio. As this report was being prepared there were indications of some flattening out of the oil production curve. The cause of this behavior is believed to be in part due to different rates of movement of fluids in different quadrants of the various five-spots and an even greater variation in the rate of movement of fluids in vertical zones of differing permeability over the pattern. These were touched upon previously in the sections dealing with individual: well performance. Further details of total pilot performance are listed in Table 28. 
The status of oil production is put into perspective in Figure 83 where the oil production rate is shown superimposed on the pretertiary rate and the original computer prediction used in designing the pilot. It should be emphasized that the predicted curve was determined before any new wells were drilled or oil saturation determinations made and is therefore highly approximate. A new prediction, being made to update this comparison, was not sufficiently far advanced to include in this report.

\section{MILESTONE CHART AND DECISION POINTS}

The Milestone Chart, which was prepared prior to the initiation of the contract period, is shown in Figure 84. At the end of the first contract year the operations were about three months behind schedule, as explained on page 53 of the First Annual Report. During the second year of operations no further delays or losses of time were encountered. Injection of the surfactant slug began on August 2, 1976, instead of on May 1, 1976. As of the writing of this report, polymer injection was on schedule. However, as discussed previously, the decline in productivity of some of the producing wells during the past several months has made it unwise to raise the injection rate beyond the 5,550 $\mathrm{BPD}$ (total pilot) rate put into effect on December 28, 1976. Studies of the injection and production rates in and around Tract 97 are being made to determine if polymer injection can be accelerated. At the current rate, injection of the polymer will be complete by the end of 1977. No major operational problems have been encountered in handling or injecting either the surfactant slug or the polymer solution. Decision Point \#4 (initiate the injection of the surfactant slug if a satisfactory base line has been established during the preflush period) was passed and approved by the Technical Project officer at the Monthly ERDA Meeting on July 20, 1976. 
Decision Point \#5 (to modify the polymer concentration and injection rate if necessary after one-half the polymer had been injected) was passed and approved by the Technical Project officer at the ERDA Meeting on February 15, 1977.

\section{SCHEDULE OF EXPENDITURES}

Prior to the initiation of the contract an estimated expenditure schedule had been submitted to ERDA covering the entire contract period, assumed to start on July 1, 1975. The contract was awarded on May 12, 1975, at which time contract expenditures actually began. Contrary to the estimated schedule, it became necessary to purchase the entire requirements of sulfonate, alcohol, and polymer about a year earlier than predicted. Consequently, as of April 1, 1976, the expenditures of $\$ 7,440,663.65$ exceeded the earlier estimate by $\$ 4,143,453.65$.

During the second year, the total additional expenditures were $\$ 1,409,225.85$ mostly for direct labor (field, home office and R\&D support) and indirect overhead. As of April 1, 1977, the total expenditures of $\$ 8,849,889.50$ exceeded the previous estimate by $\$ 652,633.50$. During the past six-month period starting October 1, 1976, the total monthly expenditures have averaged slightly over $\$ 70,000$.

\section{THIRD YEAR PLANS}

During the third year of the ERDA Contract, the injection of the polymer solution will be completed, with a gradual and stepwise reduction of polymer concentration to about $250 \mathrm{ppm}$. This phase will be followed by a two to three month injection of fresh water prior to resuming injection of produced water. Decision Point \#6 (to start injecting produced water after injecting a freshwater slug to protect the polymer solution) should be attained early in 1978 . 
Production data will be reported on a weekly basis, together with analysis of the produced water for sulfonate, alcohol and/or polymer content. Particular attention will be given to the possible appearance of emulsions in the produced fluids; if this occurs, such fluids will be isolated and treated according to the prescribed Contingency Plan.

It is expected that the production of incremental oil might peak at about the end of the third year.

\section{ACKNOWLEDGMENTS}

The planning, operation and control of this project would not have been possible without the patience, cooperation, and dedication of many people. Especially, thanks are due T. A. Matthews, retired Project Technical Director; R. L. Clampitt, Myron Jackson and W. K. Winter of Phillips R\&D; H. L. Patterson and Max Isaacs of the North Burbank engineering staff; and many others who worked Iong and hard in field, laboratory and office to assure smooth operation of the pilot. Finally, Phillips Petroleum Company wishes to acknowledge the understanding and good will of its co-owners and personnel of ERDA, especially Dr. Philip Lorenz, of the Bartlesville Energy Research Center. 


\section{REFERENCES}

(1) Phillips Petroleum Company, North Burbank Unit Tertiary Recovery Pilot Test, BERC/TPR-76-2, July 1976.

(2) Matthews, C. S. and Russe11, D. G., Pressure Buildup and Flow Tests in Wells, SPE Monograph Vol. 1, 1967, p. 73.

(3) Boneau, D. F. and Clampitt, R. I., "A Surfactant System for the Oil-Wet Sandstone of the North Burbank Unit," J. Pet. Tech. (May 1977), pp. 501-506.

(4) Smith, L., Malmberg, E. W., and Kelley, H. W.: "Measurements of Surfactant Loss in Porous Media," paper SPE 5306 presented at the SPI-AIME Symposium on Oilfield Chemistry, Dallas, January 16-17, 1975.

(5) Scoggins, M. W. and Miller, J. W.: "Spectrophotometric Determination of Water Soluble Organic Amides," Anal. Chem. (January 1975) pp. 152-154.

(6) U. S. Patent 2,784,064.

(7) U. S. Patent 3,785,437. 
TABIE NO.

1.

2.

3.

4.

5.

6.

7.

8.

9.

10.

11.

12 :

13.

14.

15.

16.

17.

18.

19.

20.

21.

22.

23.

24.

25.

26.
TITLE

Pressure Gradient and Fluid Drift Across Tract 97

Radioactive Tracer Analysis - Well 97-28

Water Analyses - Well 97-28

Distribution of Fresh Water Production as of August 2, 1976

Brine Displacement by Quadrant as of August 2, 1976

Sampling Sehedulc

NBU Tract 97 Production - Injection Data, May, 1976

NBU Tract 97 Production - Injection Data, June, 1976

NBU Tract 97 Production - Injection Data, July, 1976

NBU Tract 97 Production - Injection Data, August, 1976

NBU Tract 97 Production - Injection Data, September, 1976

NBU Tract 97 Production - Injection Data, October, 1976

NBU Tract 97 Production - Injection Data, November, 1976

NBU Tract 97 Production - Injection Data, December, 1976

NBU Tract 97 Production - Injection Data, January, 1977

NBU Tract 97 Production - Injection Data, February, 1977

NBU Tract 97 Production - Injection Data, March, 1977

NBU Tract 97 Production - Injection Data, April, 1977

NBU Tract 97 Production - Injection Data, May 1 - 15, 1977

Schedule for Gelled Polymer Treatment Well 97-W25

Recoverable Oil Contacted by Optimal Surfactant Distribution

Recoverable Oil Contacted by Equal Volume Surfactant Slugs

Recoverable Oil Contacted by Surfactant Slugs Proportional to Pore Volume

Polymer Injection Schedule

Polyacrylamide Injected in Tract 97

Comparison of Calculated and Measured Bottom Hole Pressures During 2500 ppm Polymer Injection 
Index of Tables

TABLE NO. TITLE

27.

Well Quotas During Polymer Injection

28.

Total Pilot Performance, Tract 97

29.

Size and Oil Content of Each Five-Spot 
TABLE 1

\section{PRESSURE GRADIENT AND FLUID DRIFT ACROSS TRACT 27}

\section{Date}

$4-6-76$

$7-13-76$

$7-30-76$

$9-9-76$

$1-20-77$

$2-23-77$

$3-31-77$

$4-28-77$
Pressure Gradient, PSI/Ft* North-South

East-West

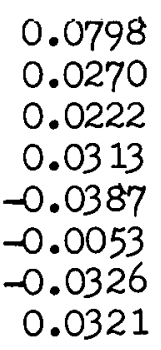

0.0233

$-0.0324$

$-0.0345$

$-0.0367$

0.0594

0.0394

0.0215

$-0.0042$
Fluid Drift, Ft/Day

North-South East-West

$$
\begin{array}{r}
0.158 \\
0.053 \\
0.044 \\
0.062 \\
-0.077 \\
-0.010 \\
-0.065 \\
0.064
\end{array}
$$

0.046

$-0.064$

$-0.068$

$-0.073$

0.118

0.078

0.043

$-0.008$

* South-to-North is positive

** West-to-East is positive 


\section{TABLE 2}

RADIOACTIVE TRACER ANALYSES - WEIL 97-28

\begin{tabular}{|c|c|c|c|c|}
\hline Date & $\begin{array}{l}\text { Cobalt } .57 \\
\mathrm{DCi} / 1\end{array}$ & $\begin{array}{l}\text { Cobalt } 58 \\
\mathrm{pCi} / 1\end{array}$ & $\begin{array}{c}\text { Cobalt } 60 \\
\mathrm{pCi} / 1\end{array}$ & $\begin{array}{l}\text { Tritium } \\
\mathrm{pCi} / \mathrm{ml} \\
\end{array}$ \\
\hline $1-24-76$ & 79 & 0 & 0 & 0 \\
\hline $1-30-76$ & 742 & 0 & 0 & 0 \\
\hline $2-6-76$ & 1110 & 0 & 0 & 0 \\
\hline $2-13-76$ & 857 & 0 & 0 & 0 \\
\hline $2-20-76$ & 449 & 0 & 0 & 0 \\
\hline $2-27-76$ & 397 & 0 & 0 & 0 \\
\hline $3-4-76$ & 272 & 0 & 0 & 0 \\
\hline $3-11-76$ & 231 & 0 & 24 & 0 \\
\hline $3-18-76$ & 232 & 0 & 15 & 0 \\
\hline $3-26-76$ & 222 & 39 & 18 & 0 \\
\hline $4-1-76$ & 212 & 0 & 0 & 0 \\
\hline $4-9-76$ & 133 & 87 & 10 & 0 \\
\hline $4-15-76$ & 137 & 101 & 12 & 0 \\
\hline $4-22-76$ & 156 & 83 & 13 & 10 \\
\hline $4-29-76$ & 118 & 100 & 0 & 54 \\
\hline $5-6-76$ & 117 & 160 & 15 & 56 \\
\hline $5-13-76$ & 110 & 155 & 0 & 54 \\
\hline $5-20-76$ & 87 & 122 & 17 & 46 \\
\hline $5-27-76$ & 91 & 160 & 0 & 44 \\
\hline $6-3-76$ & 95 & 177 & 24 & 51 \\
\hline $6-10-76$ & 97 & 160 & 24 & 33 \\
\hline $6-17-76$ & 73 & 120 & 17 & 27 \\
\hline $7-1-76$ & 111 & 116 & 24 & 30 \\
\hline $7-8-76$ & 245 & 234 & 19 & 23 \\
\hline $7-15-76$ & 540 & 179 & 30 & 21 \\
\hline $7-22-76$ & 559 & & 29 & 31 \\
\hline $7-29-70$ & 703 & 186 & 26 & 27 \\
\hline $8-14-76$ & 371 & 81 & 38 & \\
\hline $9-1-76$ & 330 & 50 & 41 & 32 \\
\hline $9-15-76$ & 276 & 86 & 38 & 30 \\
\hline $9-22-76$ & 258 & & 36 & \\
\hline $9-25-76$ & 249 & & 24 & \\
\hline $9-29-76$ & 265 & & 32 & 24 \\
\hline $10-13-76$ & 211 & & 23 & 28 \\
\hline $10-27-76$ & 281 & & 35 & 29 \\
\hline $11-10-76$ & 168 & & 18 & 28 \\
\hline $11-24-76$ & 157 & & 21 & 26 \\
\hline $12-29-76$ & 128 & & 38 & 23 \\
\hline $1-26-77$ & 104 & & 0 & 23 \\
\hline $3-2-77$ & 236 & & 23 & 17 \\
\hline $3-30-77$ & 106 & & 0 & 0 \\
\hline
\end{tabular}


Table 3

Inorganic Analysis of Produced Water, Well 97-28

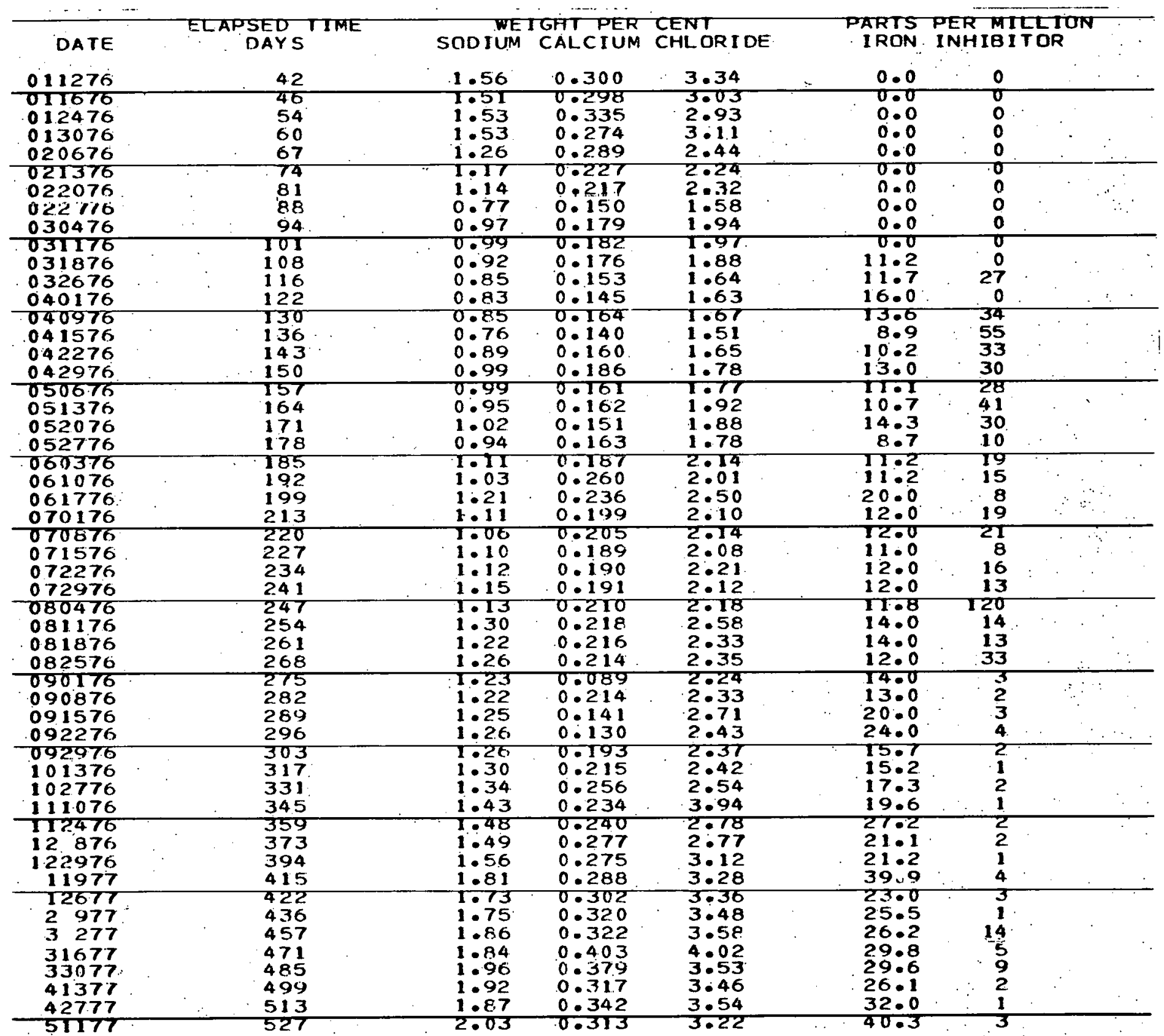




\section{TABLE 4}

DISTRIBUTION OF FRESH WATER PRODUCTION AS OF AUG. 2, 1976

Fresh Water Produced, BbI

Well No. By Chemical Analysis By Tracer Analysis

$\begin{array}{lrr}1 \mathrm{~A} & 5,115 & 4,823 \\ 6 & 54,352 & 17,507 \\ 8 & 7,175 & 5,882 \\ 9 & 12,691 & 15,731 \\ 14 \mathrm{~A} & 25,848 & 9,583 \\ 17 & 22,042 & 14,021 \\ 21 & 12,686 & 18,480 \\ 22 & 35,434 & 66,320 \\ 23 & 48,614 & 35,233 \\ 24 & 101,490 & 68,365 \\ 28 & 93,494 & 74,652 \\ 29 & 25,246 & 1,150 \\ 33 & 3,827 & 5,376 \\ 34 & 66,774 & 75,133 \\ 35 & 71,253 & 45,560 \\ 36 & 21,145 & 14,094 \\ & & \\ \text { Total } & 607,185 & 471,910 \\ \text { Percent of } & & \\ \text { Injected } & 28.0 & 21.8\end{array}$




\section{TABLE 5}

NBU TRACT 97

BRINE DISPLAGEMENT BY QUADRANT AS OF AUG. 2, 1976

Brine Displaced, $\mathrm{BbI}$

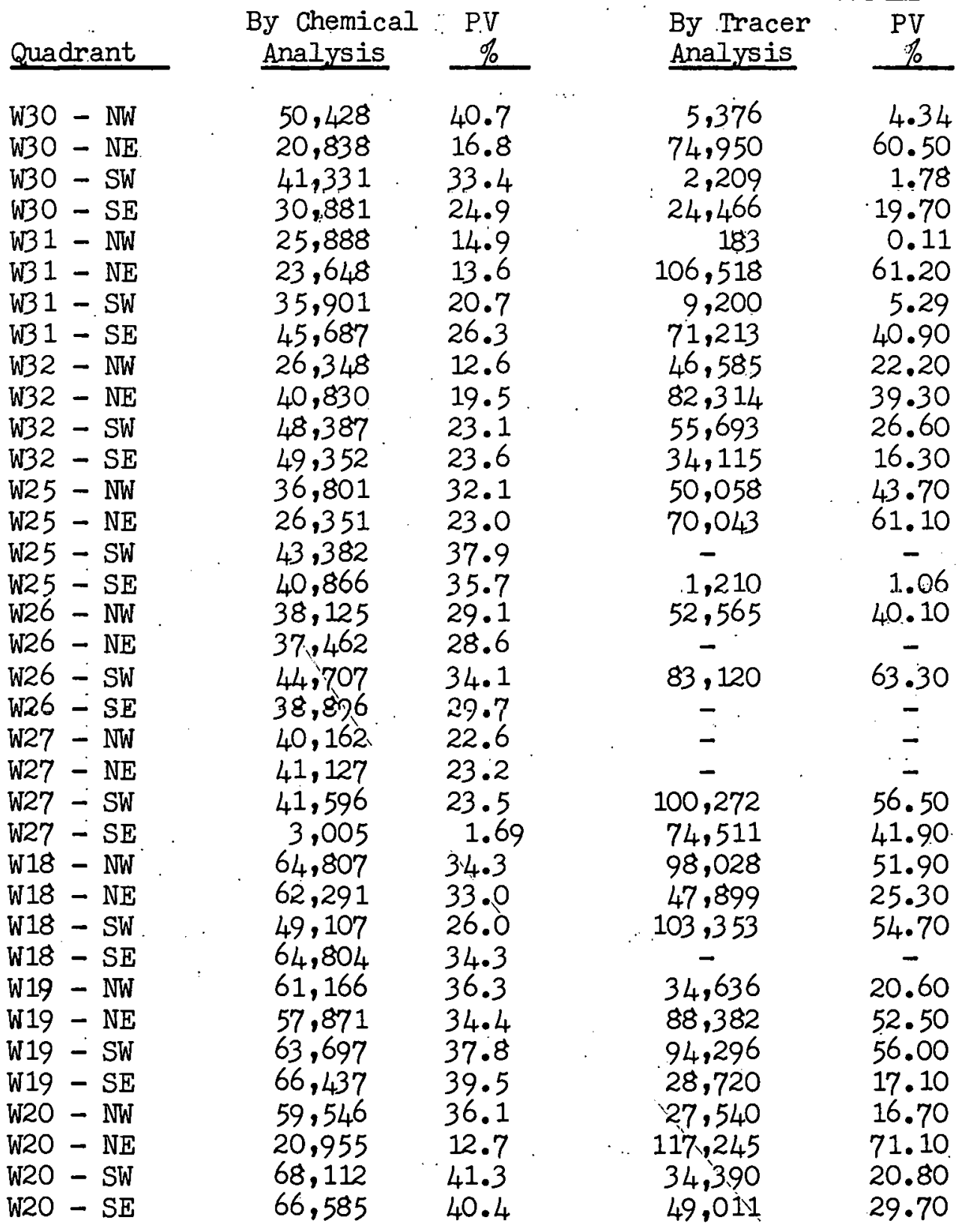


TABLE 6.

SAMPLING SCHEDULE

Origin of Sample (1) Water from Tract
97 producers
Sampling

Frequency

(Weekly through Sept. 1976;)
(then twice a month

(Twice a month, Sept. 1976 )

(thru November; then once
a month

(Weekly

(Twice a month, mid-Oct.,
(1976 to April, 1977; then
(weekly

(2) Water from near Monthly by producers and
water stations

(3) Oil from Tract Monthly 97 producers

(4) Injection line and injection wells

(5) Well 97-W18

Twice daily

(6) Wells 97-W18 and Twice weekly 97-W32

(7) Outlets of polymer Twice weekly since mixers October, 1976
Analysis

Performed

$(\mathrm{Na}, \mathrm{Cl}, \mathrm{Ca}$, ( $\mathrm{Fe}$, inhibjor
(tracers

sulfonate

alcohol $(b)$

polyacrylamide

$\mathrm{Na}, \mathrm{Cl}, \mathrm{Ca}, \mathrm{Fe}$, inhibitor, alcohol, polyacrylamide, tracers

Alcohol, sulfonate

Sulfonate, alcohol, $\mathrm{NaCl}$

Polyacrylamide concentration

Polyacrylamide concentration and viscosity, oxygen

axygen

(a) Measured once a month after November 1976

(b) Beginning September 1976

(c) Wells 88-4, 90-12,96-4, 96-16,98-3,98-14 plus Tracts 80 and 97 pump stations (See Figure 2). 
TABLE 7 .

NBU TRACT 97 PRODUCTION - INJECTION DATA

MAY, 1976

I. PRODUCTION DATA:

\begin{tabular}{|c|c|c|c|c|c|c|}
\hline $\begin{array}{l}\text { WEJLL } \\
\text { NO. }\end{array}$ & $\begin{array}{l}\text { DAILY } \\
\text { PROD. } \\
\text { OIL } \\
\text { (BBIS.) }\end{array}$ & $\begin{array}{l}\text { DAILY } \\
\text { PROD. } \\
\text { WATER } \\
\text { (BBLS.) }\end{array}$ & $\begin{array}{l}\text { MONTHLY } \\
\text { PROD. } \\
\text { OIL } \\
\text { (BBIS.) }\end{array}$ & $\begin{array}{l}\text { MONTHLY } \\
\text { PROD. } \\
\text { WATER } \\
\text { (BBLS.) }\end{array}$ & $\begin{array}{l}\text { CUM. } \\
\text { PROD. } \\
\text { OII } \\
\text { (BBIS.) }\end{array}$ & $\begin{array}{l}\text { CUM. } \\
\text { PROD. } \\
\text { WATER } \\
\text { (BBIS.) }\end{array}$ \\
\hline $97-01$ & 6 & 970 & 181 & 29,221 & 2,516 & 375,4444 \\
\hline $97-06$ & 6 & 720 & 181 & 21,690 & 3,144 & 350,539 \\
\hline $97-08$ & 5 & 720 & 126 & 18,191 & 3,071 & 233,258 \\
\hline $97-09$ & 4 & 870 & 120 & 26,209 & 1,551 & 393,265 \\
\hline $97-14$ & 5 & 995 & 151 & 29,974 & 3,823 & 512,608 \\
\hline $97-17$ & 3 & 900 & 90 & 27,112 & 445 & 170,308 \\
\hline $97-21$ & 4 & 740 & 117 & 21,573 & 984 & 150,950 \\
\hline $97-22$ & $\mathrm{Tr}$ & 920 & 6 & 26,821 & 103 & 149,589 \\
\hline $97-23$ & 1 & 870 & 26 & 22,827 & 247 & 153,589 \\
\hline $97-24$ & 4 & 865 & 117 & 25,217 & 359 & 163,085 \\
\hline $97-28$ & 10 & 750 & 291 & 21,865 & 2,085 & 149,270 \\
\hline $97-29$ & 3 & 630 & 90 & 18,979 & 821 & 173,508 \\
\hline $97-33$ & 5 & 960 & 151 & 28,920 & 930 & 163,832 \\
\hline $97-34$ & 3 & 835 & 90 & 25,154 & 725 & 218,374 \\
\hline $97-35$ & 6 & 960 & 181 & 28,920 & 1,379 & 212,566 \\
\hline $97-36$ & 4 & 990 & $\underline{113}$ & 27,900 & 920 & 200,380 \\
\hline TRACT & COTAIS: & & 2,031 & 400,573 & 23,103 & $3,770,565$ \\
\hline
\end{tabular}

II. INJECTION DATA:

\begin{tabular}{|c|c|c|c|c|c|c|}
\hline $\begin{array}{l}\text { WEIL } \\
\text { NO. }\end{array}$ & $\begin{array}{l}\text { DAIIY } \\
\text { INJECTED } \\
\text { FLUIDS } \\
\text { (BBIS.) } \\
\end{array}$ & $\begin{array}{l}\text { MONTHLY } \\
\text { INJECTED } \\
\text { FLUIDS } \\
\text { (BBIS.) }\end{array}$ & $\begin{array}{l}\text { CUM. } \\
\text { INJECTED } \\
\text { PROD. WTR. } \\
\text { (BBIS.) } \\
\end{array}$ & $\begin{array}{l}\text { CUM. } \\
\text { INJECTED } \\
\text { FRESH WTR. } \\
\text { (BBIS.) }\end{array}$ & $\begin{array}{l}\text { CUM. } \\
\text { INJECTED } \\
\text { BRINE SOL. } \\
\text { (BBLS.) }\end{array}$ & $\begin{array}{l}\text { CUM. } \\
\text { INJECTED } \\
\text { FLUIDS } \\
\text { (BBLS.) } \\
\end{array}$ \\
\hline 97-W18 & 1,199 & 37,154 & --- & -- & 50,500 & 226,598 \\
\hline 97-W19 & 1,191 & 36,933 & --- & --- & 50,276 & 228,094 \\
\hline $97-W 20$ & 1,259 & 39,037 & --- & -- & 52,475 & 236,638 \\
\hline $97-w 25$ & 851 & 25,519 & --- & --- & 35,245 & 180,268 \\
\hline $97-W 26$ & 803 & 24,090 & --- & -- & 33,931 & 180,142 \\
\hline $97-$ W27 & 908 & 28,139 & --- & --- & 38,329 & 185,585 \\
\hline $97-W 30$ & 926 & 28,718 & --- & --- & 39,511 & 179,893 \\
\hline $97-W 31$ & 801 & 24,831 & --- & --- & 34,881 & 181,269 \\
\hline $97-W 3 \cdot 2$ & 900 & 27,892 & $=-$ & $-\cdots$ & 38,232 & 177,401 \\
\hline TRACT 97 & TOTAIS: & 272,313 & 512,997 & $1,402,508$ & 373,380 & $2,288,885$ \\
\hline
\end{tabular}


TABLE 8.

NBU TRACT 97 PRODUCTION - INJECTION DATA

JUNE, 1976

I. PRODUCTION DATA:

\begin{tabular}{|c|c|c|c|c|c|c|}
\hline $\begin{array}{l}\text { WEIL } \\
\text { NO. } \\
\end{array}$ & $\begin{array}{l}\text { DAILY } \\
\text { PROD. } \\
\text { OIL } \\
\text { (BBIS.) }\end{array}$ & $\begin{array}{l}\text { DAIIY } \\
\text { PROD. } \\
\text { WATER } \\
\text { (BBLS.) }\end{array}$ & $\begin{array}{l}\text { MONTHLY } \\
\text { PROD. } \\
\text { OIL } \\
\text { (BBIS.) }\end{array}$ & $\begin{array}{l}\text { MONTHLY } \\
\text { PROD. } \\
\text { WATER } \\
\text { (BBIS.) }\end{array}$ & $\begin{array}{l}\text { CUM. } \\
\text { PROD. } \\
\text { OII } \\
\text { (BBIS.) }\end{array}$ & $\begin{array}{l}\text { CUM. } \\
\text { PROD. } \\
\text { WATER } \\
\text { (BBIS.) }\end{array}$ \\
\hline $97-01$ & 5 & 1,020 & 150 & 30,600 & 2,666 & 406,044 \\
\hline $97-06$ & 6 & 845 & 180 & 25,350 & 3,324 & 375,889 \\
\hline $97-08$ & 13 & 750 & 377 & 21,750 & 3,448 & 255,008 \\
\hline $97-09$ & 4 & 1,020 & 120 & 30,600 & 1,671 & 423,865 \\
\hline $97-14$ & $\dot{5}$ & 820 & 120 & 19,680 & 3,943 & 532,288 \\
\hline $97-17$ & 3 & 860 & 87 & 24,940 & 532 & 195,248 \\
\hline $97-21$ & 3 & 735 & 74 & 17,640 & 1,058 & 168,590 \\
\hline $97-22$ & 2 & 990 & 48 & 23,760 & 151 & 173,349 \\
\hline $97-23$ & 5 & 1,060 & 150 & 31,800 & 397 & 185,389 \\
\hline $97-24$ & $\operatorname{Tr}$. & 435 & 28 & 12,180 & 387 & 175,265 \\
\hline $97-28$ & 10 & 850 & 290 & 24,650 & 2,375 & 173,920 \\
\hline $97-29$ & 4 & 1,010 & 120 & 30,300 & 941 & 203,808 \\
\hline $97-33$ & 8 & 1,080 & 216 & 29,160 & 1,146 & 192,992 \\
\hline $97-34$ & 4 & 805 & 116 & 23,345 & 847 & 241,719 \\
\hline $97-35$ & 2 & 920 & 58 & 26,680 & 1,437 & 239,246 \\
\hline $97-36$ & 4 & 1,220 & 116 & 35,380 & 1,036 & 235,760 \\
\hline NBU TR & TOTALS & & 2,250 & 407,815 & 25,353 & $4,178,380$ \\
\hline
\end{tabular}

II. INJECTION DATA:

\begin{tabular}{|c|c|c|c|c|c|c|}
\hline $\begin{array}{l}\text { W'ETLC } \\
\text { NO. } \\
\end{array}$ & $\begin{array}{l}\text { DAILY } \\
\text { INJECTED } \\
\text { FLUIDS } \\
\text { (BBLS.) } \\
\end{array}$ & $\begin{array}{l}\text { MONTHLY } \\
\text { INJECTED } \\
\text { FLUIDS } \\
\text { (BBIS.) } \\
\end{array}$ & $\begin{array}{l}\text { CUM } \\
\text { INJECTED } \\
\text { PROD. WTR. } \\
\text { (BBLS.) }\end{array}$ & $\begin{array}{l}\text { CUM. } \\
\text { INJECTED } \\
\text { FRESH WTR. } \\
\text { (BBLS.) }\end{array}$ & $\begin{array}{l}\text { CUM. } \\
\text { INJECTED } \\
\text { BRINE SOL. } \\
\text { (BBLS.) }\end{array}$ & $\begin{array}{l}\text { CUM. } \\
\text { INJECTED } \\
\text { FIUIDS } \\
\text { (BBLS.) }\end{array}$ \\
\hline $97-w 18$ & 1,123 & 33,686 & --- & --- & 84,186 & 260,284 \\
\hline $97-W 19$ & 1,136 & 34,082 & --- & $-\cdots$ & 84,358 & 262,176 \\
\hline $97-W 20$ & 1,185 & 35,553 & --- & --- & 88,028 & 272,191 \\
\hline $97-$ W25 & 688 & 19,961 & --- & --- & 55,206 & 200,229 \\
\hline $97-W 26$ & 715 & 21,458 & --- & --- & 55,389 & 201,600 \\
\hline $97-$ W27 & 908 & 27,254 & --- & --- & 65,583 & 212,839 \\
\hline $97-W 30$ & 868 & 26,053 & --- & --- & 65,564 & 205,946 \\
\hline $97-W 31$ & 1,160 & 34,795 & --- & --- & 69,676 & 216,064 \\
\hline $97-W 32$ & 1,421 & 42,619 & $=--$ & $=--$ & 80,851 & 220,020 \\
\hline TRACT 97 & AIS: & 275,461 & 512,997 & $1,402,508$ & 648,841 & $.564,346$ \\
\hline
\end{tabular}


TABLE 9.

NBU TRACT 97 PRODUCTION - INJECTION DATA

JLY, 1976

I. PRODUCTION DATA:

\begin{tabular}{|c|c|c|c|c|c|c|}
\hline $\begin{array}{l}\text { WELL } \\
\text { NO. }\end{array}$ & $\begin{array}{l}\text { DAILY } \\
\text { PROD. } \\
\text { OIL } \\
\text { (BBLS.) } \\
\end{array}$ & $\begin{array}{l}\text { DAILY } \\
\text { PROD. } \\
\text { WATER } \\
\text { (BBIS.) }\end{array}$ & $\begin{array}{l}\text { MONTHLY } \\
\text { PROD. } \\
\text { OIL } \\
\text { (BBIS.) }\end{array}$ & $\begin{array}{l}\text { MONTHLY } \\
\text { PROD. } \\
\text { WATER } \\
\text { (BBIS.) }\end{array}$ & $\begin{array}{l}\text { CUM. } \\
\text { PROD. } \\
\text { OIL } \\
\text { (BBIS.) }\end{array}$ & $\begin{array}{l}\text { CUM. } \\
\text { PROD. } \\
\text { WATER } \\
\text { (BBLS.) }\end{array}$ \\
\hline $97-01$ & 4 & 970 & 124 & 31,250 & 2,790 & 437,294 \\
\hline $97-06$ & 8 & 1,060 & 248 & 34,149 & 3,572 & 410,038 \\
\hline $97-08$ & 12 & 690 & 372 & 22,229 & 3,820 & 277,237 \\
\hline $97-09$ & 4 & 995 & 124 & 32,055 & 1,795 & 455,920 \\
\hline $97-14$ & 6 & 1,010 & 186 & 32,539 & 4,129 & 564,827 \\
\hline $97-17$ & 4 & 1,080 & 124 & 34,794 & 656 & 230,042 \\
\hline $97-21$ & 3 & 775 & 93 & 24,968 & 1,151 & 193,558 \\
\hline $97-22$ & 1 & 990 & 31 & 31,894 & 182 & 205,243 \\
\hline $97-23$ & $\operatorname{Tr}$. & 900 & 30 & 28,060 & 427 & 213,449 \\
\hline $97-24$ & 2 & 460 & 62 & 14,820 & 449 & 190,085 \\
\hline $97-28$ & 14 & 890 & 434 & 28,673 & 2,809 & 202,593 \\
\hline $97-29$ & 4 & 1,015 & 124 & 32,700 & 1,065 & 236,508 \\
\hline $97-33$ & 8 & 1,185 & 248 & 38,176 & 1,394 & 231,168 \\
\hline $97-34$ & 4 & 820 & 124 & 26,418 & 965 & 268,137 \\
\hline $97-35$ & 2 & 1,000 & 62 & 32,216 & 1,499 & 271,462 \\
\hline $97-36$ & 4 & 1,150 & 124 & 37,049 & 1,160 & 272,809 \\
\hline NBU $T R$ & TOTALS: & & 2,510 & 481,990 & 27,863 & $, 660,370$ \\
\hline
\end{tabular}

II. INJECTION DATA:

\begin{tabular}{|c|c|c|c|c|c|c|}
\hline $\begin{array}{l}\text { WELL } \\
\text { NO. } \\
\end{array}$ & $\begin{array}{l}\text { DAIIY } \\
\text { INJECTED } \\
\text { FLUIDS } \\
\text { (BBLS.) } \\
\end{array}$ & $\begin{array}{l}\text { MONTHLY } \\
\text { INJECTED } \\
\text { FLUIDS } \\
\text { (BBLS.) } \\
\end{array}$ & $\begin{array}{l}\text { CUM. } \\
\text { INJECTED } \\
\text { PROD. WTR. } \\
\text { (BBLS.) }\end{array}$ & $\begin{array}{l}\text { CUM. } \\
\text { INJECTED } \\
\text { FRESH WTR. } \\
\text { (BBLS.) }\end{array}$ & $\begin{array}{l}\text { CUM. } \\
\text { INJECTED } \\
\text { BRINE SOL. } \\
\text { (BBLS.) }\end{array}$ & $\begin{array}{l}\text { CUM. } \\
\text { INJECTED } \\
\text { FLUIDS } \\
\text { (BBIS.) }\end{array}$ \\
\hline $97-W 18$ & 1,167 & 36,181 & --- & --- & 120,367 & 296,465 \\
\hline 97-W19 & 1,178 & 36,521 & -- & -- & 120,879 & 298,697 \\
\hline 97-W20 & 1,185 & 36,722 & --- & --- & 124,750 & 308,913 \\
\hline $97-$ W25 & 886 & 27,481 & --- & -- & 82,687 & 227,710 \\
\hline $97-w 26$ & 942 & 29,205 & --- & -- & 84,594 & 230,805 \\
\hline $97-127$ & 920 & 28,528 & --- & -- & $94 \cdot 111$ & 241,367 \\
\hline $97-W 30$ & 908 & 28,133 & --- & --- & 93,697 & 234,079 \\
\hline $97-$ W31 & 1,184 & 36,718 & -- & --- & 106,394 & 252,782 \\
\hline $97-W 32$ & 1,497 & 46,417 & $=-$ & --- & 127,262 & 266,431 \\
\hline TRACT 9 & IS: & 305,900 & 512,997 & $1,402,508$ & 954.741 & $, 870,246$ \\
\hline
\end{tabular}


TABLE 10.

NBU TRACT 97 PRODUCTION - INJECTION DATA

I. PRODUCTION DATA:

$$
\text { AUGUST, } 1976
$$

\begin{tabular}{|c|c|c|c|c|c|c|}
\hline $\begin{array}{l}\text { WETLL } \\
\text { NO. } \\
\end{array}$ & $\begin{array}{l}\text { DAILY } \\
\text { PROD. } \\
\text { OIL } \\
\text { (BBLS.) }\end{array}$ & $\begin{array}{l}\text { DAILY } \\
\text { PROD. } \\
\text { WATER } \\
\text { (BBIS.) }\end{array}$ & $\begin{array}{l}\text { MONTHLY } \\
\text { PROD. } \\
\text { OIL } \\
\text { (BBLS.) }\end{array}$ & $\begin{array}{l}\text { MONTHLY } \\
\text { PROD. } \\
\text { WATER } \\
\text { (BBLS.) }\end{array}$ & $\begin{array}{l}\text { CUM. } \\
\text { PROD. } \\
\text { OIL } \\
\text { (BBIS.) }\end{array}$ & $\begin{array}{l}\text { CUM. } \\
\text { PROD. } \\
\text { WATER } \\
\text { (BBIS.) }\end{array}$ \\
\hline $97-01$ & 6 & 1,160 & 210 & 39,101 & 3,000 & 476,395 \\
\hline $97-06$ & 8 & 820 & 280 & 27,640 & 3.852 & 437,678 \\
\hline $97-08$ & 12 & 675 & 420 & 22,752 & 4,240 & 299,989 \\
\hline $97-09$ & 4 & 1,050 & 140 & 35,393 & 1,935 & 491,313 \\
\hline $97-14$ & 4 & 910 & 140 & 30,674 & 4,269 & $595,50.2$ \\
\hline $97-17$ & 4 & 1,240 & 140 & 41.797 & 796 & 271,839 \\
\hline $97-21$ & 3 & 700 & 105 & 23.595 & 1,256 & 217,153 \\
\hline $97-22$ & $\operatorname{Tr}$. & 880 & 35 & 29,662 & 217 & 234,905 \\
\hline $97-23$ & Tr. & 910 & 34 & 29,684 & 461 & 243,133 \\
\hline $97-24$ & 2 & 710 & 70 & 23,932 & 519 & 214,017 \\
\hline $97-28$ & 17 & 670 & 595 & 22,584 & 3,404 & 225,177 \\
\hline $97-29$ & 6 & 1,020 & 203 & 33,273 & 1,268 & 269,781 \\
\hline $97-33$ & 4 & 945 & 132 & 29,798 & 1,526 & 260,966 \\
\hline $97-34$ & 2 & 695 & 70 & 23,427 & 1,035 & 291,564 \\
\hline $97-35$ & 3 & 810 & 102 & 26,422 & 1,601 & 297,884 \\
\hline $\begin{array}{l}97-36 \\
\text { NBU TRACT } 9\end{array}$ & $\begin{array}{c}6 \\
7 \text { TOTAL: }\end{array}$ & 1,005 & $\frac{210}{2,886}$ & $\frac{33,876}{473,610}$ & $\frac{1,370}{30,749}$ & $\frac{306,685}{5,133,980}$ \\
\hline
\end{tabular}

AUGUST 2, 1976: End injecting Brine Sol. Pre-fIush. Began Surfactant Solution Injection.

II. INJECTION DATA:

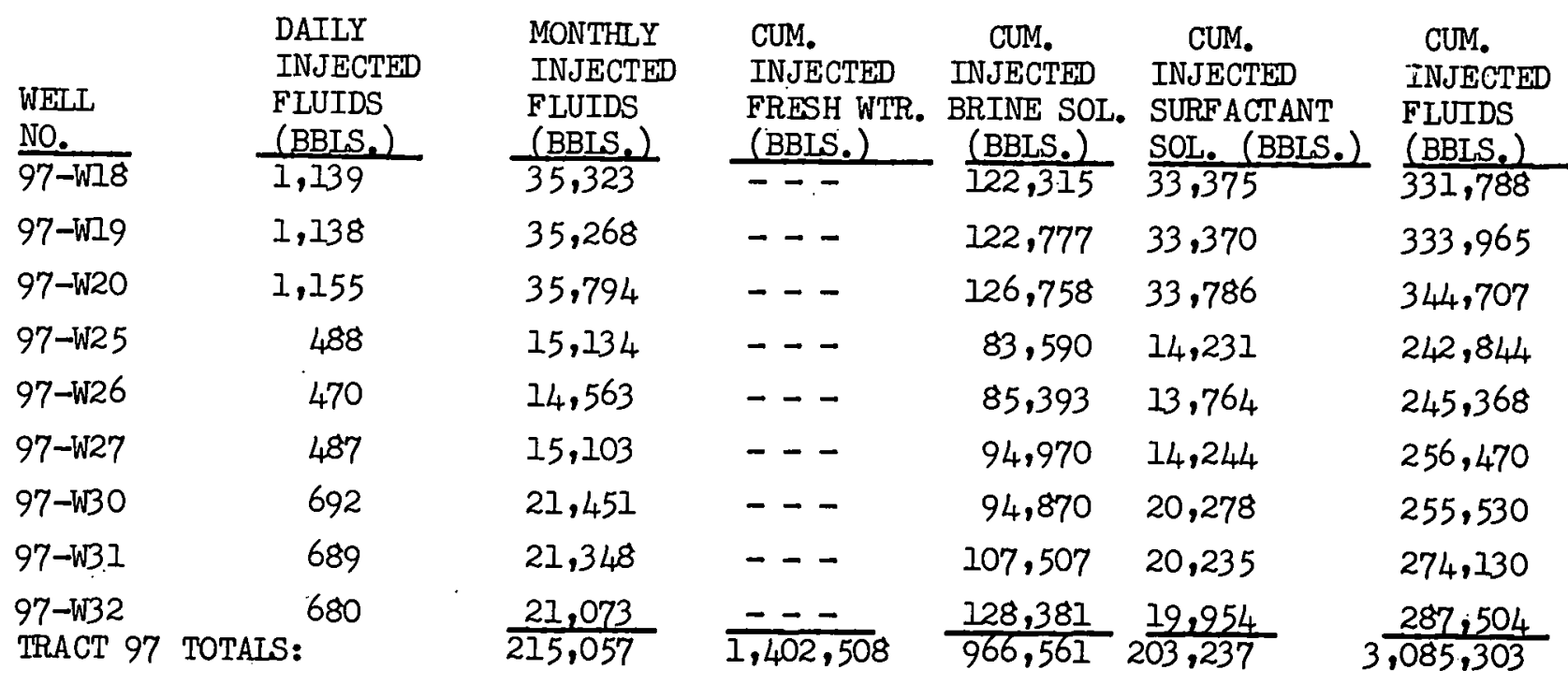


TABLE 1I.

NBU TRACT 97 PRODUCTION - INJECTION DATA

SEPTEMBFR, 1976

I. PRODUCTION DATA:

\begin{tabular}{|c|c|c|c|c|c|c|}
\hline $\begin{array}{l}\text { WEII } \\
\text { NO. }\end{array}$ & $\begin{array}{l}\text { DAIIY } \\
\text { PROD. } \\
\text { OIL } \\
\text { (BBIS.) }\end{array}$ & $\begin{array}{l}\text { DAILY } \\
\text { PROD. } \\
\text { WATER } \\
\text { (BBLS.) }\end{array}$ & $\begin{array}{l}\text { MONTHLY } \\
\text { PROD. } \\
\text { OII } \\
\text { (BBLS.) }\end{array}$ & $\begin{array}{l}\text { MONTHLY } \\
\text { PROD. } \\
\text { WATER } \\
\text { (BBLS.) }\end{array}$ & $\begin{array}{l}\text { CUM. } \\
\text { PROD. } \\
\text { OIL } \\
\text { (BBIS.) }\end{array}$ & $\begin{array}{l}\text { CUM. } \\
\text { PROD. } \\
\text { WATER } \\
\text { (BBLS.) }\end{array}$ \\
\hline $97-01$ & 6 & 960 & 198 & 30,783 & 3,198 & 507,178 \\
\hline $97-06$ & 4 & 430 & 185 & 18,964 & 4,037 & 456,642 \\
\hline $97-08$ & 7 & 445 & 179 & 14,819 & 4,479 & 314,808 \\
\hline $97-09$ & 6 & 870 & 156 & 31,821 & 2,091 & 523,134 \\
\hline $97-14$ & 4 & 880 & 144 & 28,065 & 4,413 & 623,566 \\
\hline $97-17$ & 2 & 990 & 87 & 33,262 & 883 & 305,101 \\
\hline $97-21$ & 3 & 595 & 94 & 18,596 & 1,350 & 235,749 \\
\hline $97-22$ & 0 & 430 & 17 & 20,812 & 234 & 255,717 \\
\hline $97-23$ & 0 & 420 & 11 & 21,446 & 472 & 264,579 \\
\hline $97-24$ & 0 & 615 & 37 & 17,566 & 556 & 231,583 \\
\hline $97-28$ & 12 & 465 & 447 & 17,853 & 3,851 & 243,030 \\
\hline $97-29$ & 4 & 950 & 159 & 30,298 & 1,427 & 300,079 \\
\hline $97-33$ & 7 & 920 & 262 & 28,903 & 1,788 & 289,869 \\
\hline $97-34$ & 2 & 630 & 100 & 20,712 & 1,135 & 312,276 \\
\hline $97-35$ & 3 & 670 & 161 & 23,289 & 1,762 & 321,173 \\
\hline $\begin{array}{l}97-36 \\
\text { NBU TRACT }\end{array}$ & 7 TOTALS: & 930 & $\frac{123}{2,360}$ & $\frac{30,433}{387,622}$ & $\frac{1,493}{33,109}$ & $\frac{337,718}{5,521,602}$ \\
\hline
\end{tabular}

SEPTEMBBER 15, 1976: END INJECTION OF SURFACTANT SOLUTION-

BEGAN INJECTION OF POLYMER SOLUTION @2 $500 \mathrm{ppm}$.

II. INJECTION DATA:

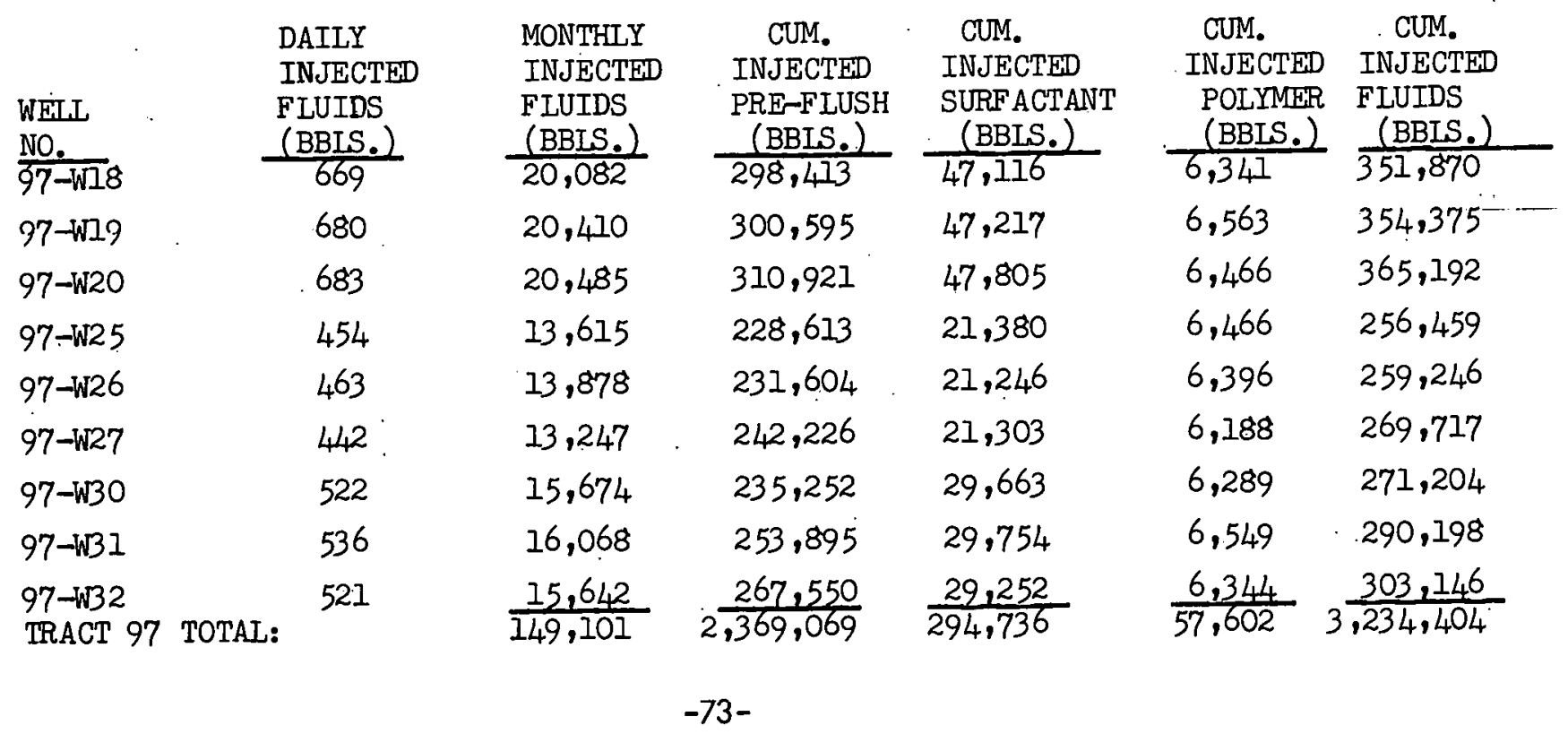


TABLE 12.

NBU TRACT 97 PRODUCTION - INJECTION DATA

OCTOBER, 1976

I. PRODUCTION DATA:

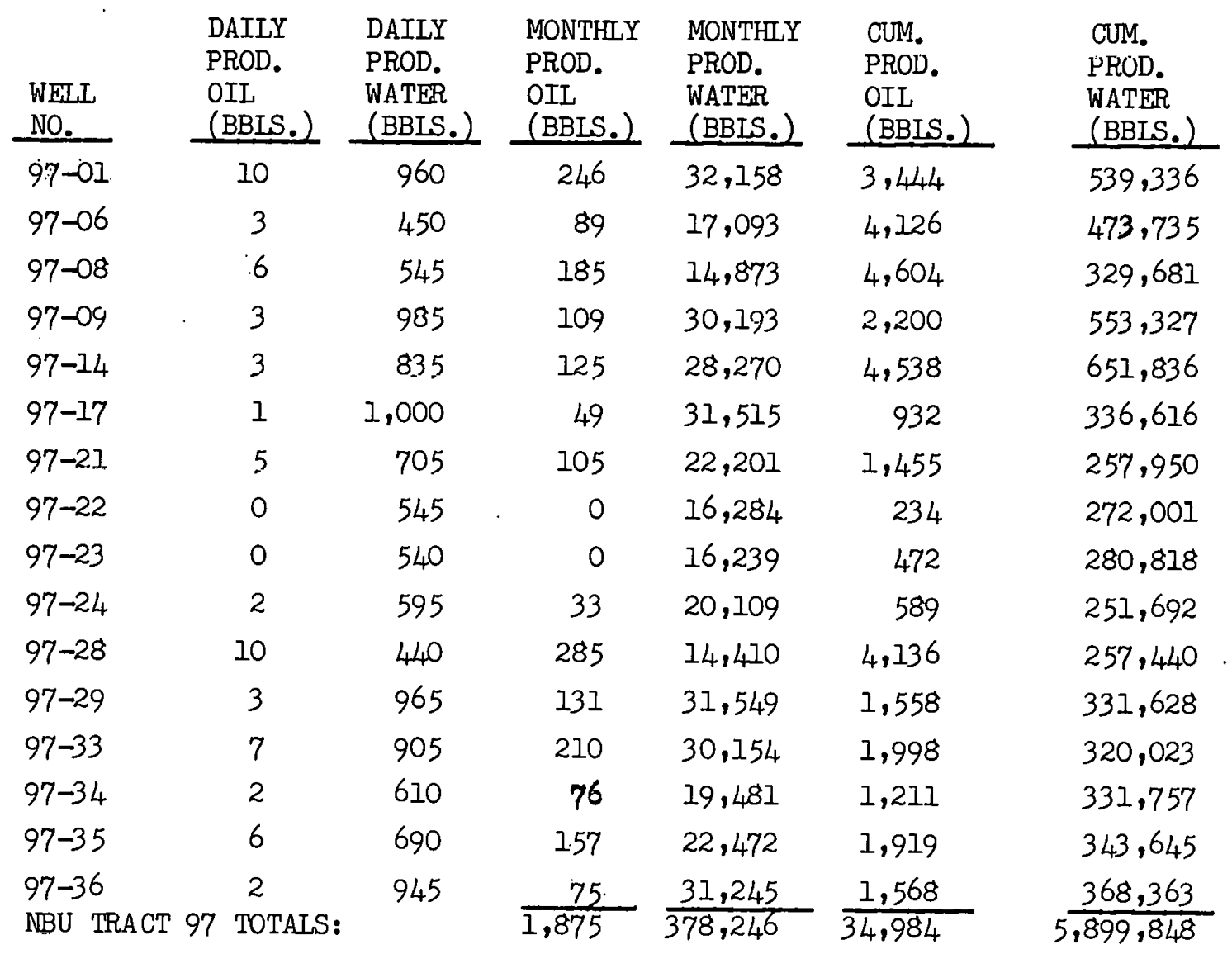

OCTOBER 14, 1976: CONCLUDED 2500 ppm POLYMER SLUG. BEGAN 2000 ppm POLYMER SLUG.

IT. INJECTION DATA:

\begin{tabular}{|c|c|c|c|c|c|c|}
\hline $\begin{array}{l}\text { WETLI } \\
\text { NO. } \\
07-\text { W7 }\end{array}$ & $\begin{array}{l}\text { DAILY } \\
\text { INJECTED } \\
\text { FLUIDS } \\
\text { (BBLS.) }\end{array}$ & $\begin{array}{l}\text { MONTHLY } \\
\text { INJECTED } \\
\text { FLUIDS } \\
\text { (BBLS.) } \\
70.575\end{array}$ & $\begin{array}{l}\text { CUM. } \\
\text { INJECTED } \\
\text { PRE-FLUSH } \\
\text { (BBLS.) } \\
\end{array}$ & $\begin{array}{l}\text { CUM. } \\
\text { INJECTED } \\
\text { SURF ACTANT } \\
\text { (BBLS.) }\end{array}$ & $\begin{array}{l}\text { CUM. } \\
\text { INJECTED } \\
\text { POLYMER } \\
\text { (BBIS.) }\end{array}$ & $\begin{array}{l}\text { CUM. } \\
\text { INJECTED } \\
\text { FLUID } \\
\text { (BBLS.) }\end{array}$ \\
\hline & & 19,515 & $-\cdots-$ & ---- & 25,856 & 371,385 \\
\hline 97-W19 & 603 & 18,694 & --- & --- & 25,257 & 373,069 \\
\hline $97-W 20$ & 630 & 19,538 & --- & --- & 26,004 & 384,730 \\
\hline $97-W 25$ & 416 & 12,900 & --- & $-\dot{-}-$ & 19,366 & 269,359 \\
\hline $97-W 26$ & 423 & 13,103 & --- & --- & 19,499 & 272,349 \\
\hline $97-W 27$ & 415 & 12,854 & ---- & ---- & $19 ; 042$ & 282,571 \\
\hline $97-W 30$ & 484 & 15,000 & $-\cdots$ & --- & 21,289 & 286,204 \\
\hline $97-W 31$ & 467 & 14,471 & --- & --- & 21,020 & 304,669 \\
\hline $\begin{array}{l}97-\text { W32 } \\
\text { TRACT } 97\end{array}$ & $\begin{array}{r}465 \\
\text { TAIS: }\end{array}$ & $\frac{14 ; 419}{140,494}$ & $\frac{---}{369,069}$ & $\frac{---}{294.736}$ & $\frac{20,763}{198,096}$ & $\frac{317,565}{3,374,898}$ \\
\hline
\end{tabular}


TABLE 13.

NBU TRACT 97 PRODUCTION - INJECTION DATA

NOVEMBER, 1976

I. PRODUCTION DATA:

\begin{tabular}{|c|c|c|c|c|c|c|}
\hline $\begin{array}{l}\text { WELI } \\
\text { NO. } \\
\end{array}$ & $\begin{array}{l}\text { DAILY } \\
\text { PROD. } \\
\text { OIL } \\
\text { (BBIS.) } \\
\end{array}$ & $\begin{array}{l}\text { DAIIY } \\
\text { PROD. } \\
\text { WATER } \\
\text { (BBIS.) }\end{array}$ & $\begin{array}{l}\text { MONTHLY } \\
\text { PROD. } \\
\text { OIL } \\
\text { (BBLS.) }\end{array}$ & $\begin{array}{l}\text { MONTHLY } \\
\text { PROD. } \\
\text { WATER } \\
\text { (BBIS.) }\end{array}$ & $\begin{array}{l}\text { CUM. } \\
\text { PROD. } \\
\text { OIL } \\
\text { (BBIS.) }\end{array}$ & $\begin{array}{l}\text { CUM. } \\
\text { PROD. } \\
\text { WATER } \\
\text { (BBIS.) }\end{array}$ \\
\hline $9 \dot{91}$ & 5 & 940 & 132 & 29,969 & 3,576 & 569,305 \\
\hline $97-06$ & 6 & 520 & 183 & 18,647 & 4,309 & 492,382 \\
\hline $97-08$ & 8 & 510 & 215 & 16,412 & 4,819 & $34,6, \cap 9,3$ \\
\hline $97-09$ & 4 & 945 & 112 & 29,641 & 2,312 & 582,968 \\
\hline $97-14$ & 3 & 850 & 95 & 29,227 & 4,633 & 681,063 \\
\hline $97-17$ & 1 & 1,000 & 80 & 32,707 & 1,012 & 369,323 \\
\hline $97-21$ & 3 & 675 & 93 & 21,887 & 1,548 & 279,837 \\
\hline $97-22$ & 0 & 550 & 4 & 17,978 & 238 & 289,979 \\
\hline $97-23$ & 1 & 550 & 48 & 15,897 . & 520 & 296,715 \\
\hline $97-24$ & 1 & 580 & 28 & 16,927 & 617 & 268,619 \\
\hline $97-28$ & 13 & 460 & 485 & 16,370 & 4,621 & 273,810 \\
\hline $97-29$ & 4 & 960 & 116 & 30,929 & 1,674 & 362,557 \\
\hline $97-33$ & 7 & 910 & 209 & 29,068 & 2,207 & 349,091 \\
\hline $97-34$ & 3 & 605 & 101 & 21,094 & 1,312 & 352,851 \\
\hline $97-35$ & 5 & 700 & 142 & 23,282 & 2,061 & 366,927 \\
\hline $\begin{array}{l}97-36 \\
\text { NBU TRACT } 97\end{array}$ & $\begin{array}{l}2 \\
7 \text { TOTALS: }\end{array}$ & 950 & $\frac{70}{.113}$ & $\frac{31,584}{381,619}$ & $\frac{1,638}{37,097}$ & $\frac{399,947}{, 281,467}$ \\
\hline
\end{tabular}

NOVEMBER 25, 1976: CHANGED POLYMER FEED RATE FROM $2000 \mathrm{ppm}$ to $1500 \mathrm{ppm}$.

II. INJECTION DATA:

\begin{tabular}{|c|c|c|c|c|c|c|}
\hline $\begin{array}{l}\text { WELL } \\
\text { NO. }\end{array}$ & $\begin{array}{l}\text { DAILY } \\
\text { INJECTED } \\
\text { FLUIDS } \\
\text { (BBIS.) } \\
\end{array}$ & $\begin{array}{l}\text { MONTHLY } \\
\text { INJECTED } \\
\text { FLUIDS } \\
\text { (BBLS.) } \\
\end{array}$ & $\begin{array}{l}\text { CUM. } \\
\text { INJECTED } \\
\text { PRE-FLUSH } \\
\text { (BBLS.) } \\
\end{array}$ & $\begin{array}{l}\text { CUM. } \\
\text { INJECTED } \\
\text { SURF ACTANT, } \\
\text { (BBIS.) }\end{array}$ & $\begin{array}{l}\text { CUM. } \\
\text { INJECTED } \\
\text { POLYMER } \\
\text { (BBLS.) }\end{array}$ & $\begin{array}{l}\text { CUM. } \\
\text { INJECTED } \\
\text { FLUIDS } \\
\text { (BBIS.) }\end{array}$ \\
\hline 97-W18 & 712 & 21,369 & --- & --- & 47,225 & 392,754 \\
\hline 97-W19 & 703 & 21,100 & $-\cdots$ & --- & 46,357 & 394,169 \\
\hline 97-W20 & 671 & 20,137 & $-\cdots$ & $--\cdots$ & 46,147 & 404,867 \\
\hline $97-$ W25 & 409 & 12,273 & --- & $-\cdots$ & 31,639 & 281,632 \\
\hline 97-W26 & 407 & 12,203 & --- & --- & 31,702 & 284,552 \\
\hline 97-W27 & 410 & 12,299 & --- & --- & 31,341 & 294,870 \\
\hline $97-W 30$ & .478 & 14,353 & --- & $-\cdots$ & 35,642 & 300,557 \\
\hline $97-W 31$ & 472 & 14,150 & --- & ---- & 35,170 & 318,819 \\
\hline $97-W 32$ & 491 & $14,7.43$ & $--\cdots$ & --- & 35,506 & 332,308 \\
\hline TRACT 97 & TOTALS: & 142,627 & $2,369,069$ & 294,736 & 340,723 & $, 517,525$ \\
\hline
\end{tabular}


TABIE 14.

NBU TRACT 97 PRODUCTION - INJECTION DATA

DECEMBER, 1976

I. PRODUCTION DATA:

\begin{tabular}{|c|c|c|c|c|c|c|}
\hline $\begin{array}{l}\text { WEELL } \\
\text { NO. }\end{array}$ & $\begin{array}{l}\text { DAILY } \\
\text { PROD. } \\
\text { OII } \\
\text { (BBIS.) }\end{array}$ & $\begin{array}{l}\text { DAIIY } \\
\text { PROD. } \\
\text { WATER } \\
\text { (BBIS.) }\end{array}$ & $\begin{array}{l}\text { MONTHLY } \\
\text { PROD. } \\
\text { OIL } \\
\text { (BBIS.) }\end{array}$ & $\begin{array}{l}\text { MONTHLY } \\
\text { PROD. } \\
\text { WATER } \\
\text { (BBIS.) }\end{array}$ & $\begin{array}{l}\text { CUM. } \\
\text { PROD. } \\
\text { OIL } \\
\text { (BBIS.) }\end{array}$ & $\begin{array}{l}\text { CUM. } \\
\text { PROD. } \\
\text { WATER } \\
\text { (BBLS.) }\end{array}$ \\
\hline $97-01$ & 3 & 1,030 & 114 & 33,400 & 3,690 & 602,705 \\
\hline $97-06$ & 6 & 560 & 211 & 20,220 & 4,520 & 512,602 \\
\hline $97-08$ & 7 & 510 & 214 & 16,628 & 5,033 & 362,721 \\
\hline $97-09$ & 5 & 1,020 & 152 & 31,128 & 2,464 & 614,096 \\
\hline $97-14$ & 3 & 880 & 115 & 31,092 & 4,748 & 712,155 \\
\hline $97-17$ & 3 & 1,020 & 135 & 36,055 & 1,147 & 405,378 \\
\hline $97-21$ & 4 & 660 & III & 22,206 & 1,659 & 302,043 \\
\hline $97-22$ & 2 & 605 & 49 & 20,476 & 287 & 310,395 \\
\hline $97-23$ & 5 & 630 & 164 & 22,272 & 684 & 318,987 \\
\hline $97-24$ & 3 & 600 & 74 & 18,615 & 691 & 287,234 \\
\hline $97-28$ & 22 & 455 & 759 & 16,848 & 5,380 & 290,658 \\
\hline $97-29$ & 6 & 960 & 180 & 33,395 & 1,854 & 395,952 \\
\hline $97-33$ & 6 & 915 & 293 & 32,137 & 2,500 & 381,228 \\
\hline $97-34$ & 4 & 615 & 134 & 21,770 & 1,446 & 374,621 \\
\hline $97-35$ & 5 & 700 & 134 & 24,786 & 2,195 & 391,713 \\
\hline $97-36$ & 6 & 960 & 172 & 33,521 & 1,817 & 433,468 \\
\hline NBU TR & 97 TOTAIS: & &, 018 & 474,489 & 40,115 & $, 695,956$ \\
\hline
\end{tabular}

II. INJECTION DATA:

\begin{tabular}{|c|c|c|c|c|c|c|}
\hline $\begin{array}{l}\text { WELL } \\
\text { NO. }\end{array}$ & $\begin{array}{l}\text { DAILY } \\
\text { INJECTED } \\
\text { FLUIDS } \\
\text { (BBIS.) } \\
\end{array}$ & $\begin{array}{l}\text { MONTHLY } \\
\text { INJECTED } \\
\text { FLUIDS } \\
\text { (BBLS.) } \\
\end{array}$ & $\begin{array}{l}\text { CUM. } \\
\text { INJECTED } \\
\text { PRE-FLUSH } \\
\text { (BBLS.) } \\
\end{array}$ & $\begin{array}{l}\text { CUM. } \\
\text { INJECTED } \\
\text { SURF ACTANT } \\
\text { (BBIS.) }\end{array}$ & $\begin{array}{l}\text { CUM. } \\
\text { INJECTED } \\
\text { POLYMER } \\
\text { (BBIS.) }\end{array}$ & $\begin{array}{l}\text { CUM. } \\
\text { INJECTED } \\
\text { FLUIDS } \\
\text { (BBLS.) } \\
\end{array}$ \\
\hline $97-w 18$ & 683 & 21,164 & --- & -- & 68,389 & 413,918 \\
\hline $97-$ w19 & 709 & 21,974 & -- & --- & 68,331 & 416,143 \\
\hline $98-W 20$ & 703 & 21,779 & -- & -- & 67,920 & 426,646 \\
\hline $97-$ W25 & 438 & $13 ; 563$ & -- & --- & 45,202 & 295,195 \\
\hline $97-W 26$ & 440 & 13,625 & -- & -- & 45,327 & 298,277 \\
\hline 97-W27 & 439 & $.13,604$ & --- & -- & 44,945 & 308,474 \\
\hline $97-W 30$ & 512 & 15,882 & --- & -- & 51,524 & 316,439 \\
\hline $97-W 31$ & 508 & 15,745 & -- & -- & 50,915 & 334,564 \\
\hline $\begin{array}{l}97-\text { W32 } \\
\text { NBU TRACT } 97\end{array}$ & $\begin{array}{c}526 \\
\text { TOTAIS: }\end{array}$ & $\frac{16,296}{153,632}$ & $2 \overline{-\overline{369} ; \overline{069}}$ & $\frac{---}{294.736}$ & $\frac{51,802}{494,355}$ & $\frac{348,604}{3,671,157}$ \\
\hline
\end{tabular}


TABLE 15.

NBU IRACT 97 PRODUCTION - INJECTION DATA

JANIJARY, 1977

I. PRODUCTION DATA:

\begin{tabular}{|c|c|c|c|c|c|c|}
\hline $\begin{array}{l}\text { WELL } \\
\text { NO. }\end{array}$ & $\begin{array}{l}\text { DAILY } \\
\text { PROD. } \\
\text { OIL. } \\
\text { (BBLS.) }\end{array}$ & $\begin{array}{l}\text { DAILY } \\
\text { PROD. } \\
\text { WATER } \\
\text { (BBLS_) }\end{array}$ & $\begin{array}{l}\text { MONTHLY } \\
\text { PROD. } \\
\text { OIL } \\
\text { (BBLS.) }\end{array}$ & $\begin{array}{l}\text { MONTHLY } \\
\text { PROD. } \\
\text { WATER } \\
\text { (BBLS.) }\end{array}$ & $\begin{array}{l}\text { CUM. } \\
\text { PROD. } \\
\text { OIL } \\
\text { (BBLS.) }\end{array}$ & $\begin{array}{l}\text { CUM. } \\
\text { PIOD. } \\
\text { WATER } \\
\text { (BBLS.) }\end{array}$ \\
\hline $97-01$ & 5 & 1,085 & 172 & 32,963 & 3,862 & 635,668 \\
\hline $97-06$ & 12 & 555 & 231 & 17,810 & 4.751 & 530,412 \\
\hline $97-08$ & 4 & 465 & 172 & 14,001 & 5,205 & 376,722 \\
\hline $97-09$ & 5 & 1,015 & 132 & 30,973 & 2,596 & 645,069 \\
\hline $97-14$ & 3 & 880 & 143 & 28,891 & 4,891 & 741,046 \\
\hline $97-17$ & 3 & 1,105 & 90 & 33,873 & 1,237 & 439,251 \\
\hline $97-21$ & 4 & 645 & 112 & 19,745 & 1.771 & 321,788 \\
\hline $97-22$ & 5 & 655 & 108 & 20,315 & 395 & 330,710 \\
\hline $97-23$ & 15 & 655 & 270 & 20,222 & 954 & 339,209 \\
\hline $97-24$ & 4 & 545 & 95 & 16.713 & 786 & 303.947 \\
\hline $97-28$ & 30 & 530 & 913 & 17,255 & 6,293 & 307,913 \\
\hline $97-29$ & 6 & 990 & 156 & 30,632 & 2,010 & 426,584 \\
\hline $97-33$ & 10 & 985 & 407 & 32,733 & 2,907 & 413,961 \\
\hline $97-34$ & 4 & 655 & 117 & 22,055 & 1,563 & 396,676 \\
\hline $97-35$ & 4 & 765 & 134 & 22,506 & 2,329 & 414,219 \\
\hline $97-36$ & 5 & 1,030 & 157 & 33,339 & 1,974 & 466,807 \\
\hline NBU TR & 97 TOTAI & & 3,409 & 394,026 & 43.524 & $, 089,982$ \\
\hline
\end{tabular}

JANUARY 17, 1977: CHANGED POLYMER CONCENTRATION FBOM $1500 \mathrm{ppm}$ to $1100 \mathrm{ppm}$.

II. INJECTION DATA:

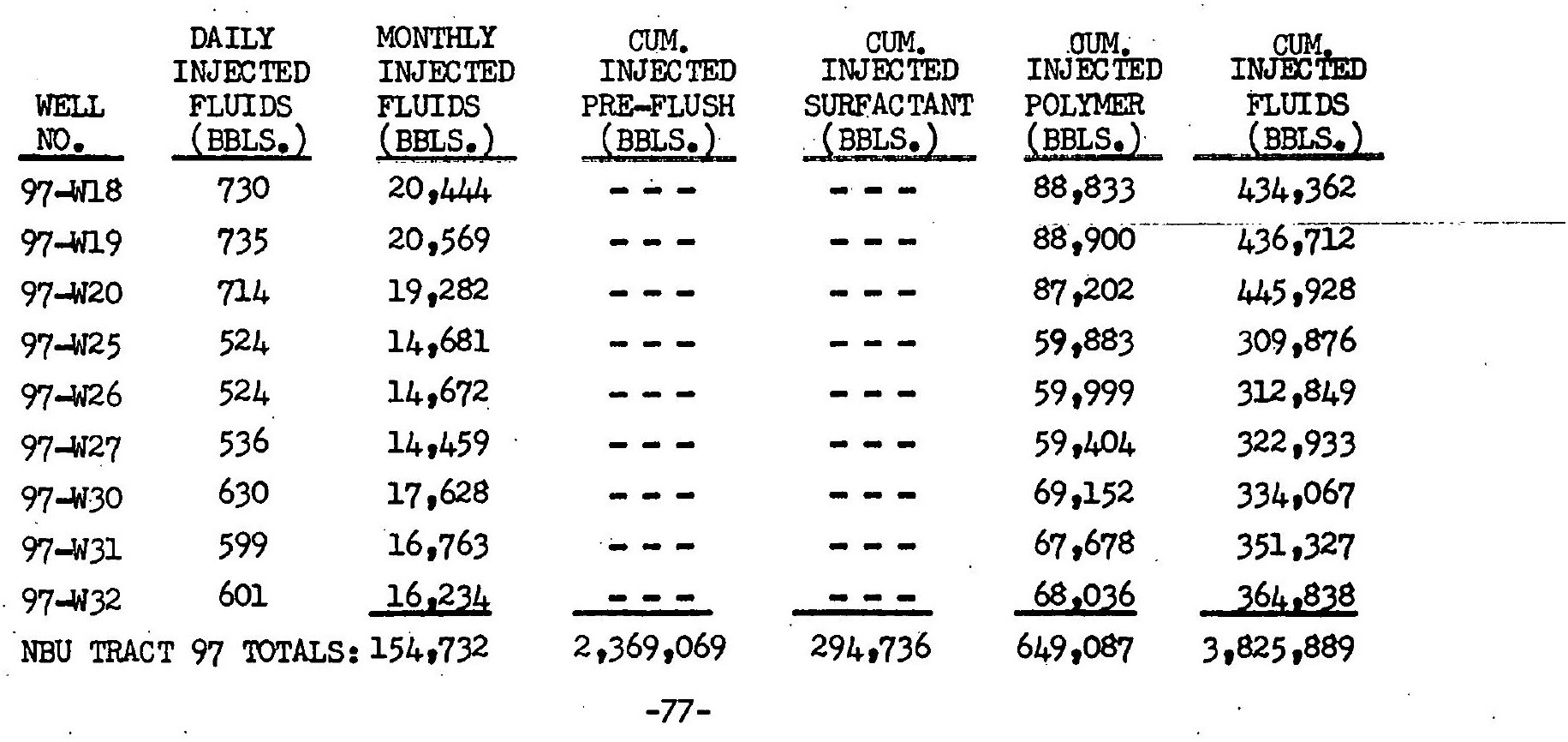


TABLE 16.

NBU TRACT 97 PRODUCTION - INUECTION DATA

FEBRUARY, 1977

I. PRODUCTION DATA:

\begin{tabular}{|c|c|c|c|c|c|c|}
\hline $\begin{array}{l}\text { WETL } \\
\text { NO. }\end{array}$ & $\begin{array}{l}\text { DAILY } \\
\text { PROD. } \\
\text { OIL } \\
\text { (BBLS.) } \\
\end{array}$ & $\begin{array}{l}\text { DAIIY } \\
\text { PROD. } \\
\text { WATHR } \\
\text { (BBLS.) }\end{array}$ & $\begin{array}{l}\text { MONTHLY } \\
\text { PROD. } \\
\text { OIL } \\
\text { (BBLS.) }\end{array}$ & $\begin{array}{l}\text { MONTHLY } \\
\text { PROD. } \\
\text { WATER } \\
\text { (BBLS.) }\end{array}$ & $\begin{array}{l}\text { COM. } \\
\text { PROD. } \\
\text { OIL } \\
\text { (BBLS.) }\end{array}$ & $\begin{array}{l}\text { CUM. } \\
\text { PEOD. } \\
\text { WATER } \\
\text { (BBLS.) }\end{array}$ \\
\hline $97-01$ & 6 & 1.105 & 154 & 31,760 & 4,016 & 667,428 \\
\hline $97-06$ & 14 & 555 & 307 & 17,010 & 5,058 & 547.422 \\
\hline $97-08$ & 6 & 435 & 172 & 12,738 & 5.377 & 389,460 \\
\hline $97-09$ & 5. & 1,025 & 148 & 29,786 & 2,744 & 674,855 \\
\hline $97-14$ & 4 & 880 & 84 & 26,524 & 4,975 & 767,570 \\
\hline $97-17$ & 3 & 1,100 & 103 & 31,275 & 1,340 & 470,526 \\
\hline $97-21$ & 4 & 655 & 83 & 19,417 & 1,854 & 341,205 \\
\hline $97-22$ & 4 & 655 & 107 & 19.878 & 502 & 350,588 \\
\hline $97-23$ & 16 & 645 & 510 & 19,852 & 1,464 & 359,061 \\
\hline $97-24$ & 4 & 495 & 67 & 13.704 & 853 & 317.651 \\
\hline $97-28$ & 42 & 530 & 1,169 & 16,285 & 7.462 & 324,198 \\
\hline $97-29$ & 5 & 965 & 151 & 29,367 & 2,161 & 455,951 \\
\hline $97-33$ & 13 & 955 & 387 & 28,945 & 3.294 & 442,906 \\
\hline $97-34$ & 3 & 695 & 107 & 20,681 & 1,670 & 417.357 \\
\hline $97-35$ & 5 & 465 & 173 & 9.739 & 2,502 & 423,958 \\
\hline $97-36$ & 3 & 1,010 & 101 & 30,054 & 2.075 & 496,861 \\
\hline \multicolumn{3}{|c|}{ NBU TRACT 97 TOTALS: } & 3,823 & 357.015 & 47.347 & $7,446,997$ \\
\hline
\end{tabular}

II. INJECTION DATA:

\begin{tabular}{|c|c|c|c|c|c|c|}
\hline $\begin{array}{l}\text { WELL } \\
\text { NO. } \\
\end{array}$ & $\begin{array}{l}\text { DAILY } \\
\text { INJECTED } \\
\text { FLUIDS } \\
\text { (BBLS.) } \\
\end{array}$ & $\begin{array}{l}\text { MONTHLY } \\
\text { INJECTED } \\
\text { FLUIDS } \\
\text { (BBLS.) } \\
\end{array}$ & $\begin{array}{c}\text { CUM. } \\
\text { INJECTED } \\
\text { PRE-FLUSH } \\
\text { (BBLS.) }\end{array}$ & $\begin{array}{c}\text { CUM. } \\
\text { INJECTED } \\
\text { SURFACTANT } \\
\text { (BBLS.) }\end{array}$ & $\begin{array}{l}\text { CUM. } \\
\text { INJEC TED } \\
\text { POLYMER } \\
\text { (BBLS.) } \\
\end{array}$ & $\begin{array}{l}\text { CUM. } \\
\text { INJECTED } \\
\text { FLUIDS } \\
\text { (BBLS.) }\end{array}$ \\
\hline $97-W 18$ & 747 & 20,924 & -- & -- & 109,757 & 455.286 \\
\hline $97-W 19$ & 734 & 20,540 & -- & -- & 109,440 & 457,252 \\
\hline $97-\$ 20$ & 729. & 20,410 & -- & -- & 107,612 & 466,338 \\
\hline $97-W 25$ & 511 & 14,302 & -- & -- & 74,185 & 324,178 \\
\hline $97-W 26$ & 490 & 13,731 & -- & -- & 73.730 & 326,580 \\
\hline $97-$ W27 & 500 & 14,006 & -- & -- & 73,410 & 336,939 \\
\hline $97-130$ & 619 & 17.344 & -- & -- & 86,496 & 351,411 \\
\hline $97-N 31$ & 602 & 16,849 & -- & & 84,527 & 368,176 \\
\hline $97-432$ & 608 & 17,032 & $=-$ & $-=$ & 85,068 & 381,870 \\
\hline NBU TRACT & I 97 TOTALS: & 155,138 & $\begin{array}{c}2,369,069 \\
-78\end{array}$ & 294,736 & 804,225 & $3,981,027$ \\
\hline
\end{tabular}


TABLE 17.

NBU TRACT 97 PRODUCTION - INUECTION DATA

$\mathrm{MARCH}, 1977$

\section{PRODUCTION DATA:}

\begin{tabular}{|c|c|c|c|c|c|c|}
\hline $\begin{array}{l}\text { WETL } \\
\text { NO. }\end{array}$ & $\begin{array}{l}\text { DAILY } \\
\text { PROD. } \\
\text { OIL } \\
\text { (BBLS.) }\end{array}$ & $\begin{array}{l}\text { DAILY } \\
\text { PROD. } \\
\text { WATER } \\
\text { (BBLS.) }\end{array}$ & $\begin{array}{l}\text { MONTHLY } \\
\text { PROD. } \\
\text { OIL } \\
\text { (BBLS.) }\end{array}$ & $\begin{array}{l}\text { MONTHLY } \\
\text { PROD. } \\
\text { WATER } \\
\text { (BBLS.) }\end{array}$ & $\begin{array}{l}\text { CUM. } \\
\text { PROD. } \\
\text { OIL } \\
\text { (BBLS.) }\end{array}$ & $\begin{array}{l}\text { CUM. } \\
\text { PEOD. } \\
\text { WATER } \\
\text { (BBLS.) }\end{array}$ \\
\hline $97-01$ & 6 & 1,105 & 169 & 33.665 & 4,185 & 701,093 \\
\hline $97-06$ & 12 & 570 & 376 & 17.464 & 5,434 & 564,886 \\
\hline $97-08$ & 8 & 510 & 189 & 14,369 & 5,566 & 403,829 \\
\hline $97-09$ & .6 & 1,045 & 147 & 32,225 & 2,891 & 707,080 \\
\hline $97-14$ & 4 & 875 & 132. & 29,120 & 5,107 & 796,690 \\
\hline $97-17$ & 7 & 1,075 & 156 & 31.536 & 1,496 & 502,062 \\
\hline $97-21$ & 3 & 635 & 97. & 19,151 & 1,951 & 360,356 \\
\hline $97-22$ & 5 & 670 & 167 & 20,520 & 669 & 371,108 \\
\hline $97-23$ & 18 & 655 & 653 & 20,243 & 2,117 & 379.304 \\
\hline $97-24$ & 2 & .445 & 65 & 13,977 & 918 & 331,628 \\
\hline $97-28$ & 45 & 520 & 1,534 & 16,414 & 8,996 & 340,612 \\
\hline $97-29$ & 5 & 975 & 1.58 & 31,544 & 2,319 & 487.495 \\
\hline $97-33$ & 10 & 975 & 301 & 31,901 & 3,595 & 474,807 \\
\hline $97-34$ & 5 & 730 & 163 & 23,330 & 1,833 & 440,687 \\
\hline $97-35$ & 7 & 340 & 221 & 10,946 & 2,723 & 434,904 \\
\hline $97-36$ & 5 & 1,035 & 155 & 33,329 & 2,230 & 530,190 \\
\hline NBU TR & 97 TOTAL & & 4,683 & 379,734 & 52,030 & $7.826,731$ \\
\hline
\end{tabular}

MARCH 8, 1977: CHANGED POLYMER CONCENTRATION FROM $1100 \mathrm{ppm}$ to $800 \mathrm{ppm}$

II. INJECTION DATA:

\begin{tabular}{|c|c|c|c|c|c|c|}
\hline $\begin{array}{l}\text { WELL } \\
\text { NO. }\end{array}$ & $\begin{array}{l}\text { DAILY } \\
\text { INJECTED } \\
\text { FLUIDS } \\
\text { (BBLS.) }\end{array}$ & $\begin{array}{l}\text { MONTHLY } \\
\text { INJECTED } \\
\text { FLUIDS } \\
\text { (BBLS.) } \\
\end{array}$ & $\begin{array}{l}\text { CUM. } \\
\text { INJECTED } \\
\text { PRE_FLUSH } \\
\text { (BBLS.) } \\
\end{array}$ & $\begin{array}{l}\text { CUM. } \\
\text { INJECTED } \\
\text { SURFACTANT } \\
\text { (BBLS.) }\end{array}$ & $\begin{array}{l}\text { CUM. } \\
\text { INJEC TED } \\
\text { POLYMER } \\
\text { (BBLS。) } \\
\end{array}$ & $\begin{array}{l}\text { CUM. } \\
\text { INJECTED } \\
\text { FLUIDS } \\
\text { (BBLS.) }\end{array}$ \\
\hline $97-w 18$ & 754 & 23,380 & --- & -- & 133.137 & 478,666 \\
\hline $97-$ W19 & 754 & 23,385 & -- & -- & 132,825 & 480,637 \\
\hline $97-$-20 & 683 & 21,161 & -- & $-\infty$ & 128,773 & 487,499 \\
\hline $97-W 25$ & 512 & 15,862 & -- & --- & 90,047 & 340,040 \\
\hline $97-W 26$ & 514 & 15,937 & -- & --- & 89,667 & 342,517 \\
\hline $97-w 27$ & 517 & 16,016 & --- & --- & 89,426 & 352,955 \\
\hline $97-130$ & 606 & 18,776 & -- & -- & 105,272 & 370,187 \\
\hline $97-W 31$ & 608 & 18,845 & -- & -- & 103,372 & 387,021 \\
\hline $97-w 32$ & 604 & 18,738 & $=-$ & -- & 103,806 & 400,608 \\
\hline \multicolumn{3}{|c|}{ NBU TRACT 97 TOTALS: 172,100} & $2,369,069$ & 294,736 & 976,325 & $4,153,127$ \\
\hline
\end{tabular}


TABLE 78.

NBU IRACT 27 PRODUCTION - INJECTION DATA

APRII, 1077

I. PRODUCTION DATA:

\begin{tabular}{|c|c|c|c|c|c|c|}
\hline $\begin{array}{l}\text { WEILL } \\
\text { NO. }\end{array}$ & $\begin{array}{l}\text { DAILY } \\
\text { PROD. } \\
\text { OIL } \\
\text { (BBLS.) }\end{array}$ & $\begin{array}{l}\text { DAILY } \\
\text { PROD. } \\
\text { WATER } \\
\text { (BBLS.) }\end{array}$ & $\begin{array}{l}\text { MONTHLY } \\
\text { FROD. } \\
\text { (IIL } \\
\text { (IBLS.) }\end{array}$ & $\begin{array}{l}\text { MONTHLY } \\
\text { PROD. } \\
\text { WATER } \\
\text { (BBLS.) }\end{array}$ & $\begin{array}{l}\text { CUM: } \\
\text { PROD. } \\
\text { OII } \\
\text { (BBLS.) }\end{array}$ & $\begin{array}{l}\text { CUM. } \\
\text { PEOD. } \\
\text { WATER } \\
\text { (BBLS.) }\end{array}$ \\
\hline $97-01$ & 6 & 1,110 & 161 & 32,196 & 4,346 & 733,289 \\
\hline $97-06$ & 18 & 608 & 546 & 18,244 & 5,980 & 583,130 \\
\hline $97-08$ & 7 & 551 & 211 & 16,539 & 5,777 & 420,368 \\
\hline $97-09$ & 5 & 1,005 & 147 & 30,141 & 3,032 & 737,221 \\
\hline $97-14$ & 5 & 1,014 & 137 & 30,431 & 5,244 & 827,121 \\
\hline $97-17$ & 34 & 1,067 & 944 & 29,884 & 2,440 & 531,946 \\
\hline $97-21$ & 4 & 865 & 124 & 24,231 & 2,075 & 384,587 \\
\hline $97-22$ & 6 & 683 & 197 & 20,499 & 866 & 391,607 \\
\hline $97-23$ & 17 & 695 & 463 & 18,770 & 2,580 & 398,074 \\
\hline $97-24$ & 3 & 393 & 84 & 11,776 & 1,002 & 343,404 \\
\hline $97-28$ & 48 & 531 & 1,453 & 15,915 & 10,449 & 356,527 \\
\hline $97-29$ & 6 & 1,026 & 185 & 30,791 & 2,504 & 518,286 \\
\hline $97-33$ & 9 & 1,070 & 238 & 28,889 & 3,833 & 503,696 \\
\hline $97-34$ & 4 & 785 & 130 & 23,556 & 1,963 & 464,243 \\
\hline $97-35$ & 8 & 359 & 246 & 10,782 & 2,969 & 445,686 \\
\hline $97-36$ & 9 & 1,097 & 255 & 31,811 & 2,485 & 562,001 \\
\hline NBU TR & 97 TOTAL & & $\overline{5,515}$ & $\overline{374,455}$ & $\overline{57,545}$ & 201,186 \\
\hline
\end{tabular}

II. INJECTION DATA:

\begin{tabular}{|c|c|c|c|c|c|c|}
\hline $\begin{array}{l}\text { WELL } \\
\text { NO. }\end{array}$ & $\begin{array}{l}\text { DAILY } \\
\text { INJECTED } \\
\text { FLUIDS } \\
\text { (BBLS.) } \\
\end{array}$ & $\begin{array}{l}\text { MONTHLY } \\
\text { INJECTED } \\
\text { FLUIDS } \\
\text { (BBLS.) } \\
\end{array}$ & $\begin{array}{l}\text { CUM. } \\
\text { INJECTED } \\
\text { PRE-FLUSH } \\
\text { (BBL. .) } \\
\end{array}$ & $\begin{array}{c}\text { CUM. } \\
\text { INJECTED } \\
\text { SUIRACTANT } \\
\text { (EELS.) }\end{array}$ & $\begin{array}{l}\text { CUM. } \\
\text { INJES TED } \\
\text { POJYVMER } \\
\text { (BELS.) }\end{array}$ & $\begin{array}{l}\text { CUM. } \\
\text { IN-ECTED } \\
\text { FLUIDS } \\
\text { (BBLS.) }\end{array}$ \\
\hline $97-w 18$ & 730 & 21,905 & -- & -- & 155,042 & 500,571 \\
\hline $97-519$ & 729 & 21,883 & -- & --- & 154,708 & 502,520 \\
\hline $97-W 20$ & 690 & 20,708 & -- & -- & 149,481 & 508,207 \\
\hline $97-W 25$ & 517 & 15,500 & -- & --- & 105,547 & 355,540 \\
\hline $97-w 26$ & 500 & 15,002 & -- & -- & 104,669 & 357,519 \\
\hline $97-W 27$ & 523 & 15,682 & -- & -- & 105,108 & 368,637 \\
\hline $97-W 30$ & 610 & 18,299 & -- & --- & 123,571 & 388,486 \\
\hline $97-w 31$ & 617 & 18,500 & -- & -- & 121,872 & 405,521 \\
\hline $97-w 32$ & 616 & 18,470 & --- & $=-$ & 122,276 & 419,078 \\
\hline NBU TRA & 97 TOTA & 65,949 & $\begin{array}{c}2,369,069 \\
-80-\end{array}$ & 294,736 & $, 142,274$ & $4,319,076$ \\
\hline
\end{tabular}


TABLE 19.

NBU TRACT 97 PRODUCTION - INJECTION DATA

May 1, 1977 thru May 15, 1977 Incl.

I. PRODUCTION DATA:

\begin{tabular}{|c|c|c|c|c|c|c|}
\hline $\begin{array}{l}\text { WELL } \\
\text { NO. }\end{array}$ & $\begin{array}{l}\text { DAIA: } \\
\text { DAILY } \\
\text { PROD. } \\
\text { OIL } \\
\text { (BBLS.) }\end{array}$ & $\begin{array}{l}\text { DAILY } \\
\text { PROD. } \\
\text { WATER } \\
\text { (BBLS.) }\end{array}$ & $\begin{array}{l}\text { SEMI- } \\
\text { MONTHLY } \\
\text { PROD. } \\
\text { OIL } \\
\text { (BBLS.) }\end{array}$ & $\begin{array}{l}\text { SEMI- } \\
\text { MONTHLY } \\
\text { PROD. } \\
\text { WATER } \\
\text { (BBLS.) }\end{array}$ & $\begin{array}{l}\text { CUM. } \\
\text { PROD. } \\
\text { OIL } \\
\text { (BBLS.) }\end{array}$ & $\begin{array}{l}\text { CUM: } \\
\text { PBOD. } \\
\text { WATER } \\
\text { (BBLS.) }\end{array}$ \\
\hline $97-01$ & 6 & 1,137 & 94 & 17,059 & 4,440 & 750,348 \\
\hline $97-06$ & 21 & 590 & 309 & 8,844 & 6,289 & 591,974 \\
\hline $97-08$ & 8 & 551 & 122 & 8,268 & 5,899 & 428,636 \\
\hline $97-09$ & 4 & 1,012 & 60 & 15,174 & 3,092 & 752,395 \\
\hline $97-14$ & 3 & 935 & 46 & 14,031 & 5,290 & 841,152 \\
\hline $97-17$ & 19 & 1,077 & 266 & 15,078 & 2,706 & 547,024 \\
\hline $97-21$ & 5 & 736 & 78 & 11,041 & 2,153 & 395,628 \\
\hline $97-22$ & 7 & 678 & 111 & 10,177 & 977 & 401,784 \\
\hline $97-23$ & 13 & 686 & 195 & 10,289 & 2,775 & 408,363 \\
\hline $97-24$ & 3 & 338 & 46 & 5,072 & 1,048 & $.348,476$ \\
\hline $97-28$ & 49 & 500 & 742 & 7,501 & 11,191 & 364,028 \\
\hline $97-29$ & 7 & 994 & 106 & 14,905 & 2,610 & 533,191 \\
\hline $97-33$ & 15 & 1,050 & 220 & 15.753 & 4,053 & 519,449 \\
\hline $97-34$ & 6 & 750 & 85 & 11,219 & 2,048 & 475,462 \\
\hline $97-35$ & 7 & 320 & 105 & 4,793 & 3,074 & 450,479 \\
\hline $97-36$ & 7 & 1,096 & 101 & 16,437 & 2,586 & 578,438 \\
\hline $\mathrm{NBU} T$ & 97 TOTAI & & 2,685 & 185,641 & 60,231 & $8,386,827$ \\
\hline
\end{tabular}

MAY 1, 1977: Changed Polymer Concentration from $800 \mathrm{ppm}$ to $600 \mathrm{ppm}$.

II. INJECTION DATA:

\begin{tabular}{|c|c|c|c|c|c|c|}
\hline $\begin{array}{l}\text { WEIL } \\
\text { NO. } \\
\end{array}$ & $\begin{array}{l}\text { DAILY } \\
\text { INJECTED } \\
\text { FLUIDS } \\
\text { (BBLS.) } \\
\end{array}$ & \begin{tabular}{l}
\multicolumn{1}{c}{ SEMI- } \\
MONTHLY \\
INJECTED \\
FLUIDS \\
(BBLS.) \\
\end{tabular} & $\begin{array}{c}\text { CUM: } \\
\text { INJECTED } \\
\text { PRE-FLUSH } \\
\text { (BBLS.) }\end{array}$ & $\begin{array}{l}\text { CUM. } \\
\text { INJECTED } \\
\text { SURFACTANT } \\
\text { (BBLS.) }\end{array}$ & $\begin{array}{l}\text { CUM. } \\
\text { INJECTED } \\
\text { POLYMER } \\
\text { (BBLS。) } \\
\end{array}$ & $\begin{array}{l}\text { CUM. } \\
\text { INJEC'L'D } \\
\text { FLUIDS } \\
\text { (BBLS.) }\end{array}$ \\
\hline $97-w 18$ & 724 & 10,857 & --- & --- & 165,899 & 511,428 \\
\hline $97-w 19$ & 847 & 12,702 & --- & -- & 167,410 & 515,222 \\
\hline $97-W 20$ & 712 & 10,675 & -- & -- & 160,156 & 518,882 \\
\hline $97-W 25$ & 521 & 7,819 & -- & -- & 113,366 & 363,359 \\
\hline $97-$ W26 & 529 & 7,938 & --- & --- & 112,607 & 365,457 \\
\hline $97-w 27$ & 467 & 7,006 & -- & -- & 112,114 & 375,643 \\
\hline $97-W 30$ & 607 & 9,102 & -- & -- & 132,673 & 397,588 \\
\hline $97-W 31$ & 608 & 7,905 & -- & -- & 129,777 & 413,426 \\
\hline $97-132$ & 643 & 9,646 & $--=$ & -- & 131,922 & 428,724 \\
\hline NBU TRAC & T 97 TOTALS & 83,650 & $\begin{array}{c}2,369,069 \\
-81-\end{array}$ & 294,736 & $1,225,924$ & $4,402,726$ \\
\hline
\end{tabular}


TABIE 20.

\section{SCHFDULE FOR GEILED POLYMER TREATMENT, WELL 97-W25}

1. Shut in Wells $97-14,97-21,97-22$.

2. Inject 19 barrels of brine spacer.

3. Inject 100 barrels of $5000 \mathrm{ppm}$ Betz Hi-Vis polyacrylamide and $500 \mathrm{ppm}$ sodium dichromate dihydrate.

4. Inject 16 barrels of brine spacer.

5. Inject 100 barrels of $700 \mathrm{ppm}$ sodium hydrosulfite.

6. Repeat steps 2 through 5 three times.

7. Shut in Wells $97-$ W25 and 97-28 for 24 hours before reopening all wells. 
TABLE 21.

RECOVERABLE OIL CONTACTED BY OPTTMAL SURFACTANT DISTRTBUTION

SLUG SIZE, BBI FRACTION OF PV

OII CONTACTED, STB

FRACTION OF OOIP

STB OII/BBL SLUG

SLUG SIZE, BBL

FRACTION OF PV

OIL CONTACTED, STB

' FRACTION OF OOIP

$\stackrel{\omega}{\omega}$ STB OIL/BBL SLUG

SLUG SIZE, BBL

FRACTION OF PV

OIL CONTACTED, STB

FRACTION OF OOIP

STB OII/BBL SLUG

$\begin{array}{llllllllll}\text { W30 } & \text { W31 } & \text { W32 } & \text { W25 } & \text { W26 } & \text { W27 } & \text { W18 } & \text { W19 } & \text { W20 } & \text { TOTAL } \\ 23796 & 25172 & 24072 & 10524 & 17024 & 21496 & 63438 & 30359 & 66192 & 288000 \\ .048 & .036 & .029 & .036 & .032 & .030 & .084 & .045 & .100 & .049557 \\ 32200 & 38000 & 41200 & 22300 & 31000 & 35500 & 82000 & 42900 & 92600 & 417700 \\ .202 & .173 & .158 & .152 & .184 & .157 & .336 & .197 & .429 & .225 \\ 1.35 & 1.51 & 1.71 & 1.35 & 1.82 & 1.65 & 1.29 & 1.41 & 1.40 & 1.45\end{array}$

TABLE 22.

RECOVERABLE OIL CONTACTED BY EQUALL VOLUME SURFACTANT SLUGS

$\begin{array}{llllllllll}\frac{\text { W30 }}{32000} & \frac{\text { W31 }}{32000} & \frac{\text { W32 }}{32000} & \frac{W 25}{32000} & \frac{\text { W26 }}{32000} & \frac{\text { W27 }}{32000} & \frac{\text { W18 }}{32000} & \frac{\text { W19 }}{32000} & \frac{\text { W20 }}{32000} & \frac{\text { TOTAL }}{288000} \\ .065 & .046 & .038 & .070 & .061 & .045 & .042 & .048 & .049 & .049557 \\ 38552 & 42850 & 47429 & 31206 & 39246 & 43466 & 53360 & 44165 & 53200 & 393474 \\ .242 & .195 & .182 & .213 & .233 & .192 & .218 & .203 & .247 & .212 \\ 1.20 & 1.34 & 1.48 & 0.98 & 1.23 & 1.36 & 1.67 & 1.38 & 1.66 & 1.37\end{array}$

TABLE 23

RECOVERABLE OIL CONTACTED BY SURFACTANT SLUGS PROPORT IONAL TO PORE VOLUME

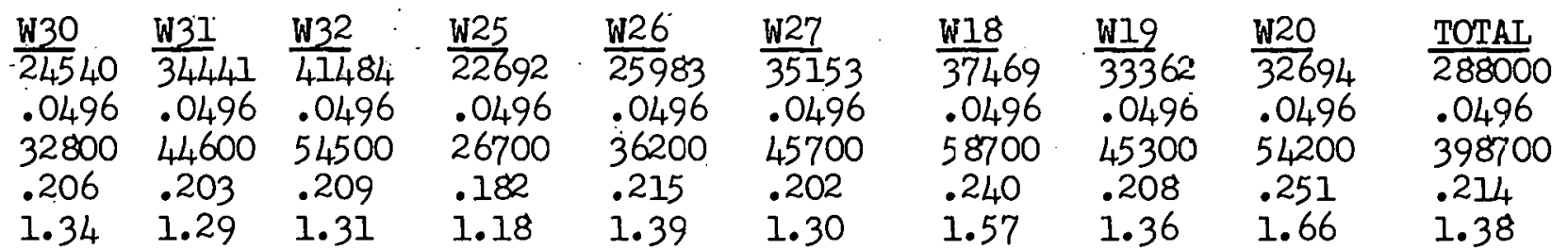


TABLE 24.

POLYMER INJECTION SCHEDULE

\begin{tabular}{|c|c|c|c|c|c|c|c|c|}
\hline \multirow[b]{2}{*}{ Phase } & \multicolumn{2}{|c|}{ Concentration, PPM } & \multicolumn{2}{|c|}{ Vol. of Phase, BBL } & \multirow{2}{*}{$\begin{array}{c}\text { Pore } \\
\text { Volume }\end{array}$} & \multicolumn{2}{|c|}{ Cum. Vol., BBL } & \multirow{2}{*}{$\begin{array}{c}\text { Pore } \\
\text { Volume }\end{array}$} \\
\hline & Planned & Realized & Planned & Realized & & Planined & Realized & \\
\hline I & 2500 & 2372 & 100,800 & 114,743 & 0.020 & 100,800 & 114,743 & 0.020 \\
\hline II & 2000 & 1951 & 198,000 & 199,005 & 0.035 & 298,800 & 313.748 & 0.055 \\
\hline III & 1500 & 1645 & 365,000 & 252,189 & 0.044 & 663,800 & 565,937 & 0.098 \\
\hline IV & 1100 & 1169 & 280,800 & 279,272 & 0.049 & 944,600 & 845,209 & 0.147 \\
\hline V & 800 & 849 & 302,400 & 298,876 & 0.052 & $1,247,000$ & $1,144,085$ & 0.199 \\
\hline VI & 600 & - & 302,400 & - & - & $1,549,400$ & - & - \\
\hline VII & 460 & - & 302,400 & - & - & $1,851,800$ & - & - \\
\hline VIII & 350 & - & 252,450 & - & - & $2,104,250$ & - & - \\
\hline IX & 250 & - & 369,050 & - & - & $2,473,300$ & - & - \\
\hline
\end{tabular}




\section{TABIE 25.}

POLYACRYLAMIDE INJECTED IN TRACT 97

\begin{tabular}{|c|c|c|c|c|}
\hline STARTING & \multicolumn{3}{|c|}{ AVERAGE CONCENTRATION, ppm } & AVERAGE \\
\hline DATE & NOMTNAT & WEICHT/VOLUME & ANALYSIS & VISCOSTTY, $c p$ \\
\hline $9-15-76$ & 2500 & 2375 & 2308 & 81 \\
\hline $10-14-76$ & 2000 & 1954 & 1934 & 53 \\
\hline $11-25-76$ & 1500 & 1648 & 1605 & 29 \\
\hline $1-17-77$ & 1100 & 1170 & 1165 & 13 \\
\hline $3-8-77$ & 800 & 850 & 936 & 8.4 \\
\hline $5-1-77$ & 600 (a) & 599 & 630 & 4.8 \\
\hline
\end{tabular}

(a) Through May 19, 1977 
TABLE 26.

COMPARISON OF CALCULATED AND MEASURED

BOTTOM HOLE PRESSURES DURING 2500 PPM POLYMER INJECTION

WELC 97-W31

\begin{tabular}{|c|c|c|c|c|c|}
\hline \multirow[b]{2}{*}{ Date } & \multirow[b]{2}{*}{$I_{\text {poly }}$} & \multirow[b]{2}{*}{$\begin{array}{c}\text { pw, } \\
\text { Meas'd. }\end{array}$} & \multicolumn{3}{|c|}{$\dot{p}_{\mathrm{w}}(\mathrm{Calc}) *$} \\
\hline & & & $p_{e}=650$ & $\underline{p_{e}=600}$ & $\mathrm{p}_{\mathrm{e}}=670$ \\
\hline $9-17$ & 0.50 & 827 & 790 & 748 & 807 \\
\hline $9-18$ & 0.76 & 828 & 807 & 771 & 823 \\
\hline 9 & 1.01 & 828 & 825 & 792 & 838 \\
\hline $9-20$ & 1.27 & 838 & 842 & $84_{4}$ & 854 \\
\hline $9-21$ & 1.54 & 854 & 861 & 837 & 871 \\
\hline $9-22$ & 1.93 & 892 & 887 & 870 & 895 \\
\hline $9-23$ & 2.22 & 916 & 907 & 895 & 913 \\
\hline $9-24$ & 2.49 & 947 & 925 & 918 & 930 \\
\hline $9-25$ & 2.77 & 962 & 944 & 942 & 947 \\
\hline 926 & 3.05 & 979 & 964 & 966 & 965 \\
\hline $9-27$ & 3.32 & 990 & 982 & 989 & 981 \\
\hline $9-28$ & 3.60 & 998 & 1001 & 1013 & 999 \\
\hline $9-29$ & 3.87 & 1020 & 1019 & $103 \overline{6}$ & 1015 \\
\hline $9-30$ & 4.14 & 1028 & 1038 & 1059 & 1032 \\
\hline $10-1$ & 4.40 & 1046 & 1056 & 1081 & 1048 \\
\hline \multicolumn{6}{|c|}{$* \mathrm{BHP}=$ Res. press. $+\Delta \mathrm{p}_{\text {poly }}+\Delta \mathrm{p}_{\text {pref }}+\Delta \mathrm{p}_{\text {mic }}$} \\
\hline \multicolumn{3}{|c|}{ for $p_{e}=600, \lambda_{\text {poly }}=0.08$} & \multicolumn{3}{|c|}{ BHP $=705.7+85.33 \mathrm{~L}_{\text {poly }}$} \\
\hline & $=650$, & $=0.10$ & \multicolumn{3}{|c|}{$\mathrm{BHP}=755.7+68.15 \mathrm{~L}_{\text {poly }}$} \\
\hline & 670 & $=0.11$ & \multicolumn{3}{|c|}{$\mathrm{BHP}=775.7+61.90 \mathrm{~L}_{\text {poly }}$} \\
\hline
\end{tabular}


WELI QUOTAS DURING POLYMER INJECTION

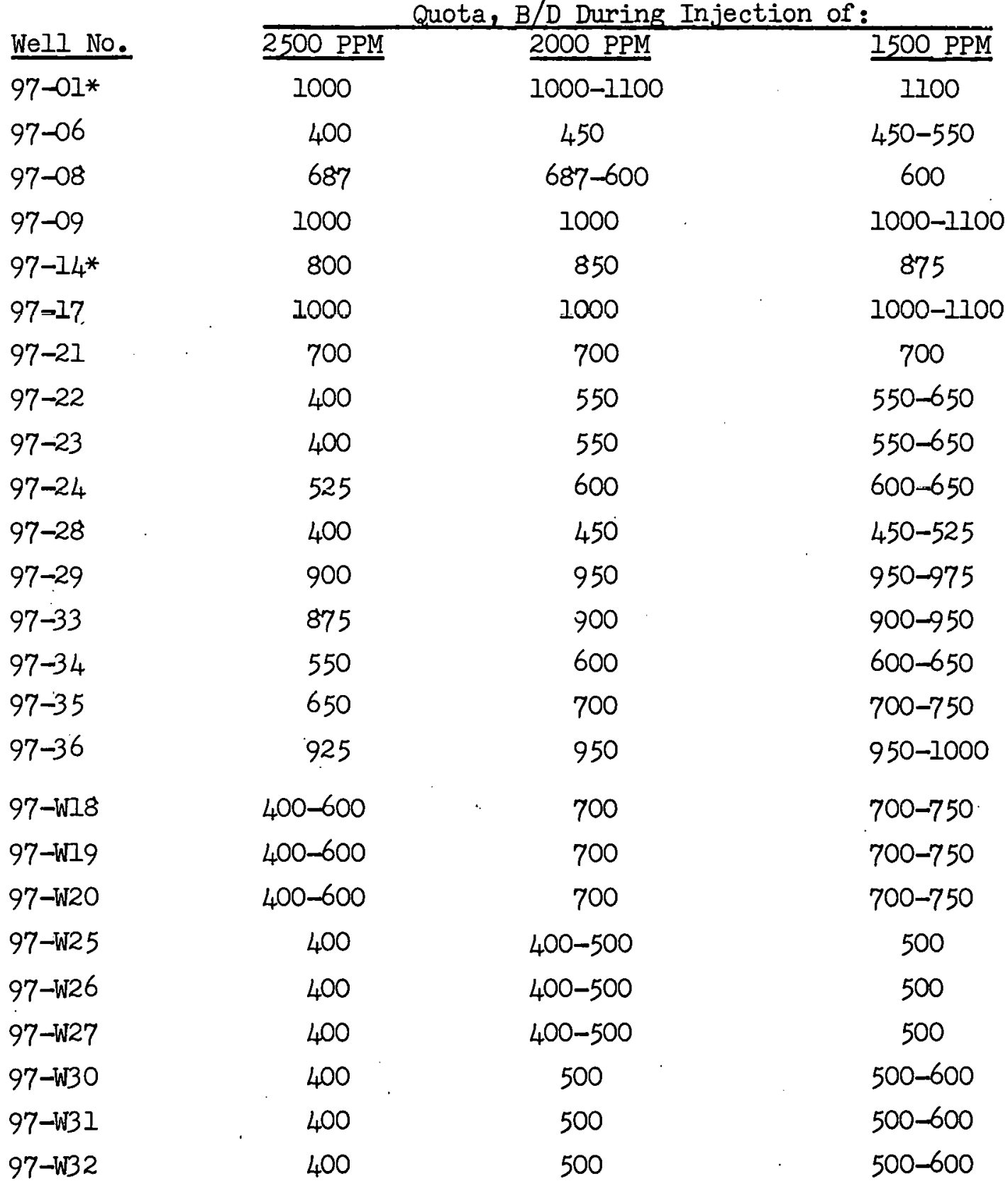

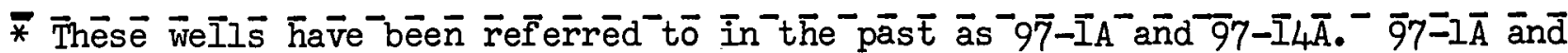
97-14A were replacement wells drilled near 97-01 and 97-14, respectively which were plugged and abandoned. With the abandonments, production records used the replacement well data but retained the original numbers. This same practice is used_in this_report for all data except in dealing_with well locations. - . - 
TABLE 28.

TOTAT. PTIOT PFRFORMANCE, TRACT OI

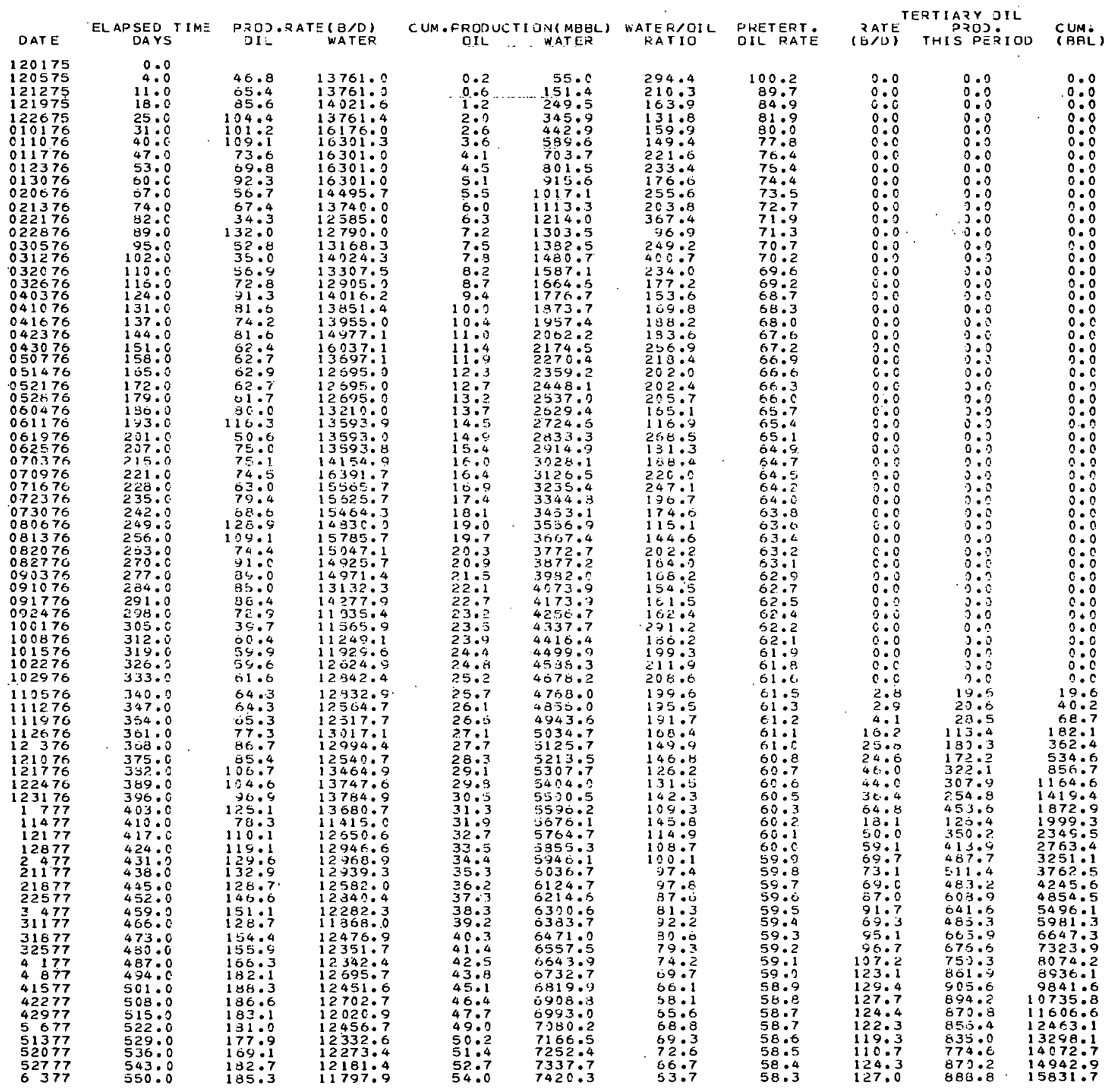


TABLE 29.

SIZE AND OIL CONTENT OF EACH FIVE-SPOT

S SURFACE AREA, FT ${ }^{2}$

INTERWELL DIST, FT.

AVERAGE THICKNESS, FT.

PORE VOLUME, BBL

ORIGINAL OII IN PIACE, STB

$\begin{array}{llllllllll}\text { W30 } & \text { W31 } & \text { W32 } & \text { W25 } & \text { W26 } & \text { W27 } & \text { W18 } & \text { W19 } & \text { W20 } & \text { TOTAL } \\ 418600 & 443300 & 443300 & 360900 & 424700 & 424700 & 561800 & 555500 & 585100 & 4217900 \\ 457.49 & 470.80 & 470.80 & 424.79 & 460.81 & 460.81 & 530.00 & 527.02 & 540.88 & \\ 39.6 & 49.8 & 55.5 & 42.2 & 41.3 & 54.7 & 45.6 & 41.7 & 40.4 & \\ 495180 & 694970 & 837080 & 457890 & 524310 & 709330 & 756080 & 673190 & 659720 & 5807750 \\ 159321 & 219746 & 261114 & 146655 & 168156 & 226484 & 244355 & 217870 & 215722 & 1859423\end{array}$




\section{INDEX OF FTGURES}

FIGURE NO.

1.

2.

3.

4.

5.

6.

7.

8.

9.

10.

11.

12.

13.

14.

15.

16.

17.

18.

19.

TITLE

North Burbank Tertiary Recovery Pilot

Superposition Model to Establish Pressure Gradient Across Pilot

History Match of Pressure During Shut-in, Well 96-W7

Calculated Pressure Across Pilot

Effect of Outside Wells on Pattern Streamlines in an Idealized Pattern

Cumulative Fresh Water and Tracer Production to April 1, 1976

Status of Injection/Production Balance, North Burbank Unit, March 1976

Radioactive Tracer Response, NBU Tract 97 Pilot Pattern, September 15, 1976

Preflush Distribution as of January 22, 1976, Determined by Radioactive Tracers

Preflush Distribution as of April 29, 1976 Determined by Radioactive Tracers

Preflush Distribution as of August 2, 1976 Determined by Radioactive Tracers

Preflush Distribution as of August 2, 1976 Determined from Chemical Analyses of Produced Water

Five-Spot Pore Volumes and Pore Volumes Injected, May, 1976

Well Quotas for Final Two Months Preflush Injection

Phase Behavior for Surfactant System Equilibrated with Dead Burbank Crude Oil (5 Per Cent, TRS 10-410)

Phase Behavior for Surfactant System Equilibrated with Dead Burbank Crude Oil (6 Per Cent TRS 10-410)

Phase Behavior for Surfactant System Equilibrated with Iive Burbank Crude Oil at 30 to 50 psig (6 Per Cent TRS 10-410)

Phase Behavior for Surfactant System Equilibrated with Iive Burbank Crude Oil at Atmospheric Pressure (6 Per Cent TRS 10-410)

Interfacial Tensions Between Adjacent Phases from Phase Volume Diagrams. 
Index of Figures

FIGURE NO.

TITLE

20. Permeability Distributions for Eavluation of Gelled Polymer Treatment Well 97-W25

21. Computer Fit to Tracer Profile Before Gelled Polymer Treatment

22. Predicted Effect of Gelled Polymer Treatment on Oil Recovery from Affected Quadrant, Well 97-W25 NE

23. Comparison of Tracer Profiles Before and After Gelled Polymer Treatment

24. Computer Fit to 'I'racer Profiile Af'ter Gelled Polymer Treatment

25. Mechanical Flow Sheet for Surfactant Solution Injection

26. Polymer Solution Mechanical Flow Sheet

26A. Mechanical Flow Sheet for Polymer Solution Injection

27. Recoverable Oil Contacted by Surfactant Slug Size for the Nine Five-Spots of Tract 97

28. Surfactant Solution Analysis Tract 97 Discharge

29. Composition of Injected Surfactant Solution We17 97-W19

30. Bottom Hole Pressure and Injection History, Well 97-W19

31. Well Quotas During Surfactant Injection

32. Polymer Injection Schedule

33. Injected Fluid Analysis, Well 97-W18

34. Injected Fluid Analysis, Well 97-W32

35. Oxygen Control Chemical Analysis, Mixer Inlet

36. Oxygen Control Chemical Analysis, East Mixer Outlet

37. Oxygen Control Chemical Analysis, West Mixer Outlet

38. Schematic of 97-W31 Five-Spot

39. Streamline Map of 97-W31 Five-Spot

40. Iinear Flow Model for Mobility Calculation

41. Estimation of 2500 ppm Polymer Mobility

42. Bottom Hole Pressure at 97-W31 During $2500 \mathrm{ppm}$ Polymer Injection 
Index of Figures

FIGURE NO.

TITLE

43.

44.

45.

46.

47.

48.

49.

50.

51.

52.

53.

54.

55.

56.

57.

58.

59.

60.

61.

62.

63.

64.

65.

66.

67.

68.

69.
Injection History, Well 97-W18

Injection History, Well 97-W19

Injection History, Well 97-W20

Injection History, Well 97-W25

Injection History, Well 97-W26

Injection History, Well 97-W27

Injection History, Well 97-W30

Injection History, Well 97-W31

Injection History, Well 97-W32

Production History, Well 97-01

Production History, Well 97-06

Production History, Well 97-08

Production History, Well 97-09

Production History, Well 97-14

Production History, well 97-17

Production History, Well 97-21

Production History, Well 97-22

Production History, Well 97-23

Production History, well 97-24

Production History, Well 97-28

Production History, Well 97-29

Production History, Well 97-33

Production History, Well 97-34

Production History, Well 97-35

Production History, Well 97-36

TRS 10-410 Sulfonate in Produced 0il, well 97-28

Isobutyl Alcohol at Producing Wells 
Index of Figures

FIGURE NO.

70.

Trend of Chemical Content of Produced Water, well 97-06

71. Trend of Chemical Content of Produced Water, Well 97-17

72. Trend of Chemical Content of Produced Water, Well 97-23

73. Trend of Chemical Content of Produced Water, Well 97-24

74. Trend of Chemical Content of Produced Water, Well 97-28

75.

Trend of Chemical Content of Produced Water, Well 97-35

76. Polyacrylamide at Producing Wells

77. Fluid Level History, Well 97-08

78. Fluid Ievel History, Well 97-21

79.

Fluid Level History, Well 97-24

80.

Fluid Level History, Well 97-35

81.

Fluid Level History, Well 97-23

82.

Tract 97 Total Pilot Performance

83.

Comparison of Pilot Performance with Prediction

84.

Mile atone Chart

85.

Permeability Distribution Around Well 97-W30

86.

Permeability Distribution Around Well 97-W32

87.

Correlation Between Permeability and Porosity Based on Core Ana.lysis

88.

Correlation Betweem Porosity and Initial Oil Saturation

89.

Relative Permeability Curves Used in Model 


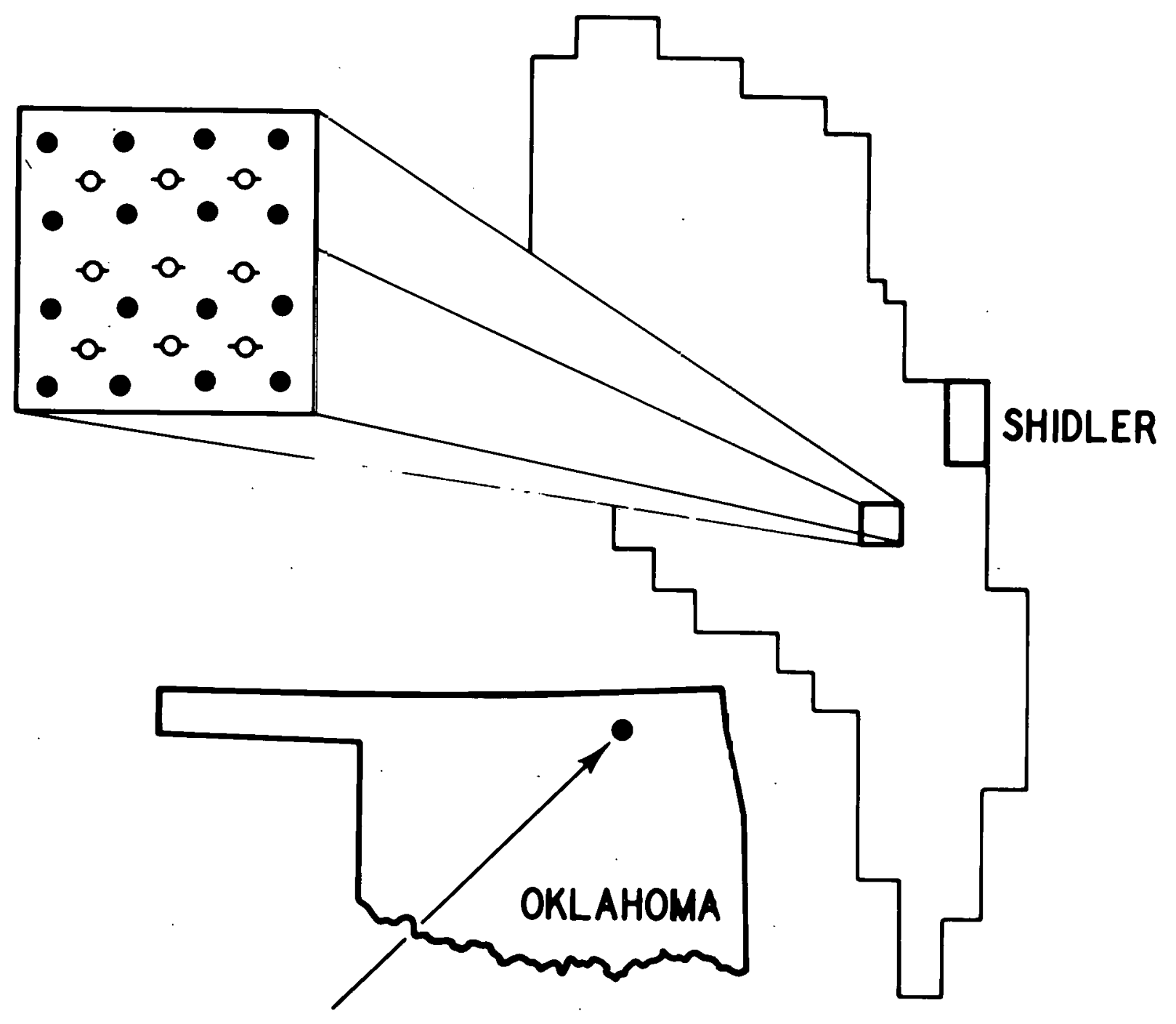

FIGURE 1

NORTH BURBANK TERTIARY RECOVERY PILOT 


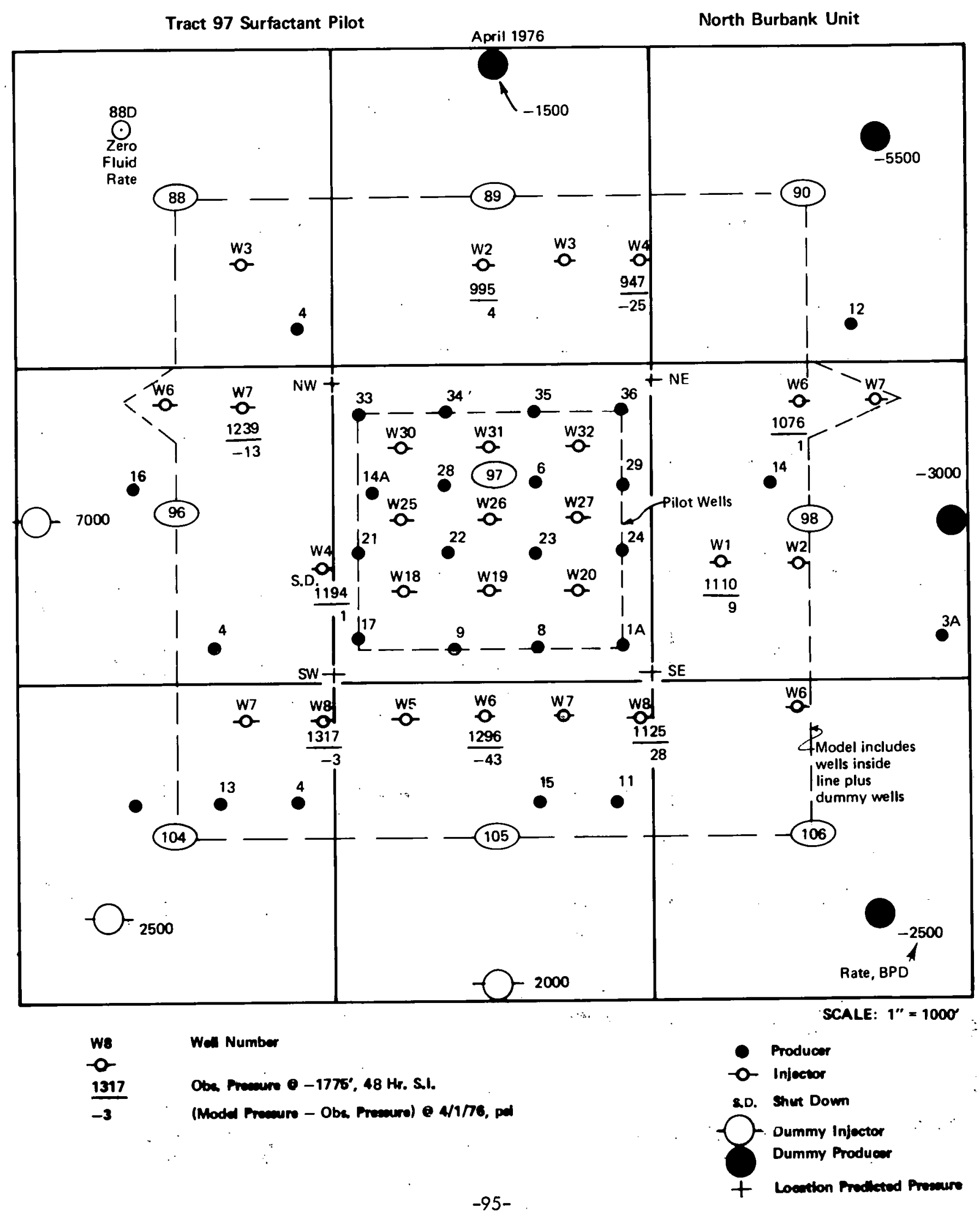




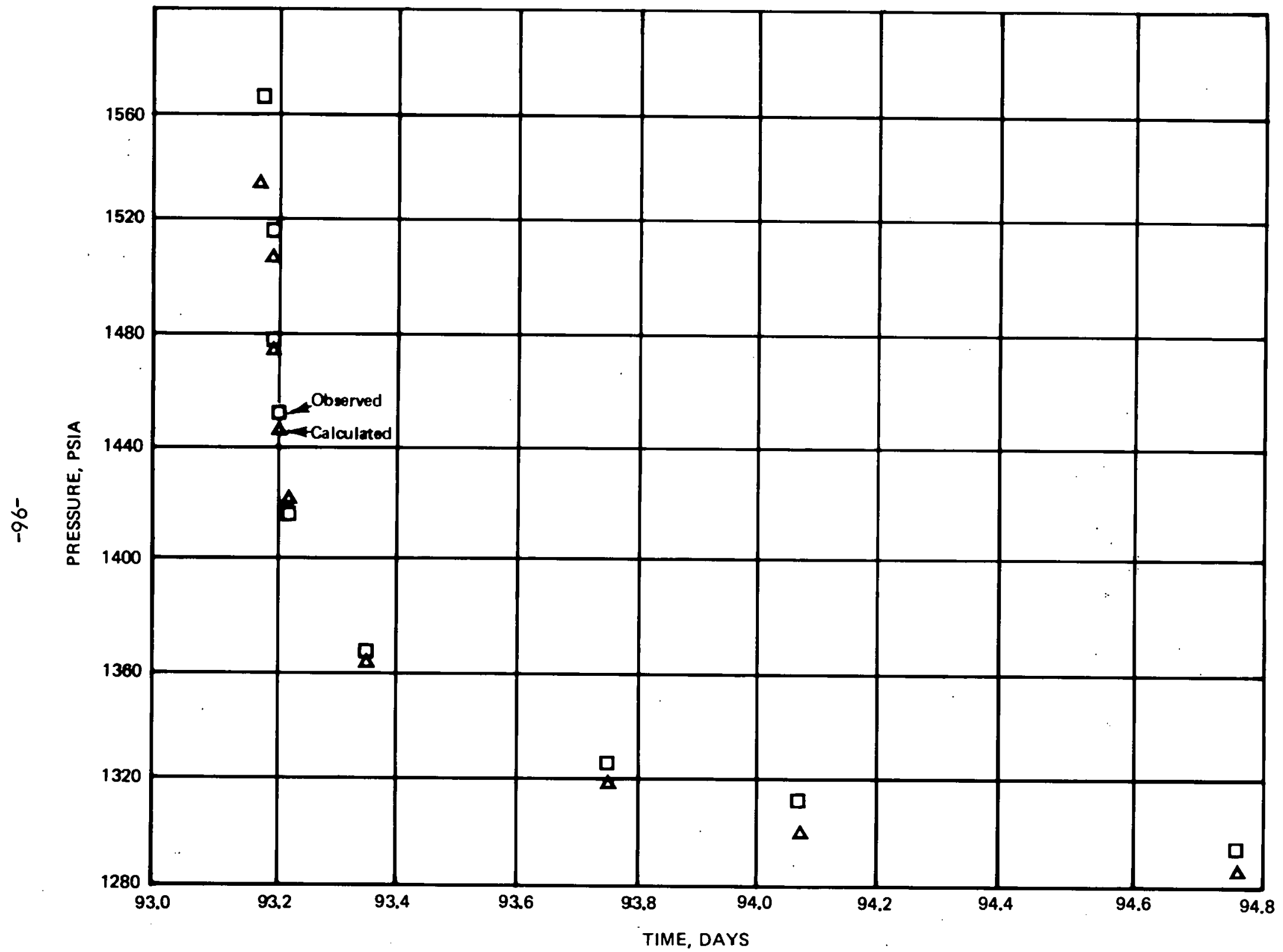

HISTORY MATCH OF PRESSURE DURING SHUT-IN, WELL 96-W7

FIGURE 3. 


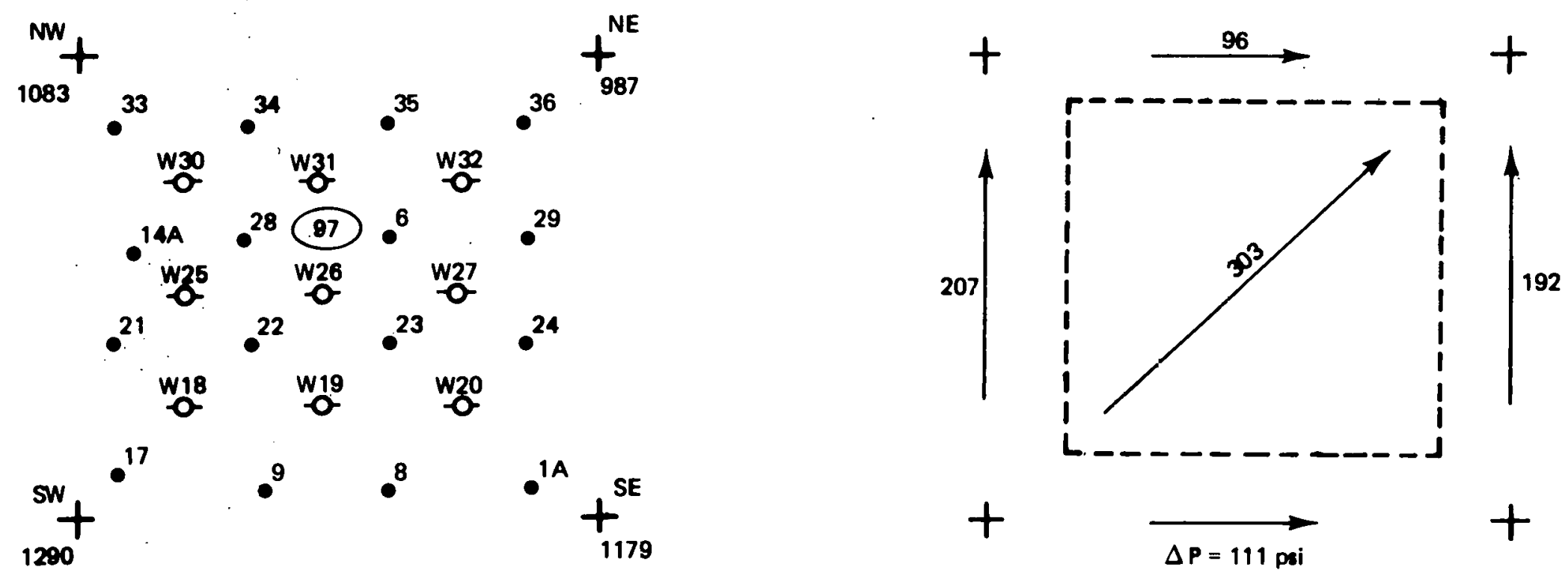

CALCULATED PRESSURE ACROSS PILOT

FIGURE 4. 


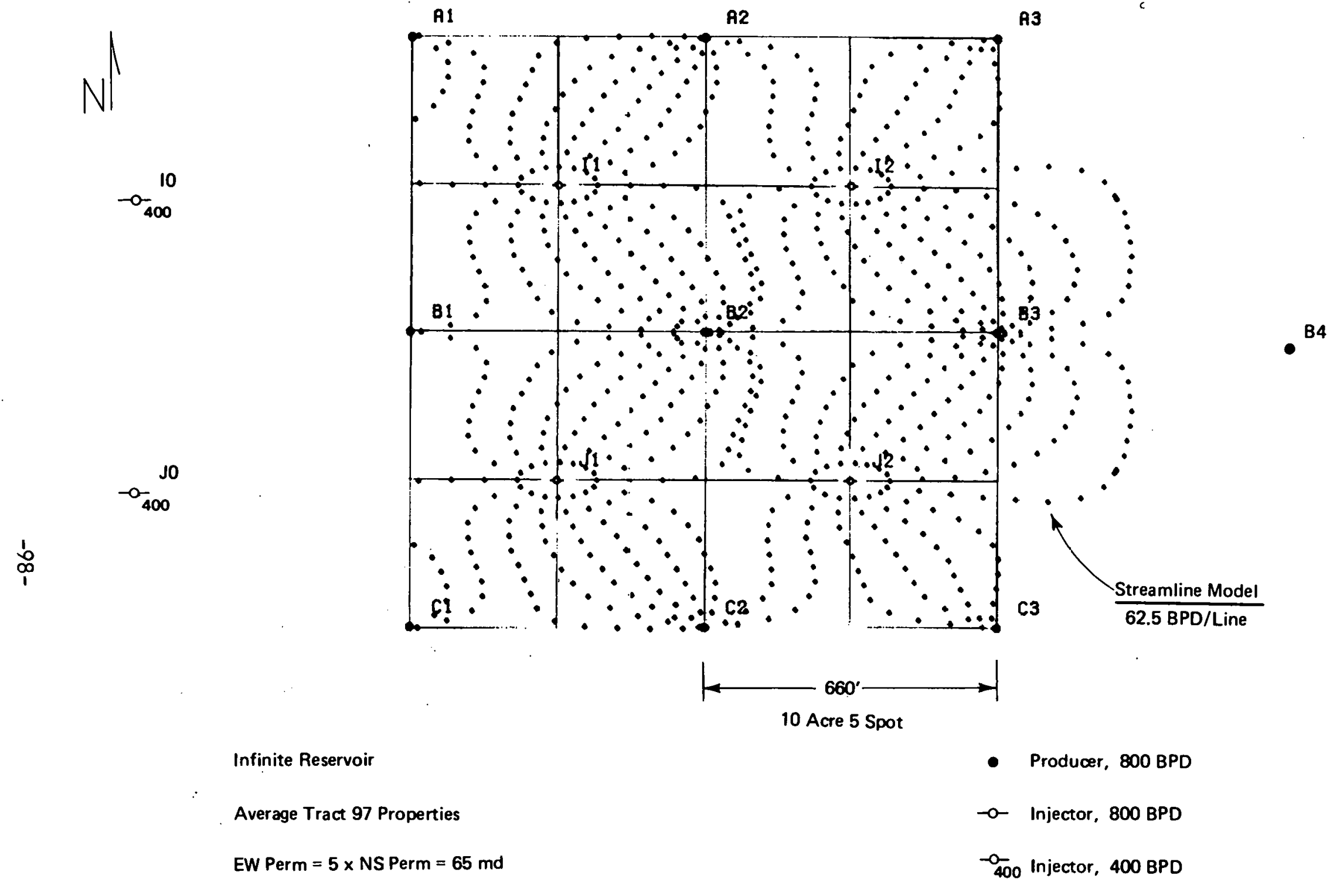

EFFECT OF OUTSIDE WELLS ON PATTERN STREAMLINES

IN AN IDEALIZED PATTERN

FIGURE 5. 


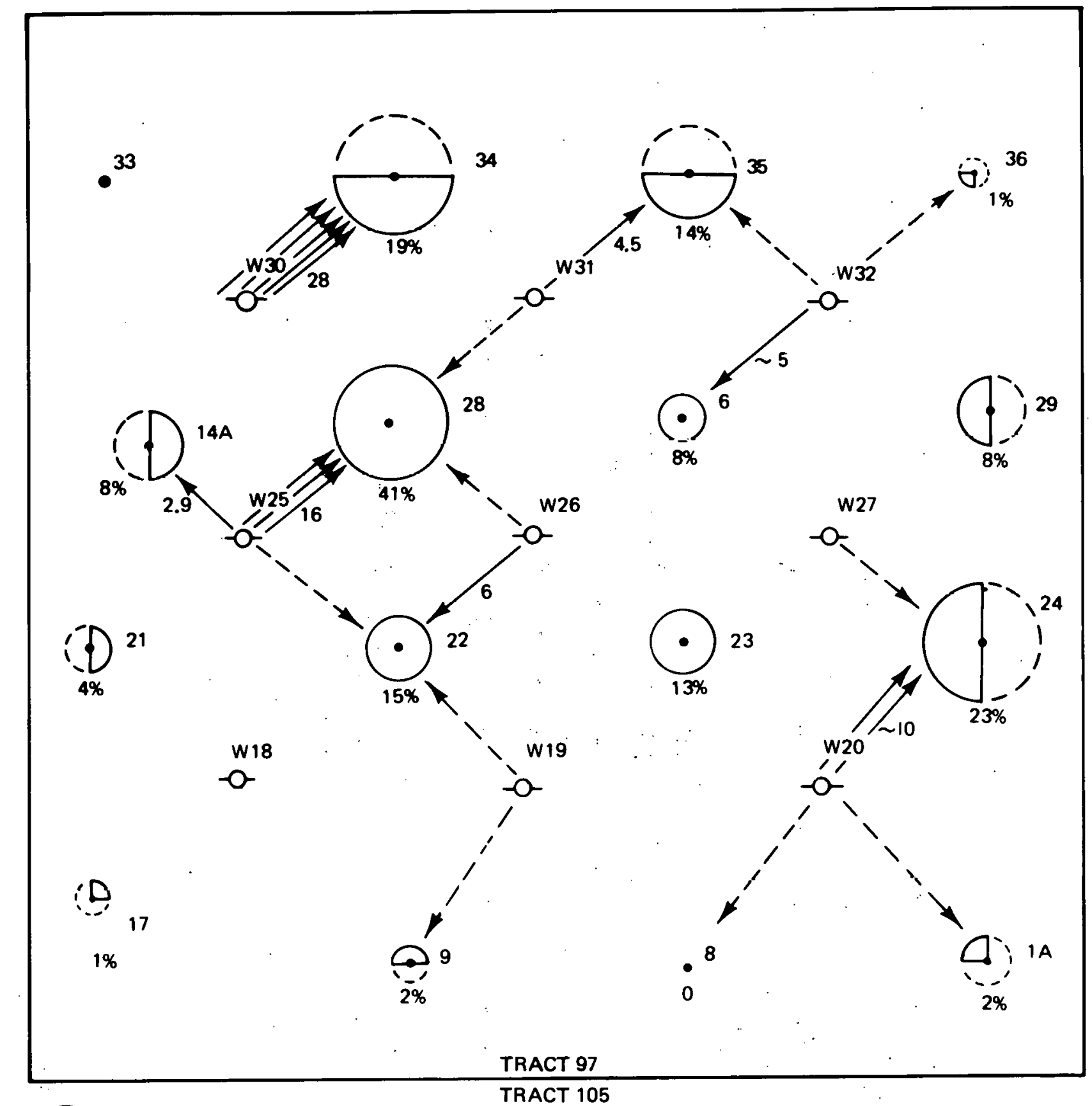

TRACT 105

(-)

$13 \%$

23 Well Number

Cum. fresh water at total water prod. of 108 MBBL

(about 4/1/76). Area enclosed by solid line

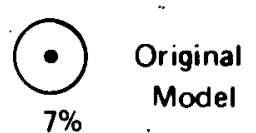
proportional to \% fresh water.

Cum. tracer produced \% of injected amount.

Tracer detected but less than $2.5 \%$ produced. 


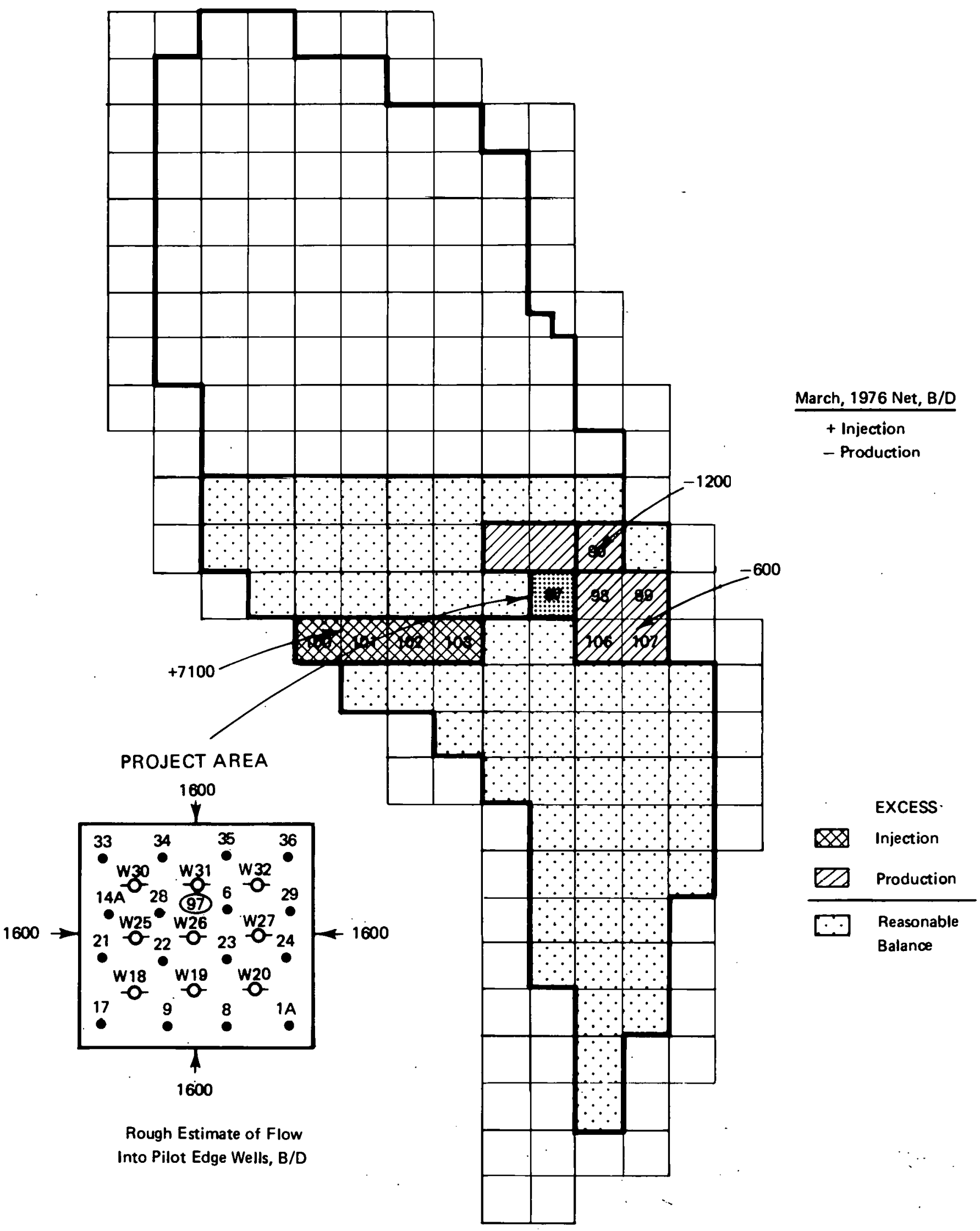

STATUS OF INJECTION/PRODUCTION BALANCE, NORTH BURBANK UNIT, MARCH, 1976

FIGURE 7

$-100-$ 


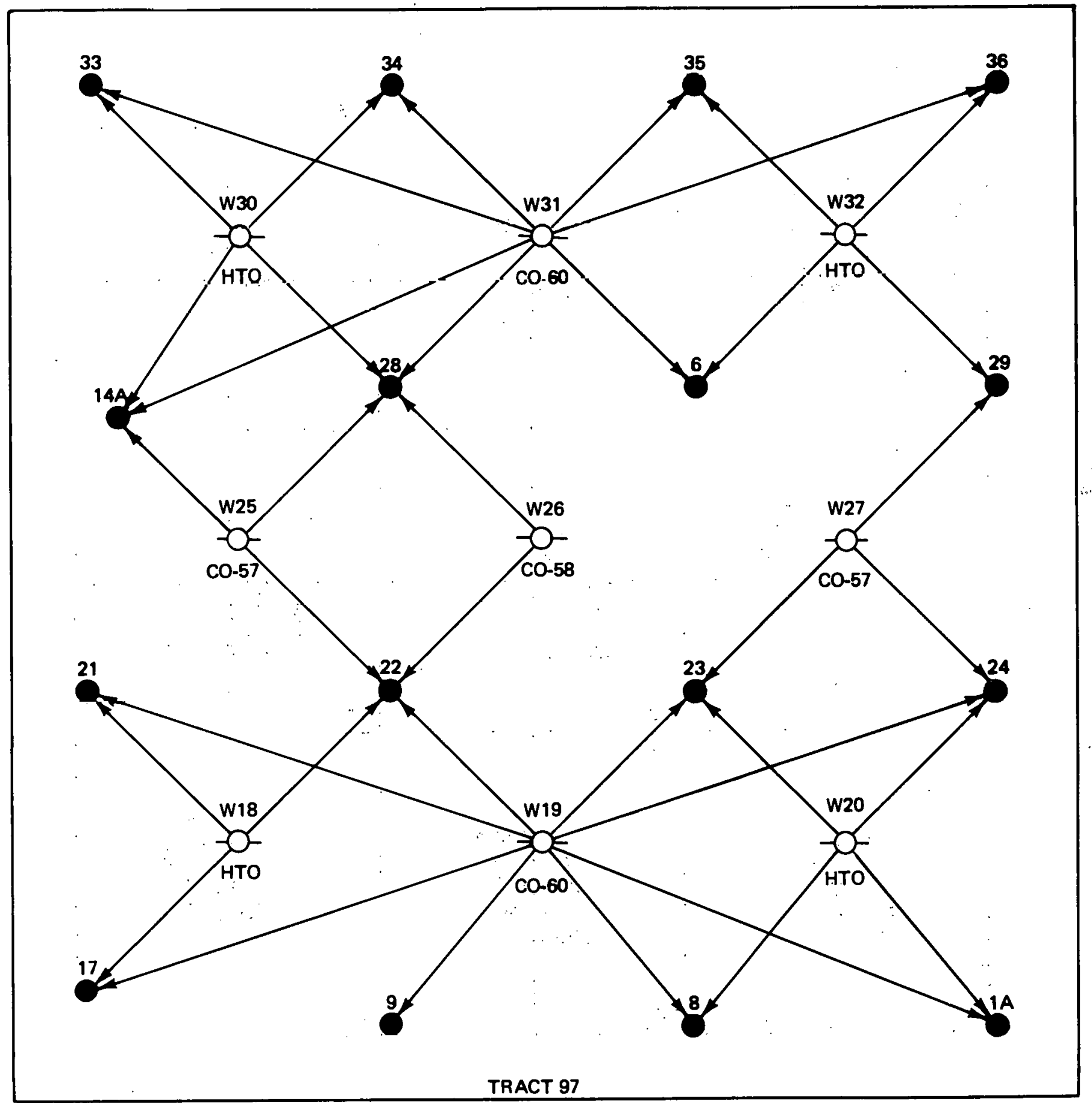

TRACT 105

RADIOACTIVE TRACER RESPONSE

NBU TRACT 97 PILOT PATTERN, 9-15-76

FIGURE 8

$-101-$ 
NORTH BURBANK UNIT - TRACT 97

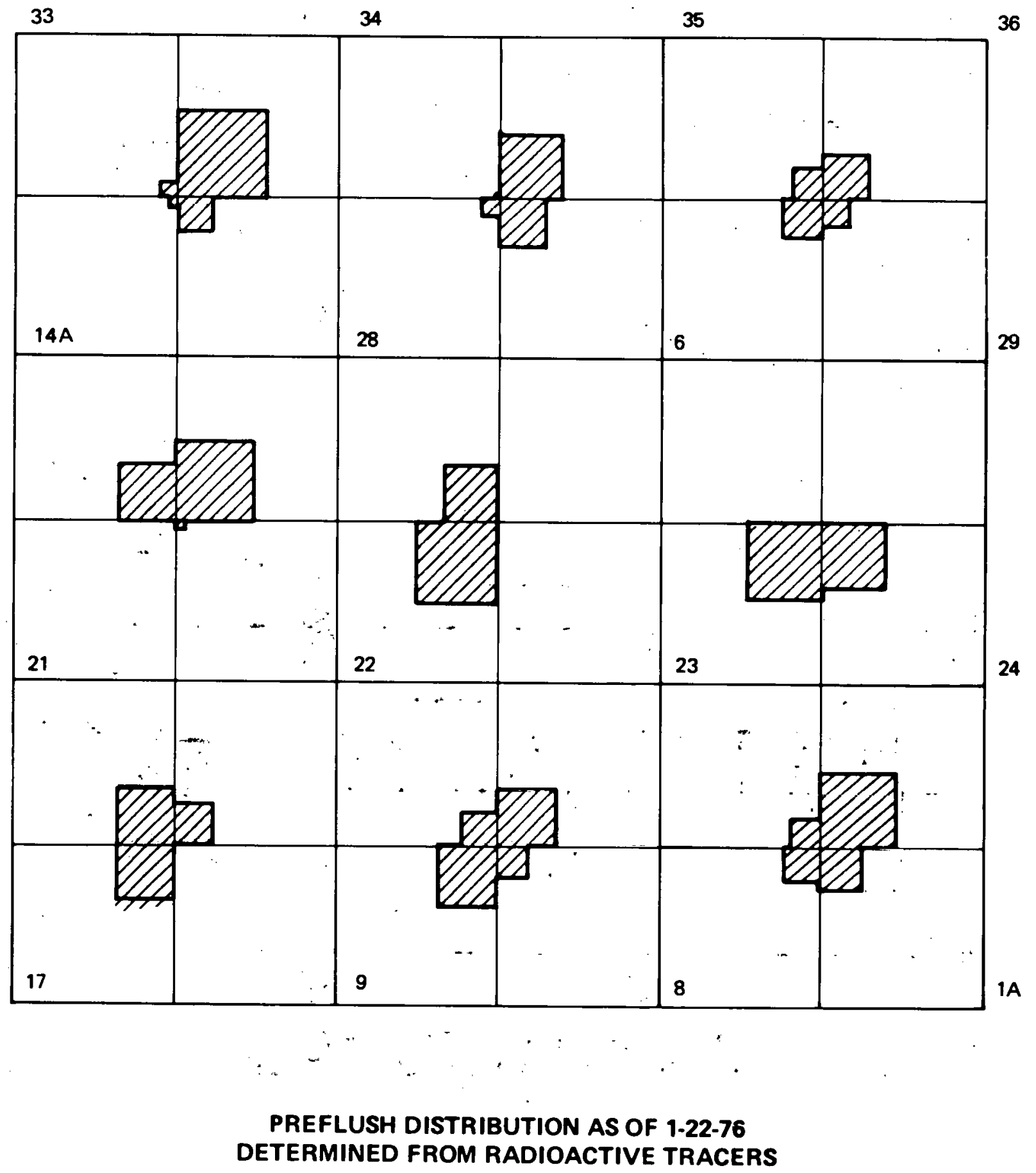

FIGURE 9 
NORTH BURBANK UNIT - TRACT 97

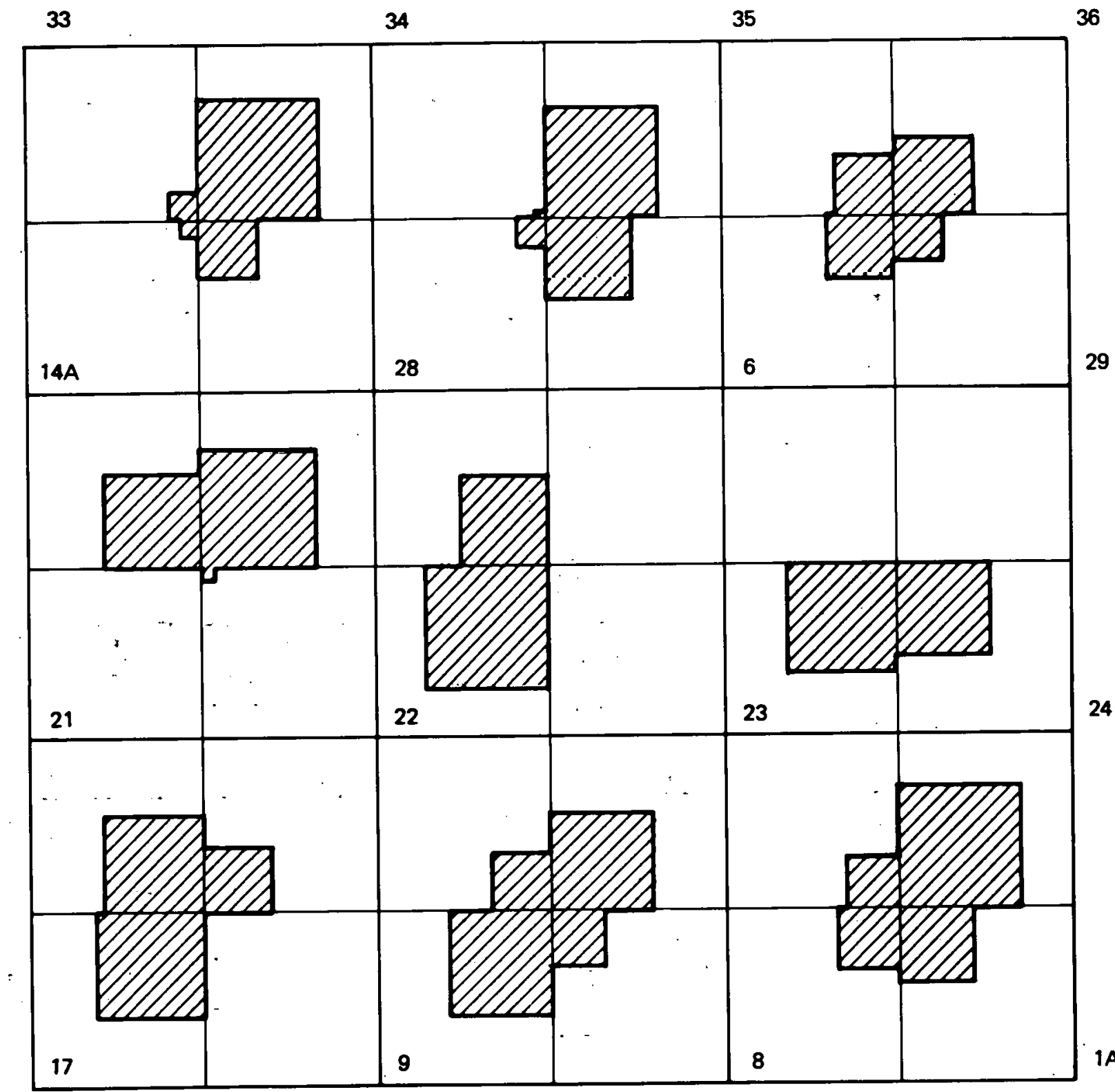

IA

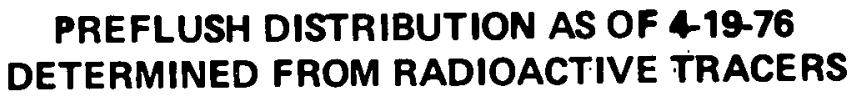

FIGURE 10 


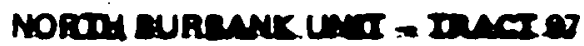

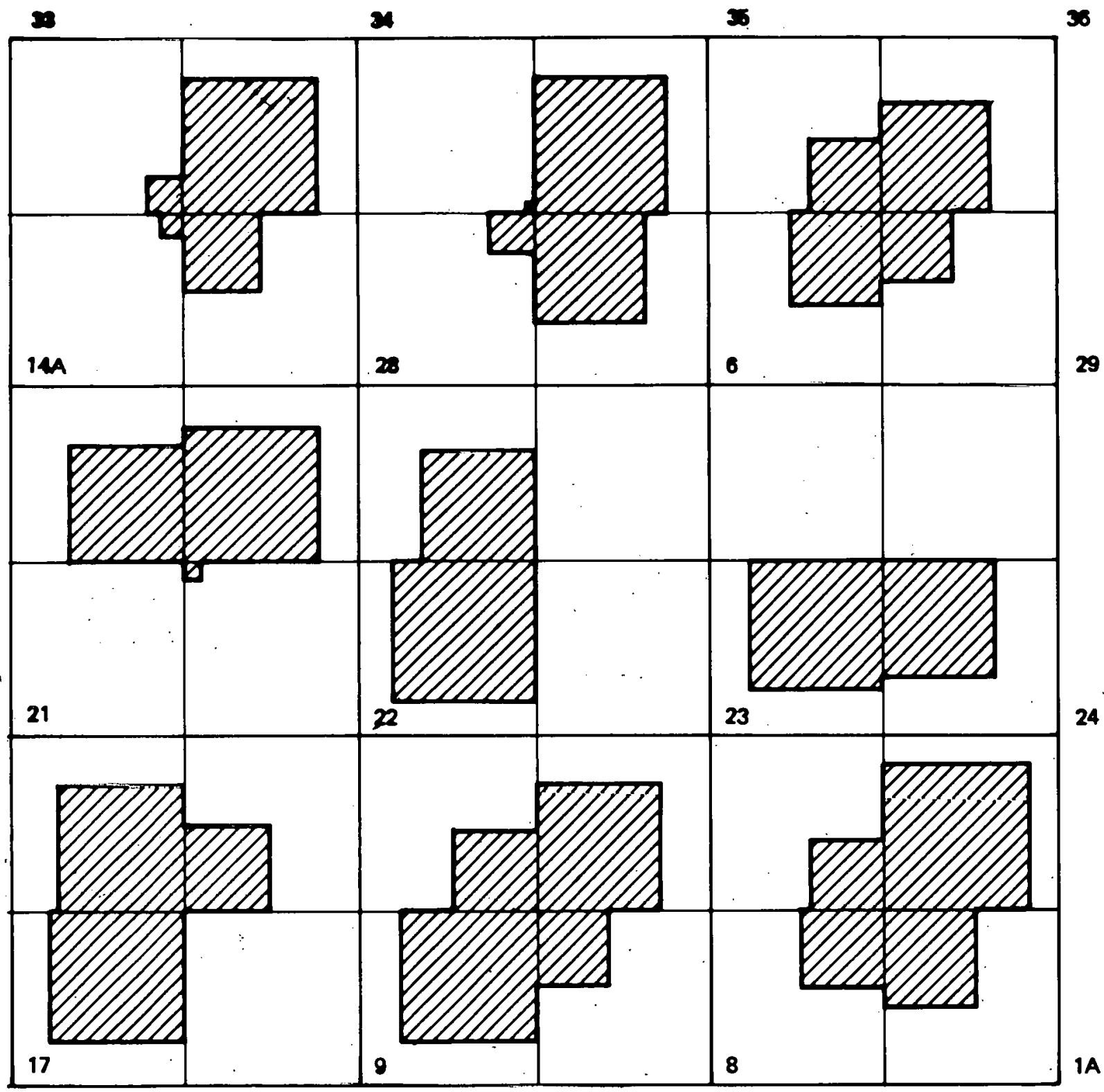

PRETLUSH DISTRIBUTION AS OF 8-2-76 DETERMINED FROM RADIOACTIVE TRACERS (TOTAL PORE VOLUME DIEPLACED - 2R.4\%)

FIGURE 11 
NORTH BURBANK UNIT - TRACT 97

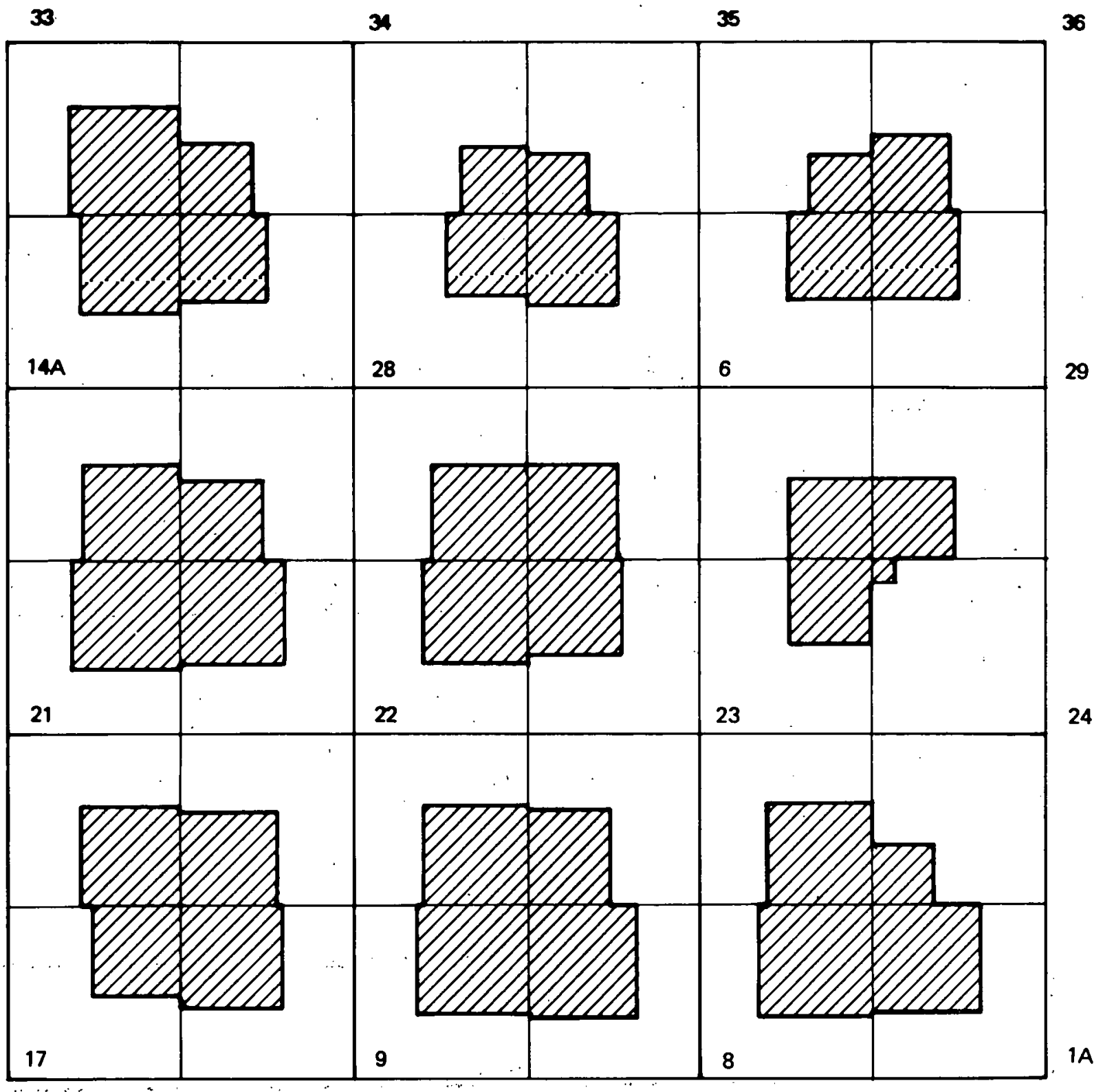

PREFLUSH DISTRIBUTION AS OF 8-2-76

DETERMINED FROM CHEMICAL ANALYSIS OF PRODUCED WATER

(TOTAL PORE VOLUME DISPLACED = 27.7\%)

FIGURE 12 


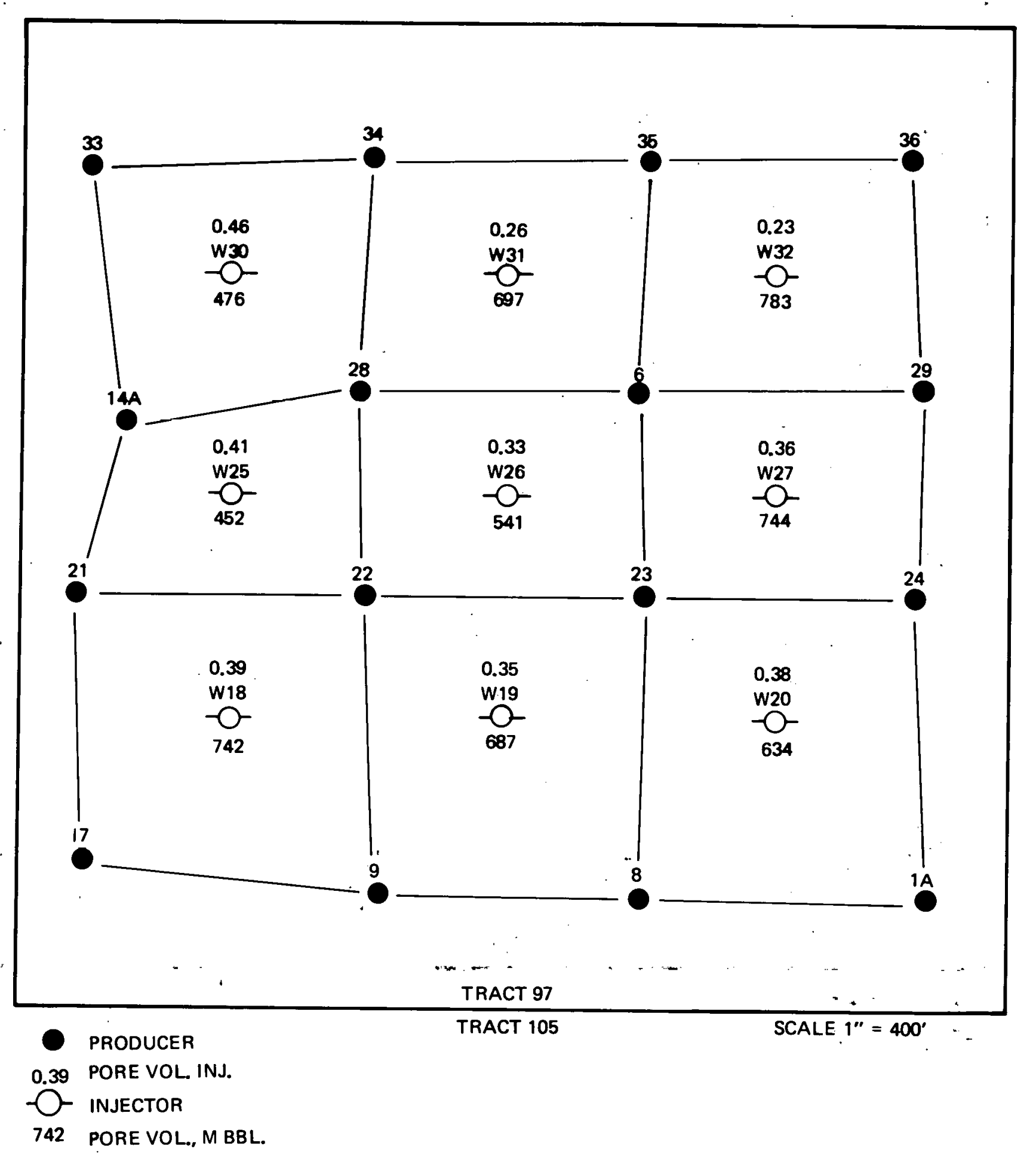

FIVE-SPOT PORE VOLUMES AND PORE VOLUMES INJECTED, MAY, 1976

$$
\text { I } A \text { FIGURE } 13 .
$$


33

1200 .

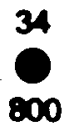

800
35

000
36

1200 $\overbrace{900}^{w 30}$

${ }_{900}^{28}$

14A

800
W31

$-\mathrm{O}$

1200 w32

-1000 :

$\underbrace{14 A}_{900}$

21

1000

(800)

$\overbrace{1200}^{W 18}$
22

1000

23

24

1060

400

w20

w19

$-\mathrm{O}$

1200

\section{9} 1000

w27

1000

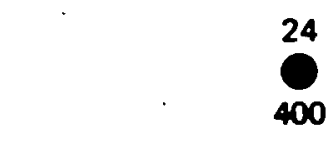

$\mathrm{C}_{1200}$

17

1200

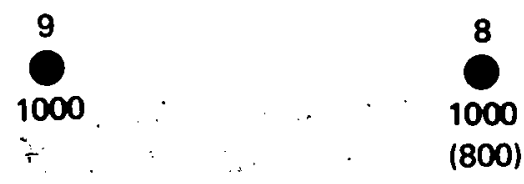

$(800)$

TRACT 97

TRACT 105

PRODUCER

-O INJECTOR

WELLL QUOTAS FOR FINAL TWO MONTHËSPREFLUSH INJECTION

FIGURE 14. 


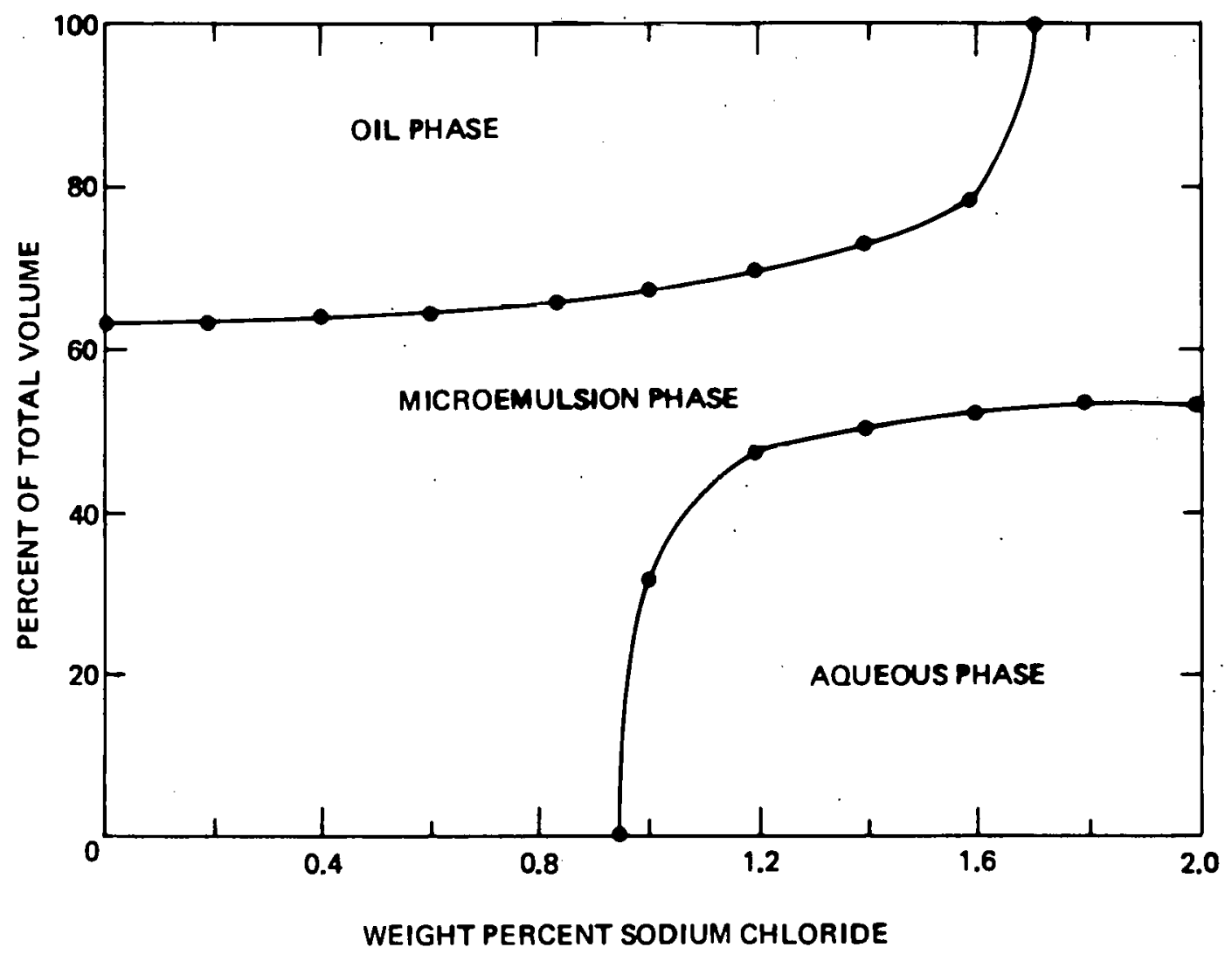

PHASE BEHAVIOR FOR SURFACTANT SYSTEM EQUILIBRATED WITH DEAD BURBANK CRUDE OIL

(E* TRS 10-410;

FIGURE 15 


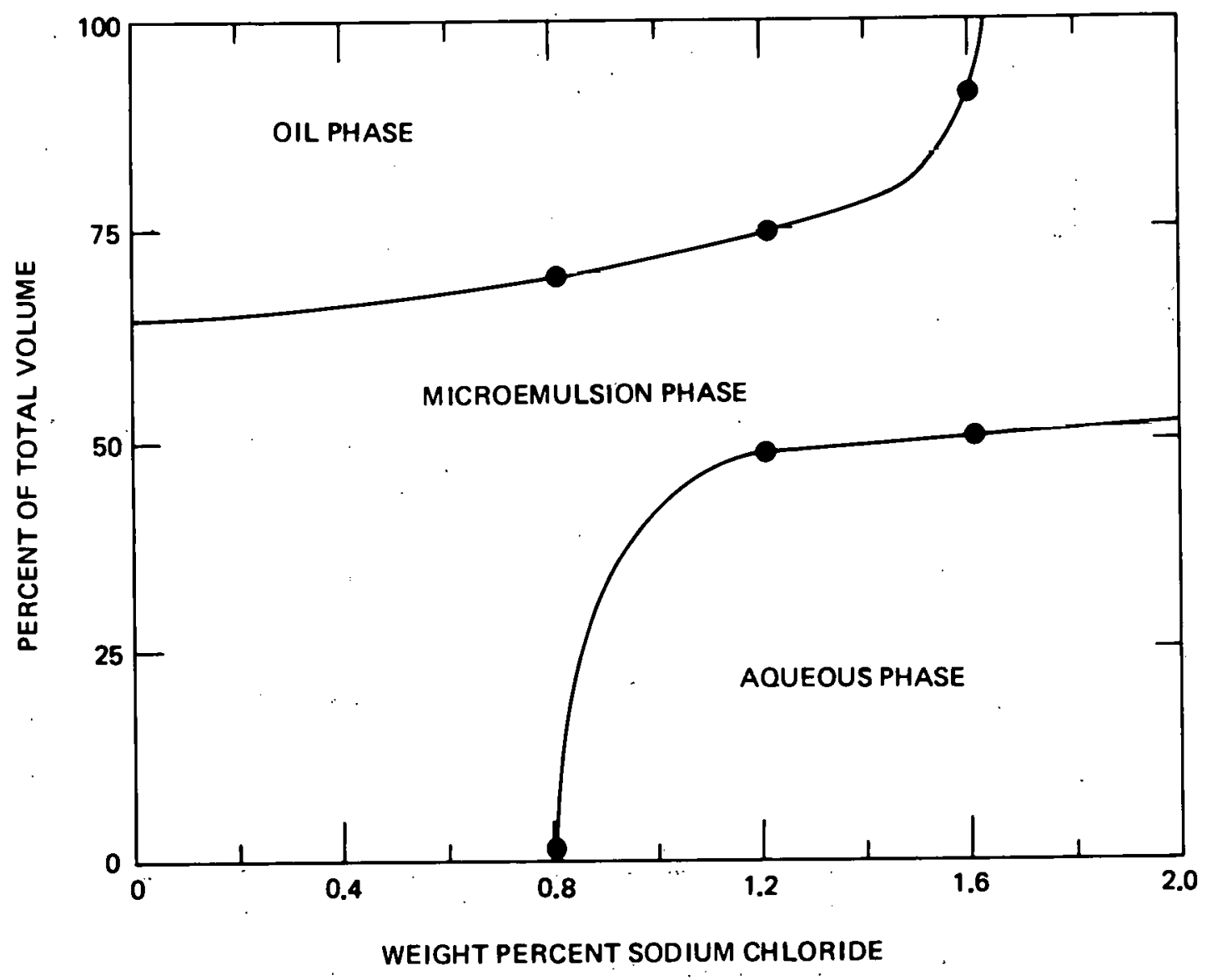

PHASE BEHAVIOR FOR SURFACTANT SYSTEM EQUILIBRATED WITH DEAD BURBANK CRUDE OIL

(6\% TRS 10-410)

FIGURE 16 


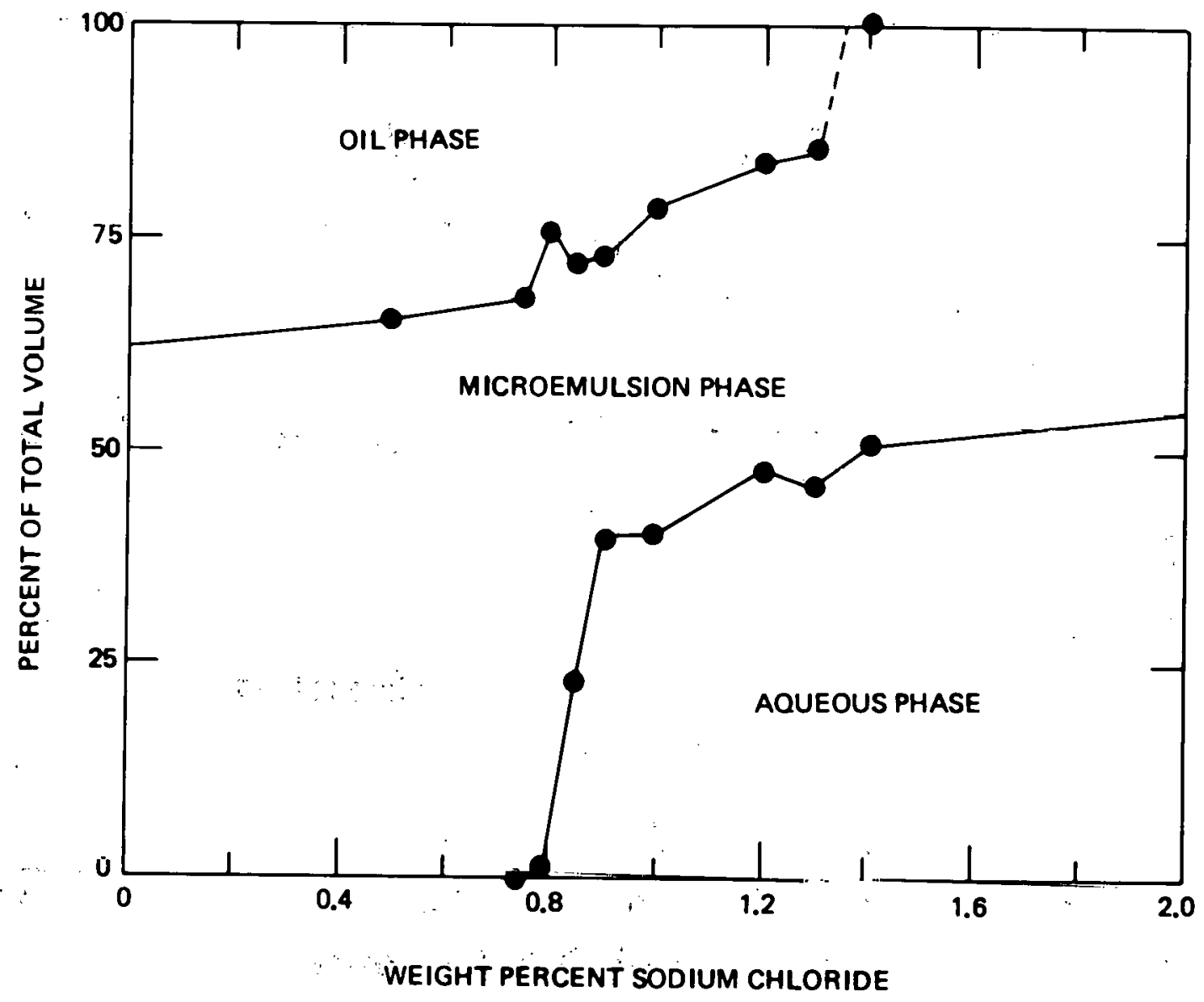

PHASE BEHAVIOR FOR SURFACTANT SYSTEM EQUILIBRATED WITH LIVE BURBANK CRUDE. OIL AT 30 TO 50 PSIG (6X. TRS 10.410)

FIGURE 17 


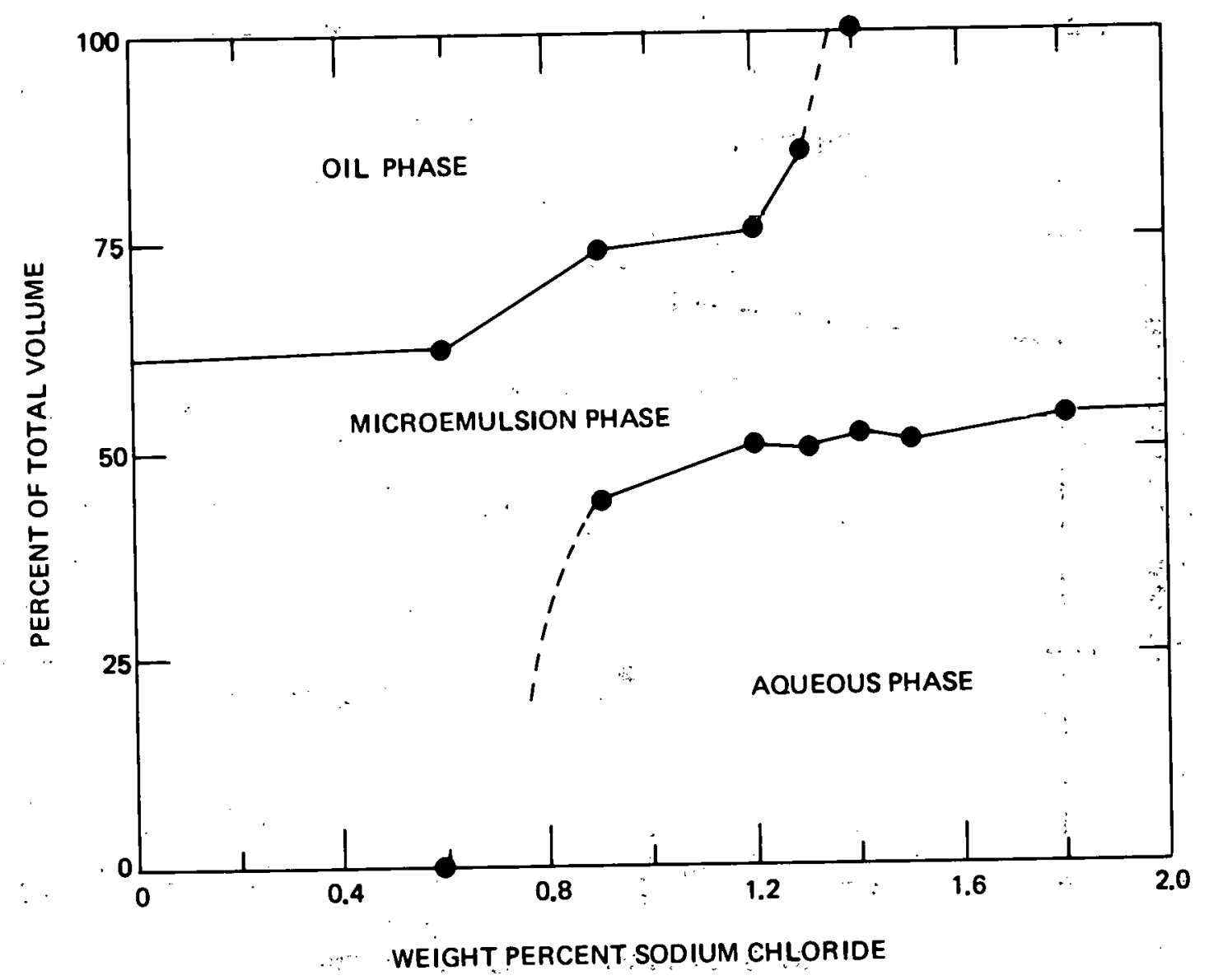

PHASE BEHAVIOR FOR SURFACTANT SYSTEM EQUILIBRATED WITH LIVE BURBANK CRUDE OIL AT ATMOSPHERIC PRESSURE

(6\% TRS 10-410)

$\therefore$ FIGURE 18 


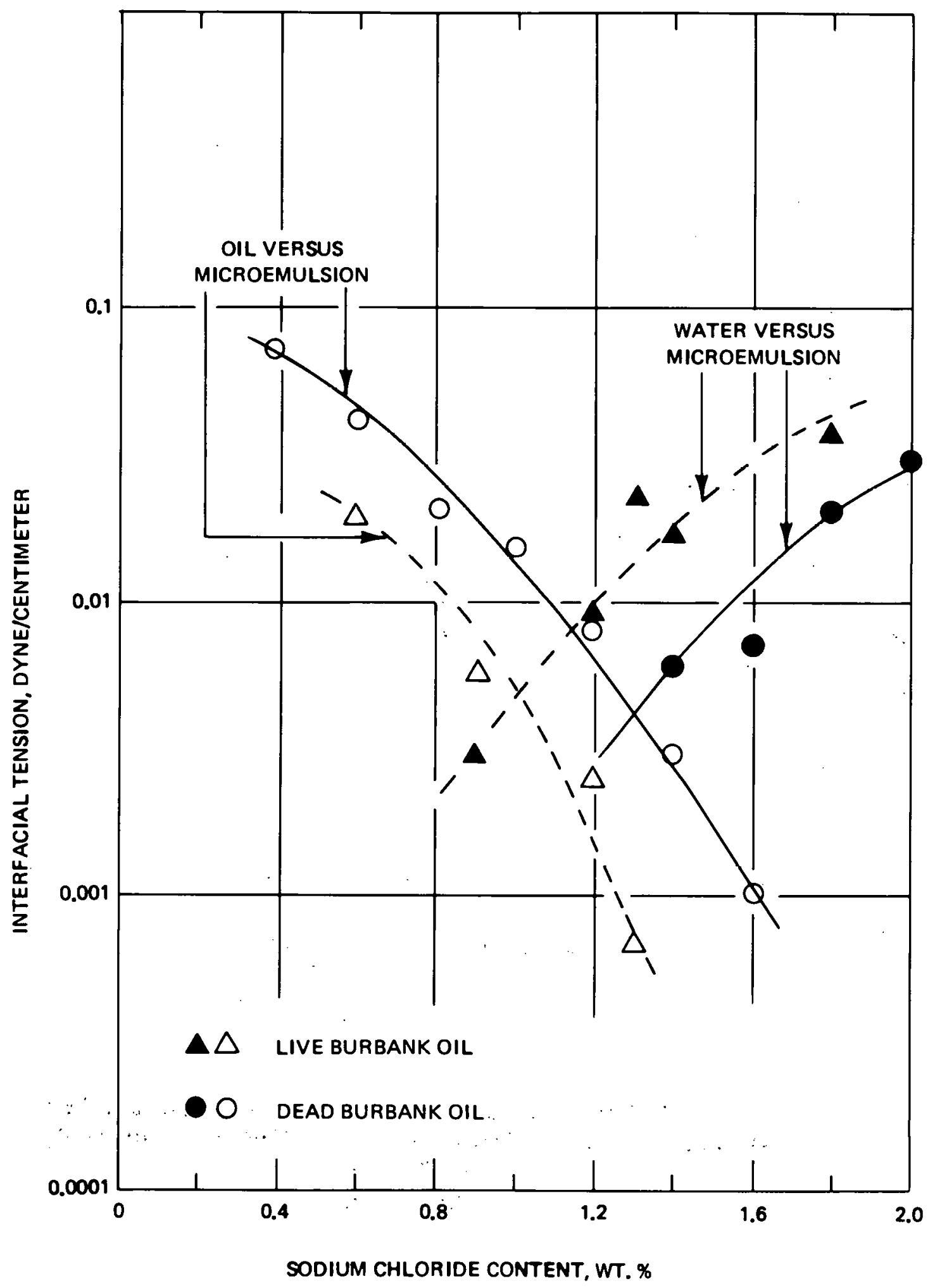

INTERFACIAL TENSIONS BETWEEN ADJACENT

PHASES FROM PHASE-VOLUME DIAGRAMS

FIGURE 19 


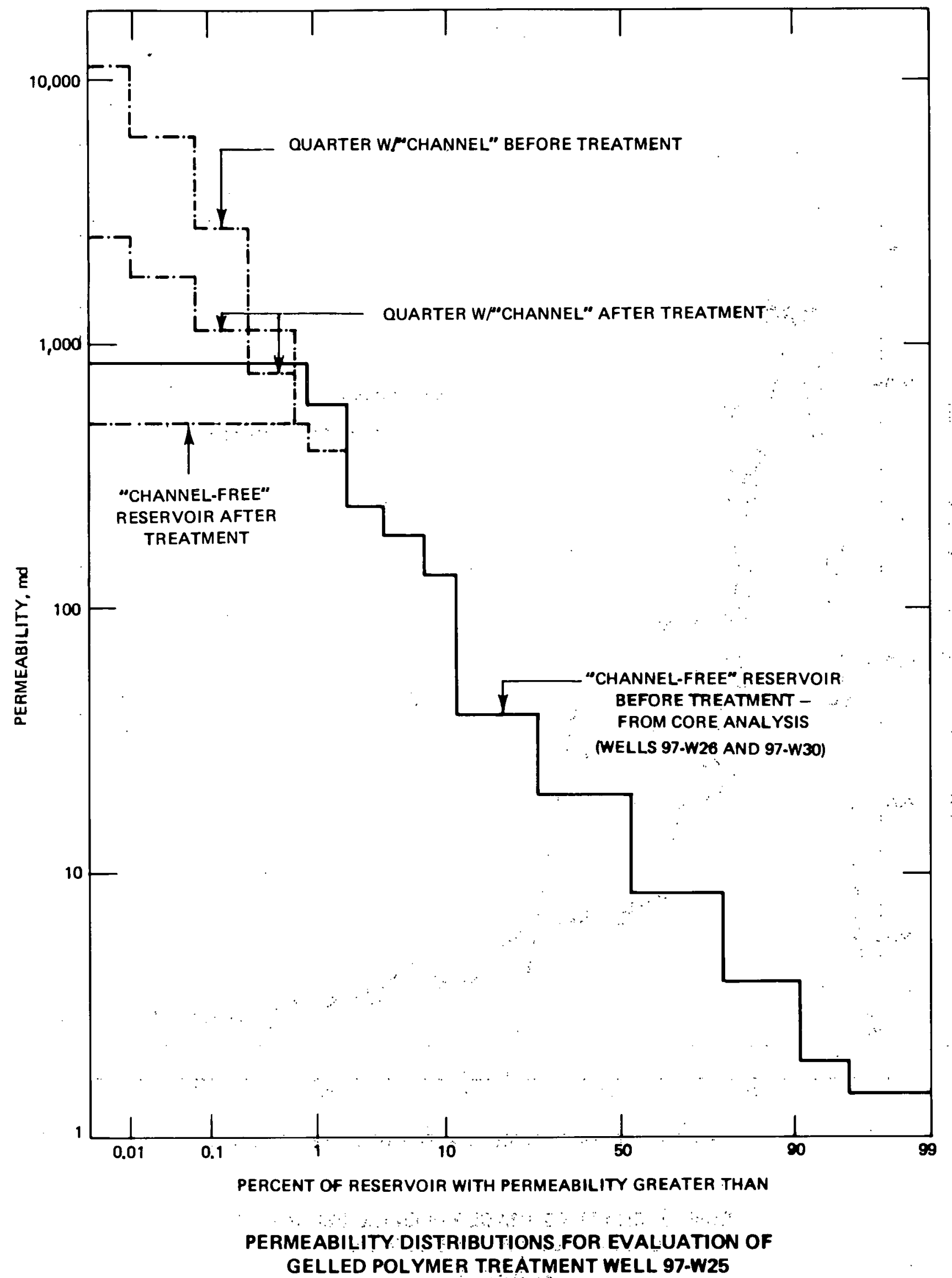

FIGURE 20

$-113-$ 


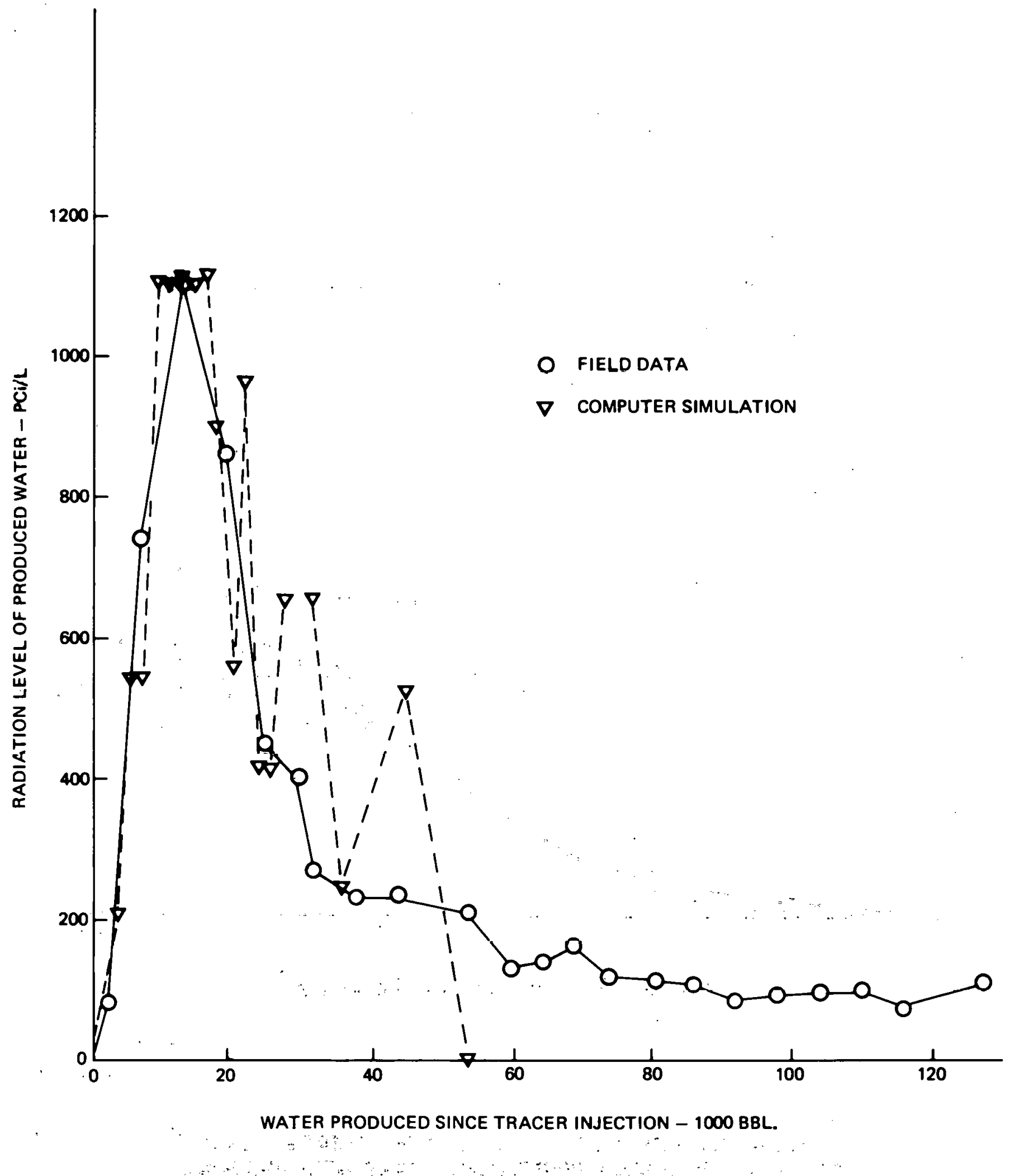

COMPUTER FIT TO TRACER PROFILE BEFORE - GELLED POLYMER TREATMENT

FIGURE 21

$-114-$. 


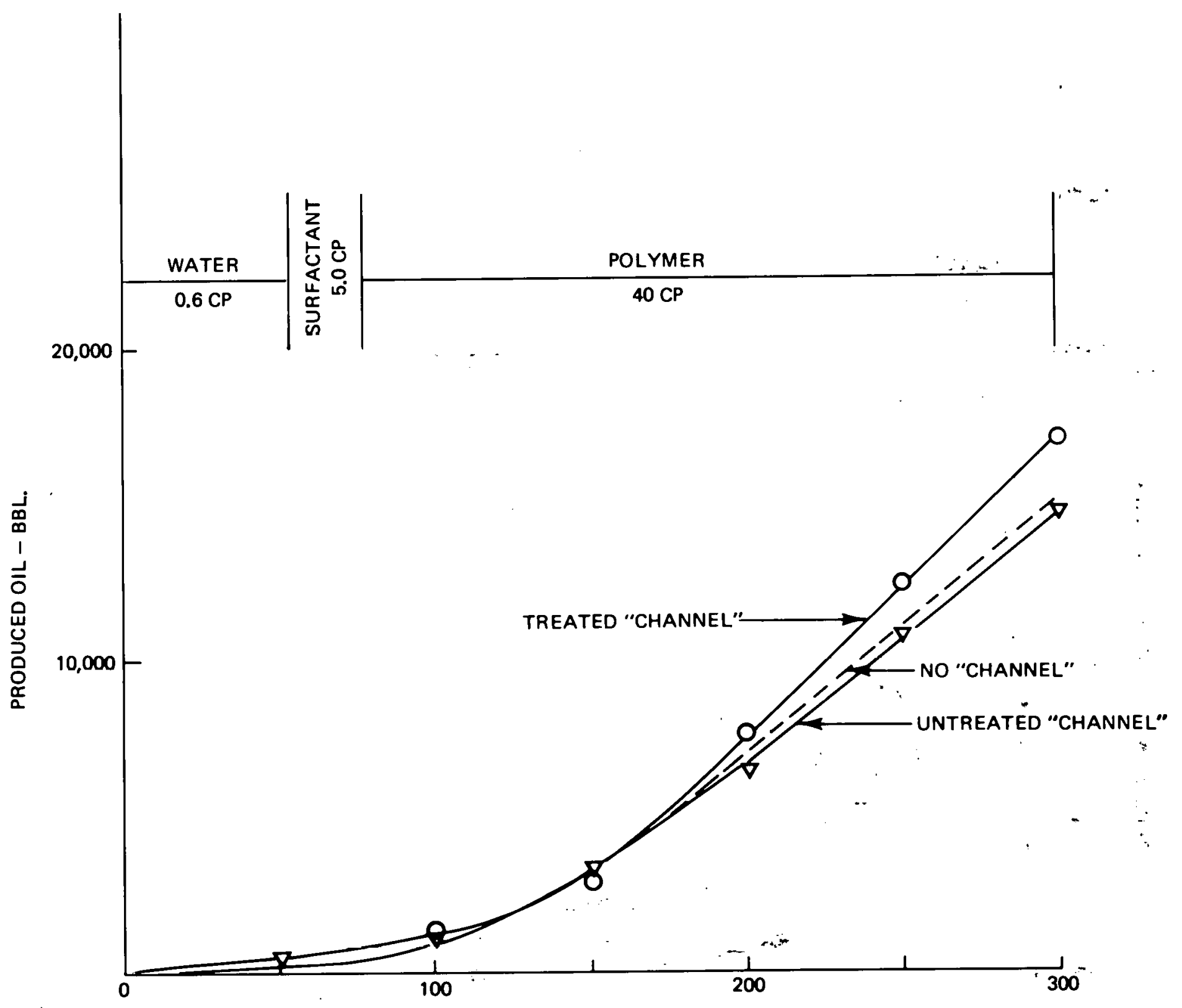

TIME SINCE GELLED POLYMER TREATMENT - DAYS

PREDICTED EFFECT OF GELLED POLYMER TREATMENT ON OIL RECOVERY FROM AFFECTED QUADRANT, WELL 97-W25 NE

$\because \cdots \quad$ FIGURE $22 \quad \therefore \ldots$

$$
-115-\cdots \cdot
$$




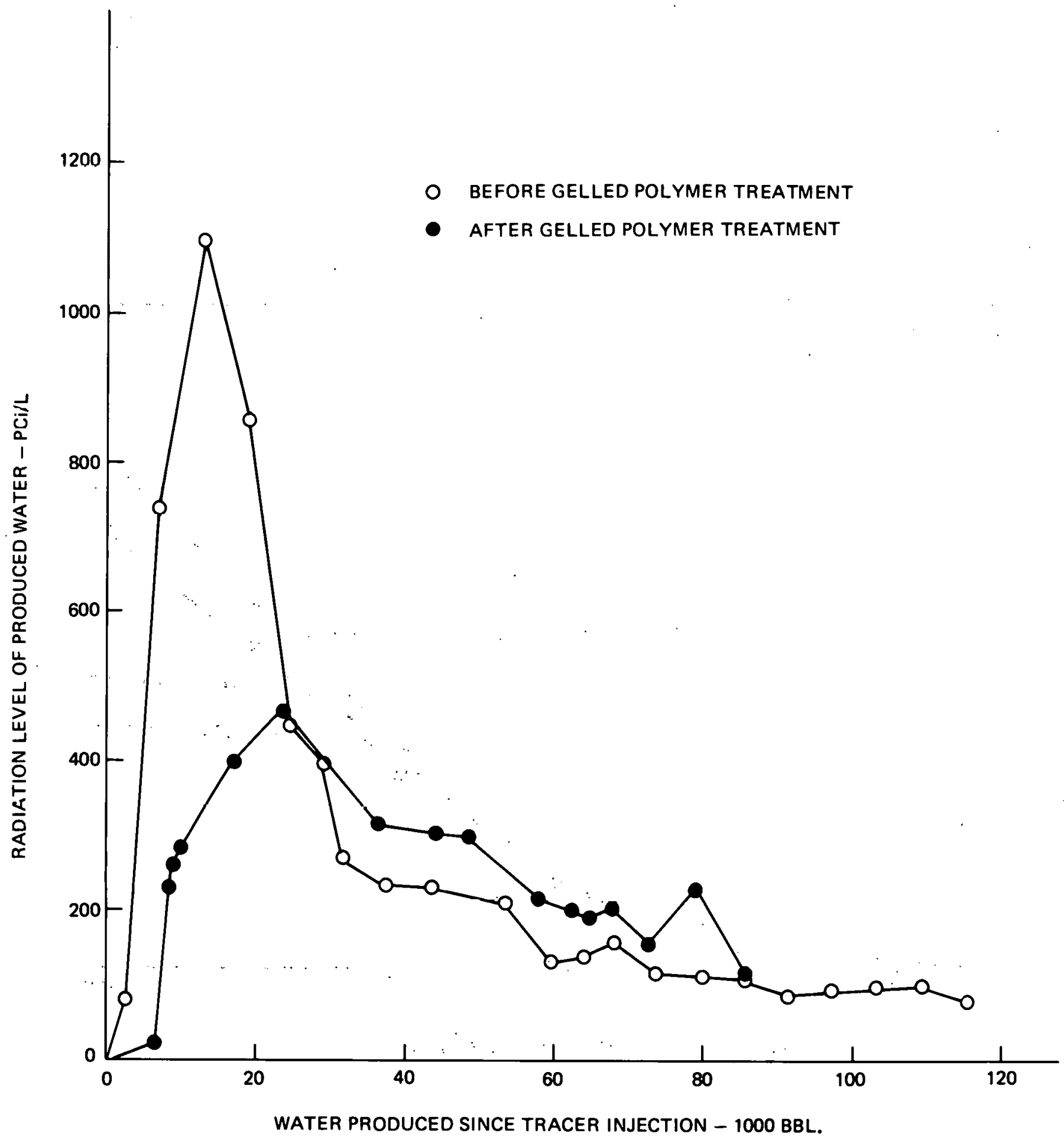

COMPARISON OF TRACER PROFILE BEFORE AND AFTER

GELLED POLYMER TREATMENT

FIGURE 23 


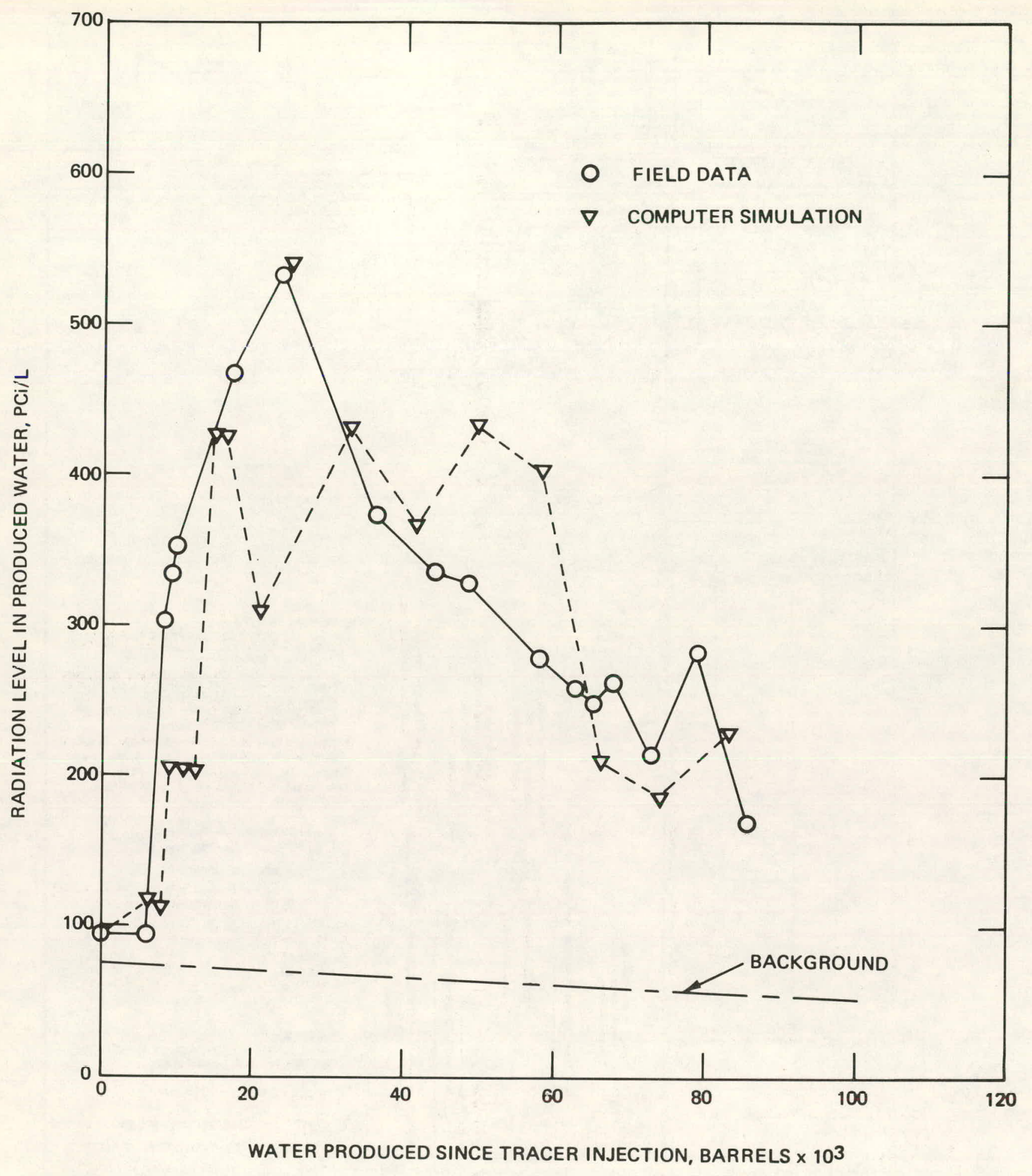

-

COMPUTER FIT TO TRACER PROFILE AFTER

GELLED POLYMER TREATMENT

FIGURE 24 


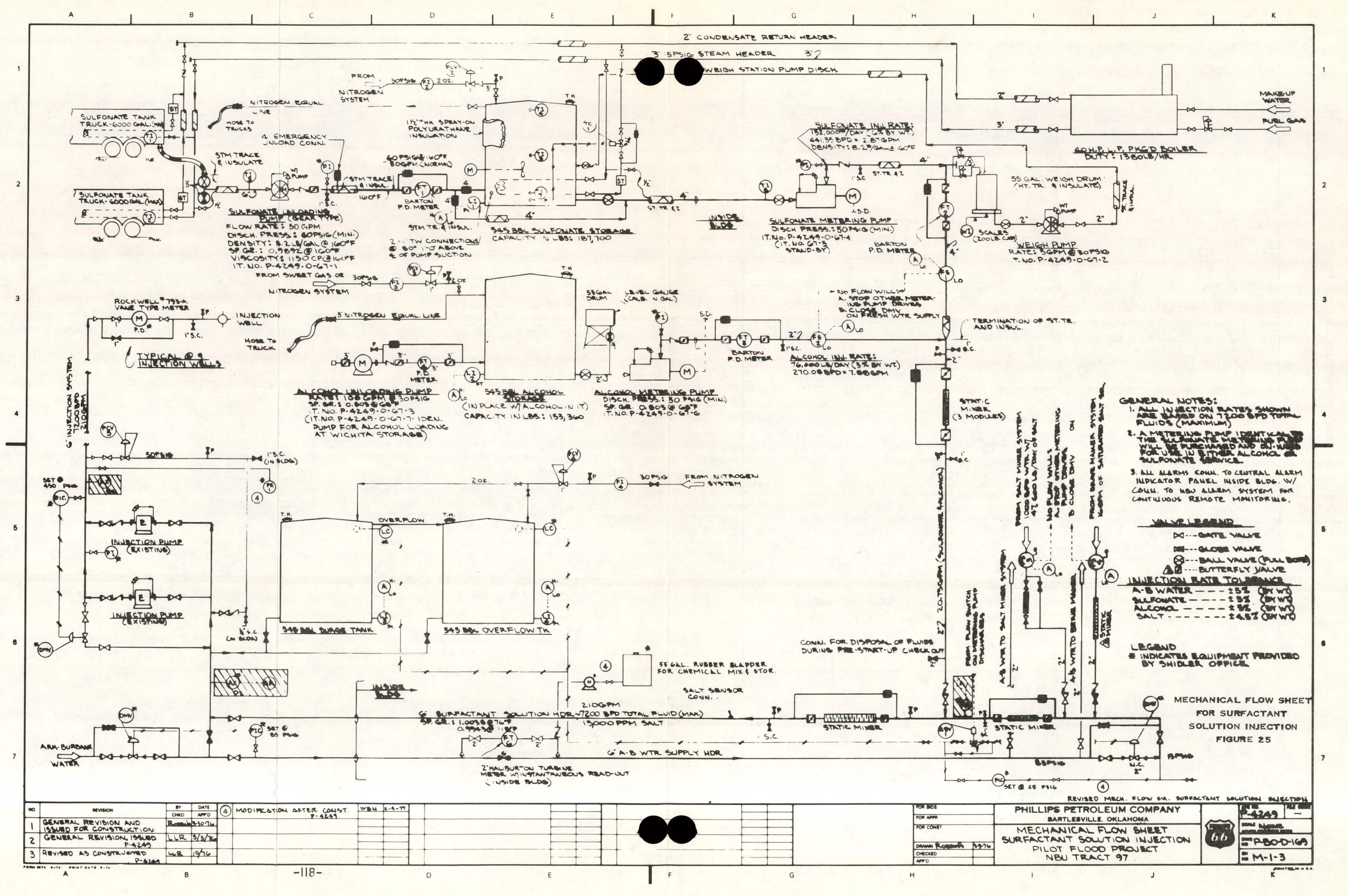




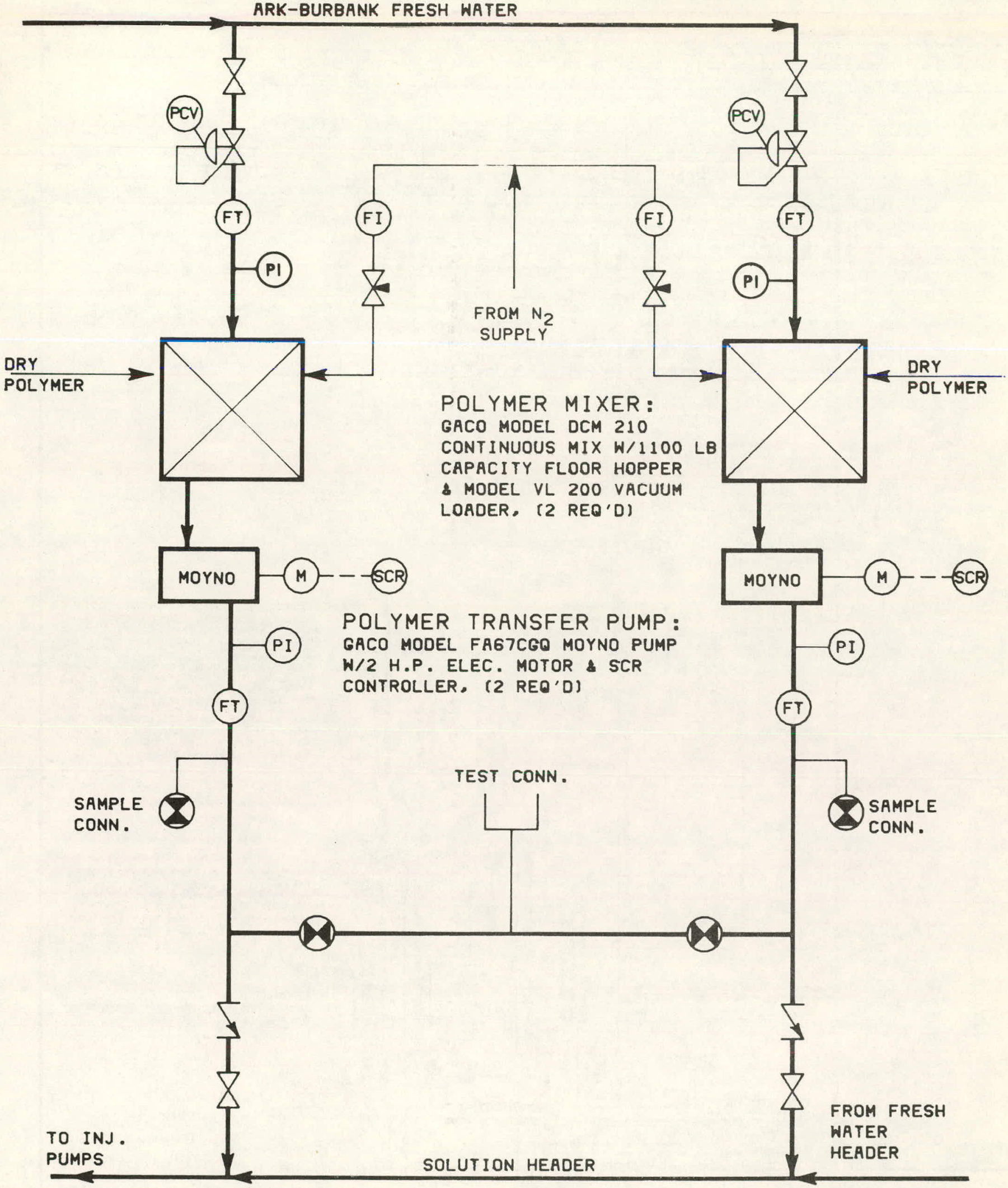

POLYMER SOLUTION

MECHANICAL FLOW SHEET

FIGURE 26

$-119-$ 


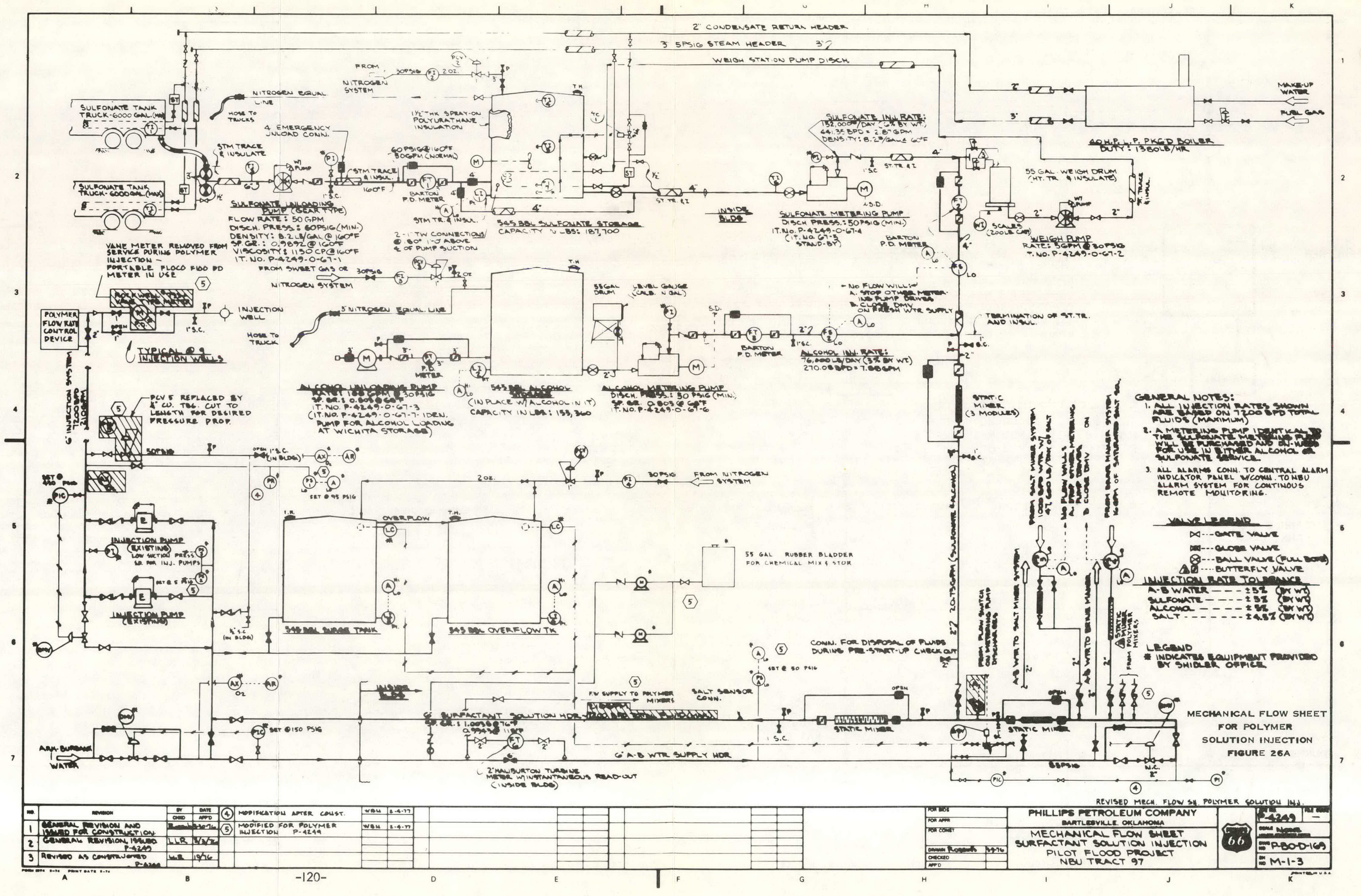




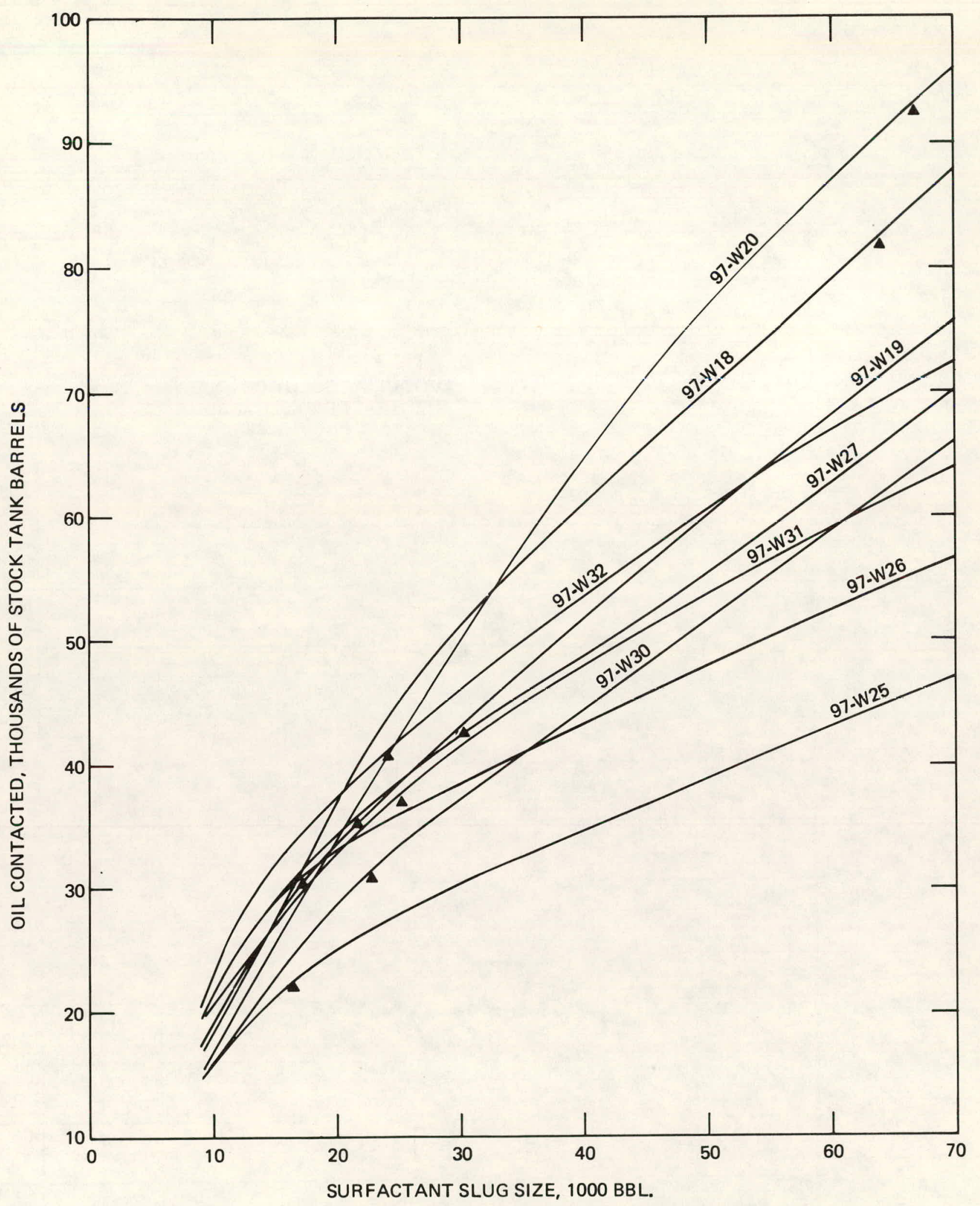

RECOVERABLE OIL CONTACTED VERSUS SURFACTANT SLUG SIZE FOR THE NINE FIVE-SPOTS IN NBU TRACT 97

FIGURE 27 


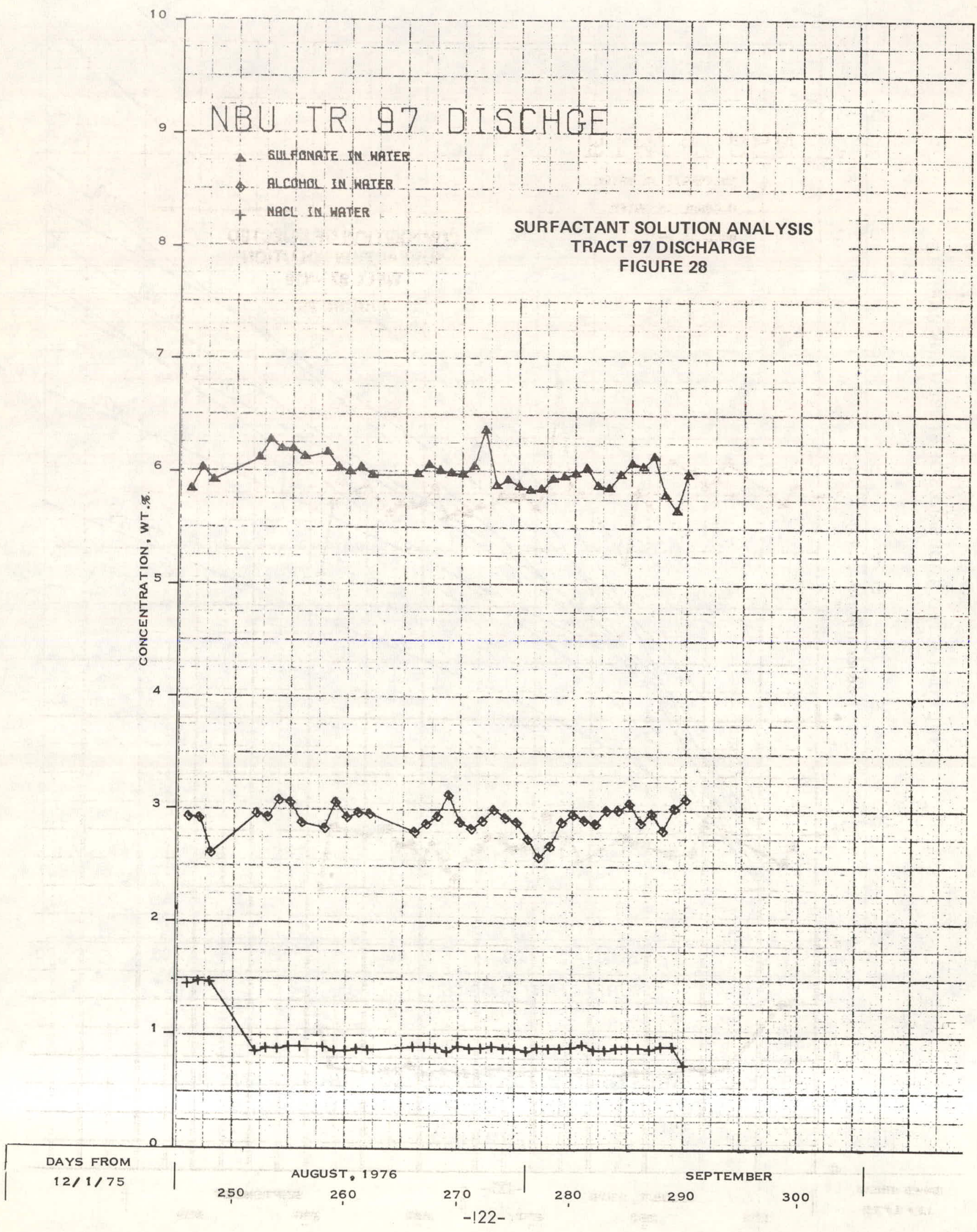




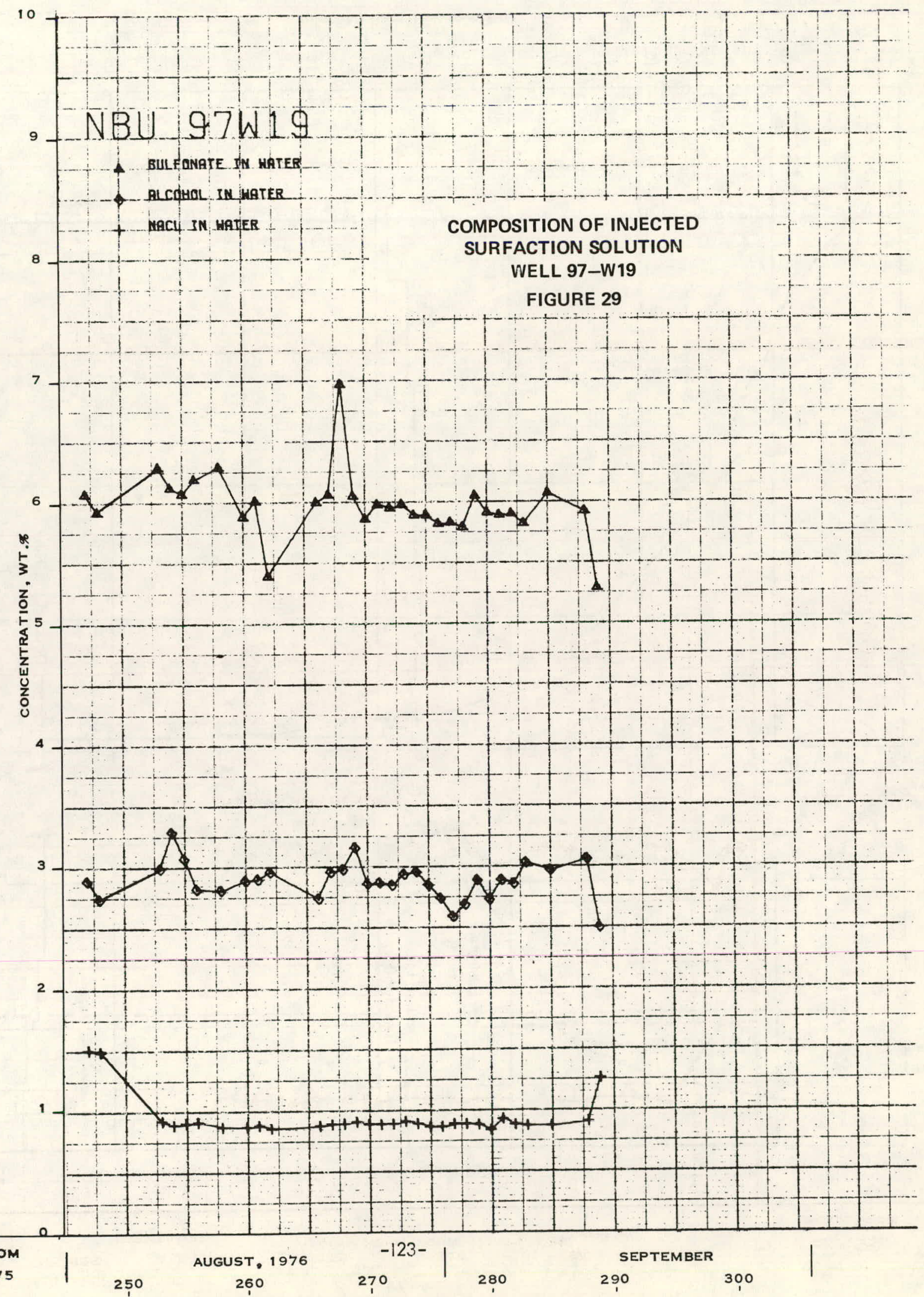




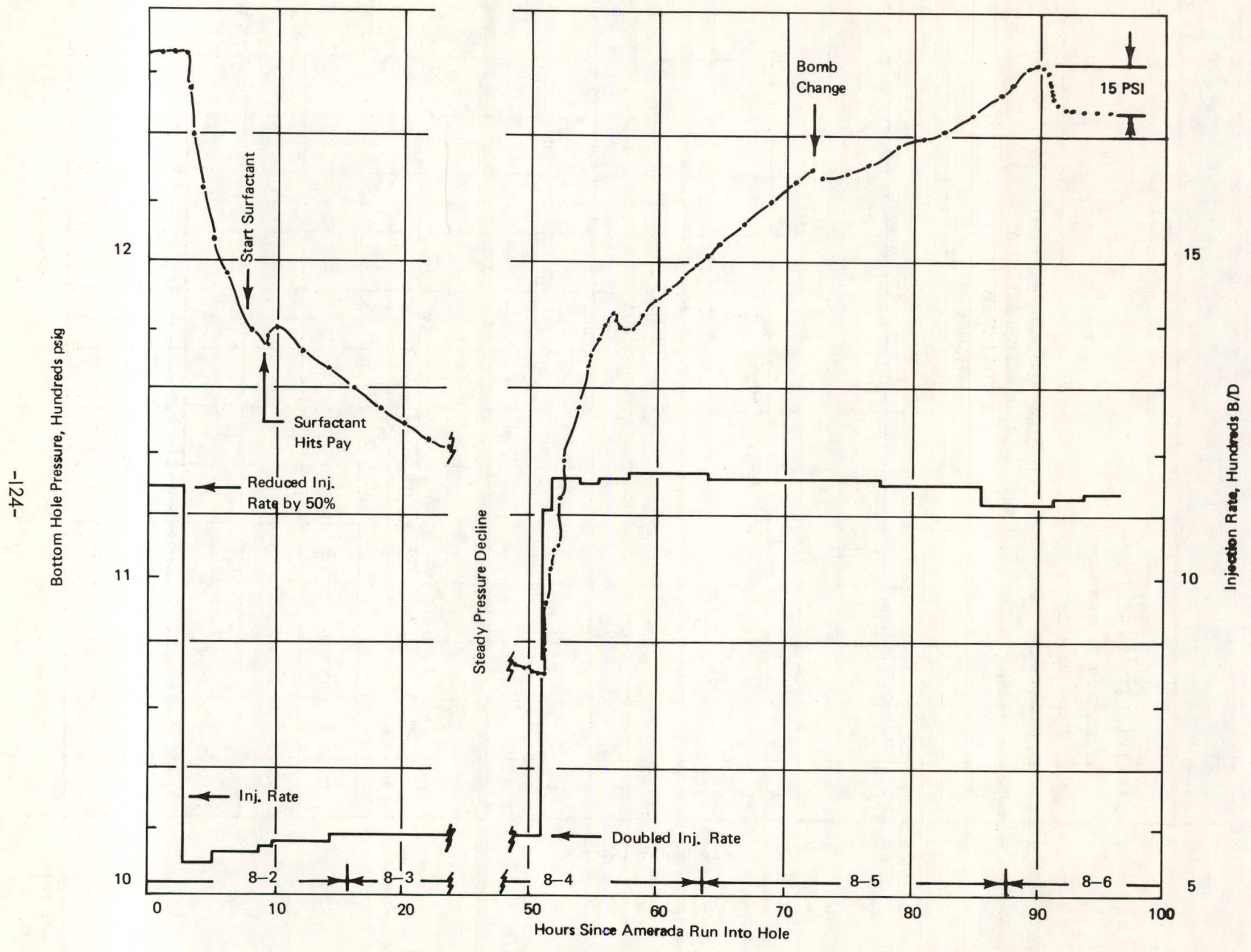

BOTTOM HOLE PRESSURE AND INJECTION HISTORY - WELL 97-W19

FIGURE 30. 
50

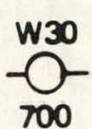

$\overbrace{700}^{\text {W31 }}$

w32

-

700

650

800

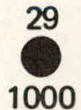

W25

$-\mathrm{O}-$

$\stackrel{-626}{-100}$

W27

$-$

21

1000

(Max.)
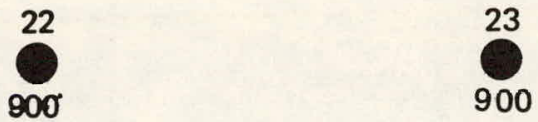

$\overbrace{700}^{24}$

w18

$-\mathrm{O}$

W19

$-$

w20

1200

17
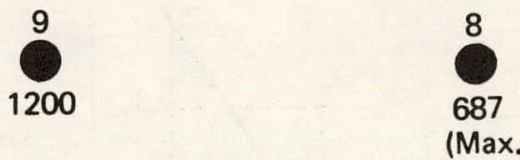

$\overbrace{1200}^{1 A}$

TRACT 97

TRACT 105

Producer

- Injector

PILOT PATTERN NBU TRACT 97 PLOT

SCALE $1 "=400^{\prime}$

WELL QUOTAS DURING SURFACTANT INJECTION

FIGURE 31. 


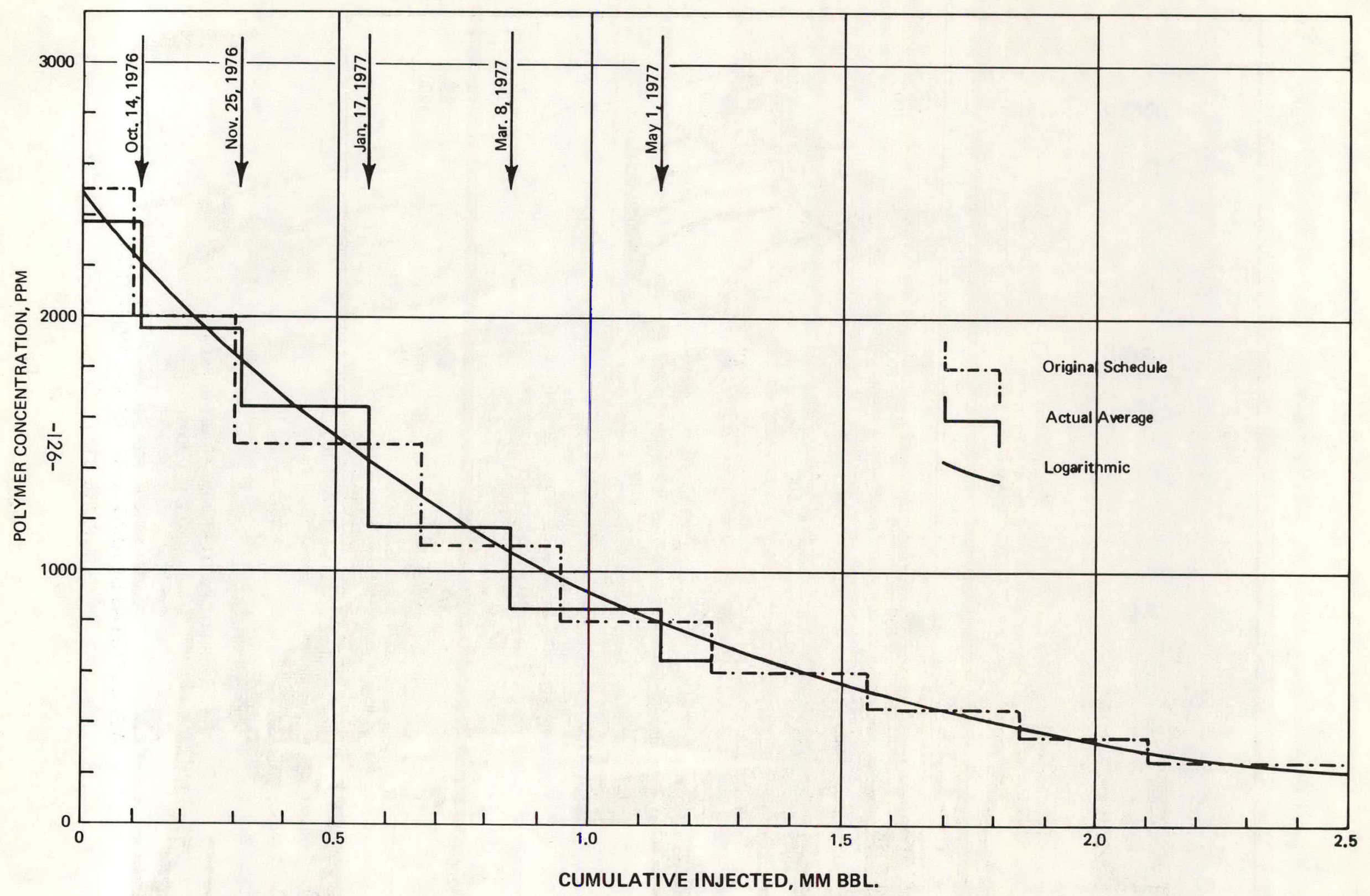

POLYMER INJECTION SCHEDULE

FIGURE 32. 


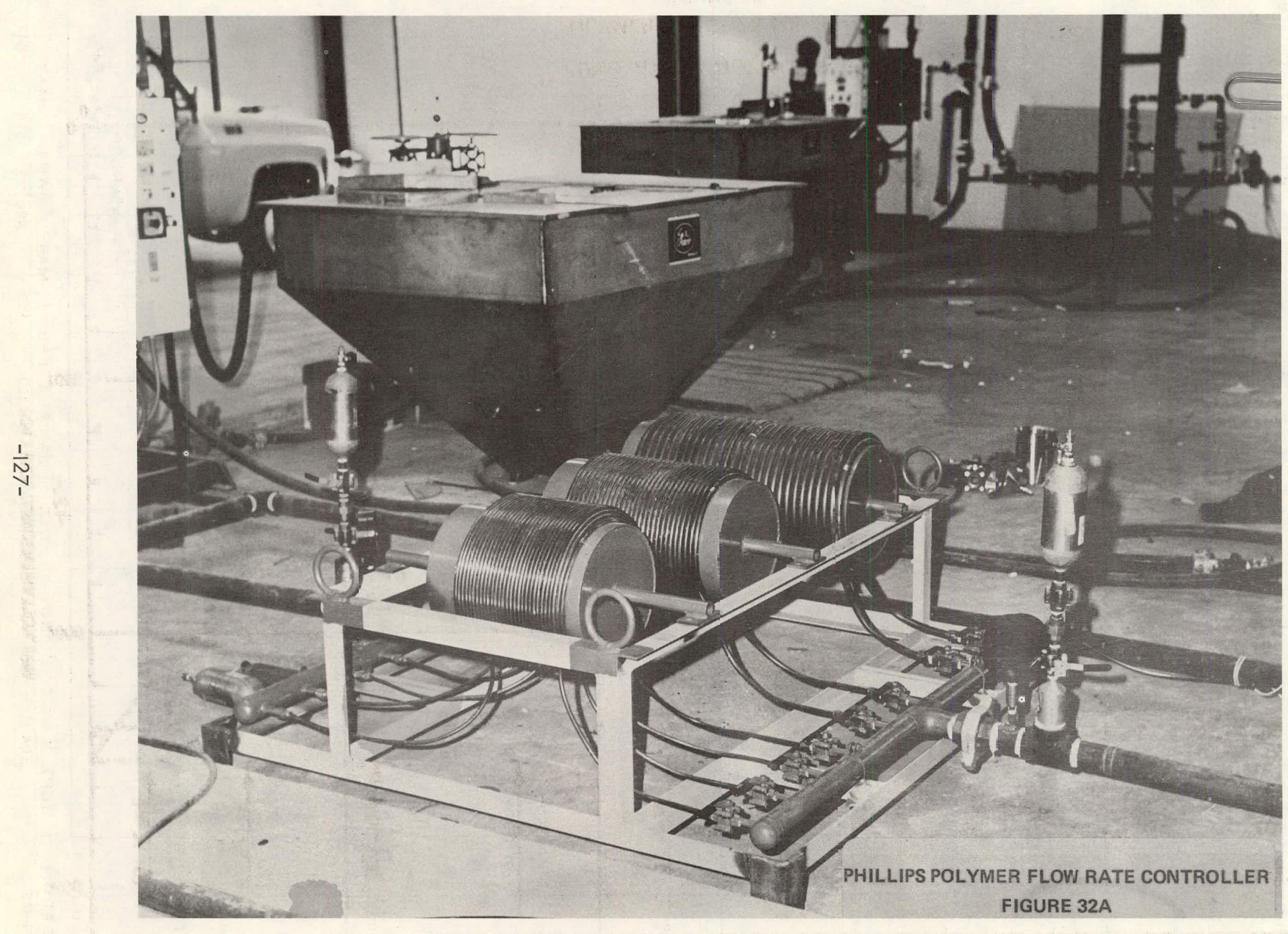




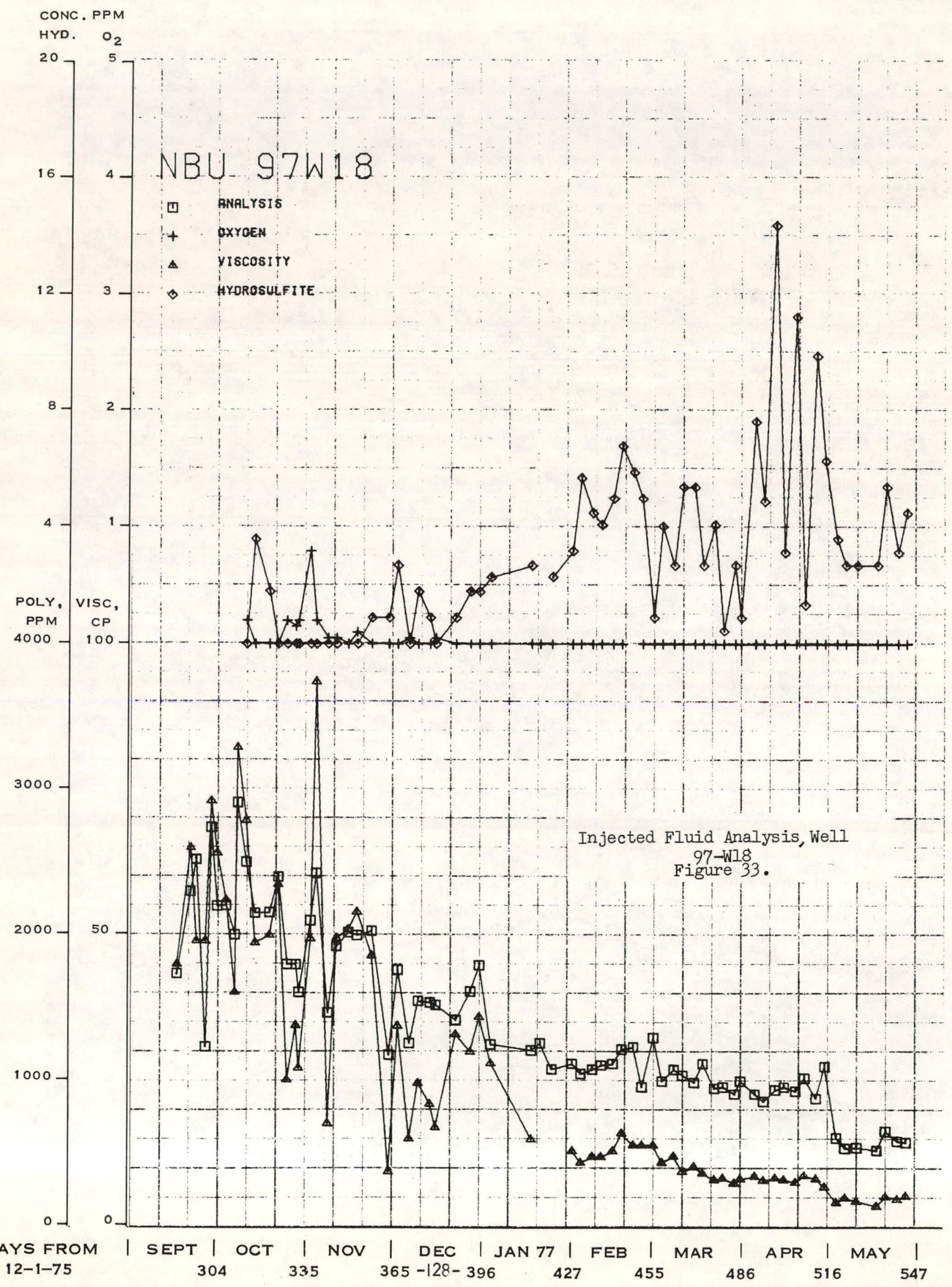




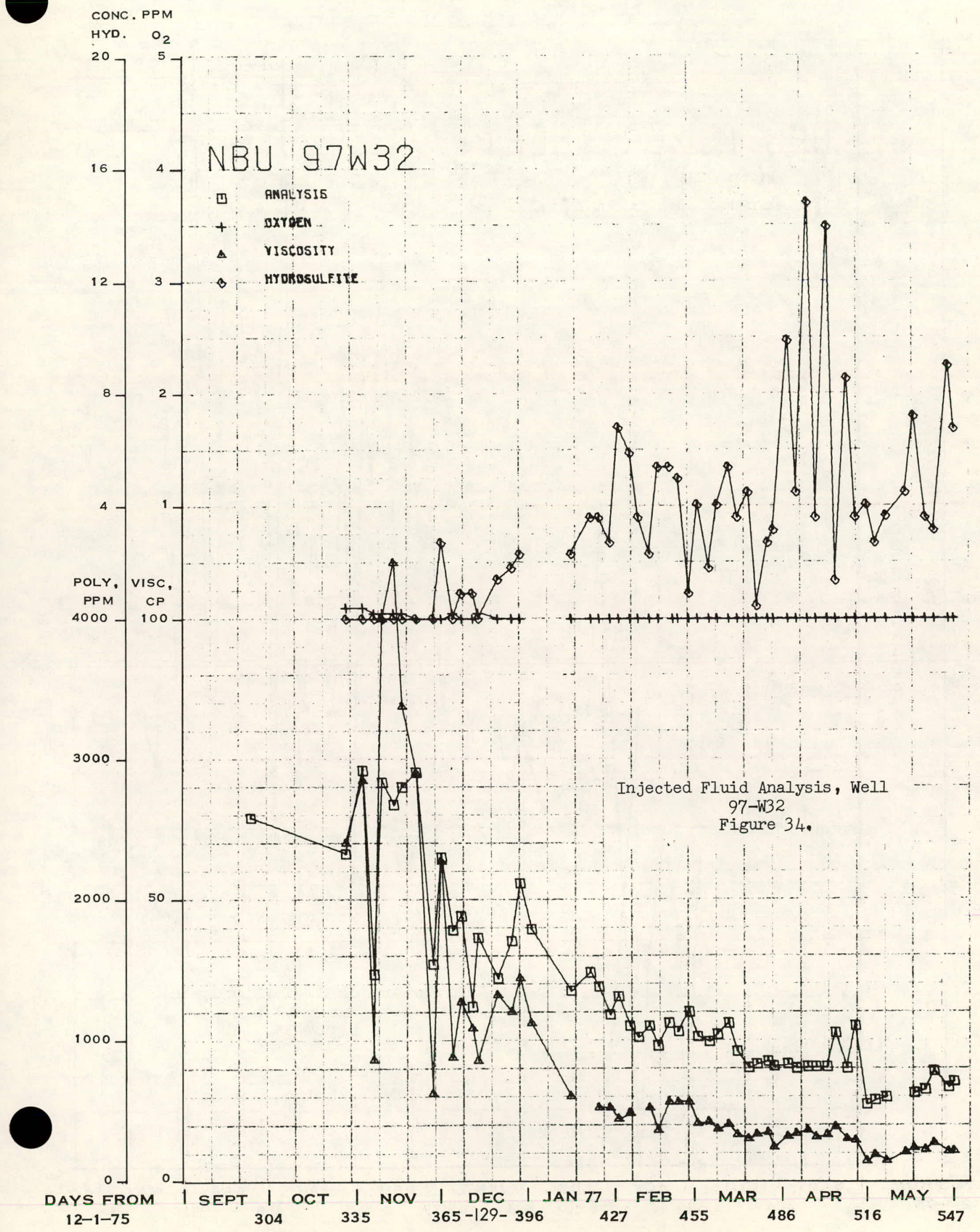




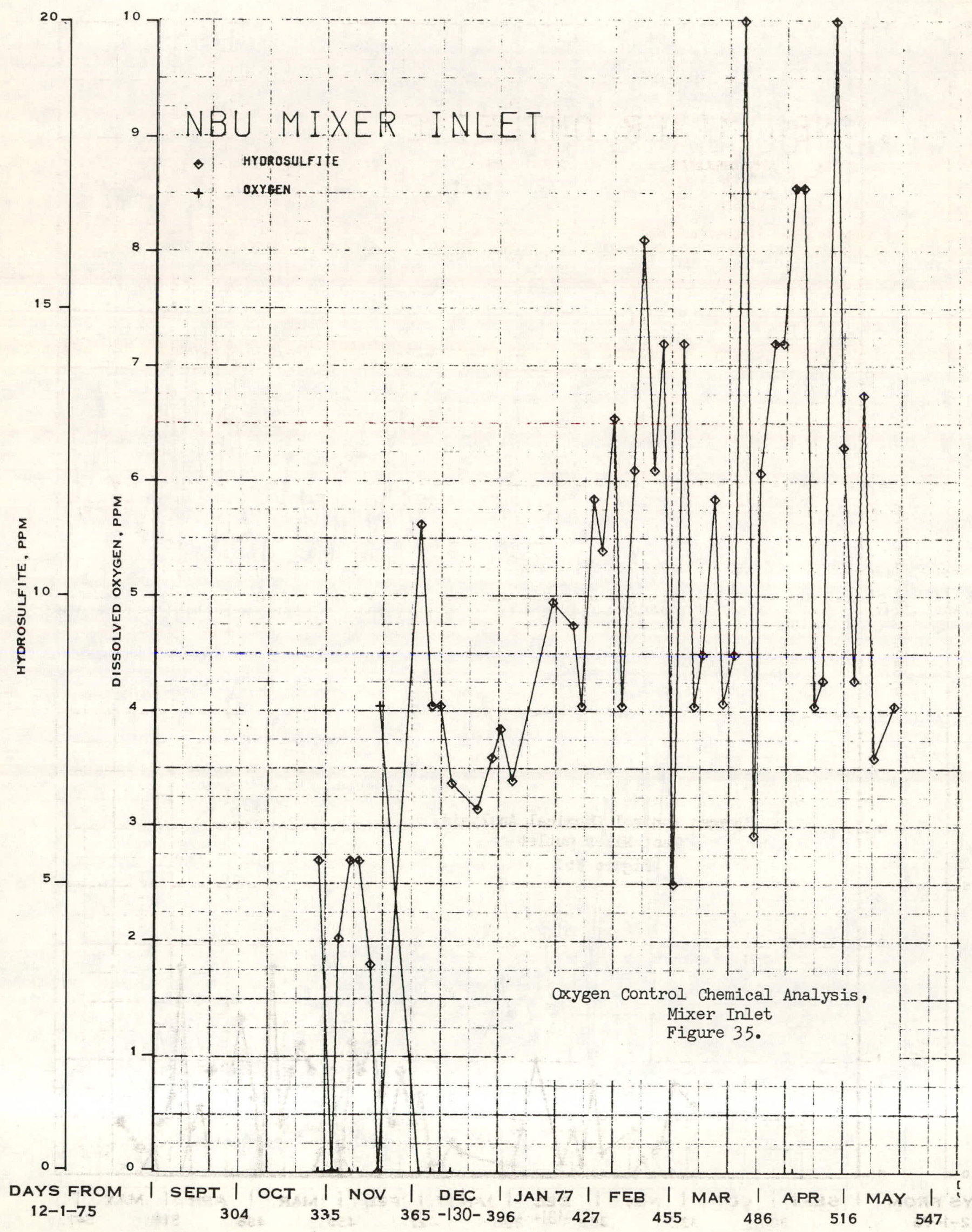




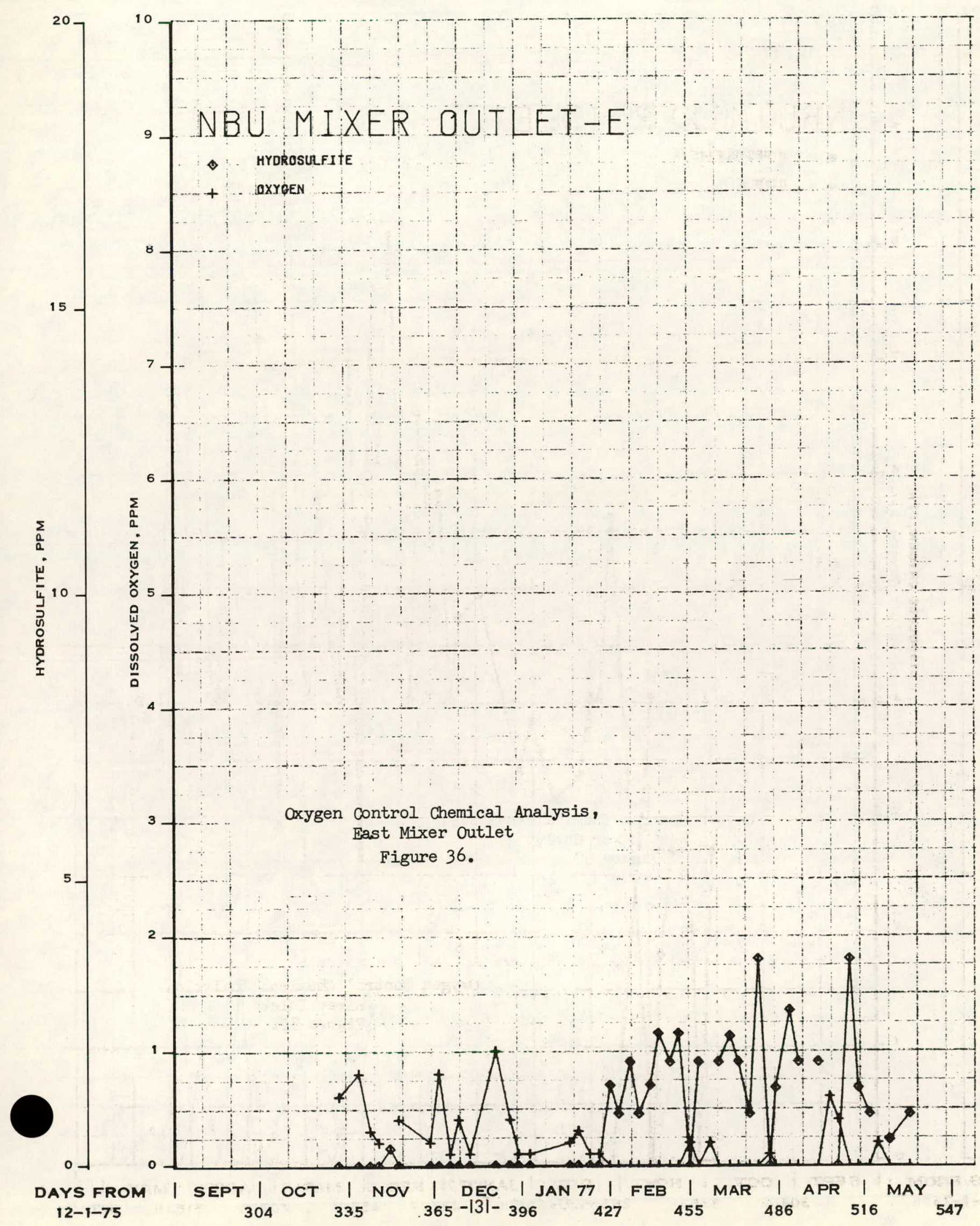




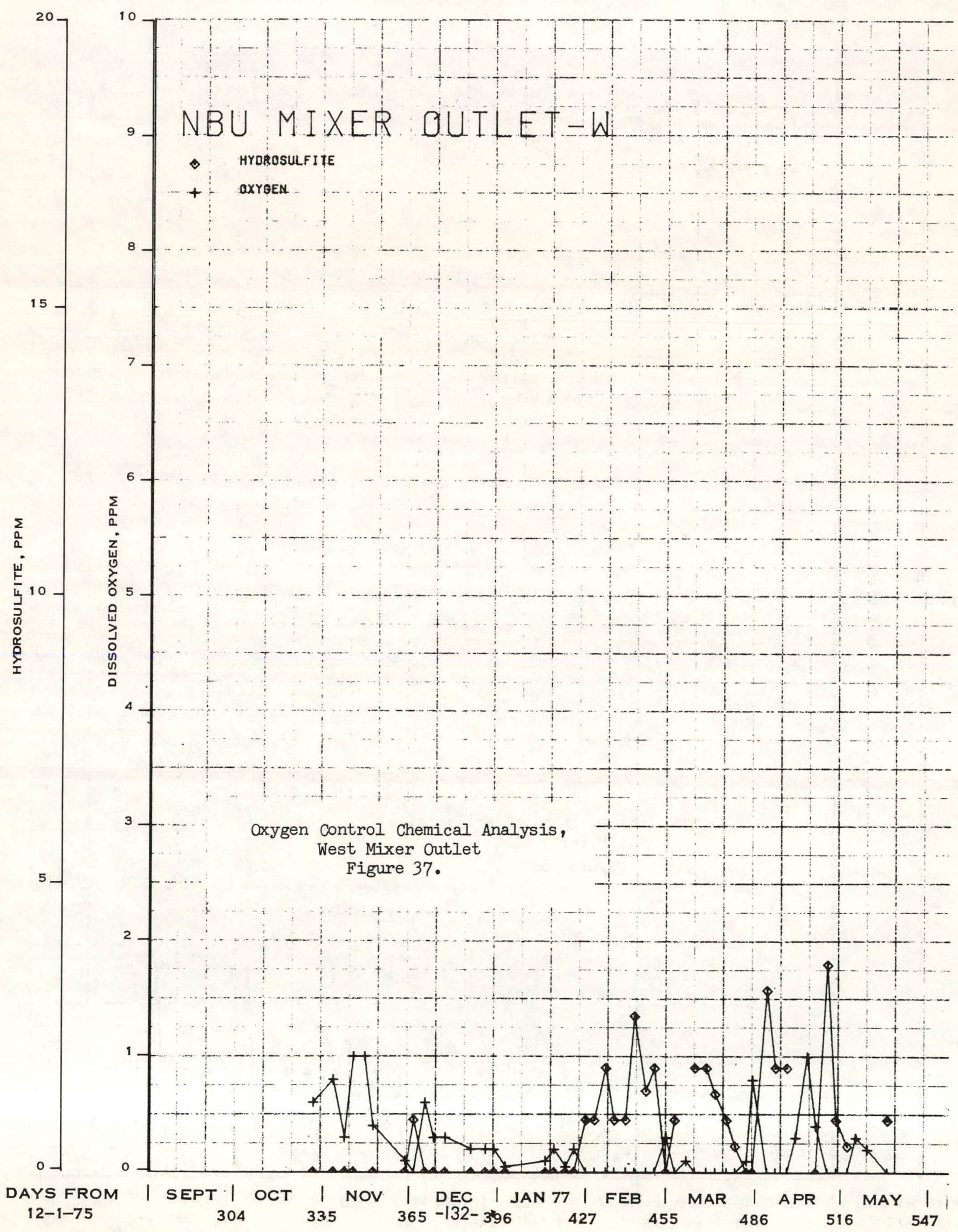




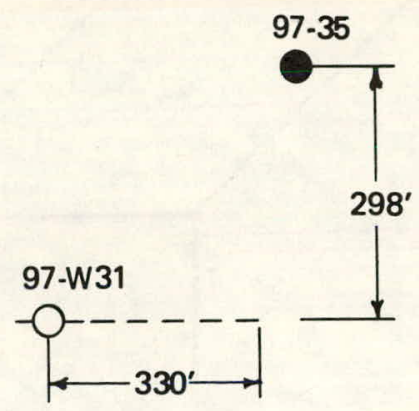

NBU Micellar Pilot, Tract 97. A/B $=0$ 05. Flow From Fracture. Well 97-W31

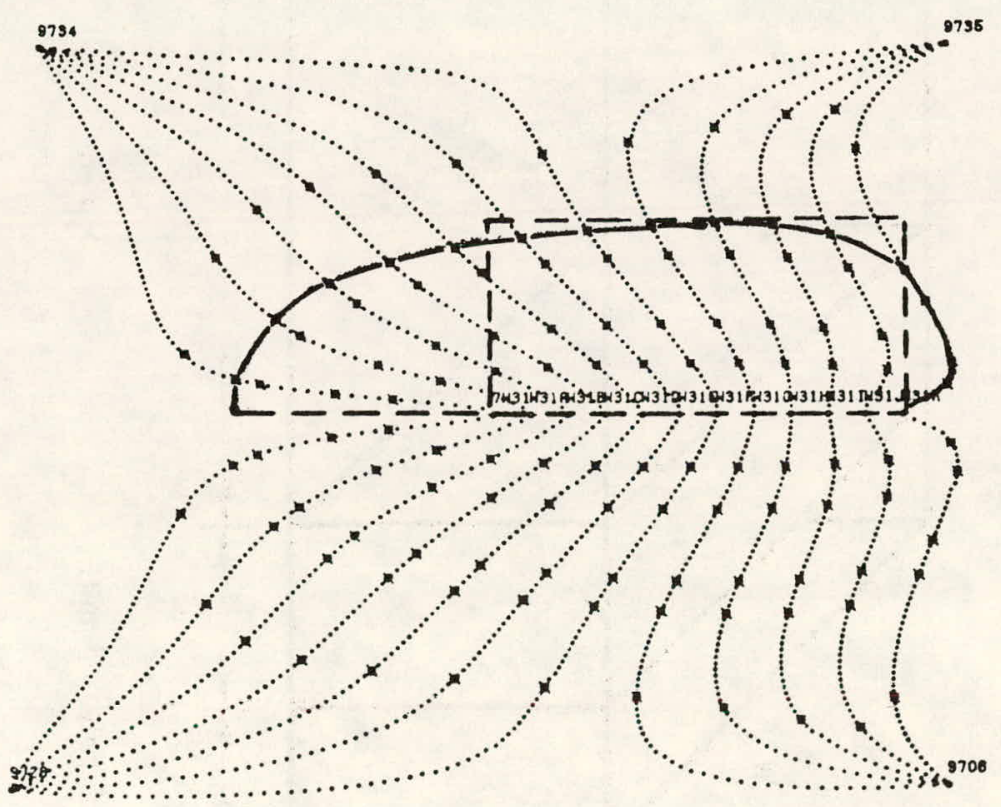




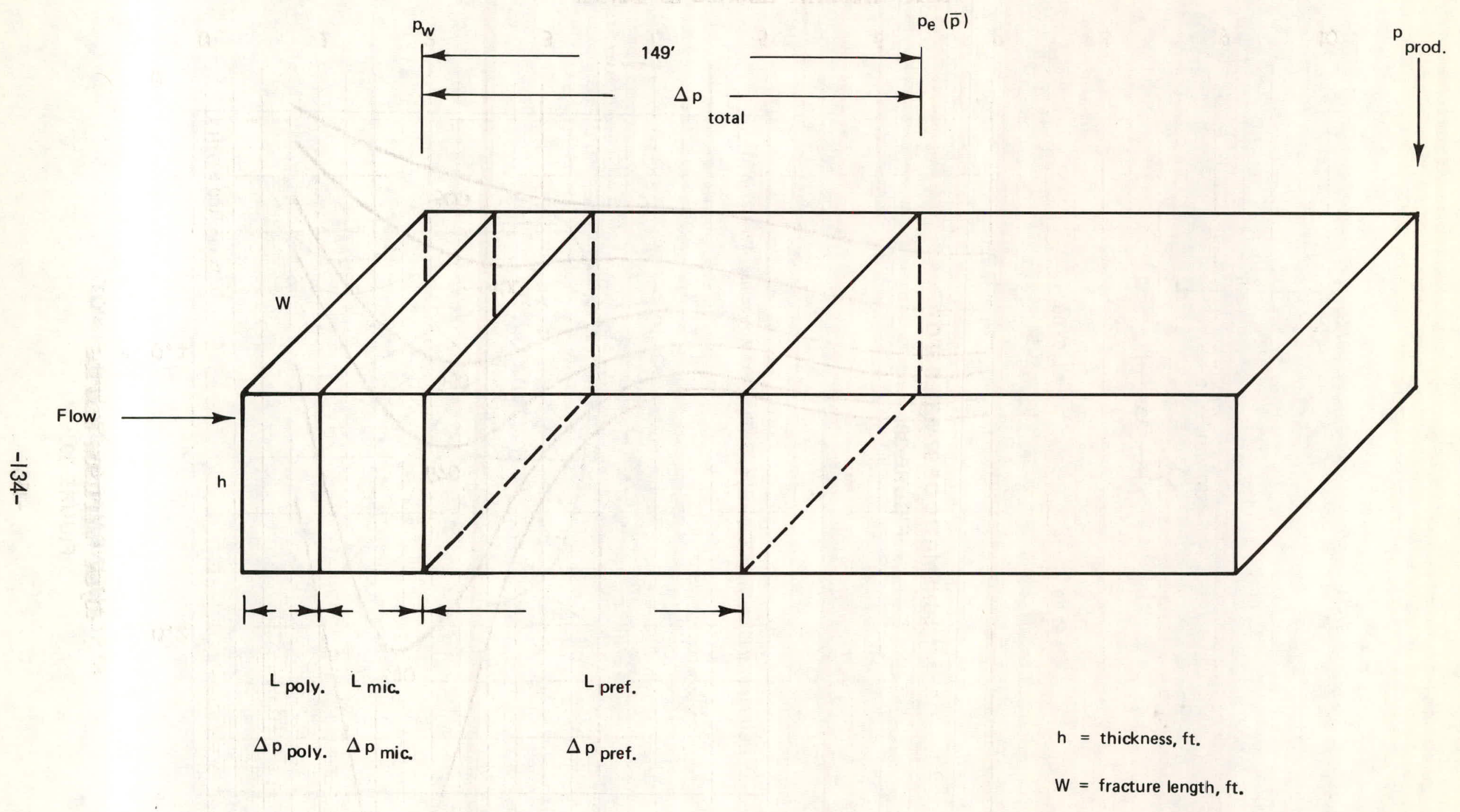

LINEAR FLOW MODEL FOR MOBILITY CALCULATION

FIGURE 40. 


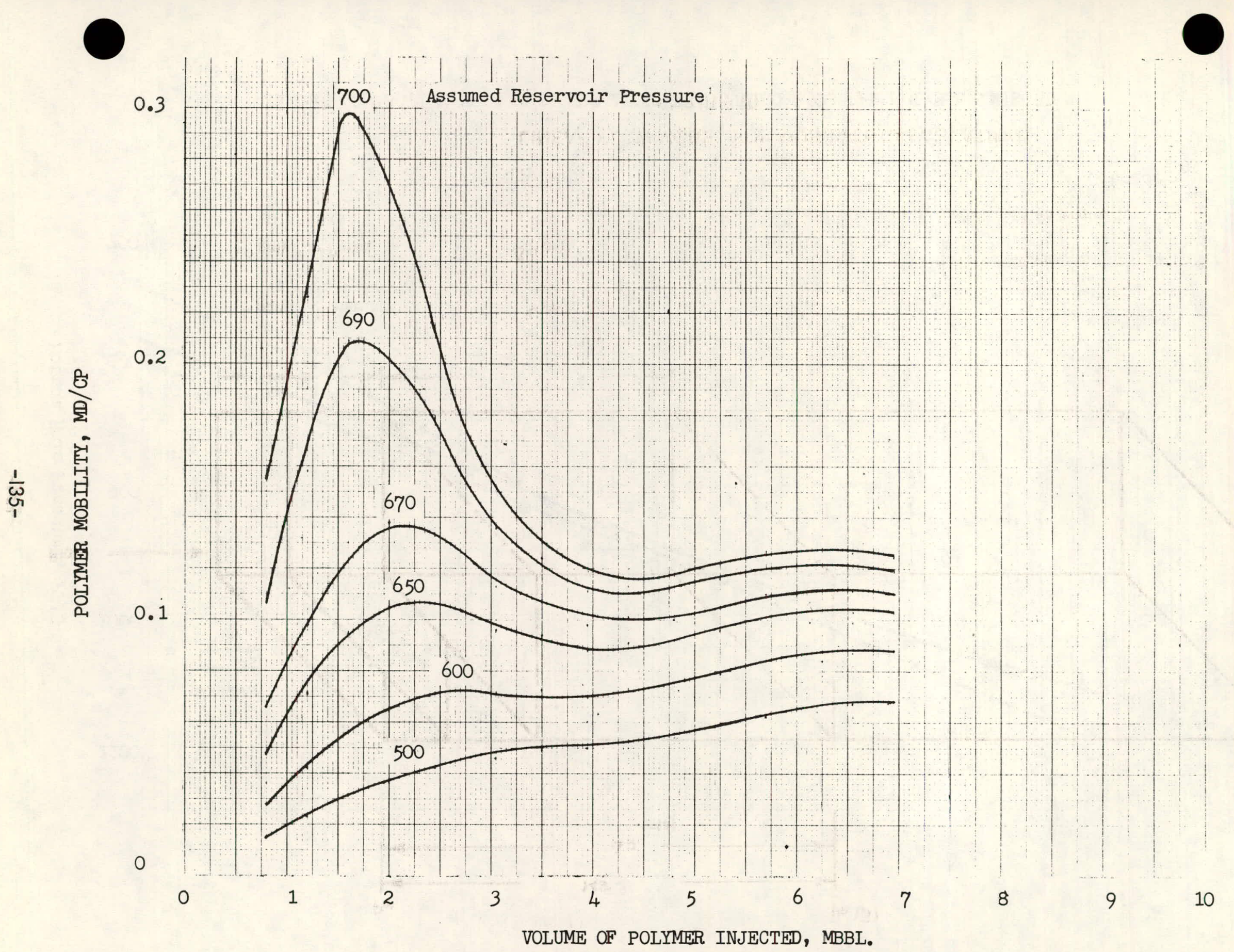

FIGURE 47. ESTIMATION OF 2500 PPM POLYMER MOBILITY 


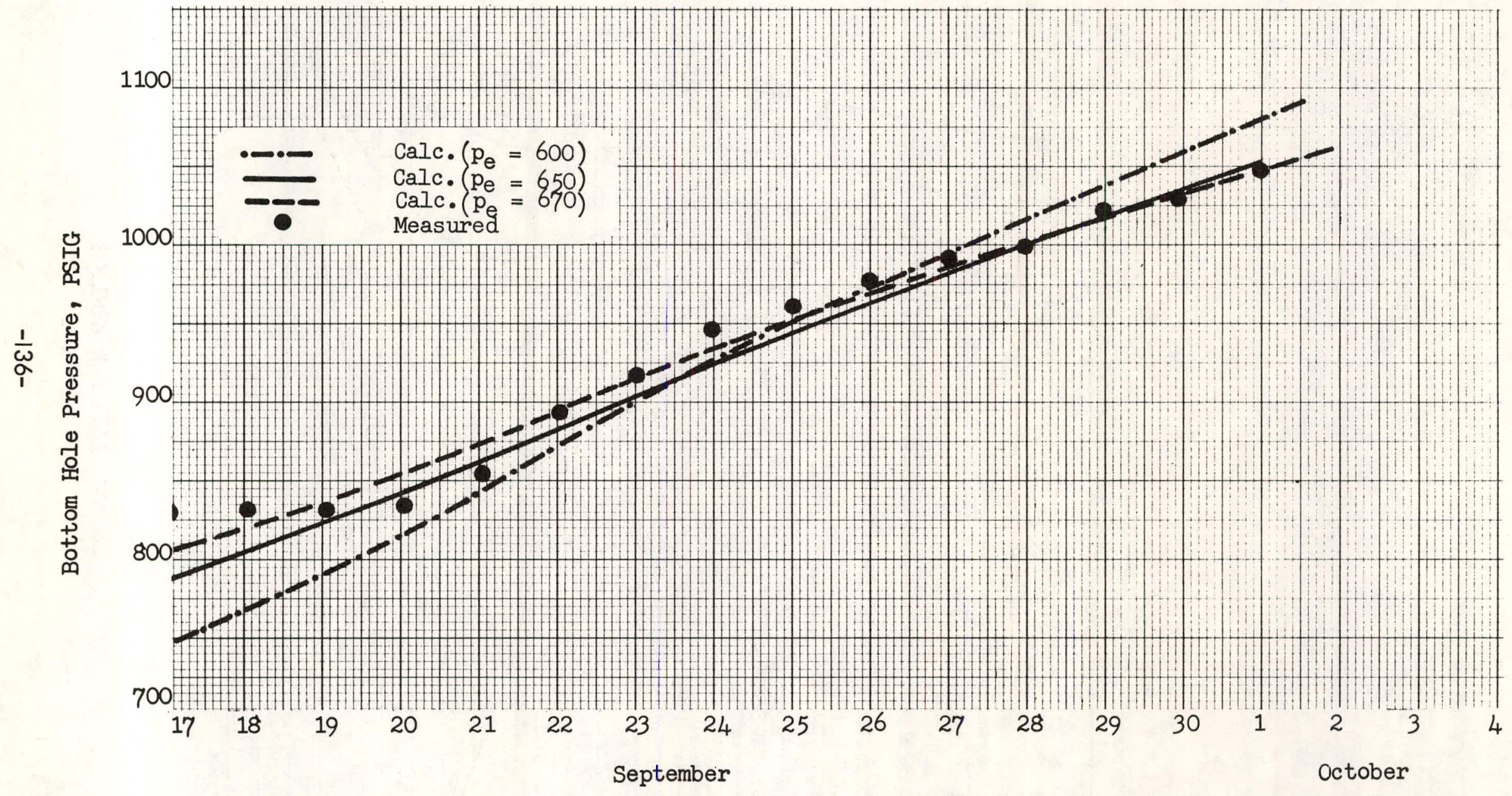

FIGURE 42. BOTTOM HOLE PRESSURE AT 97-WB1 DURING 2500 PPM POLYMER INJECTION 


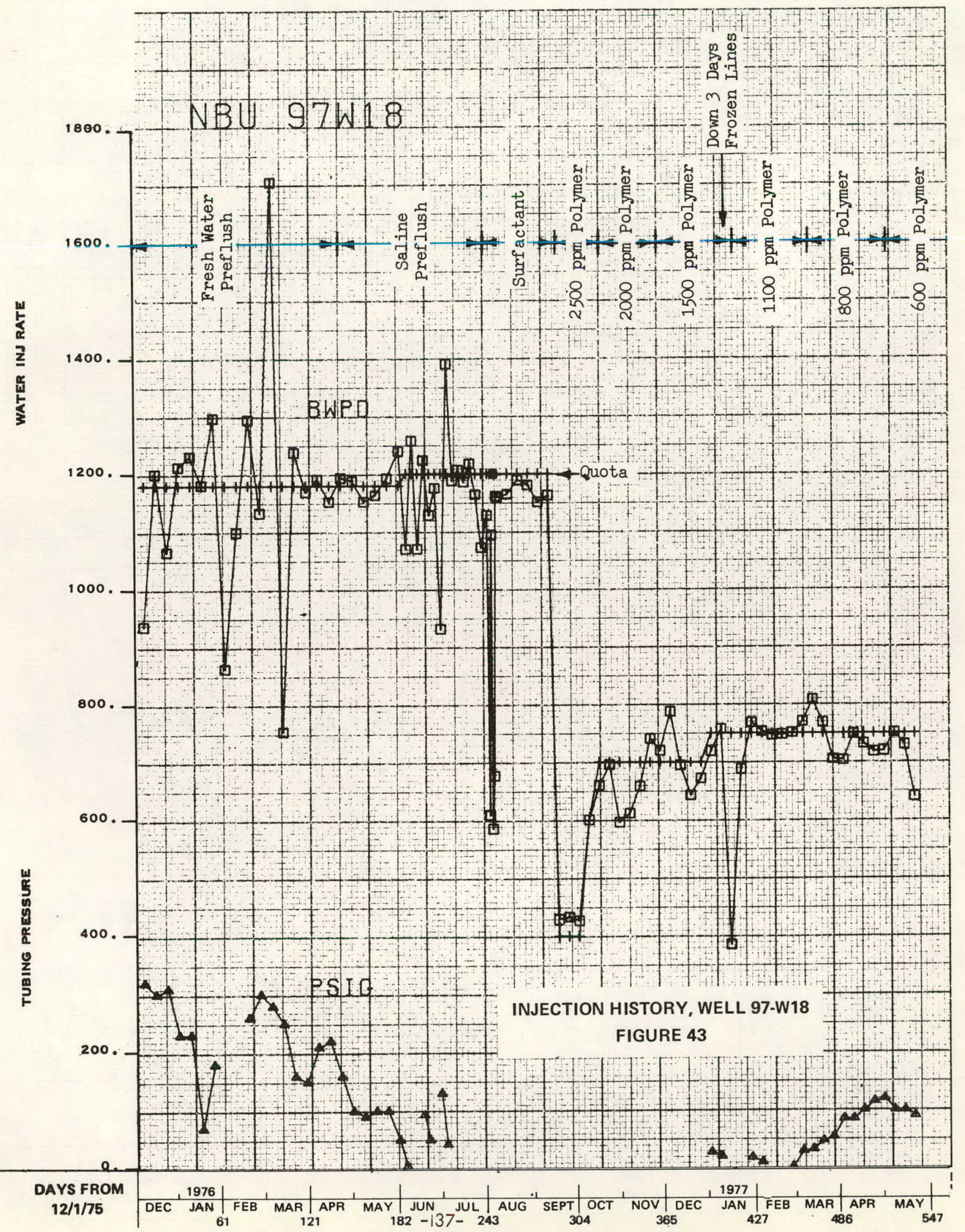




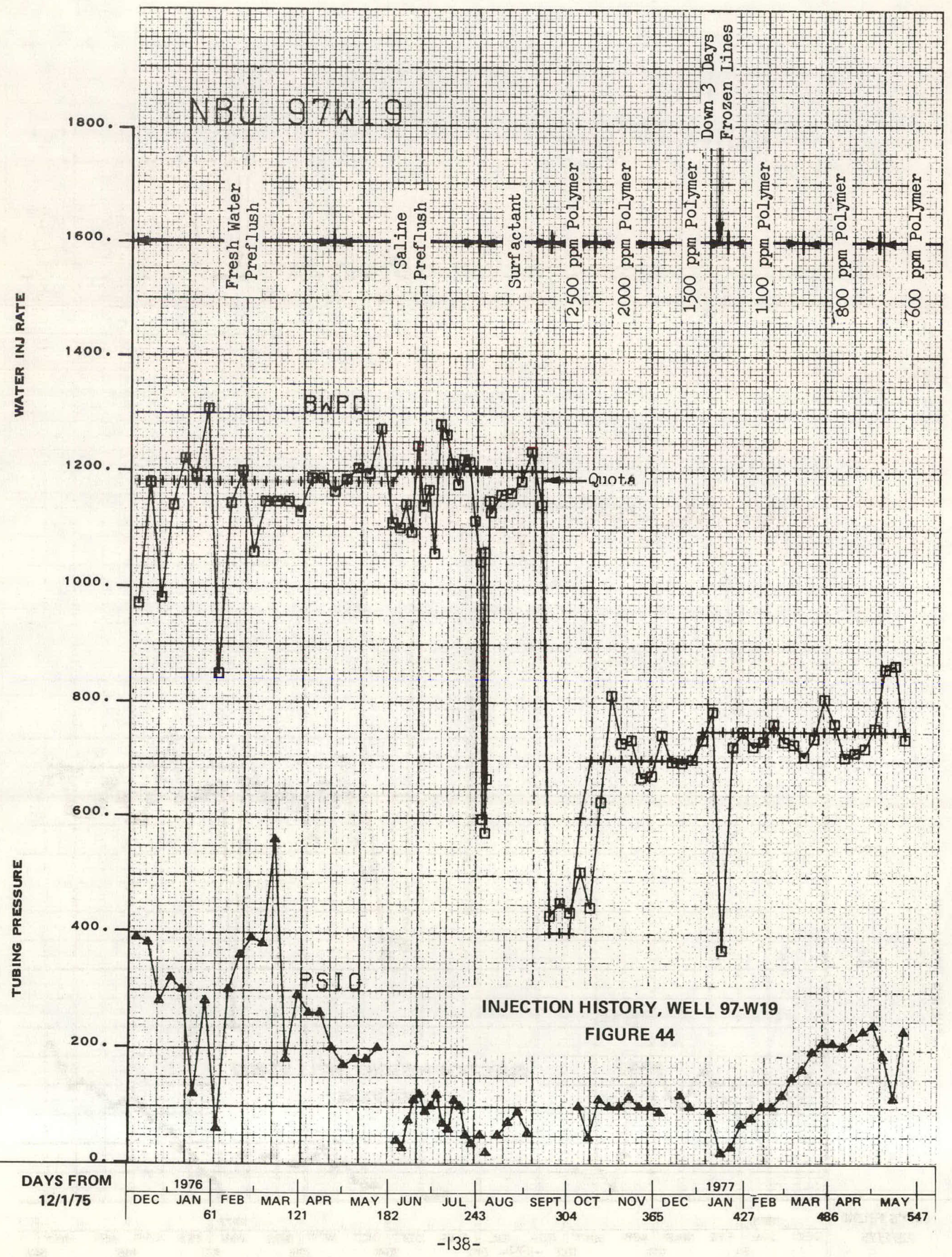




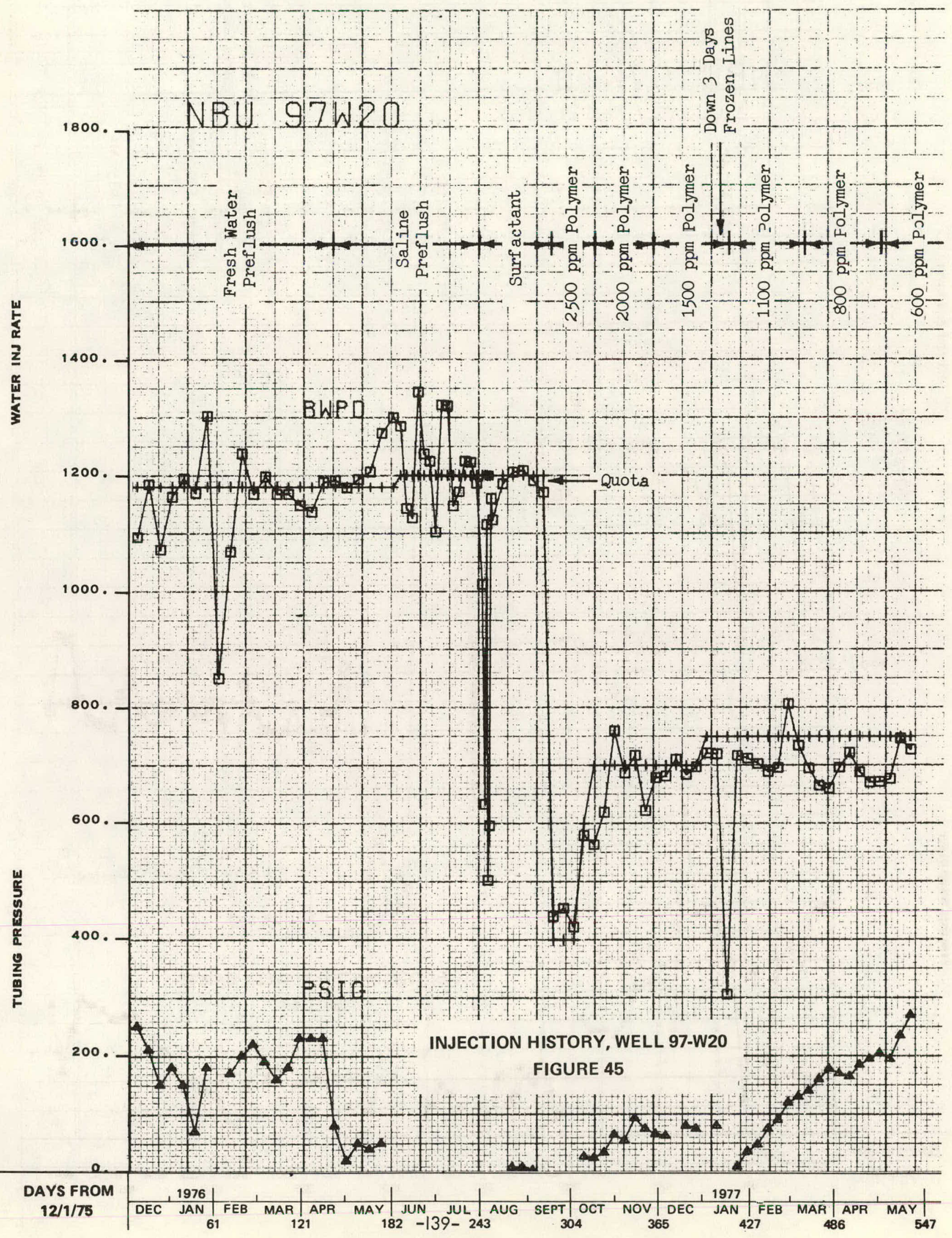




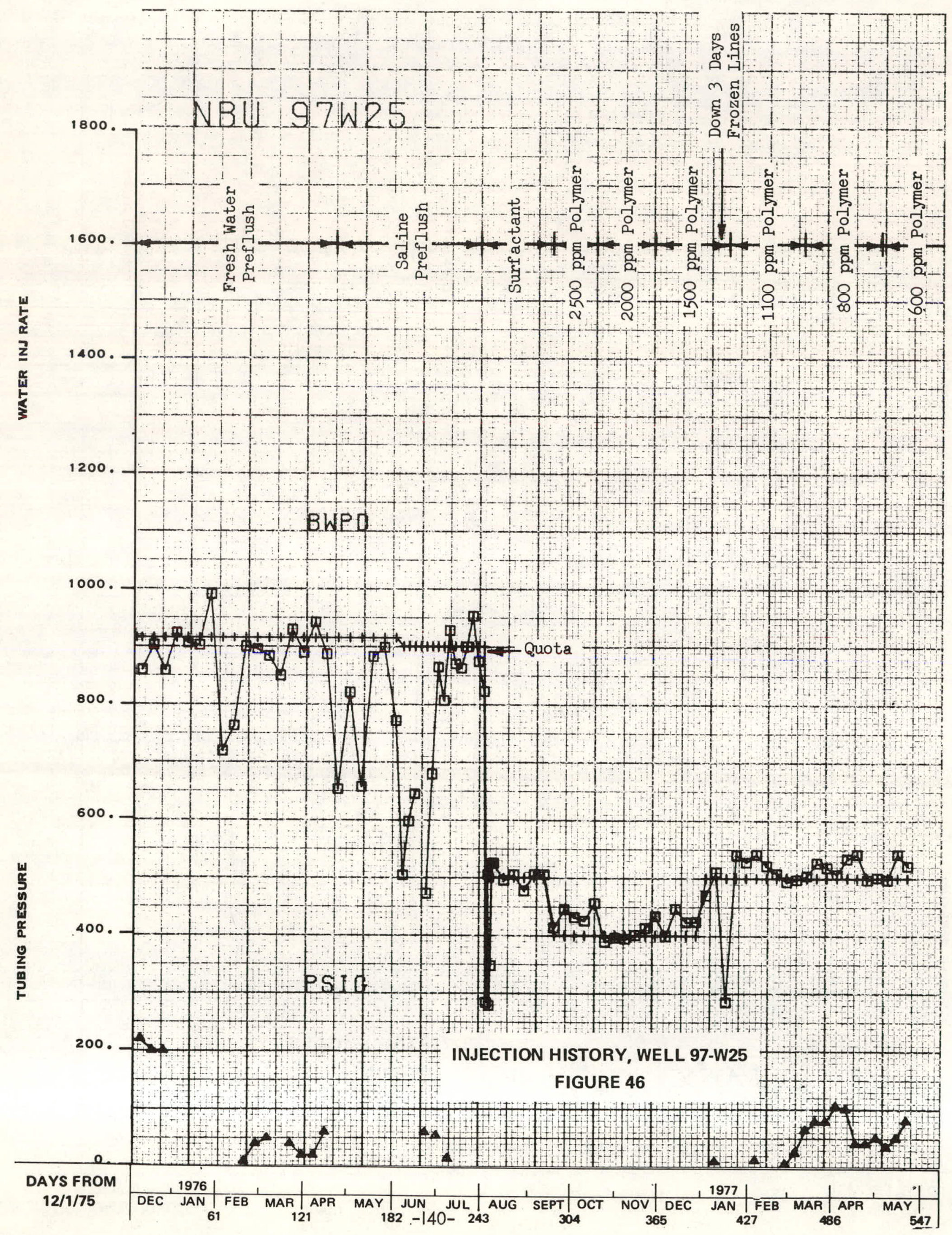




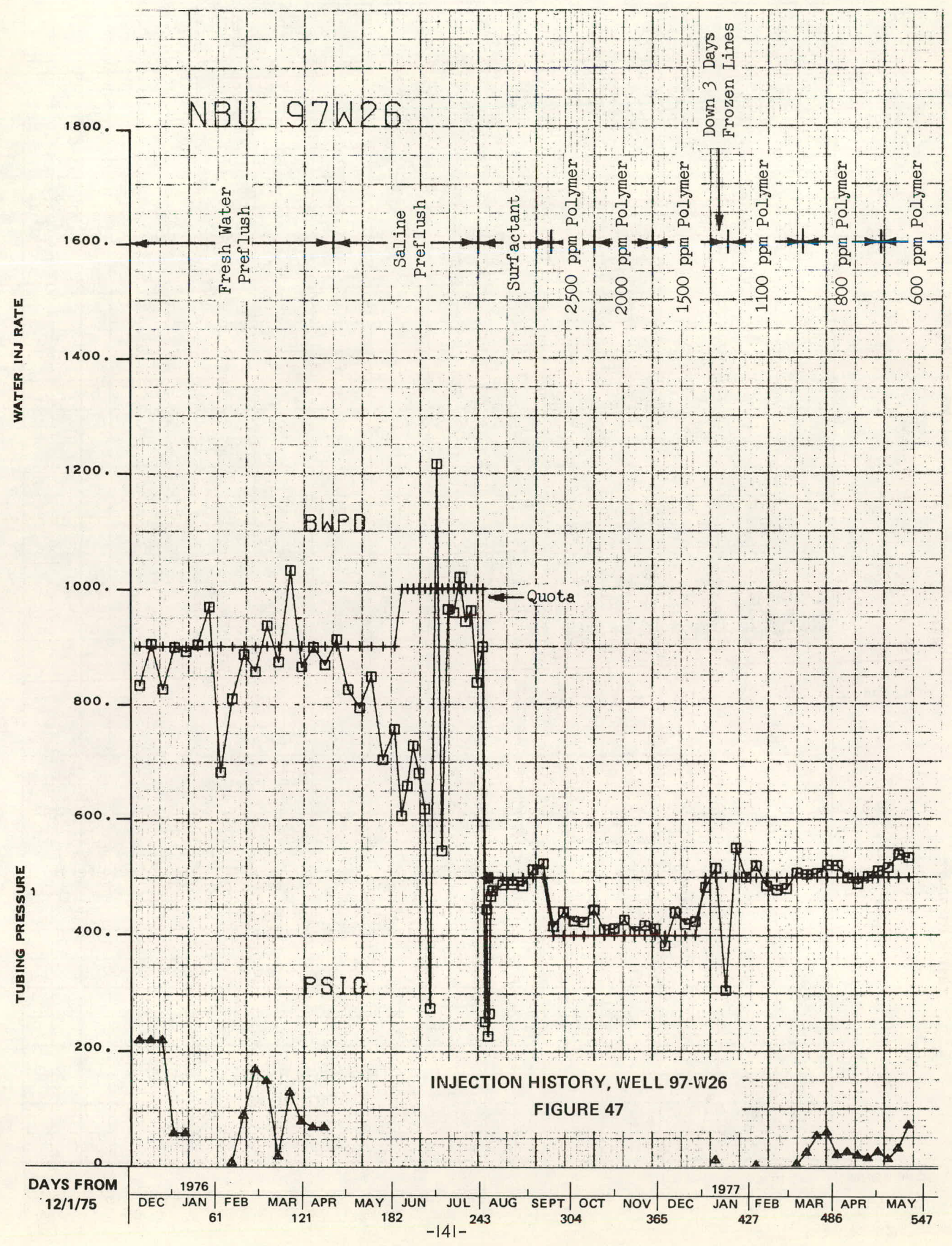




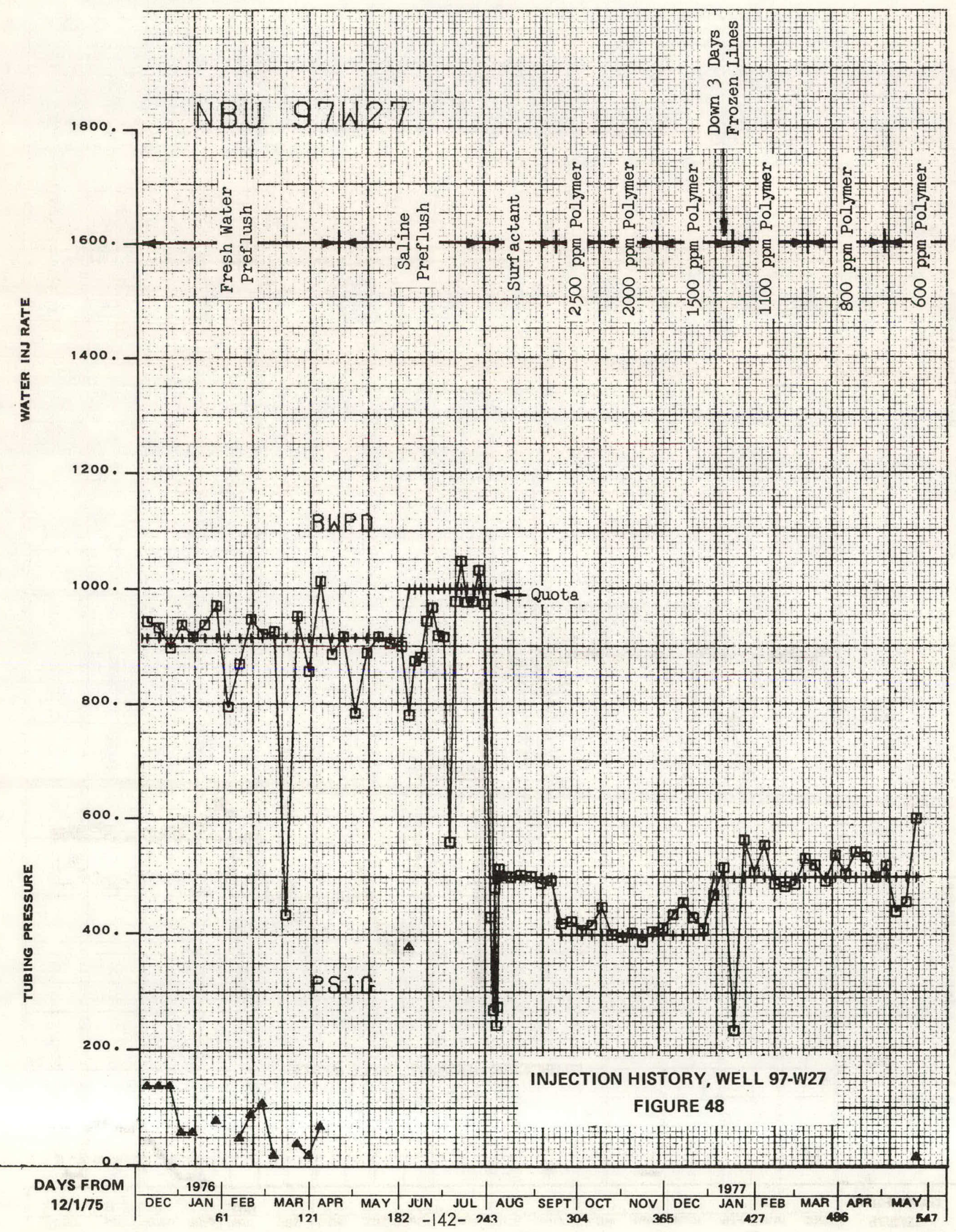




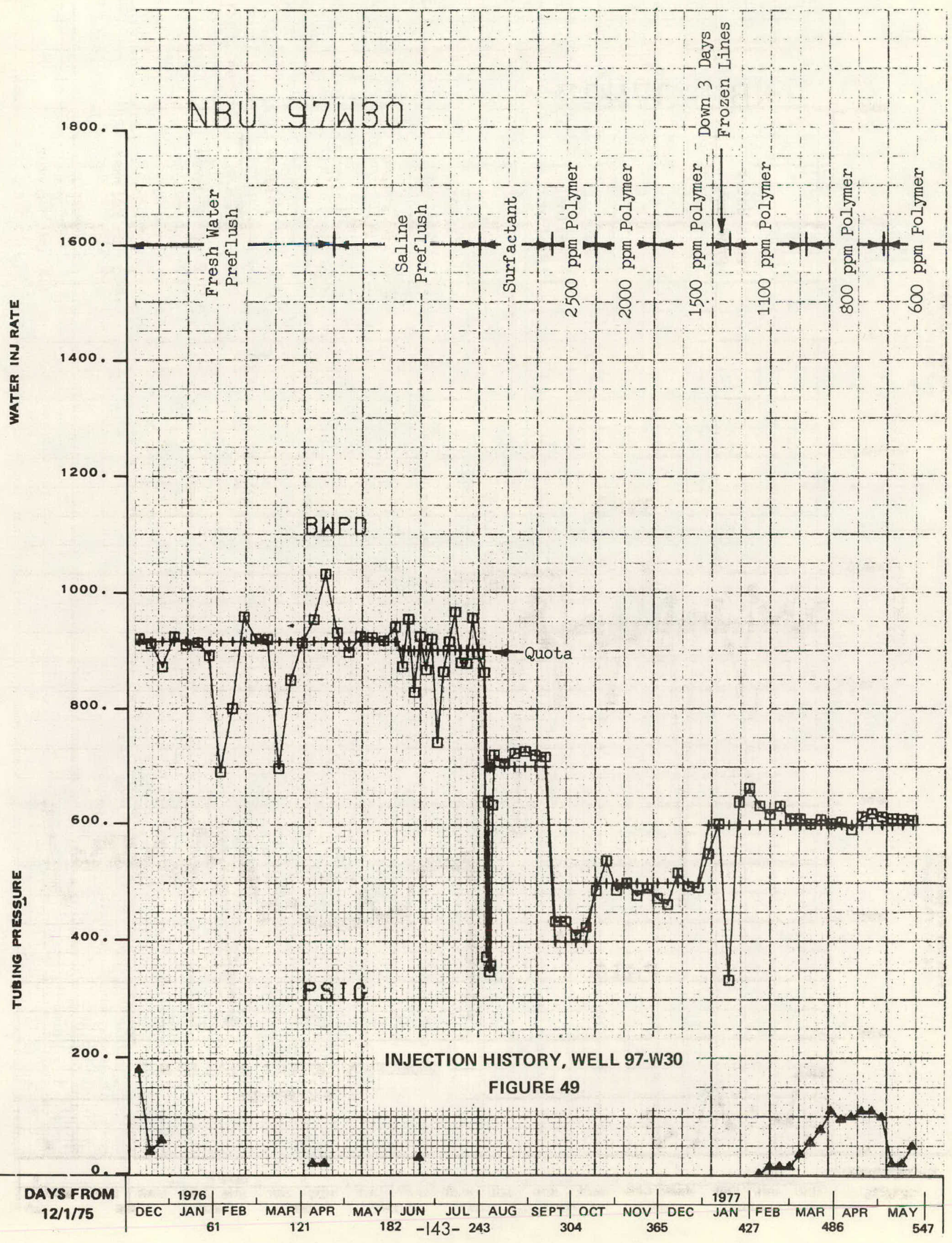




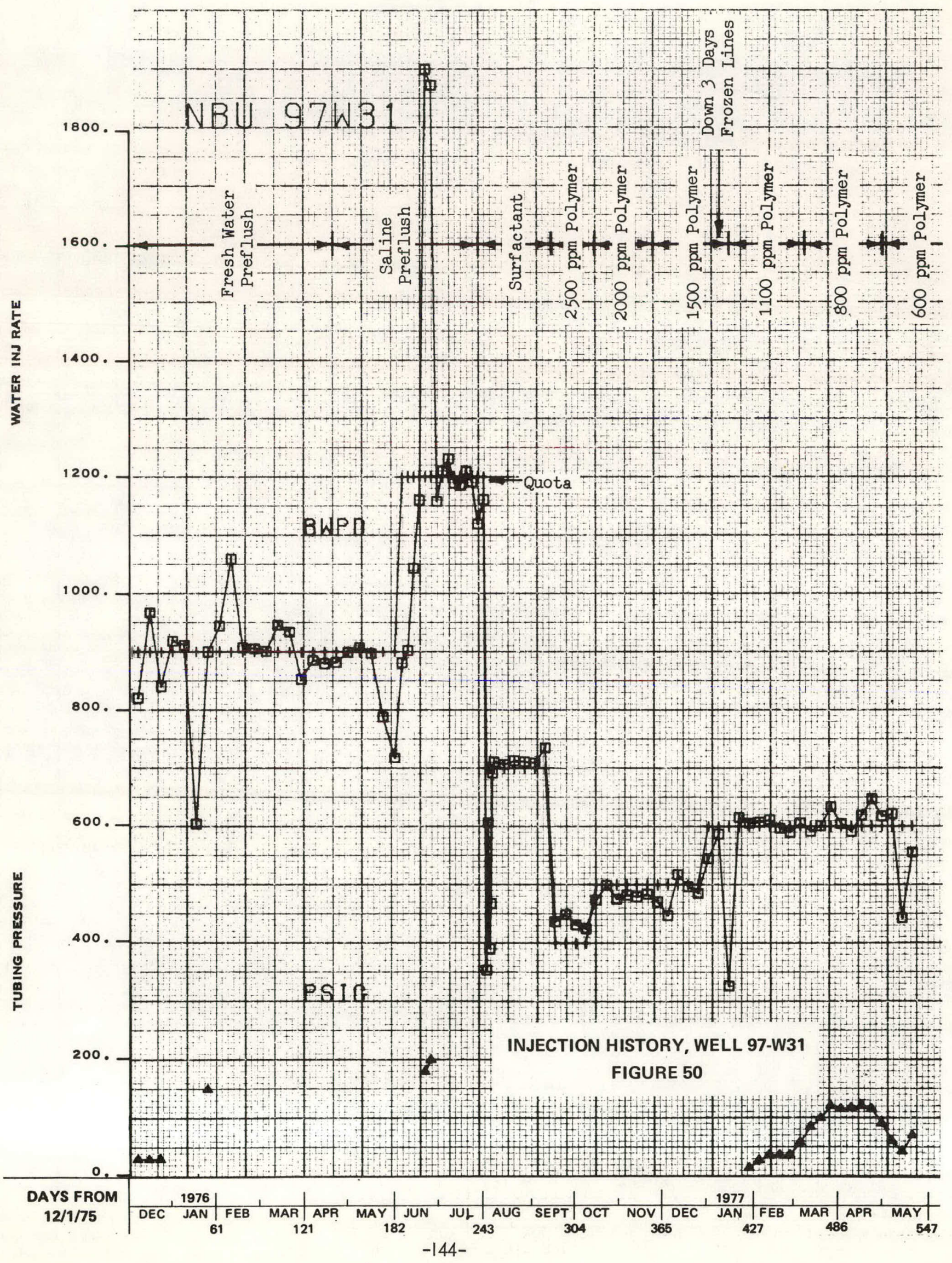




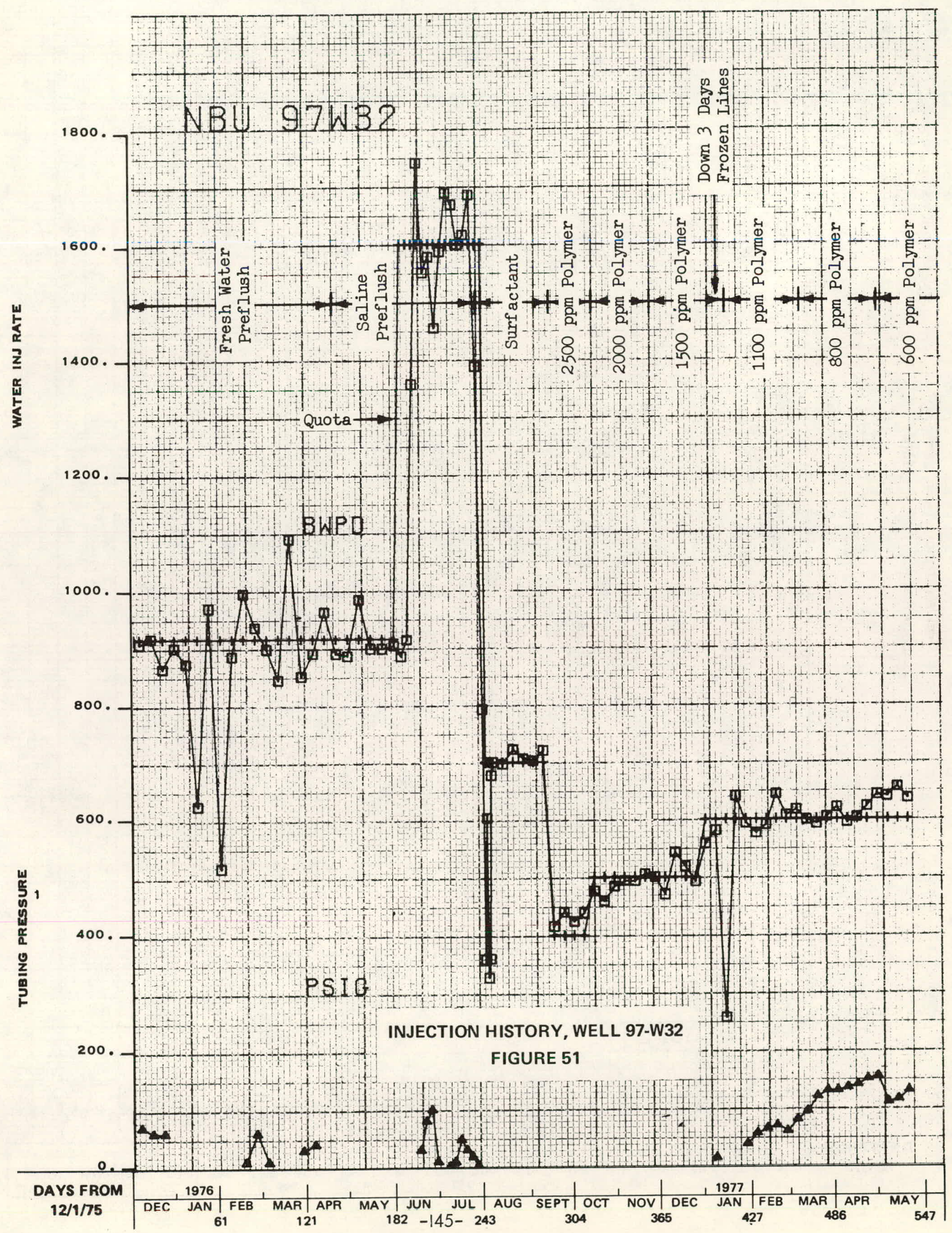



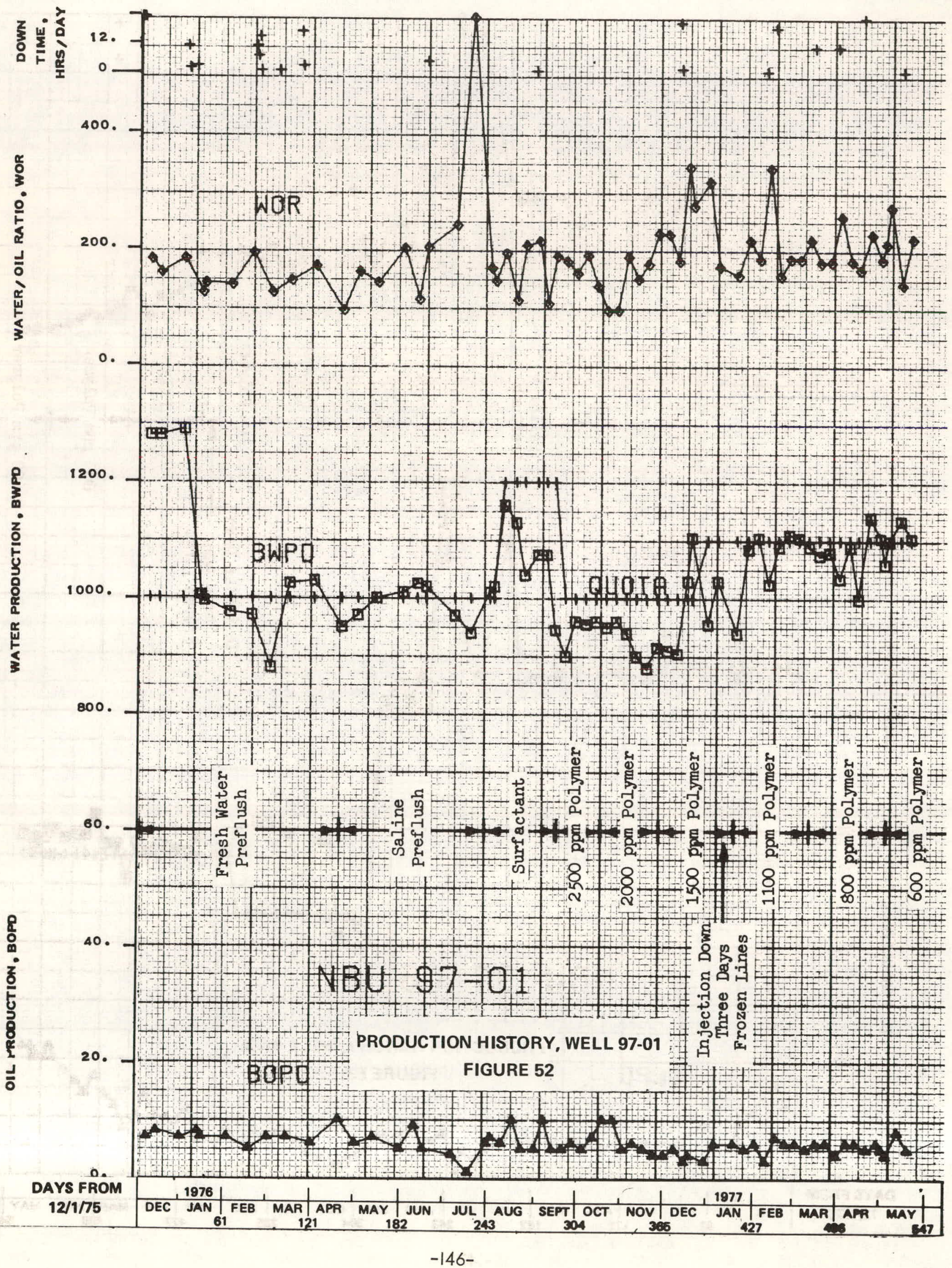


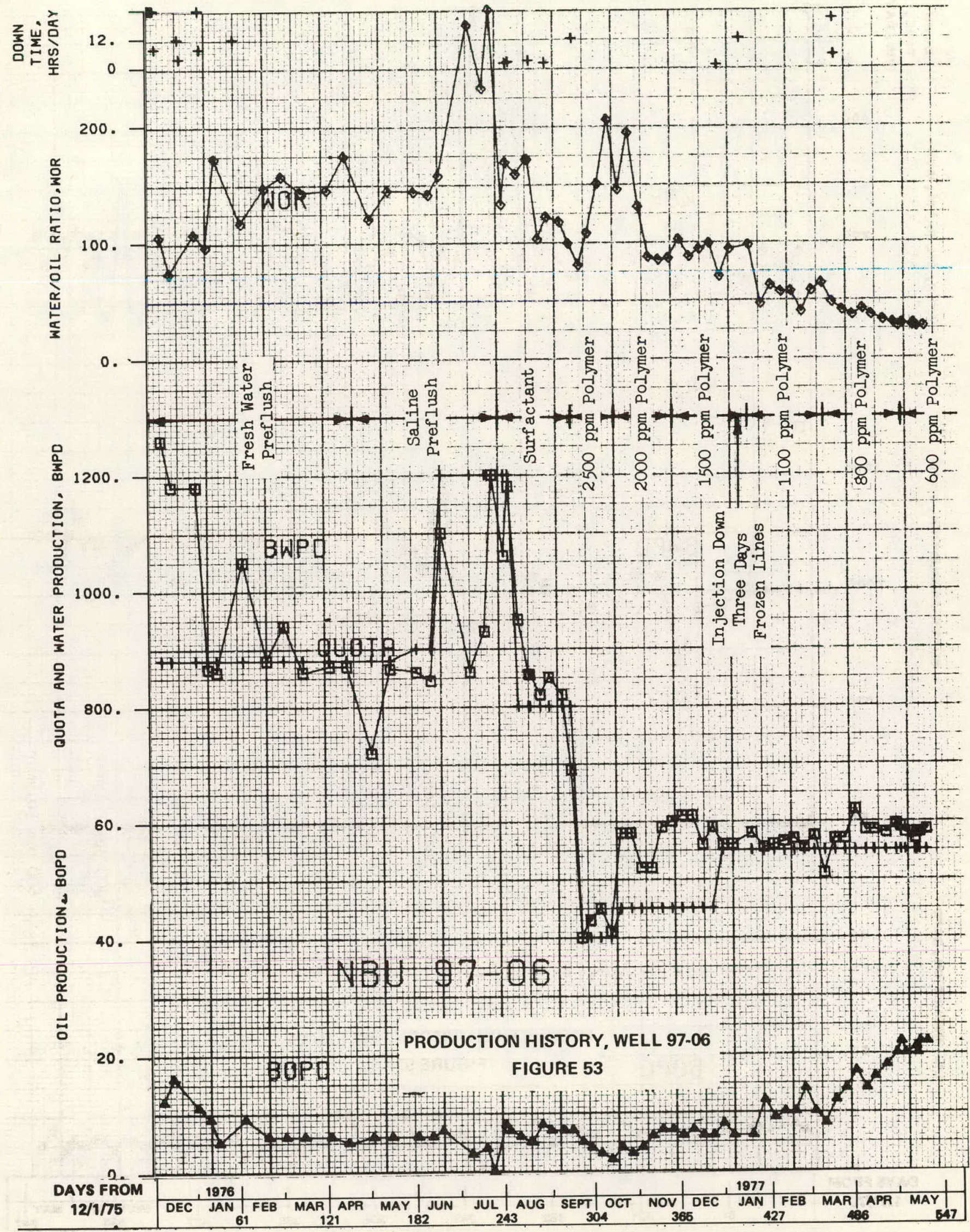




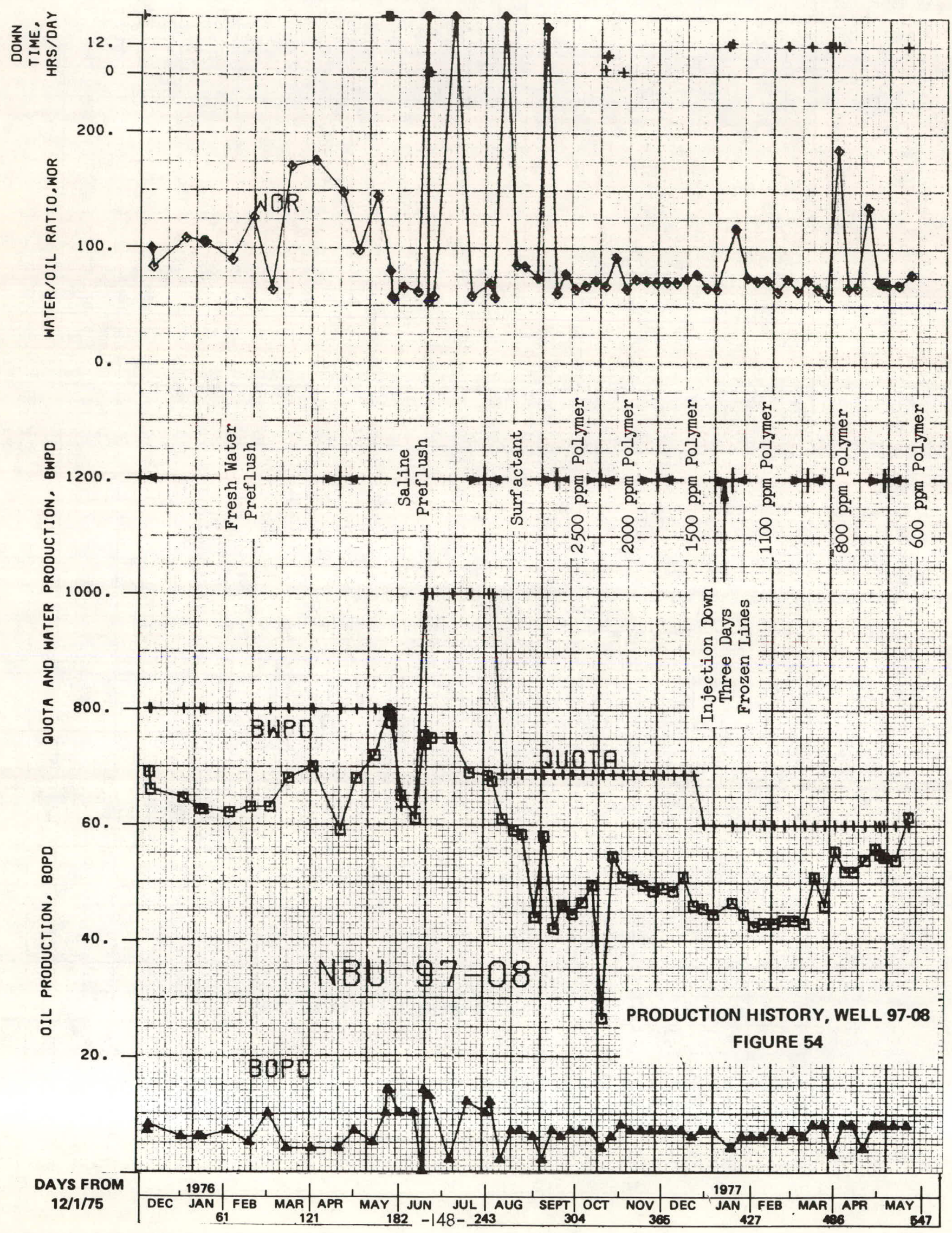




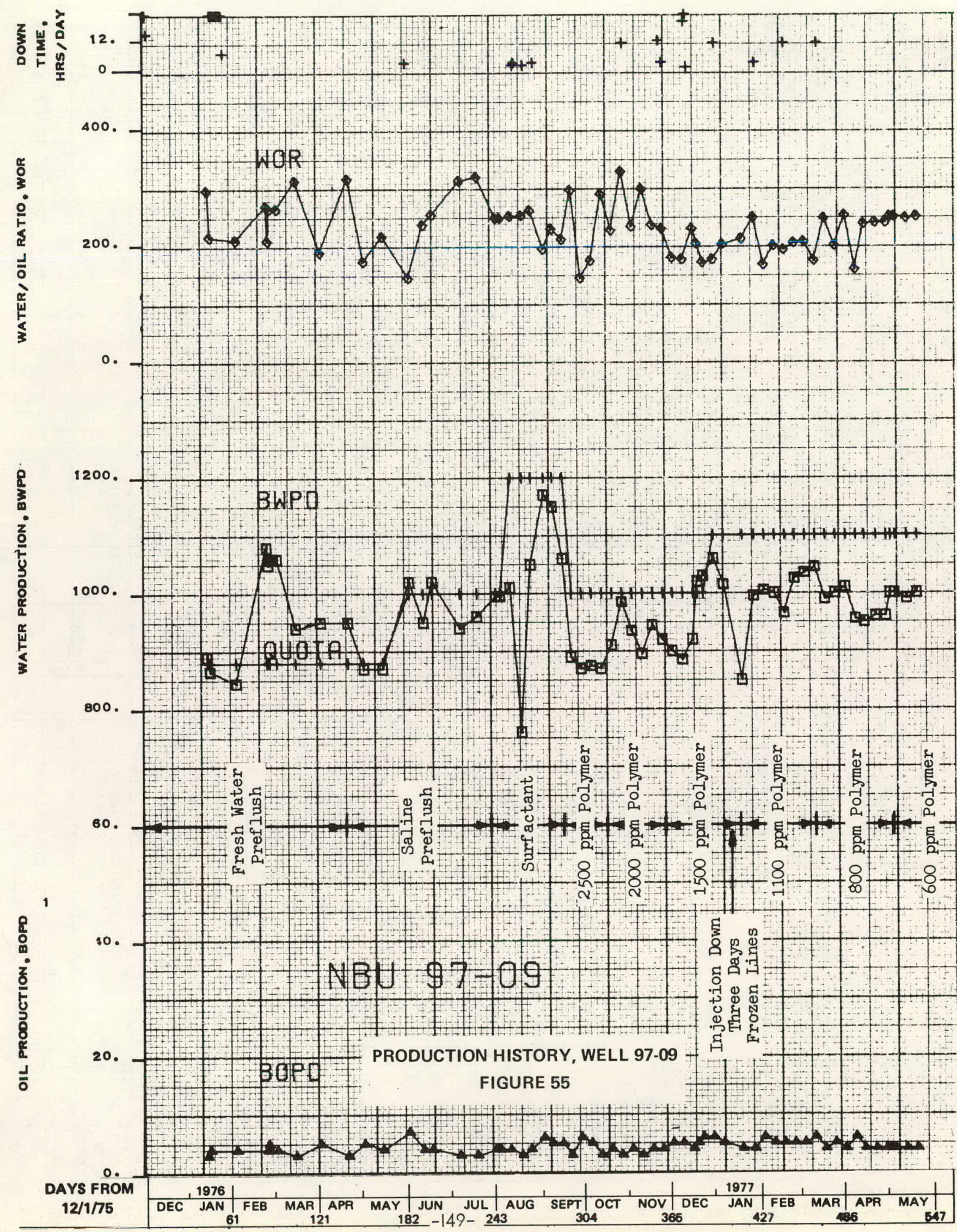




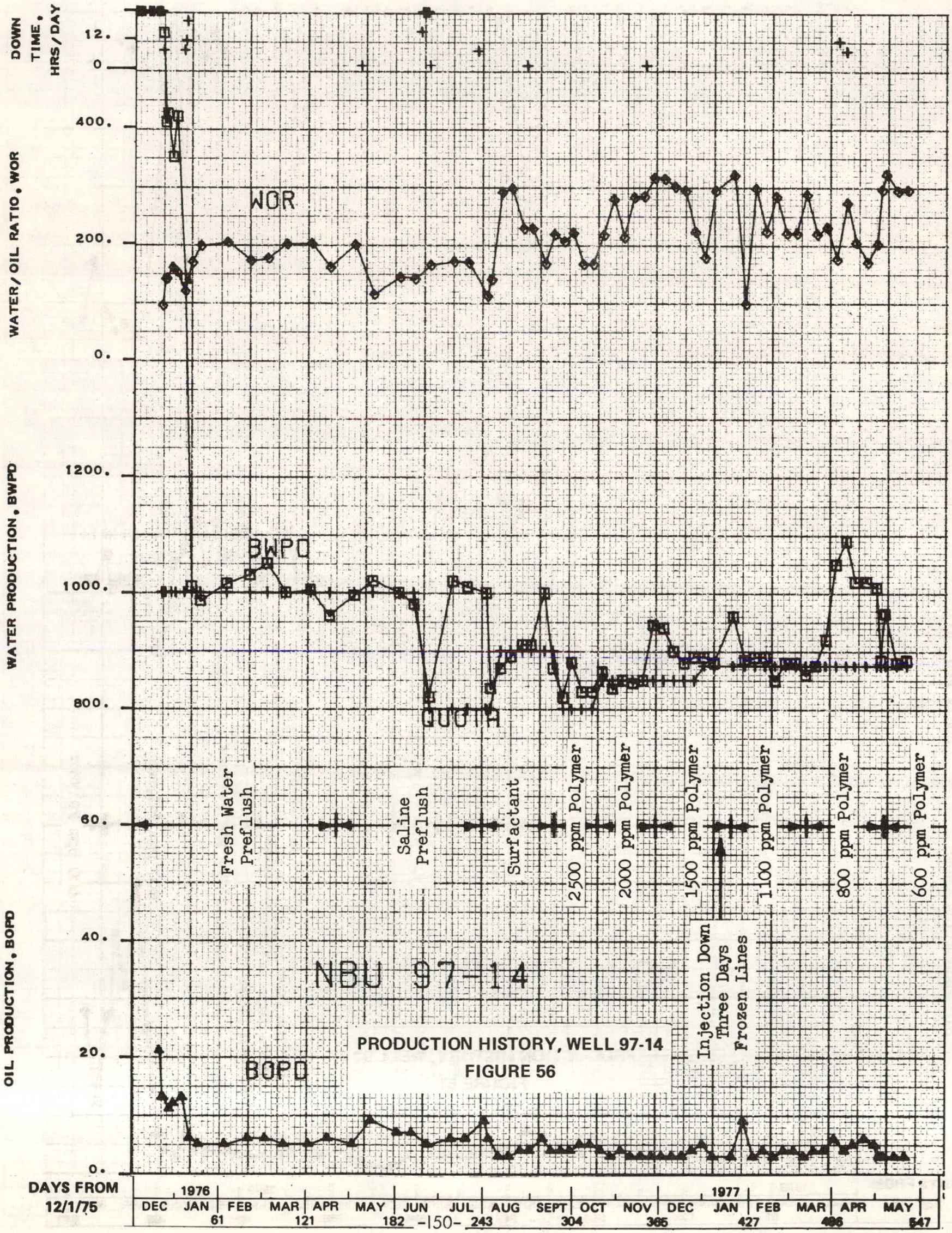




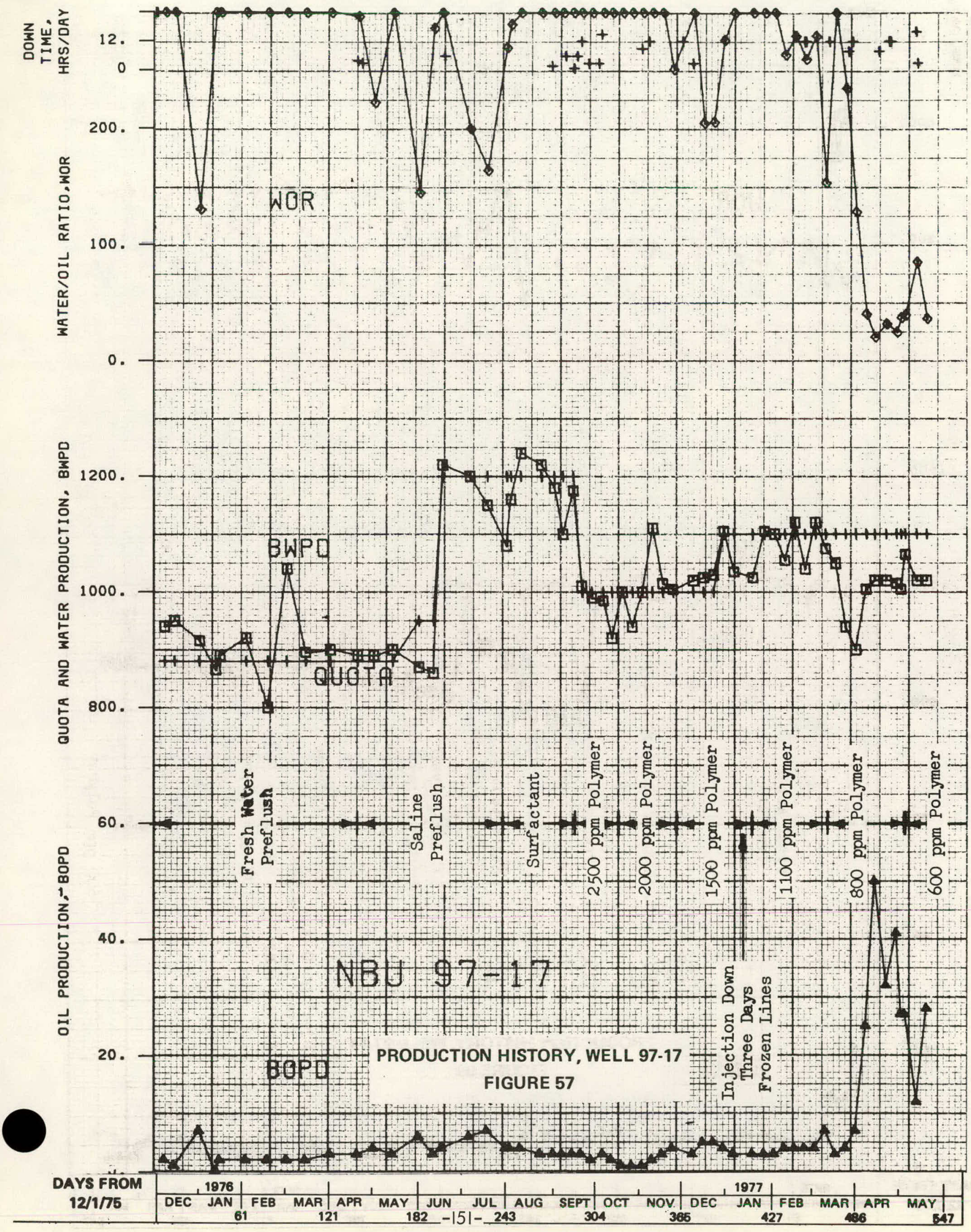




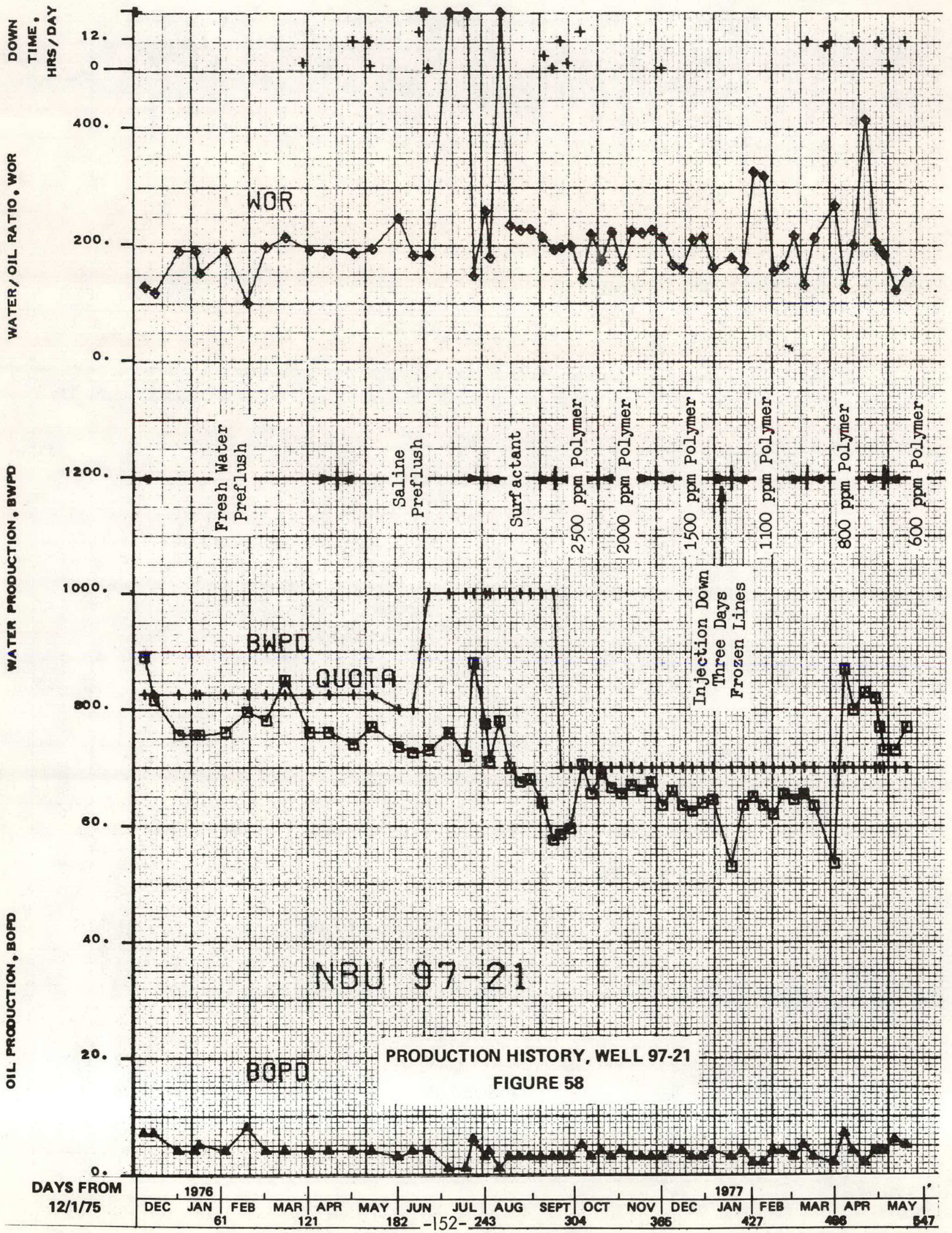




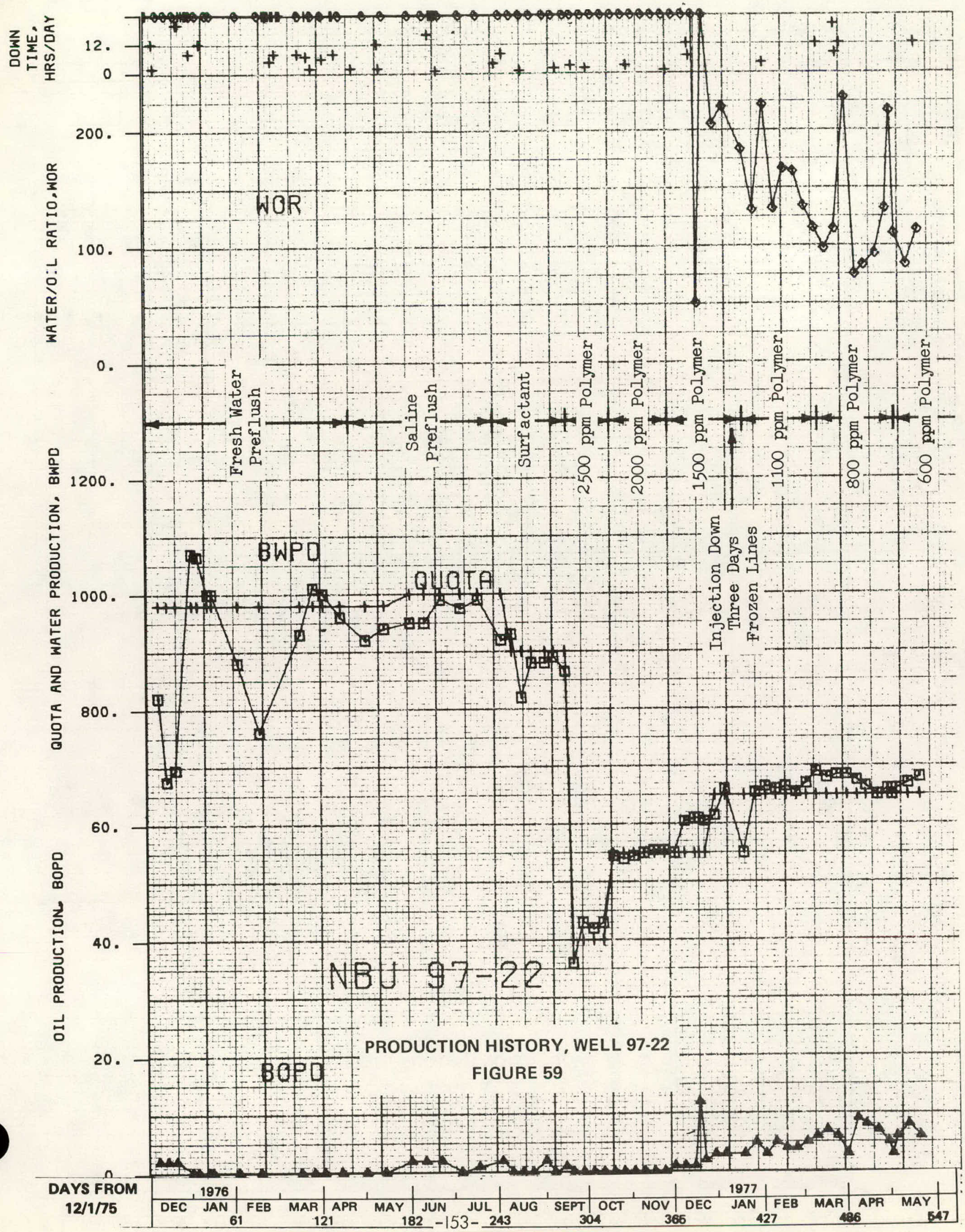




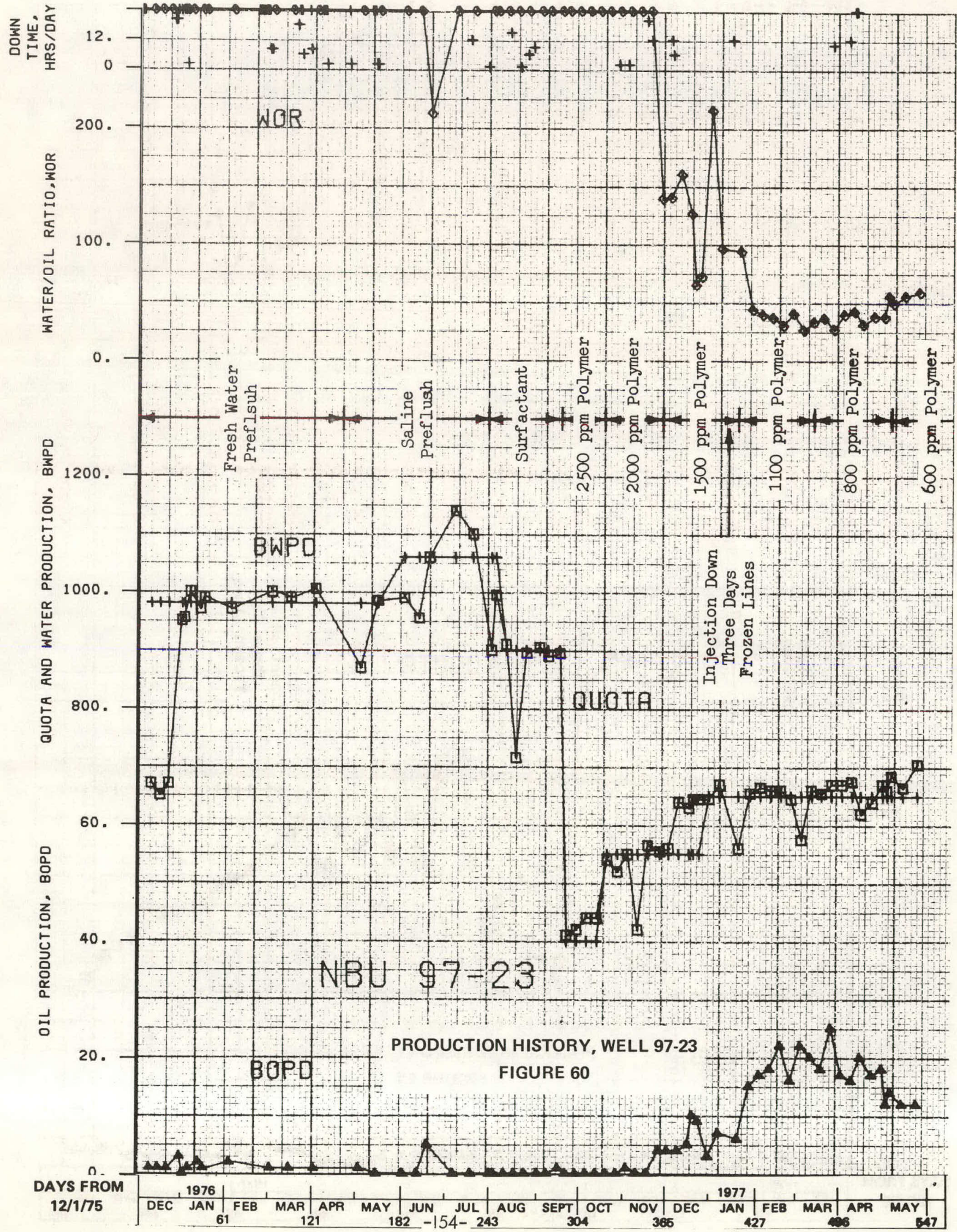




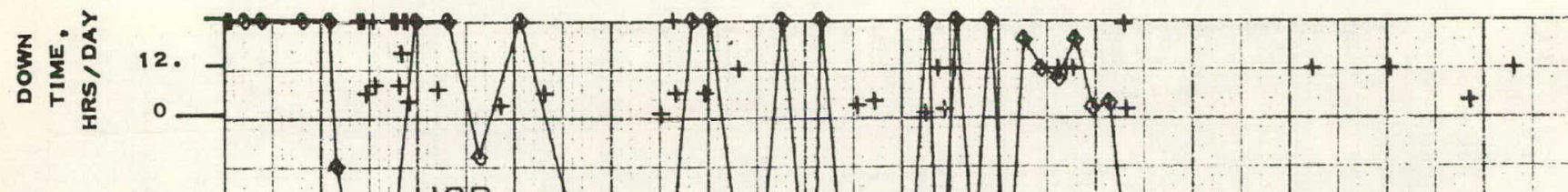
400. WOR क $+1+$

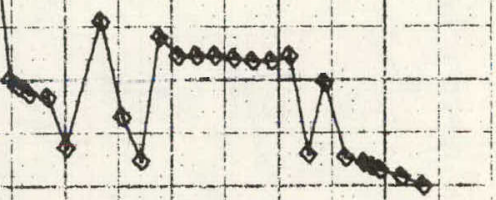

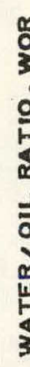

8

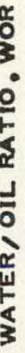

1200.

o.

$+$

1000.

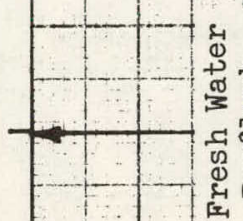

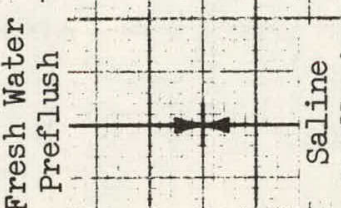

离

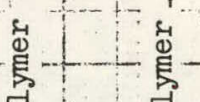

崩 $\quad$ ⿷匚

BWPC

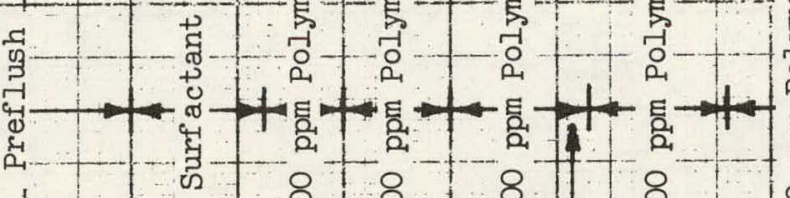

ने न

$\begin{array}{ccc}2 & 2 \\ 8 & 8 & 8 \\ 2 & 8 & -2 \\ 2 & -1\end{array}$

18

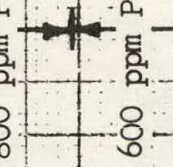

8

800.

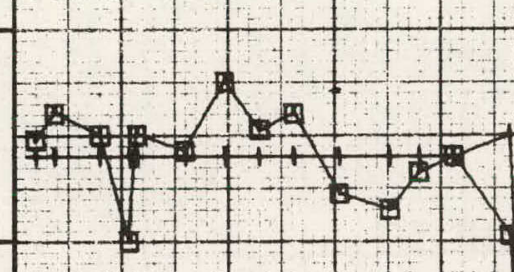

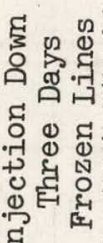

Qutge

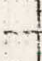

$1+1+1 \quad+$

$+1+1+1+1+1+1+1+$

60.

19
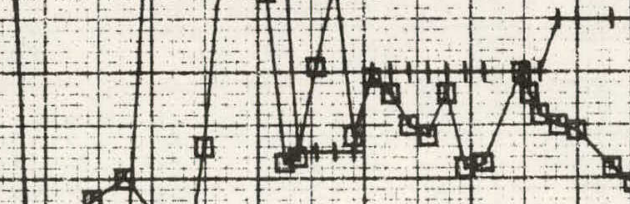

$-4$

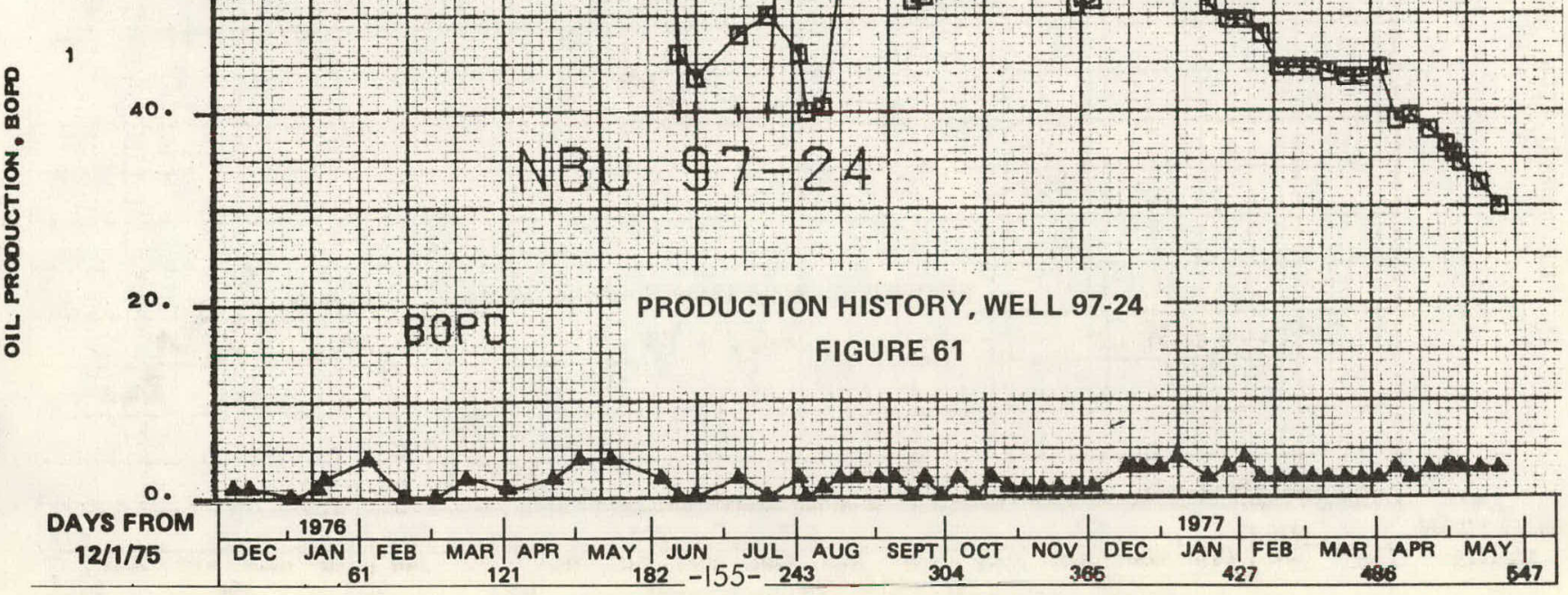




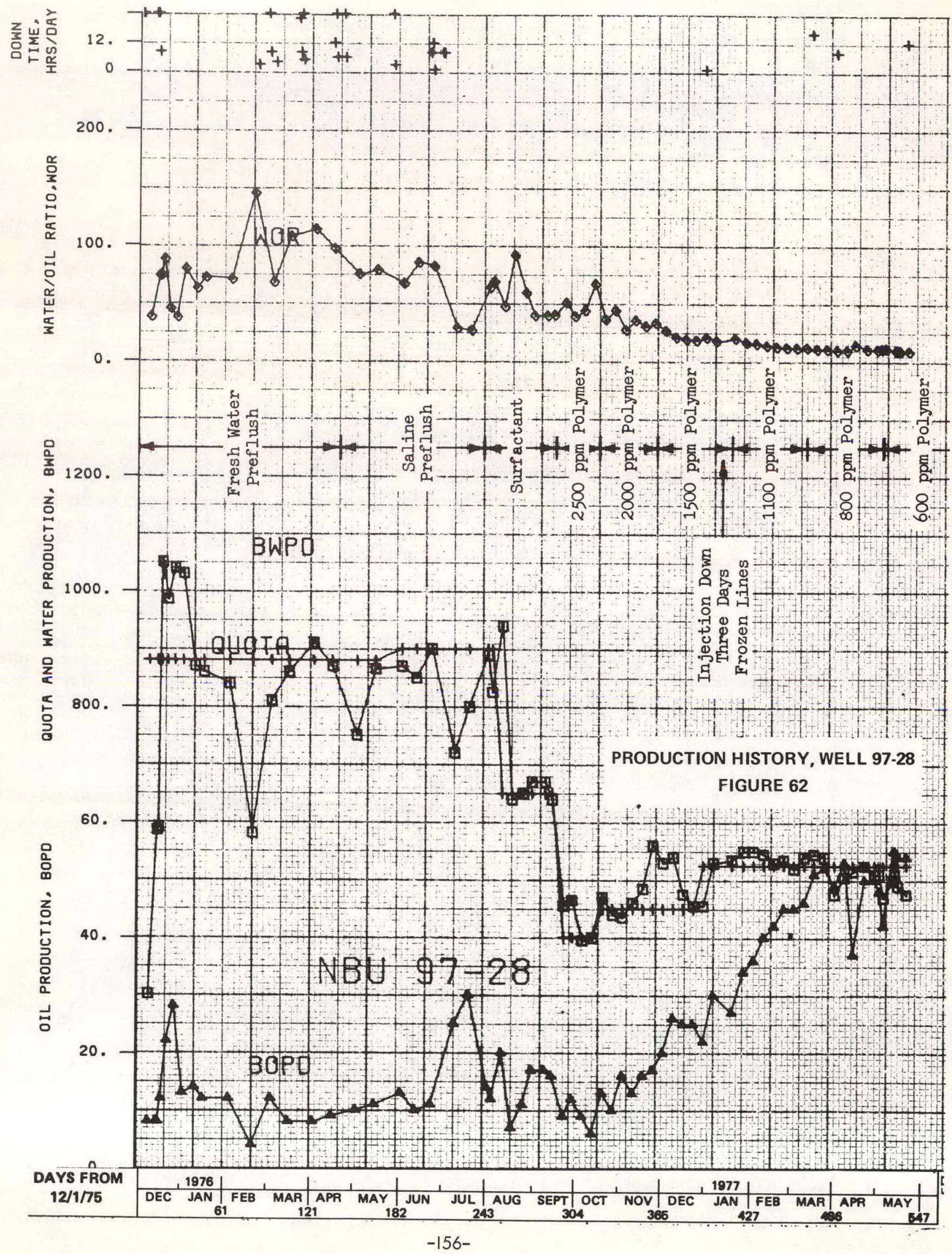




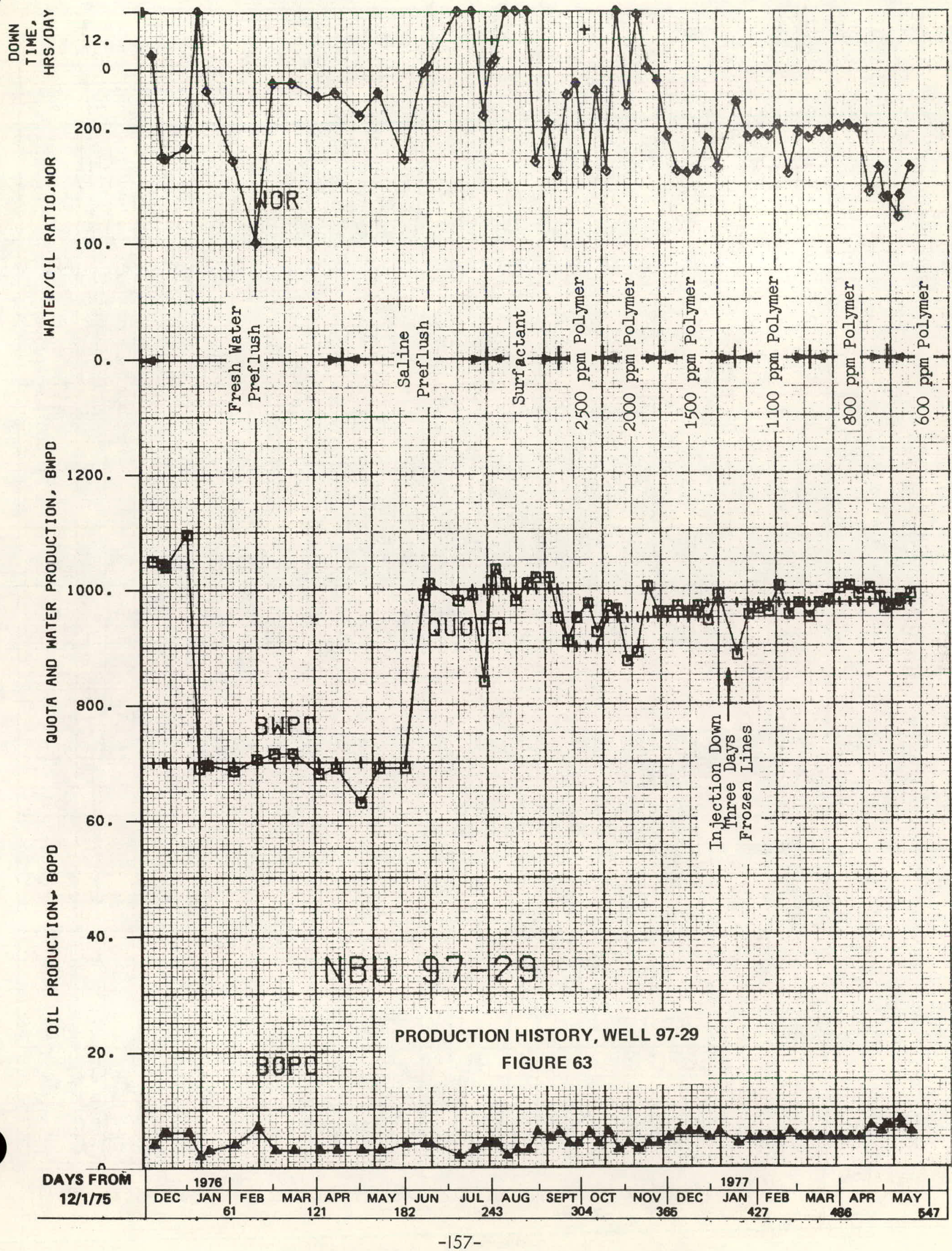




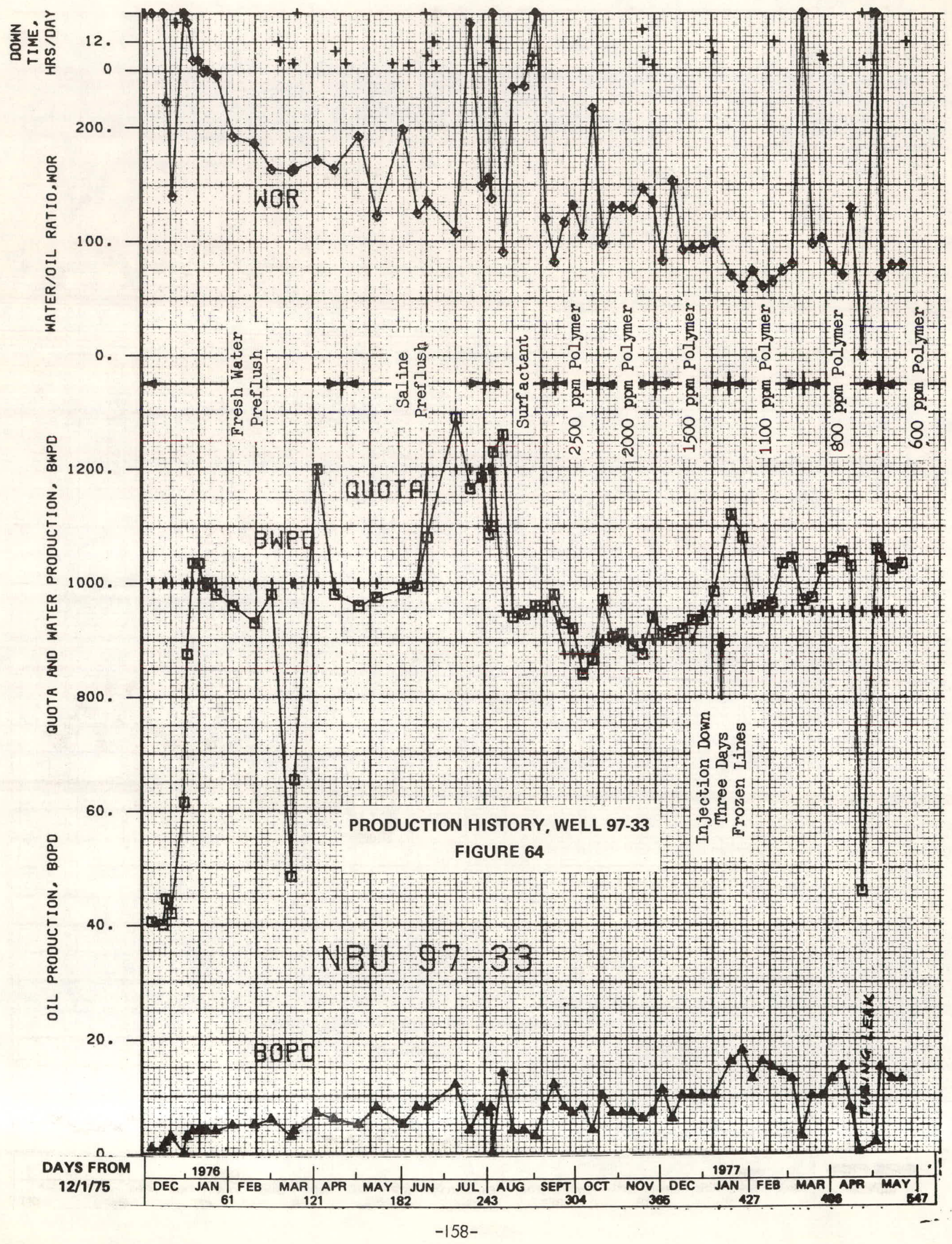




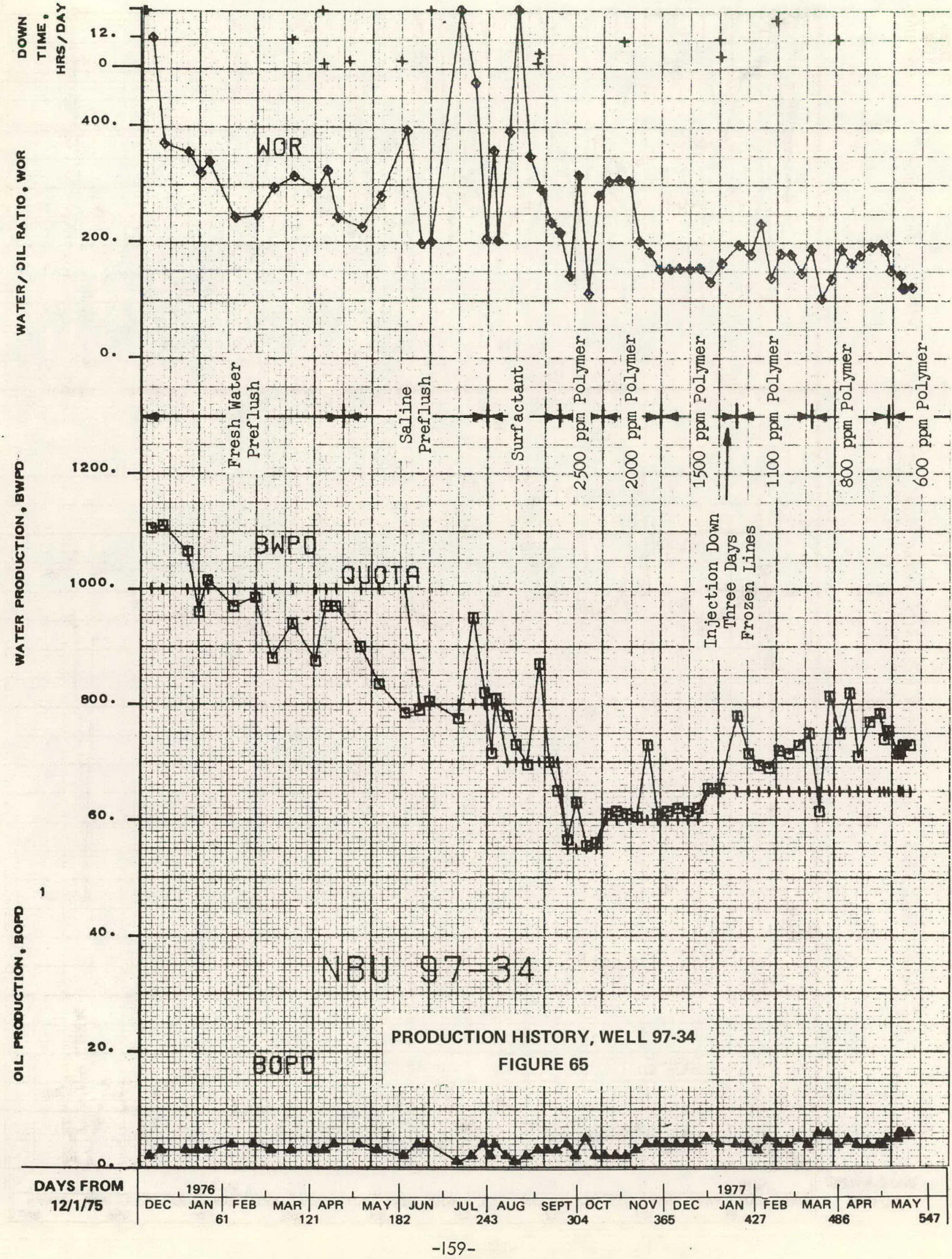




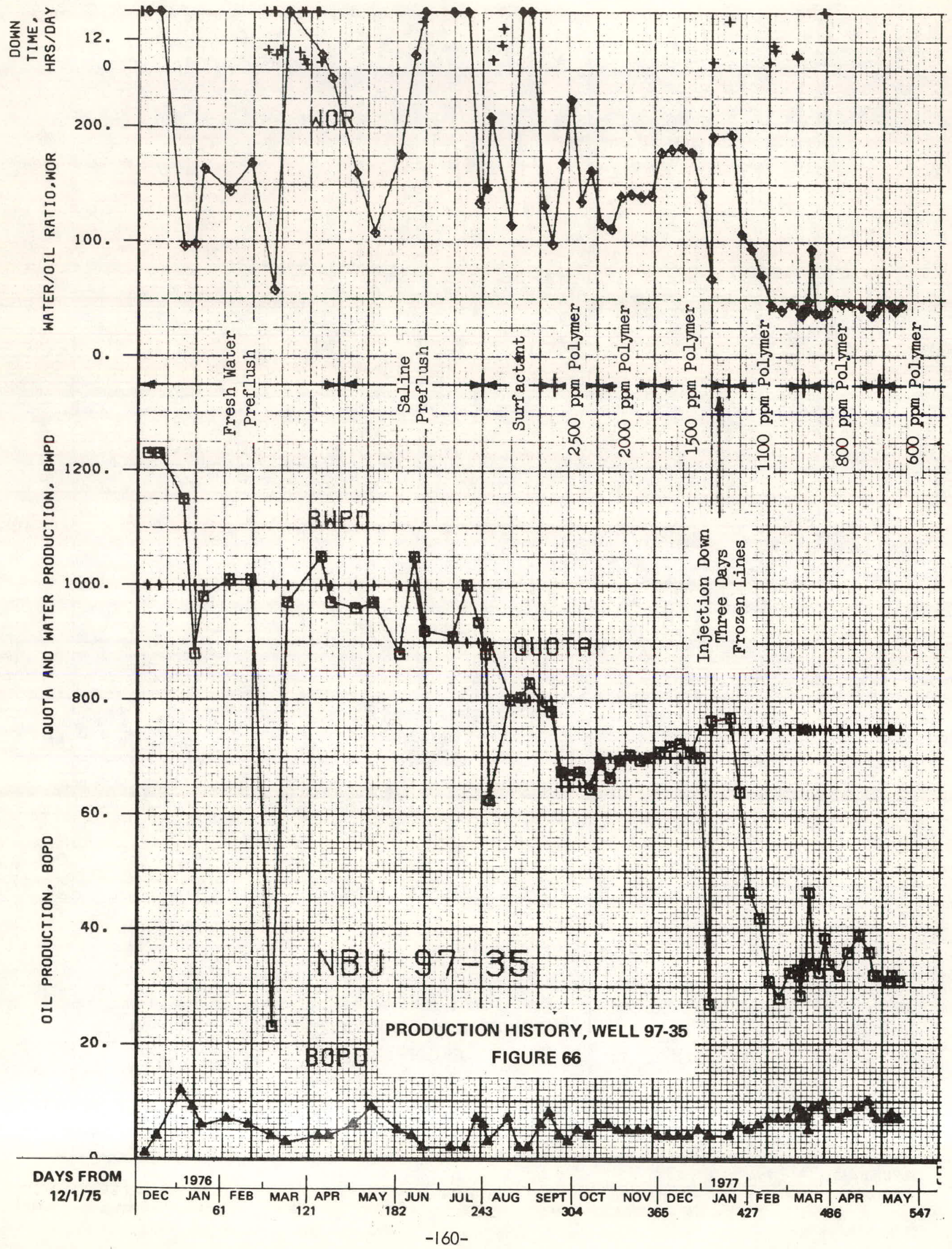




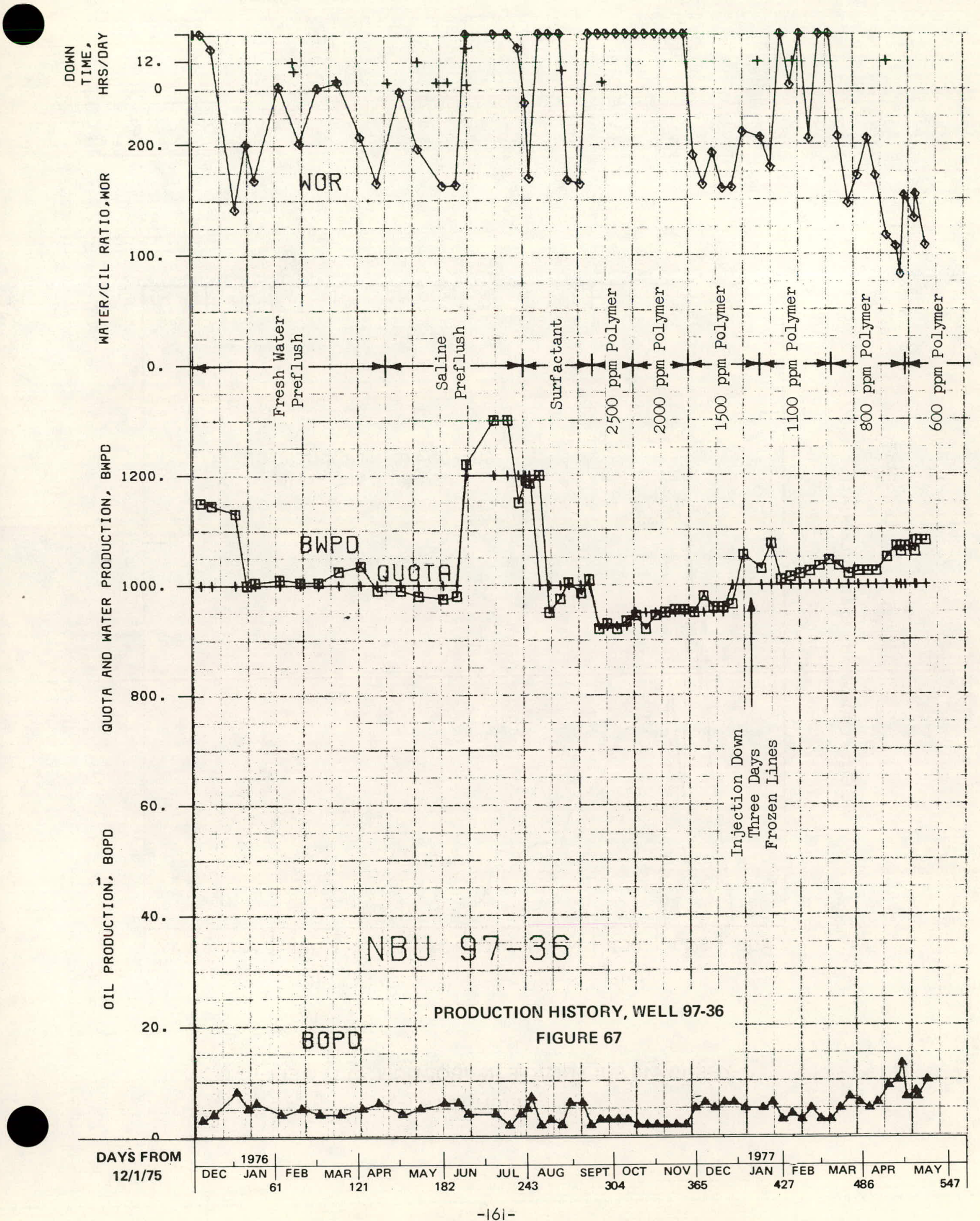




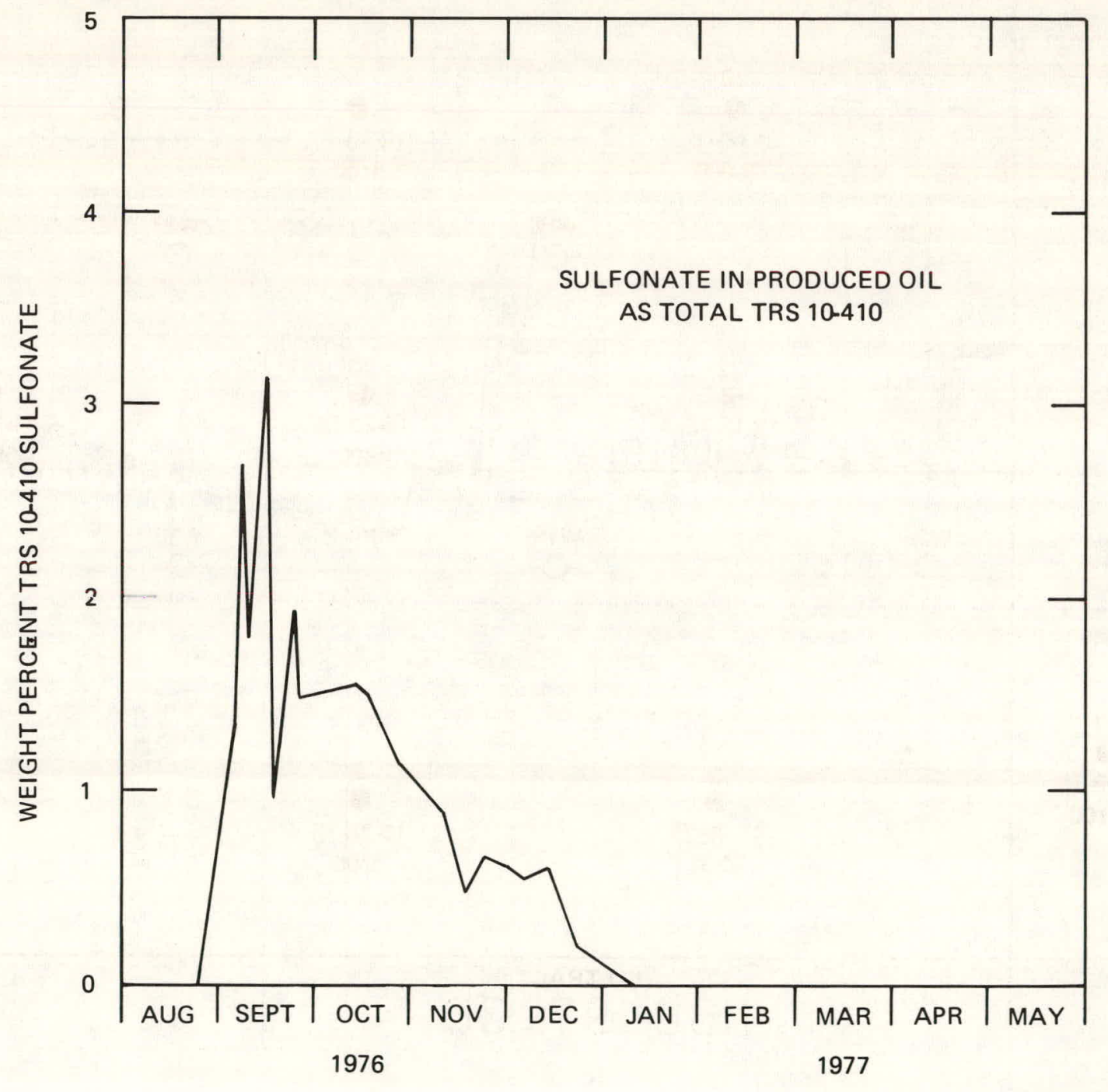

TRS 10-410 SULFONATE IN PRODUCED OIL, WELL 97-28 FIGURE 68 


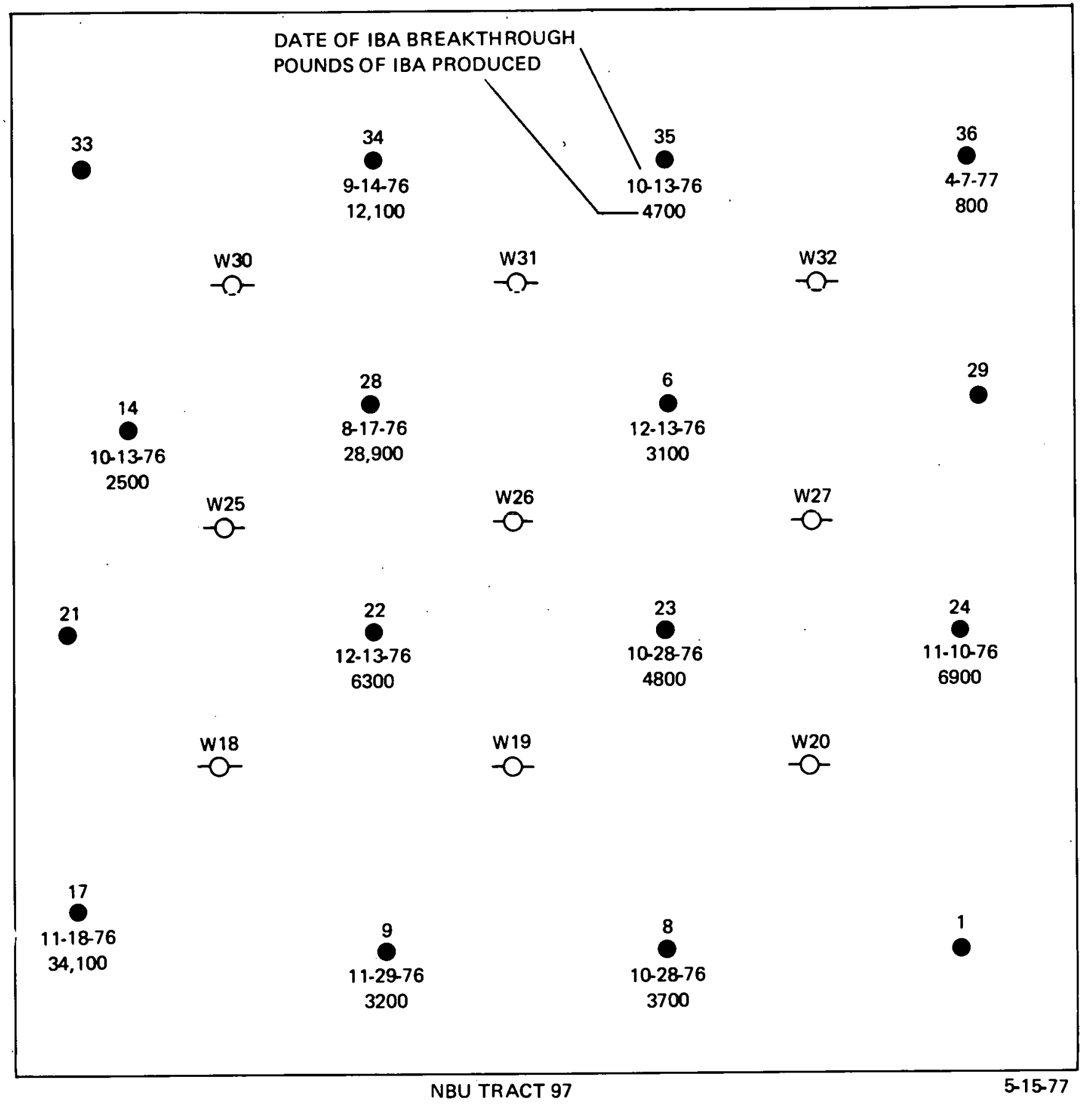

ISOBUTYL ALCOHOL AT PRODUCING WELLS

FIGURE 69 


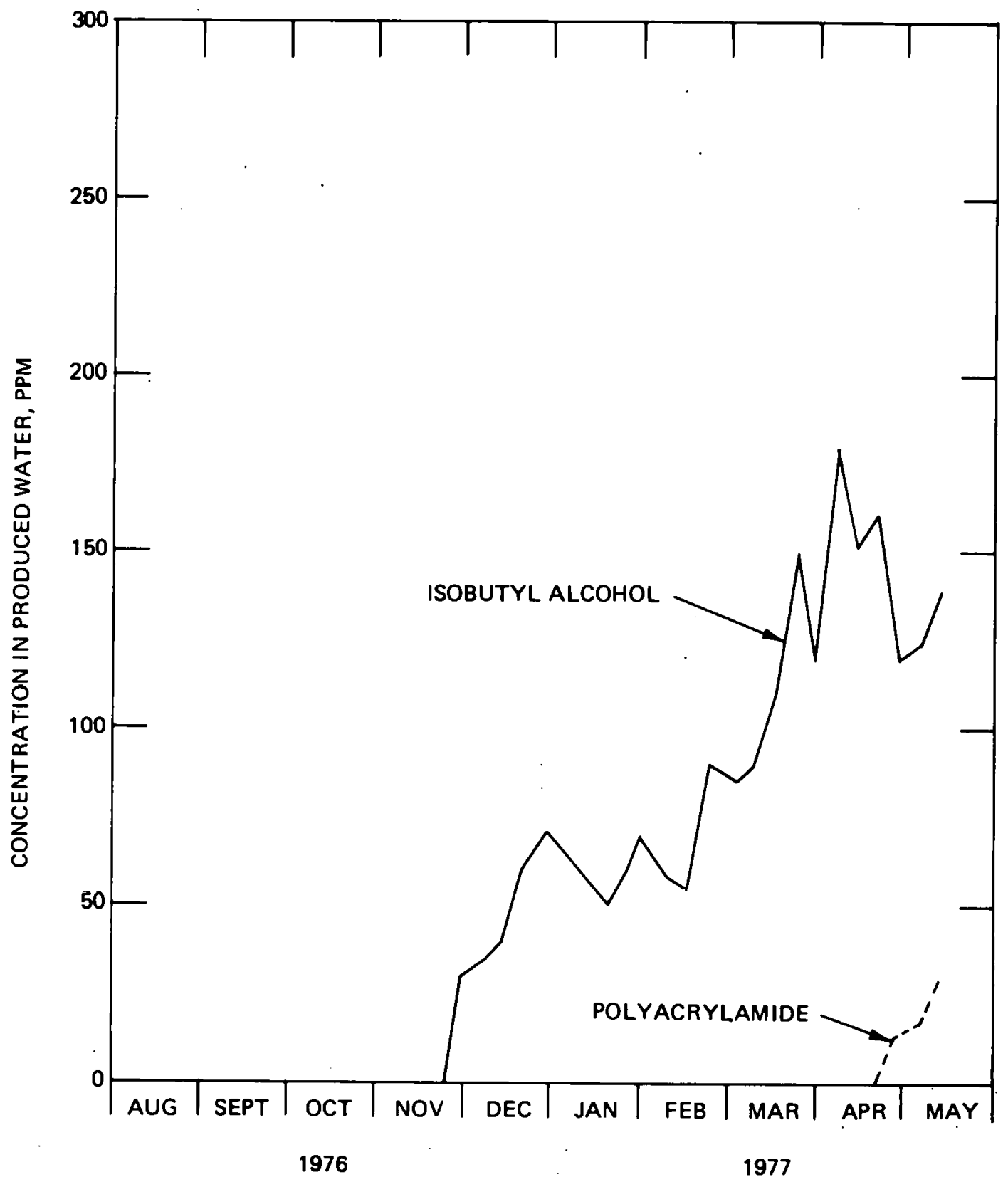

TREND OF CHEMICAL CONTENT OF PRODUCED WATER, WELL 97-06

: FIGURE 70 


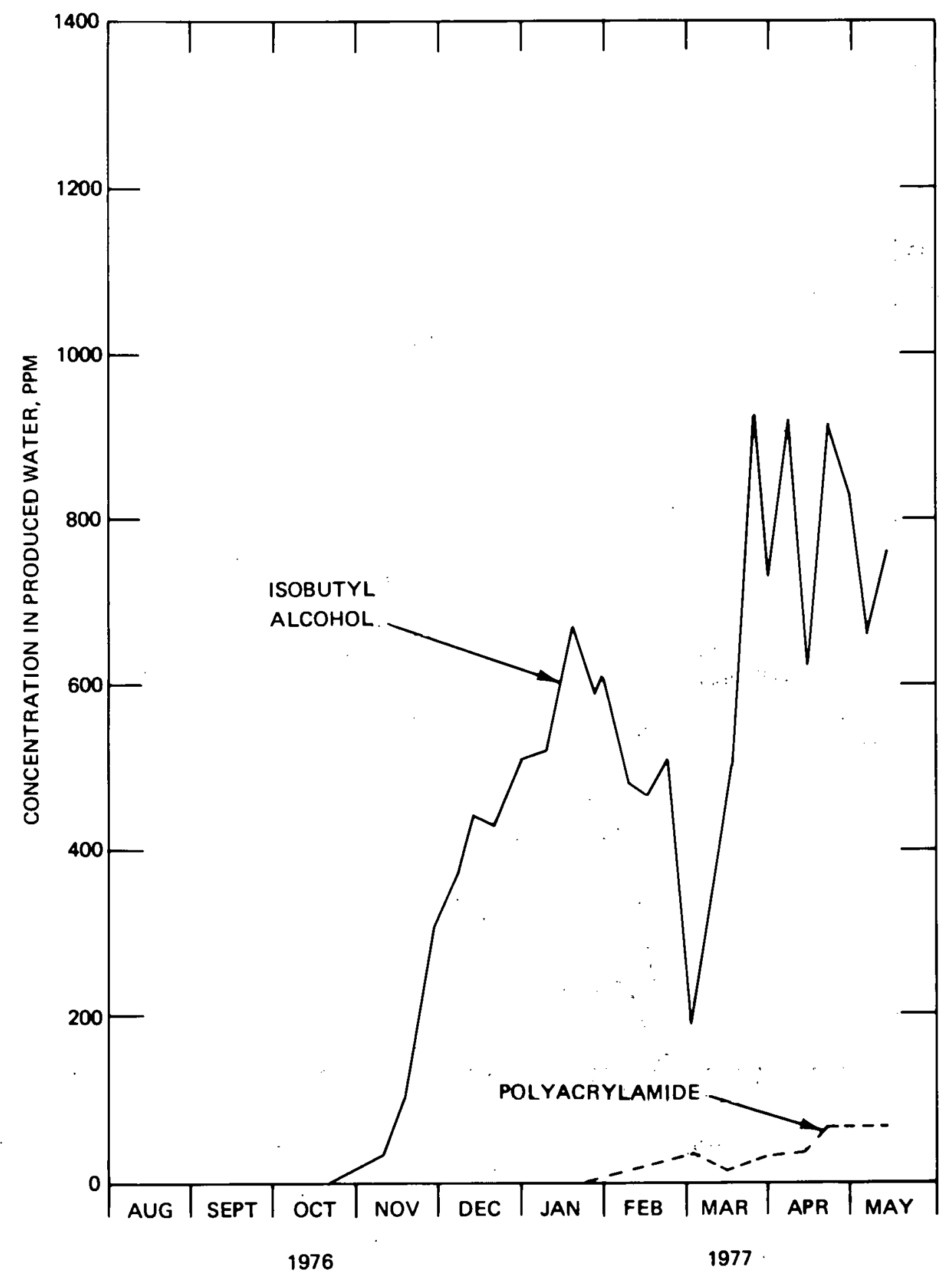

TREND OF CHEMICAL CONTENT OF PRODUCED WATER, WELL 97-17 FIGURE 71 


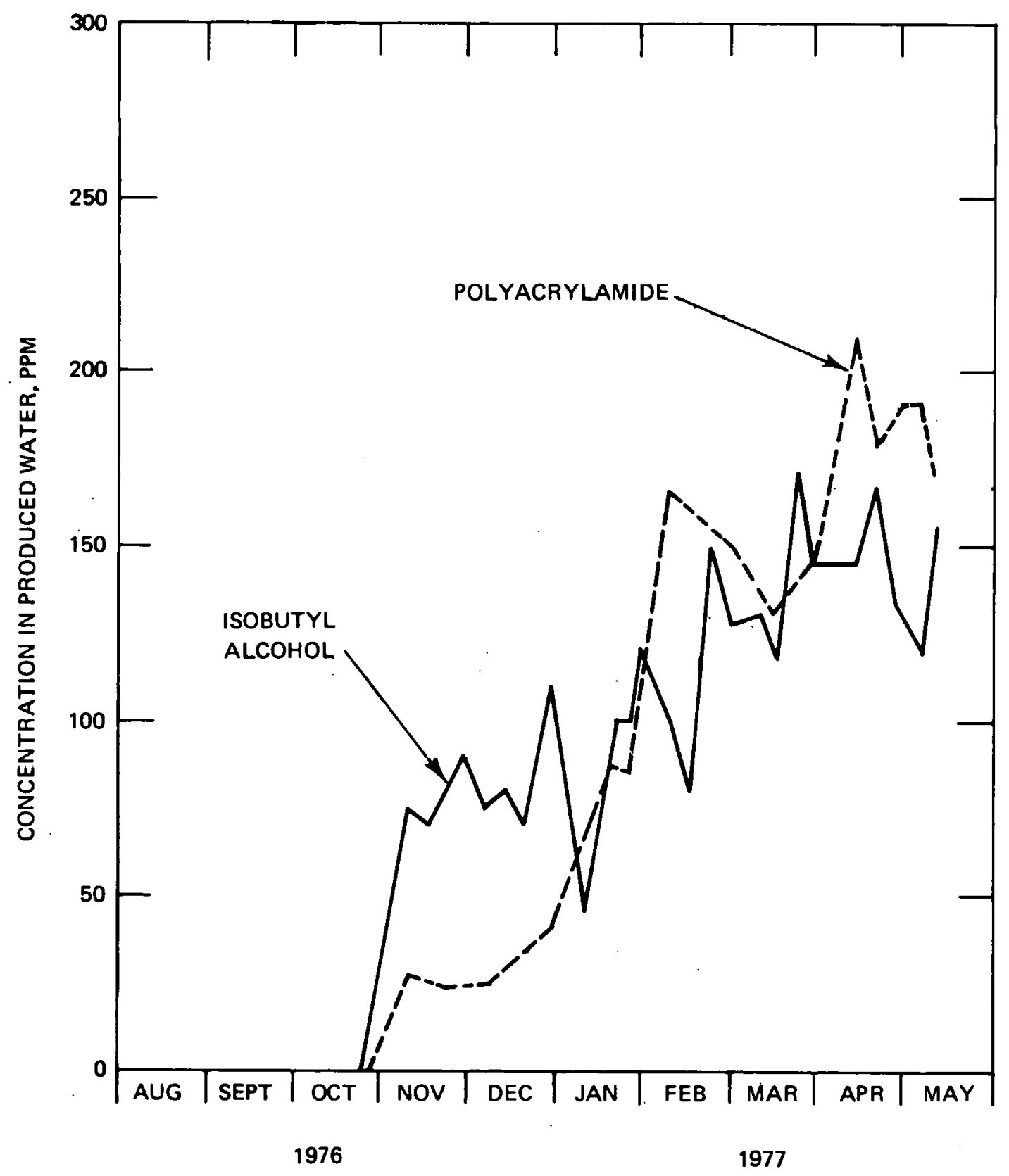

TREND OF CHEMICAL CONTENT OF PRODUCED WATER, WELL 97-23 FIGURE 72 


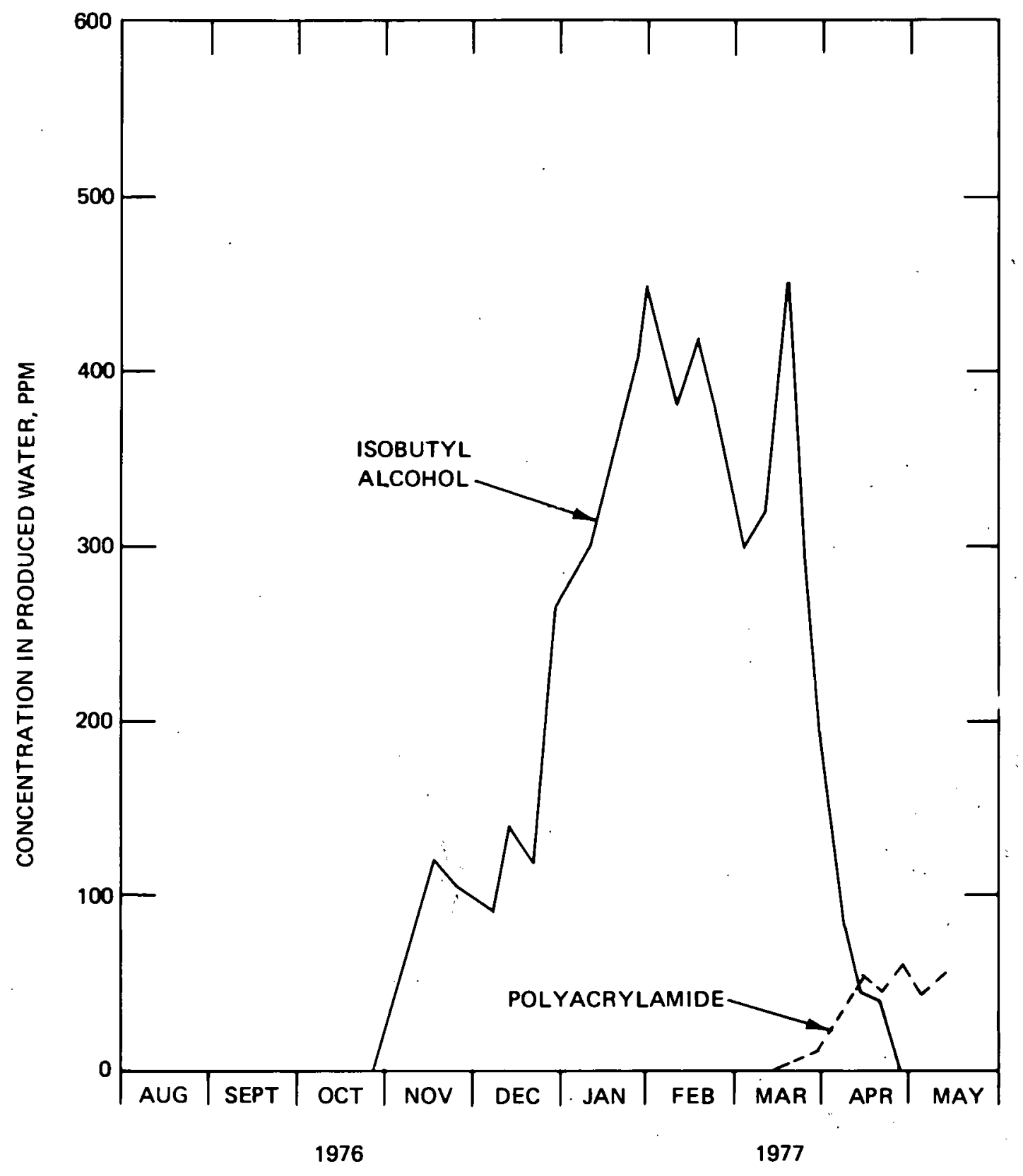

TREND OF CHEMICAL CONTENT OF PRODUCED WATER, WELL 97-24 FIGURE 73 


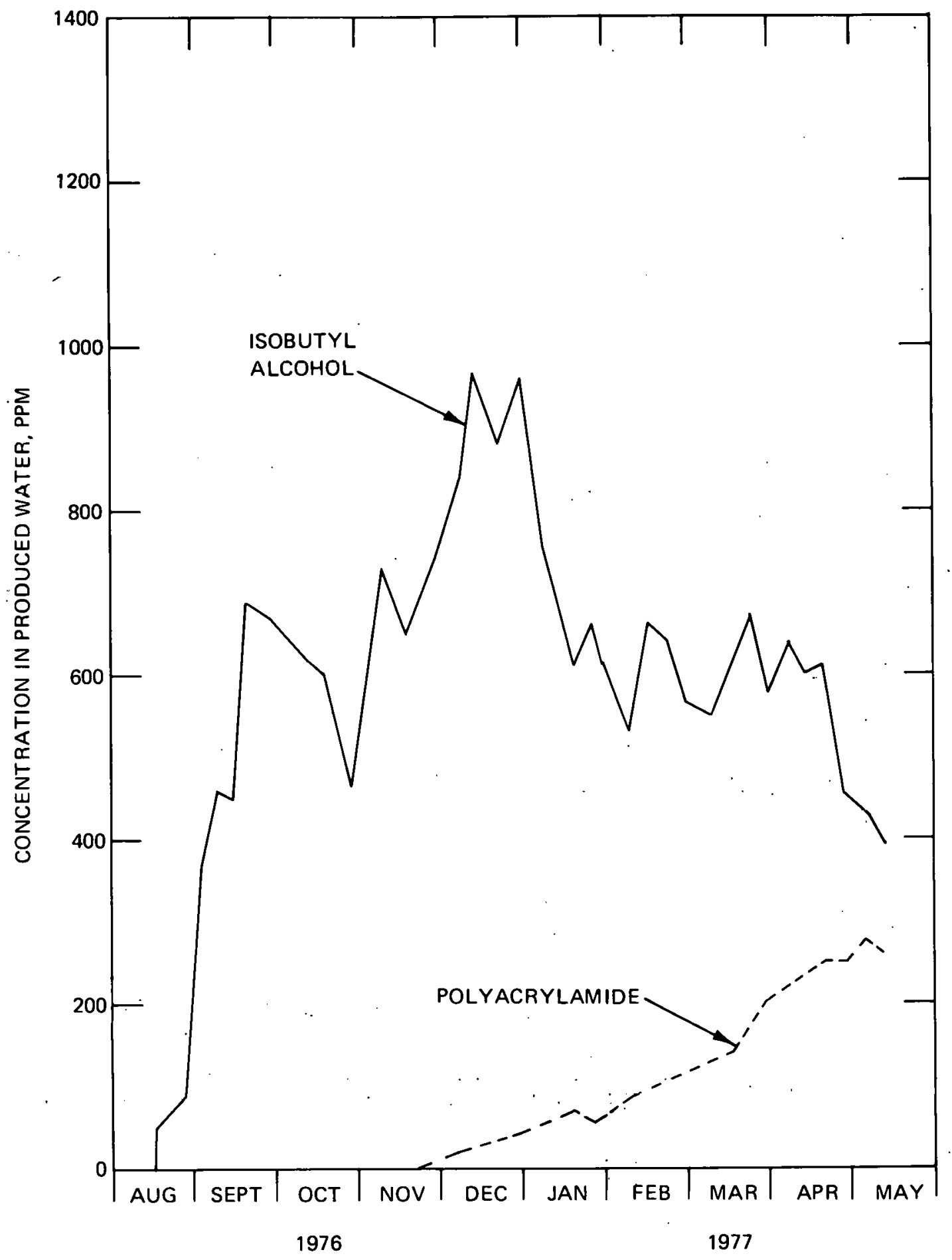

TREND OF CHEMICAL CONTENT OF PRODUCED WATER, WELL 97-28 FIGURE 74 


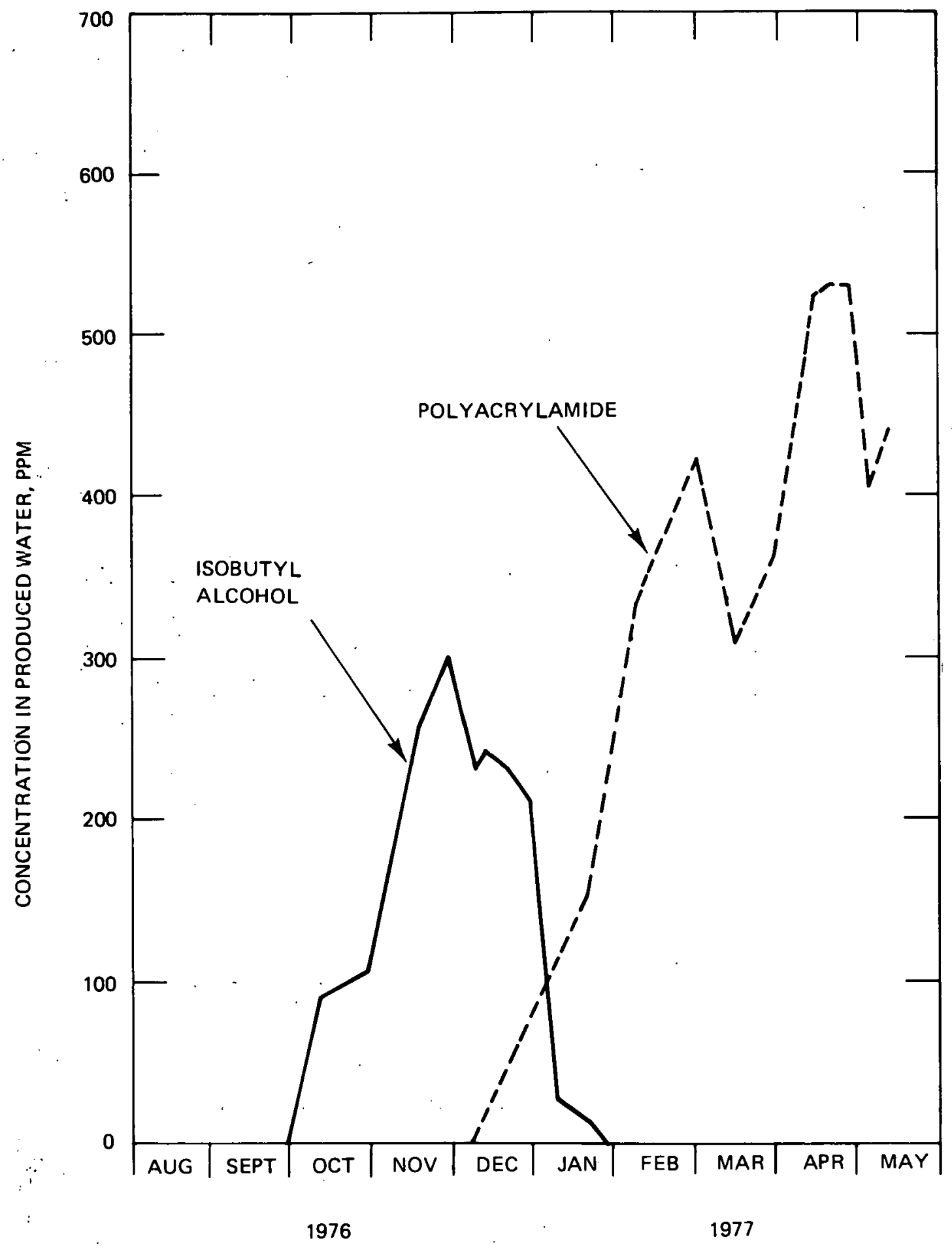

TREND OF CHEMICAL CONTENT OF PRODUCED WATER, WELL 97-35 FIGURE 75 


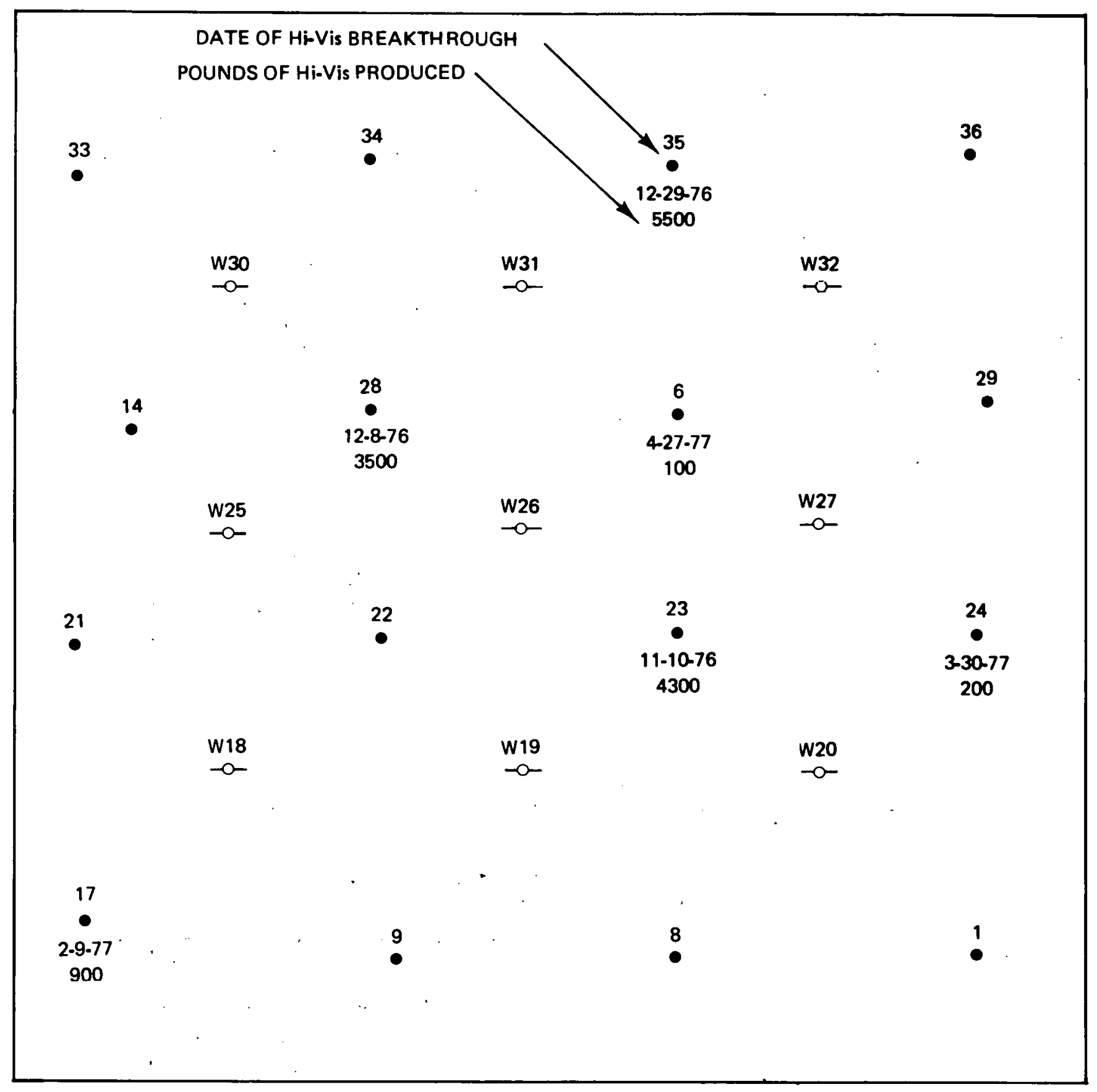

NBU TRACT 97

\section{POLYACRYLAMIDE AT PRODUCING WELLS}

FIGURE 76 


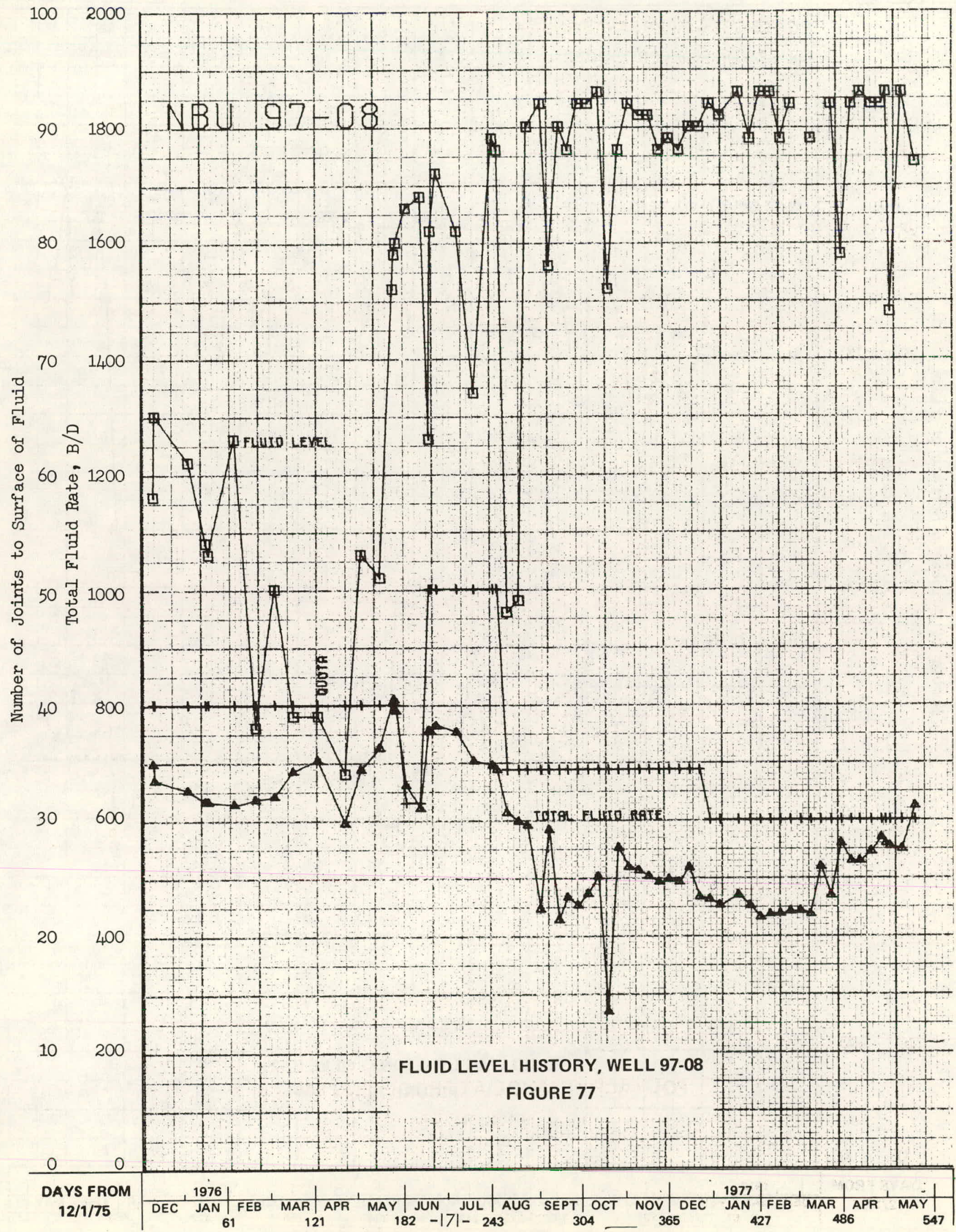




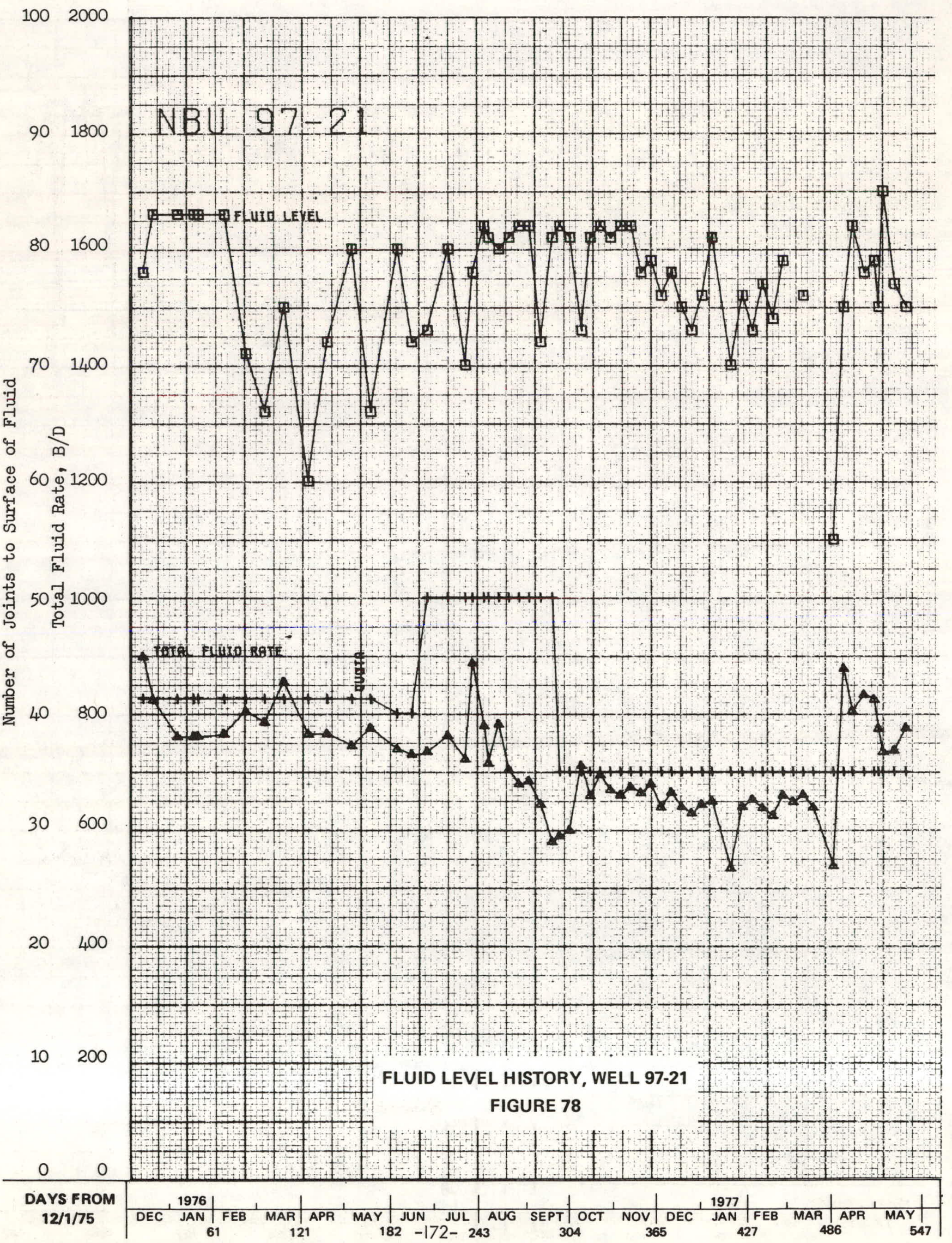




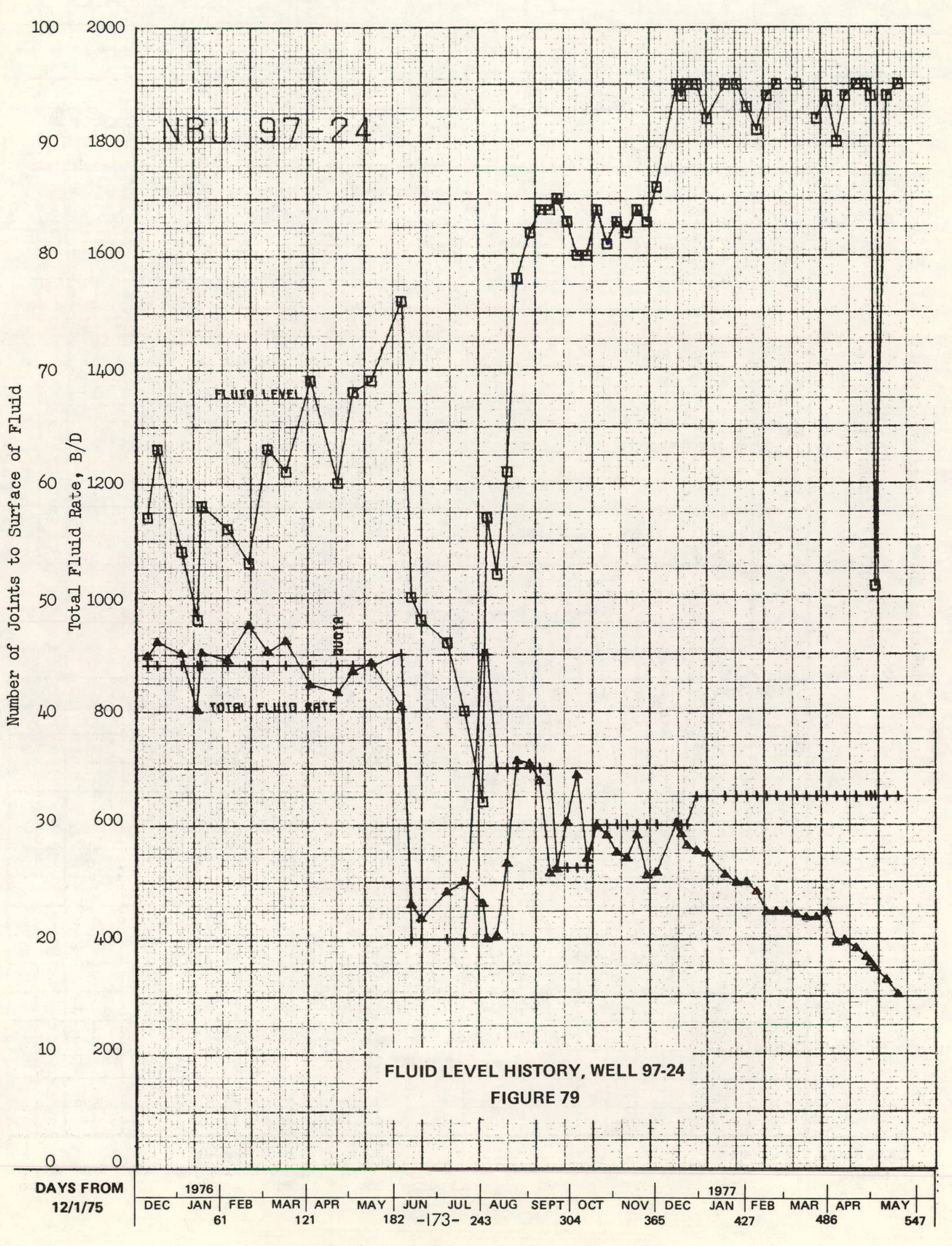




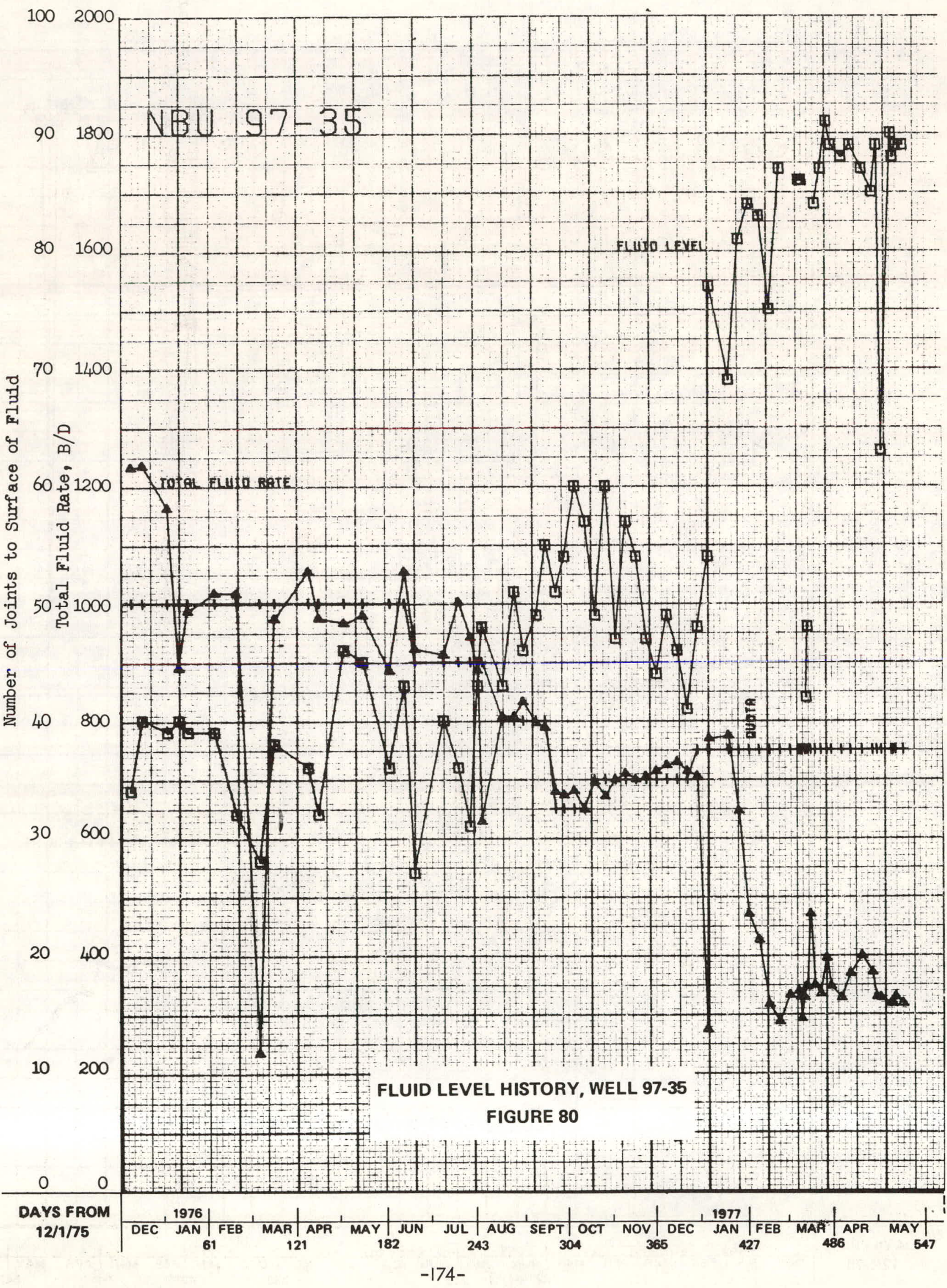


1002000

901800 NBU $97-23$

801600

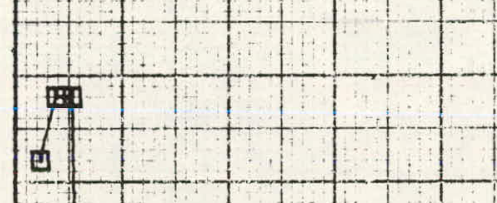

701400 Flivo LeVta

말

की

: 60 i -1200

苟 范

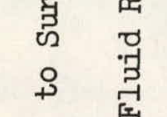

贻 50 न 1000

땅

离 40800

$30 \quad 600$

$20 \quad 400$

Felwo Lex 

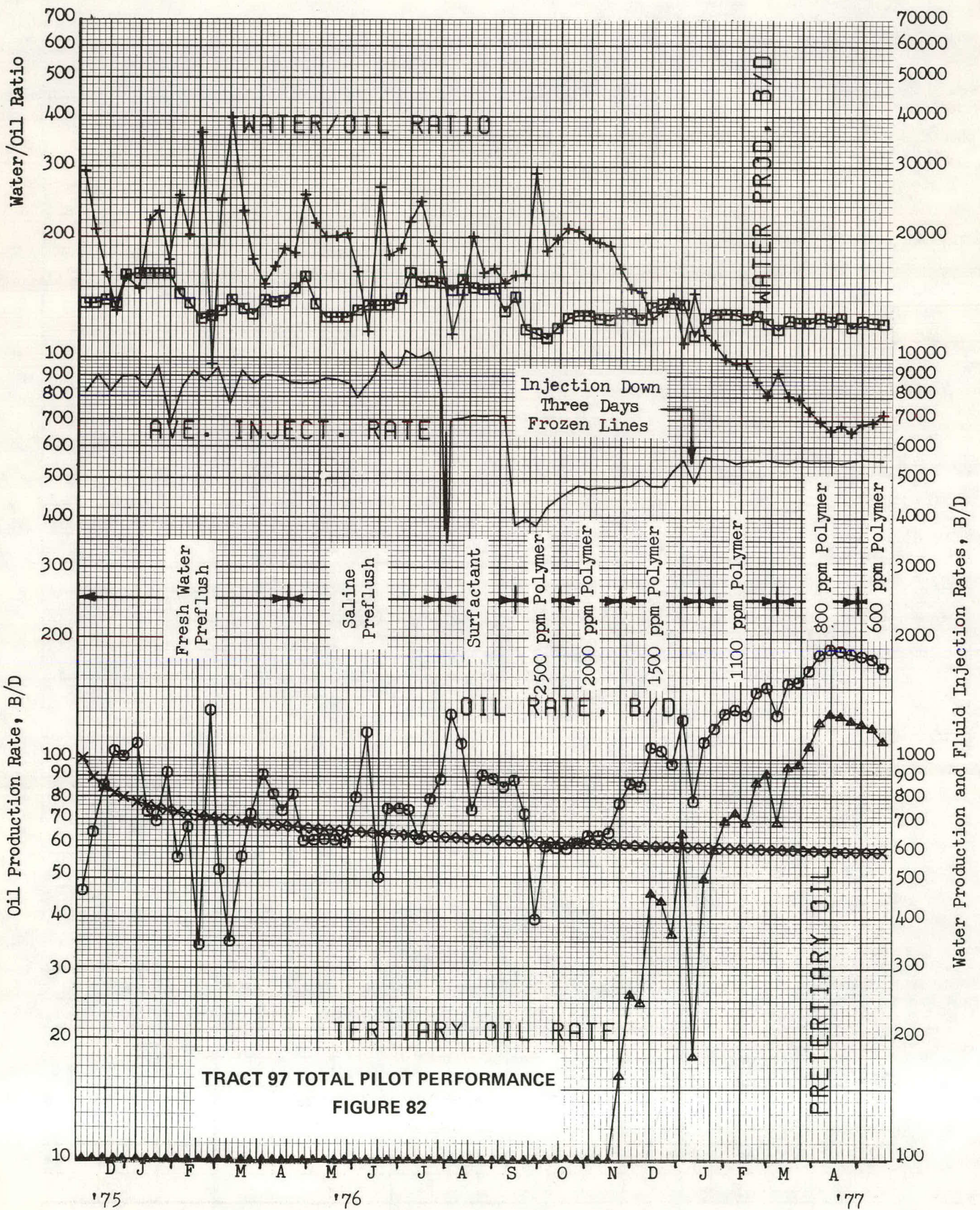


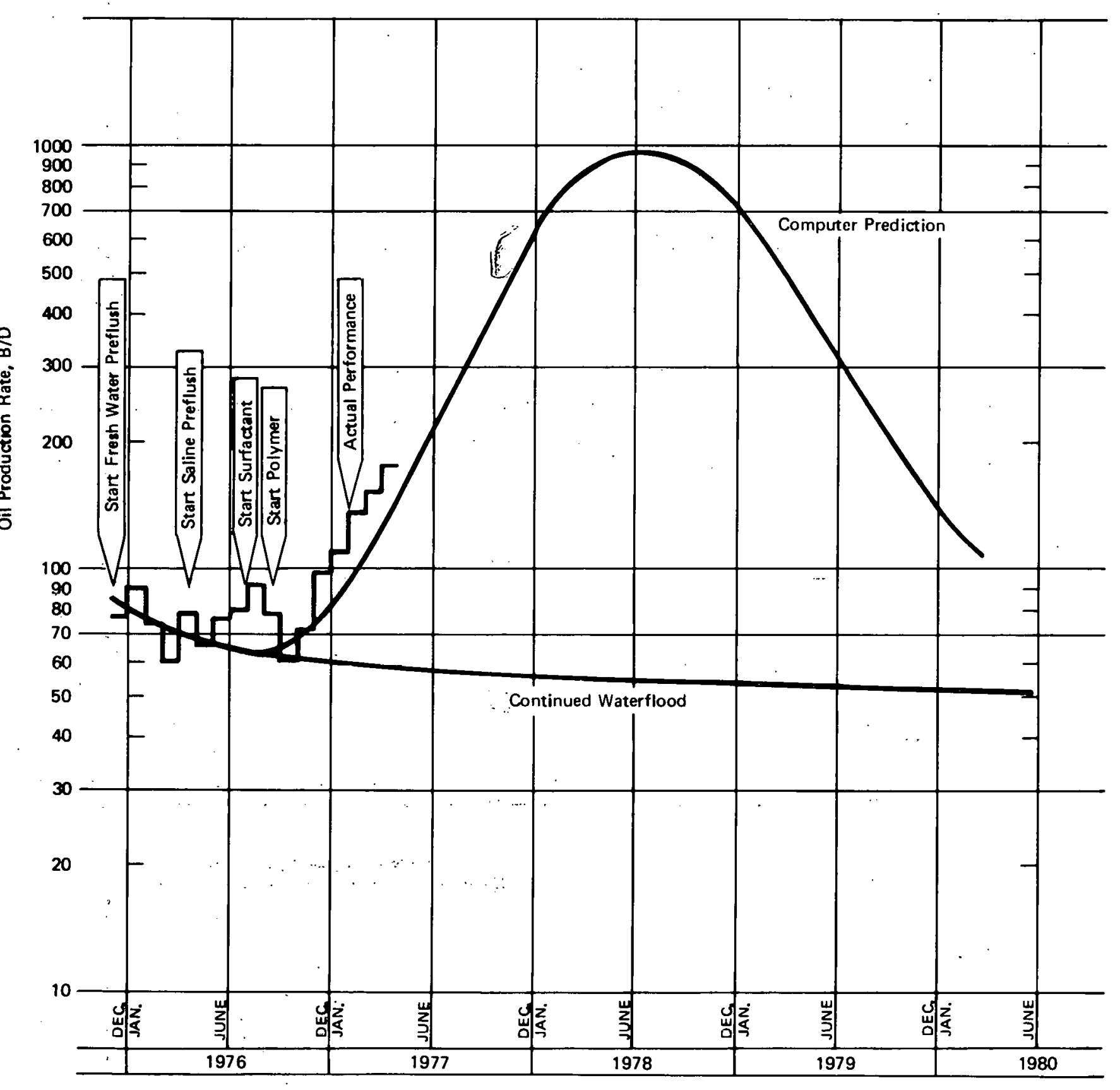

COMPARISON OF PILOT PERFORIANANCE WITH PREDICTION FIGURE 83. -177- 


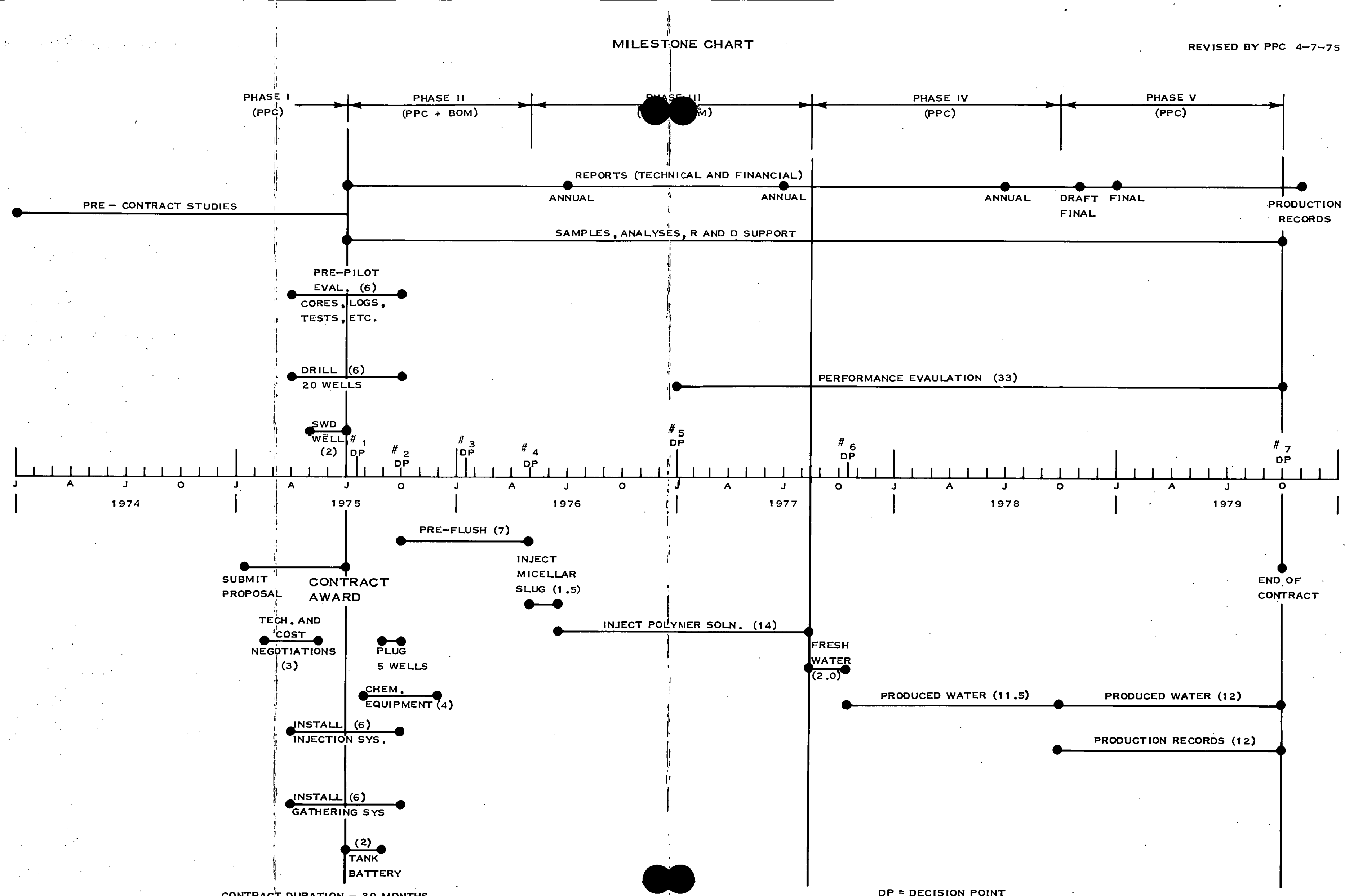




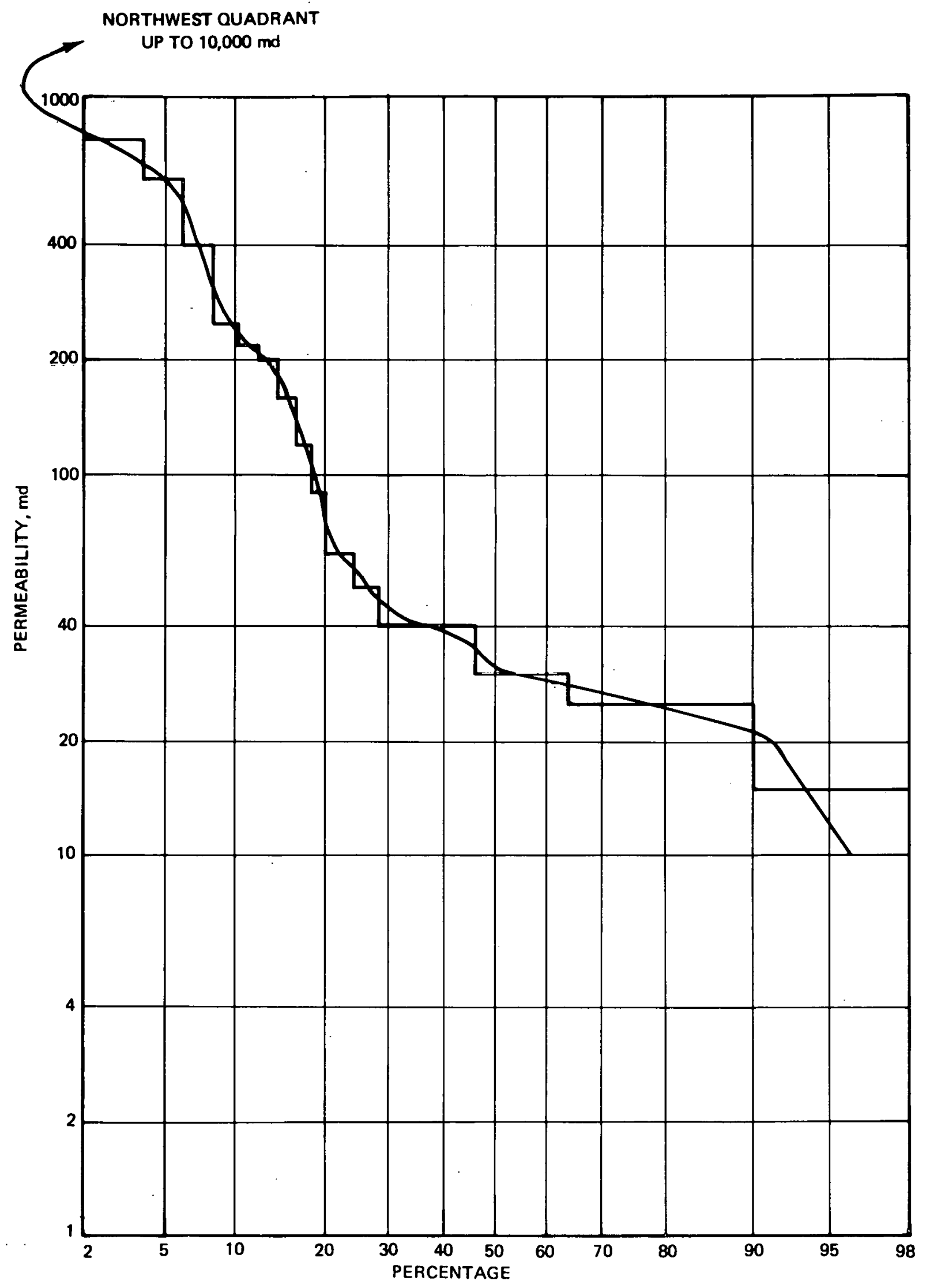

PERMEABILITY DISTRIBUTION AROUND WELL 97-W30

FIGURE 85 


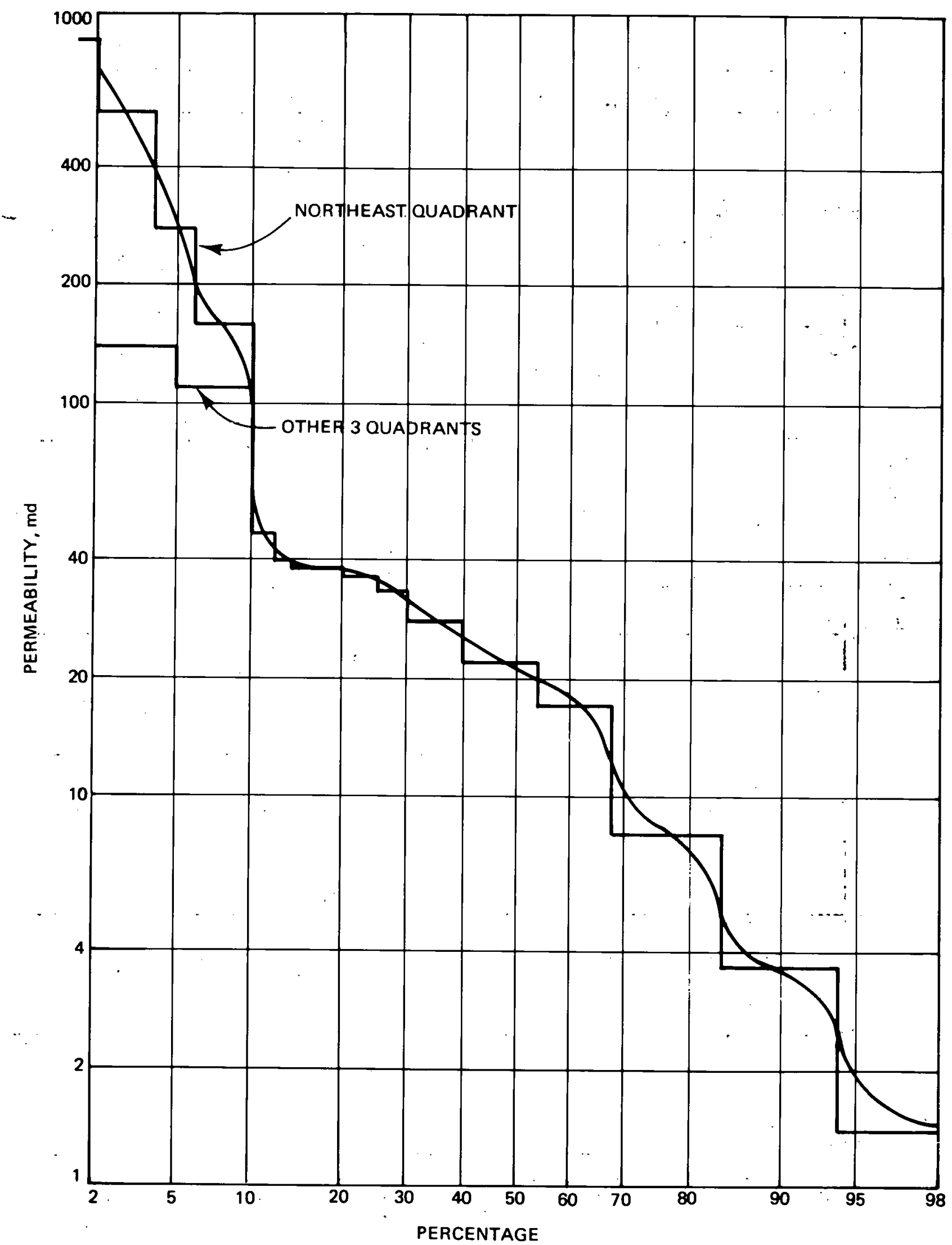

PERMEABILITY DISTRIBUTION AROUND WELL 97-W32

FIGURE 86

$-180-$ 


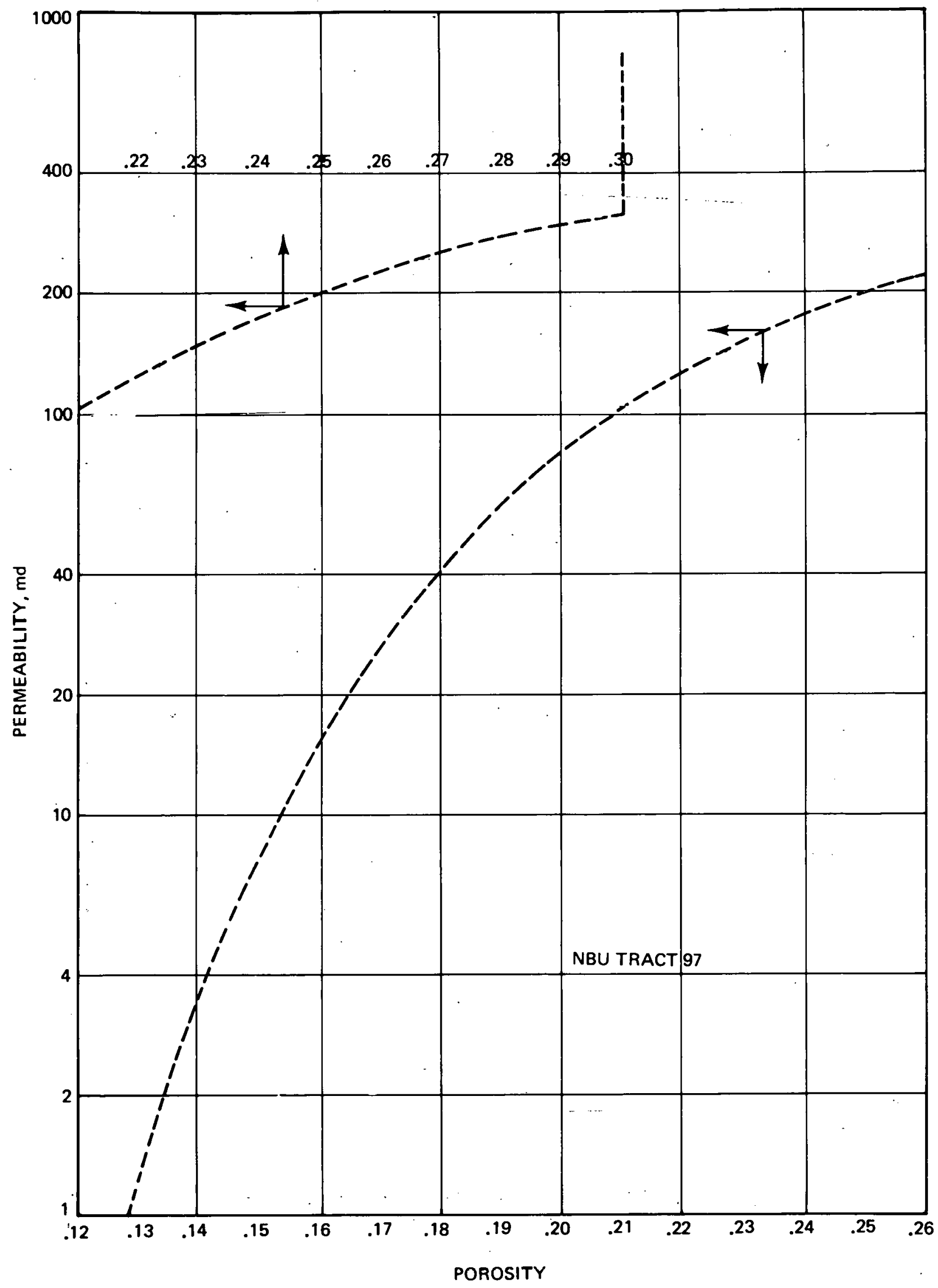

CORRELATION BETWEEN PERMEABILITY AND POROSITY

BASED ON CORE ANALYSIS

FIGURE 87

$-181-$ 


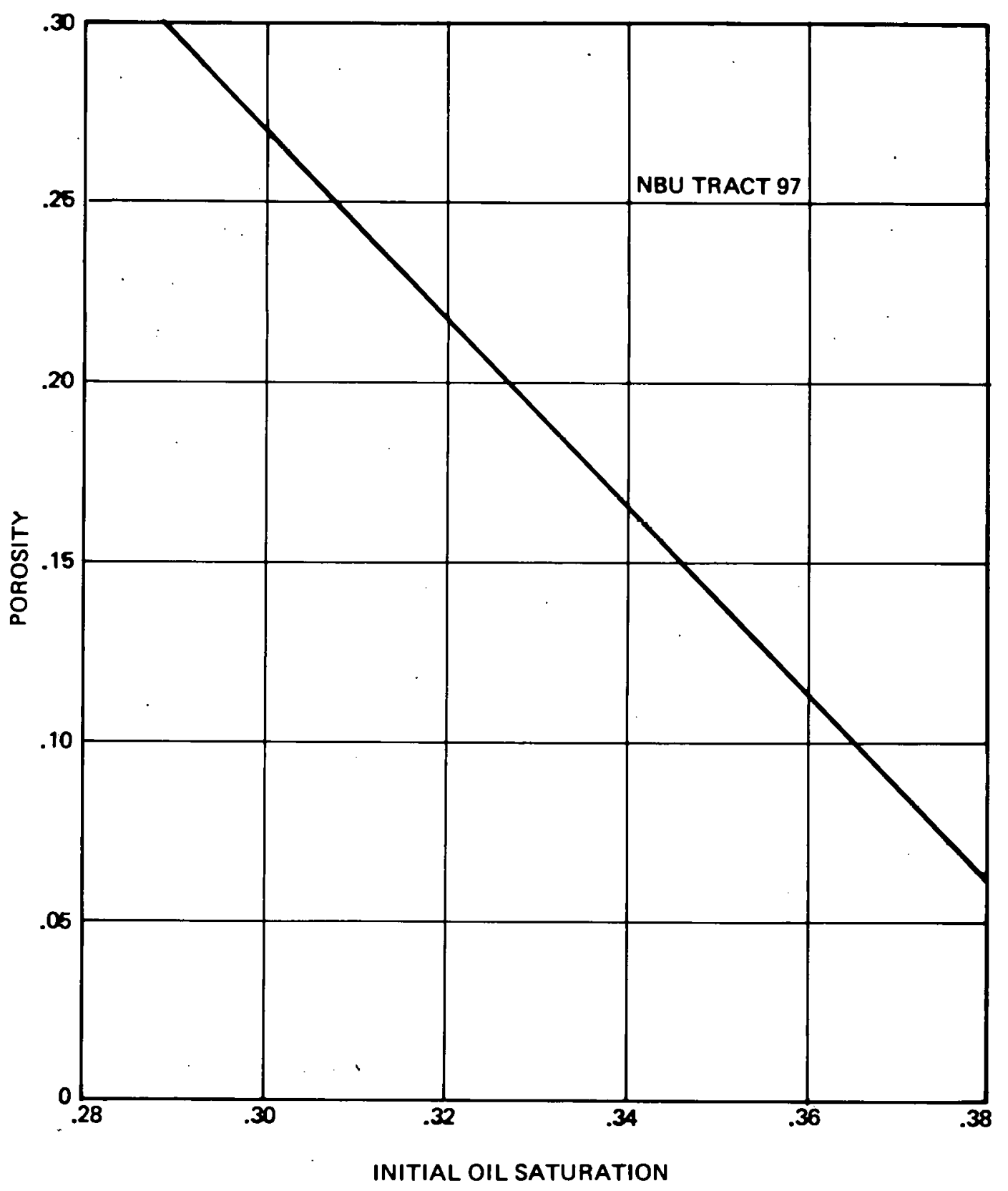

CORRELATION BETWEEN POROSITY AND

INITIAL OIL SATURATION

FIGURE 88 


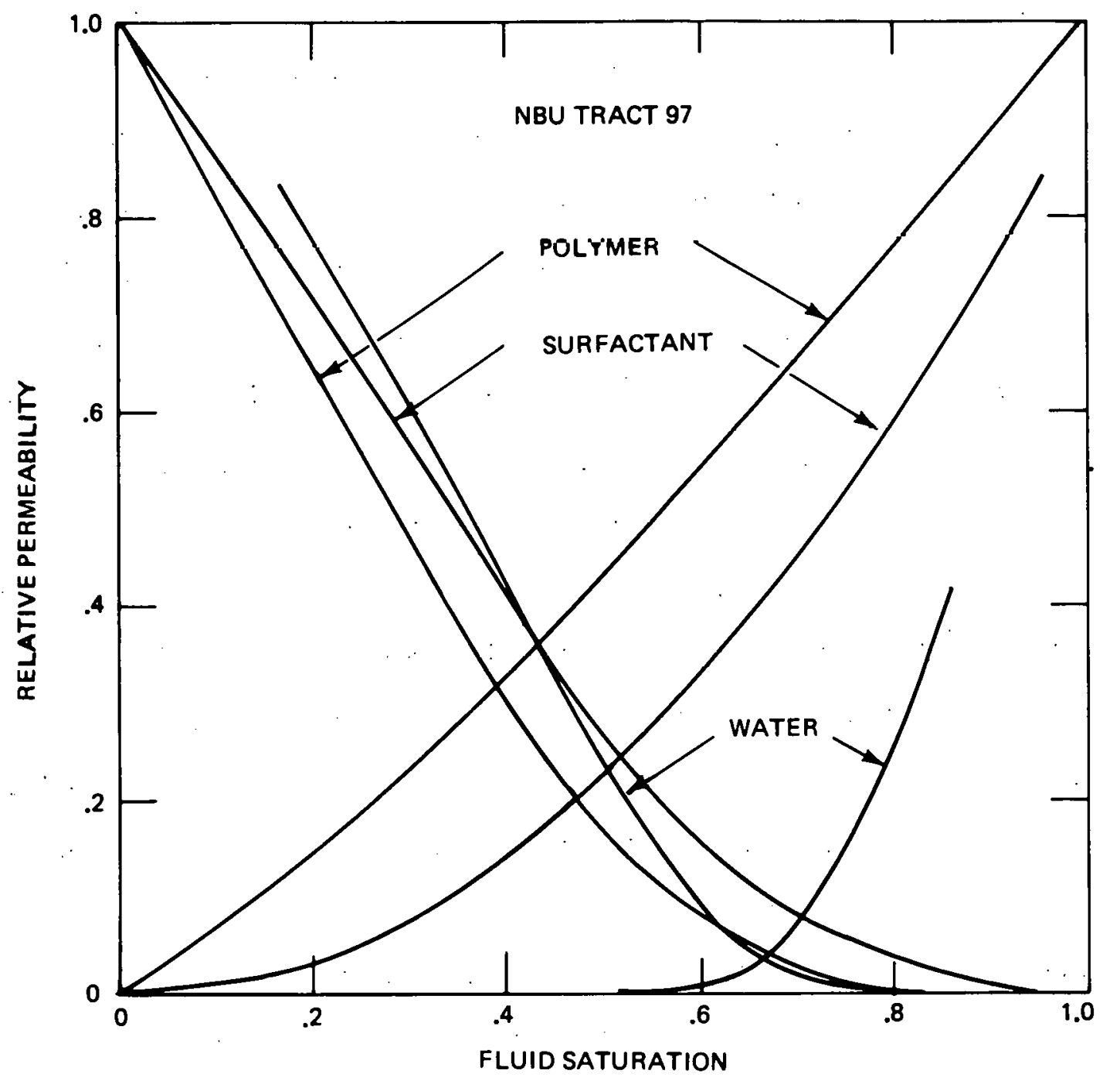

RELATIVE PERMEABILITY CURVES USED IN MODEL STUDY

FIGURE 89 


\section{APPENDIX A}

MODEL USED IN ALLOCATING SURFACTANT TO INDIVIDUAL FIVE-SPOTS

In determining the curves for oil contacted as a function of surfactant slug sizes the non-communicating layered reservoir model was used. Each fivespot was assigned a system of layers of different permeabilities to represent its heterogeneity. The distributions used for Wells 97-W18, 97-W20, and 97-W26 were taken directly from the core analyses of those wells. The distribution for each of Wells 97-W19, 97-W27, and 97-W31, for which no core analysis was available, was taken as the average of the distributions for the three cored injection wells surrounding it. Permeability distributions for the three remaining wells (97-W25, 97-W30, and 97-W32) had been determined during the course of the preliminary tracer study. (1) Because of the preliminary nature of the earlier study, figures showing the distributions in these areas were not included at that time but are given in Figures 20, 85, and 86 of this report. The distributions for Wells 97-W30 and 97-W32 were obtained directly from the core analyses of these wells. Since Well 97-W25 was not cored its distribution was estimated from the composite of two adjacent cored weIls 97-W26 and 97-W30. The surface area of each pattern was calculated from well locations with the results shown in Table 29, and the average pay thickness for each pattern was determined by integration of the most recent isopach map. Pore volumes were obtained as follows:

(1) Layer permeabilities were assigned on the basis of permeability distribution graphs (e.g. Figures 20, 85, and 86).

(2) Corresponding layer porosities were obtained from a correlation (Figure 87) between porosity and permeability based on all available Tract 97 core data and were assigned as model input.

(3) The computer model then calculated the pore volumes of the patterns. 
Appendix A

Oil saturation was correlated with porosity to determine oil in place. The particular correlation in Figure 88 is rather arbitrary and was chosen primarily to yield an average oil saturation in the range of 30 to 35 per cent. The relative permeability curves used for all patterns are shown in Figure 89. The residual oil saturation to waterflooding was 15 per cent and the residual to surfactant solution is 5 per cent. Other values used were: oil viscosity $3 \mathrm{cp}$, water $0.6 \mathrm{cp}$, surfactant solution $5 \mathrm{cp}$, and oil formation volume factor 1.05. The sulfonate concentration in the 288,000 barrels of surfactant solution was 21 pounds per barrel ( 6 per cent). The sulfonate adsorption level was estimated to be 4500 pounds per acre-foot.* Oil recovery was not calculated by the reservoir model. Rather, the computer program was used only to determine the amount of surfactant solution injected into each layer when a given total volume of surfactant solution had been injected into the pattern. Then recoverable oil contacted was calculated by

$$
R O C=\sum_{j=I}^{\text {NLAYRS }} \frac{V_{j} \times C \times 7757.8 \times \phi_{j} \times\left(s_{O j j}-s_{O r}\right)}{A \times \beta}
$$

where

$$
\begin{aligned}
\text { ROC } & =\text { recoverable oil contacted, STB } \\
V_{j} & =\text { volume of surfactant injected into layer } j, \text { bbl } \\
\phi_{j} & =\text { porosity of layer } j, \text { dimensionless fraction } \\
S_{\text {oij }} & =\text { initial oil saturation in layer } j, \text { dimensionless fraction } \\
S_{\text {or }} & =\text { residual oil saturation, dimensionless fraction } \\
C & =\text { surfactant concentration, lbs/bbl }
\end{aligned}
$$

* In previous studies with this model, 3,500 pounds per acre-foot have been used. This value was based on laboratory core tests. Through evaluation of the pilot we expect to confirm or revise this estimate. The value 4,500 pounds per acre-foot was taken as a more conservative value in the allocation study, but the allocation should not be very sensitive to the value used. 
Appendix A

$$
\beta=\text { oil formation volume factor, reservoir bbl/STB }
$$

7757.8 = conversion factor, bbl/acre-foot

$$
A=\text { sulfonate adsorption, Ibs/acre-foot }
$$

The contacted oil, as calculated by the above equation, was then plotted as shown in Figure 27 for all nine five-spots. 


\section{APPENDIX B}

\section{IN SITU MOBILITY OF 2500 PPM POLYMER SOLUTION}

The approach to estimating in situ polymer mobility was to select a suitable flow model, estimate the mobilities in all flowing slugs except the polymer, calculate the pressure drops across these zones, calculate the pressure drop across the polymer slug by difference and then calculate the mobility in the polymer slug from its pressure drop.

\section{Selection of Model}

a. General

The 25 years of waterflooding experience in the North Burbank Unit have led to general agreement that the injection wells have vertical fractures running east-west. Waterflood development was based on a staggered line drive array with like wells in east-west lines with flow assumed to be substantially linear, in a gross sense, in a north-south direction.

Therefore, it is logical to consider a linear flow model in evaluating the pressure data. Considerable caution must be exercised, however, in applying the linear model to a single fractured injection well with four offset producers.

b. Fracture Orientation and Length

Field measurements made several years ago showed that the fractures tend to run in only one direction from an injection well (either east or west). The orientation of the fracture in Well 97-W31 was inferred from the freshwater breakthrough data and radioactive tracer analysis (Figure 6), both of which indicated that it must mun towards the east. Fracture length was determined by pressure fall-off measurements to be 330 feet. Figure 38 shows the effective pattern for the 97-W31 five-spot. 
c. Fluid Flow Paths

To determine whether a linear flow model would be applicable to WeIl 97-W31 and how much of the fluid could be assigned to linear flow, a streamltne mapping program was run using 12 injection wells spaced 30 feet apart to simulate the 330-foot fracture. The total fluid input was divided equally among these 12 wells, 40 BPD each. The four offset wells 97-06, 97-28, 97-34, and 97-35 were assumed to produce by radial flow since the fracture treatments at 97-06 and 97-28 were small and 97-34 and 97-35 were not fractured. The permeability in the east-west direction was assumed to be five times that in the north-south direction. All the active wells in the nine tract area centered on Tract 97 were operating at their August 1976 rates, but streamlines were calculated for the wells in the 97-W3I five-spot only.

Figure 39 shows the streamlines and flood front positions (indicated by asterisks) at selected times. The fluid front remains fairly straight and roughly parallel to tho fracture out. to the mid-line between the injection and production well lines. The indications of linear flow are only fair, with extreme departure of the streamlines from this geometry in the southwestern quarter of the rectangular region of Figure 39. It should be adequate for present purposes, however, since we are seeking only a rough approximation in this calculation. The rectangular area will be referred to as the "linear flow" region.

By planimeter it was estimated that 33 per cent of the injected fluid moves through the "linear flow" region assuming that the south half of the 97-W31 five-spot is the mirror image of the north half. 
d. Calculation Procedure

Figure 40 shows the fluid flow geometry for the "linear flow" approximation. In this model three* fluid slugs are flowing:

(1) preflush, (2) microemulsion, and (3) polymer,-(2,500 ppm, nominal). The lengths and pressure drops across these slugs are shown and the total sequence is flowing at the rate set by the injection rate of the polymer. The resulting pressure drop $\Delta \mathrm{p}=\mathrm{p}_{\mathrm{w}}-\mathrm{p}_{\mathrm{e}}$ can be broken up into

$$
\mathrm{p}_{\mathrm{w}}-\mathrm{p}_{\mathrm{e}}=\Delta \mathrm{p}_{\mathrm{poly}}+\Delta \mathrm{p}_{\text {mic. }}+\Delta \mathrm{p}_{\text {pref. }}---(\mathrm{B}-\mathrm{l})
$$

The linear form of Darcy's law

$$
q=\frac{1.127 \mathrm{~A} \Delta \mathrm{p}}{1000 \mathrm{~L}} \times \frac{\mathrm{k}_{\mathrm{e}}}{\mu_{\mathrm{e}}}
$$

can be written

$$
\lambda=\frac{k_{e}}{e}=\frac{1000 \mathrm{~g}}{1.127 \mathrm{hW}} \times \frac{\mathrm{L}}{\Delta \mathrm{p}}-\cdots-\cdots(\mathrm{B}-2)
$$

where $\lambda=$ mobility of a fluid in the porous medium, $\mathrm{md} / \mathrm{cp}$

$\mathrm{k}_{\mathrm{e}} \quad=$ effective permeability to a fluid, $\mathrm{md}$

$\mu_{e}=$ effective viscosity of a fluid, $\mathrm{cp}$

$\mathrm{q}$ = flow rate from fracture in "linear flow" region, bbl/day

$h$ = thickness of formation taking fluid, feet

$\mathrm{W}$ = fracture length, feet

$I \quad=$ length of a slug, feet

$\Delta p=$ pressure drop across distance $L, p s i$

* This is oversimplified since oil is also flowing with the preflush and also in the microemulsion zone. This is neglected since the measurements were performed before much oil had been mobilized. The oil in the preflush zone was included in the measurements. 
For our estimate, values were taken to be constant for

$$
\begin{aligned}
& \mathrm{h}=55 \text { feet (net pay thickness) } \\
& W=330 \text { feet (from pressure fall-off measurements) } \\
& \mathrm{q}=426 \times 0.33 \mathrm{bbl} / \text { day }
\end{aligned}
$$

Three equations may now be written

for preflush $\quad \lambda$ pref $=\frac{(1000)(426)(0.33)}{(1.127)(55)(330)} \times \frac{L_{\text {pref }}}{\Delta p_{\text {pref }}}=6.87 \frac{L_{\text {pref }}}{\Delta p_{\text {pref }}}$

for microemulsion $\lambda_{\text {mic }}=6.87 \frac{\mathrm{L}_{\text {mic }}}{\Delta p_{\text {mic }}}$

for polymer $\quad \lambda_{\text {poly }}=6.87 \frac{L_{\text {poly }}}{\Delta p_{\text {poly }}} \quad-\ldots-\ldots-\ldots-\ldots(B-3)$

The length of the polymer and microemulsion slugs can be calculated volumetrically from

$$
L=\frac{(5.6146(0.33)}{h W \phi\left(1-E_{O_{r}}\right)} \times \text { volume fluid injected into well. }
$$

Taking previously used values and $\phi=0.17$ and $\mathrm{S}_{\mathrm{O}_{\mathrm{r}}}=0.05$

$$
I=6.32 \times 10^{-4} \times \text { volume injected } \ldots \ldots \ldots
$$

The distance from $\mathrm{p}_{\mathrm{w}}$ to $\mathrm{p}_{\mathrm{e}}$ is 149 feet. Therefore the length of the pref'lush zone is

$$
I_{\text {pref }}=149-I_{\text {poly }}-I_{\text {mic }}
$$

To calculate the mobility of the polymer we need $\Delta p_{\text {poly }}$. This can be obtained from eq. $(\mathrm{B}-\mathrm{l})$ if we have $\Delta \mathrm{p}_{\mathrm{mic}}$ and $\Delta \mathrm{p}_{\mathrm{pref}}$. Let us consider the slugs individually. 


\section{(1) Preflush}

During stabilized preflush injection, pressure fall-off measurements at Well 97-W26 on May 14, 1976, gave an average reservoir pressure $\bar{p}=953$ psig. The corresponding injection pressure $p_{W}$ was 1,128 psig while the rate, q, was 858 BWPD. Taking $\bar{p}$ as the pressure along the mid-line between the wells and applying eq. ( $B-2)$.

$$
\lambda_{\text {pref }}=\frac{(1000)(858)(0.33)}{(1.127)(55)(330)} \times \frac{149}{(1128-953)}=11.8 \mathrm{md} / \mathrm{cp}
$$

\section{(2) Microemulsion Zone}

During the injection of surfactant at Well 97-W31, a 19,754 barrel slug was injected. If it is assumed that the oil saturation is reduced to 5 percent of pore volume swept by the surfactant and that the resulting fresh plus "spent" surfactant occupied the same volume as the injected surfactant, the length of the zone would be

$$
I_{\text {mic }}=6.32 \times 10^{-4} \times 29,754=18.8 \text { feet }(\text { From eq. } B-4)
$$

Laboratory measurements have shown that in total mixing of surfactant and oil, 50 volumes of surfactant mixed with 30 volumes of oil produce three phases in the proportions

\section{AQUEOUS: 17 MICROEMULSION: $10 \mathrm{OIL}$}

In the porous medium, microemulsion will be formed as surfactant encounters oil. If all the surfactant could interact with the required amount of oil at one time, a microemulsion bank with a 
volume $17 / 50$ ( 34 percent) of the surfactant volume would be formed and would occupy $0.34 \times 18.8=6.4$ feet. Actually there would be a continuously increasing microemulsion bank (up to a point) as the surfactant moves through the sand. At the point where injection of the surfactant slug is just completed, there will certainly be less microemulsion than 34 percent of the total surfactant volume. Thus, the assumption that the microemulsion zone is 6.4 feet wide in the "linear flow" region will result in a larger pressure drop across the entire three-phase zone than a partially formed microemulsion zone because the microemulsion is much more viscous than the surfactant itself, the aqueous phase in the partitioned zone, or the oil phase, but at present there is no way to est,imate this.

The mobility of the microemulsion zone was estimated using

$$
\begin{aligned}
\mathrm{k}_{\mathrm{e}} & =38 \mathrm{md}(\text { from fall-off data }) \\
\mu_{\text {mic }} & =20 \mathrm{cp}(\text { estimate from R\&D }) \\
\text { then } \lambda_{\text {mic }} & =\frac{38}{20}=1.9 \mathrm{md} / \mathrm{cp}
\end{aligned}
$$

As polymer was injected $\mathrm{I}_{\text {poly }}$ increased, $\mathrm{I}_{\text {mic }}$ remained constant at 6.4 feet and the preflush zone decreased. Since all three zones moved at the same rate during $2,500 \mathrm{ppm}$ polymer injection from September 17 to October 1,1976 , the corresponding $\Delta p$ values were calculated using the equations developed previously. Thus 


$$
\begin{aligned}
\Delta p_{\text {pref }} & =6.87 \frac{L_{\text {pref }}}{\lambda \text { pref }}=\frac{6.87\left(149-6.4-L_{\text {poly }}\right)}{11.8} \\
& =0.58\left(142.6-L_{\text {poly }}\right) \\
\Delta p_{\text {mic }} & =\frac{6.87 \times 6.4}{1.9}=23.0 \mathrm{psi}
\end{aligned}
$$

Then, from eq. (

$$
\Delta p_{p o l y}=p_{w}-p_{e}-0.58\left(142.6-L_{p o l y}\right)-23.0-(B-5)
$$

We can now make calculations of polymer mobility using equations $B-3, B-4$ and $B-5$. Since no measurements were available for $p_{e}$ it had to be estimated. This was done by making the calculations for a series of assumed $\mathrm{p}_{\mathrm{e}}$ values and selecting the one which led to the most reasonable mobility. The calculations were made for each day of polymer injection and then mobility was plotted as a function of the volume of polymer injected as shown in Figure 41. 


\section{APPENDIX C}

\section{ESTABLISH ING PRETERTIARY OIL PRODUCTION DECLINE}

\section{Correction for Injection Rate Variations}

Since the injection rates were varied from time to time during preflush injection and this has some influence of the fluid production rates, the oil rates for the pattern producers were corrected to a constant average injection rate. This was done as follows:

a. Calculated the average total injection rate for the four nearest of fsets to each pattern producer for the period December 1, 1975, to December 31, 1976. Designated this as $\mathrm{q}_{\text {ave }}$.

b. Calculated the sum of the instantaneous rates of the injection wells in a. above at time "t". Called this $q_{\text {total }}$.

c. Called total fluid production rate of the pattern producer at time "t", $q_{\text {fluid }}$

d. Then $\frac{q_{\text {ave }}}{\text { total }} \times q_{\text {fluid }}=$ corrected total fluid rate at time " $t$ "

e. "Corrected oil rate" was then calculated by assuming the WOR did not vary with injection rates so that

$$
\text { Corrected oil rate }=\frac{q_{\text {ave }} q_{\text {fluid }}}{q_{\text {total }}(1+\text { WOR })}
$$

f. The "corrected oil rates" were calculated for all 16 pattern producers and were plotted.

\section{Establishing Decline Curves for Individual Producers}

Attempts were made to apply type curve analysis to the decline of individual wells but the curves were too flat and were undifferentiated as 
to decline curve type (i.e. exponential, hyperbolic, etc.). Two alternate procedures were then tried:

a. Decline curves were drawn to fit the data as well as subjective judg ment would permit.

b. Declịne curves were determined statistically $\underset{i}{\text { assuming the decline was }}$ some hyperbolic relationship such that a plot of the logarithm of the production rate versus the logarithm of time would give a linear plot. Then a linear regression was run to obtain the best fit.

In both these procedures, data were excluded when it was known that localized conditions significantly affected the oil production rate. An example of this was the response at Well 97-28, in July and August of 1976, to the gelled polymer treatment at Well $97-$ W25.

For some wells, the data appeared to indicate a slightly increasing rate rather than a decline. In these cases, the rate was assumed to be constant, not declining or increasing, for the purposes of this study. In Well 97-22 the production rate was essentially zero and was so considered. Well 97-23 gave very low rates but a satisfactory curve was found.

3. Establishing the Total Tract Decline Curve

a. Rates were read from the curves obtained from both procedures given above for selected times; these were then totaled to provide rates for Tract 97 as a whole.

b. Linear regression was used to find the best logarithmic expression for Tract 97 for both procedures. 
APPENDIX C

The final equations were:

$$
\begin{aligned}
& \text { for 2. a. } \quad \text { In } q_{t}=-0.12 \ln t+4.88 \\
& \text { for 2. b. } \quad \text { In } q_{t}=-0.11 \ln t+4.76
\end{aligned}
$$

The latter is considered a better relationship since there is less individual prejudice involved in it than in the former.

2. b. was finally expressed as its mathematical equivalent

$$
q_{t}=116.75 t^{-0.11}
$$

where $q_{t}=0 i l$ production rate at time, $t$

$$
t=\text { elapsed time in days }
$$

$-196-$ 